\title{
Diet and other risk factors for prostate cancer
}

Citation for published version (APA):

Schuurman, A. G. (1999). Diet and other risk factors for prostate cancer. [Doctoral Thesis, Maastricht University]. Universiteit Maastricht. https://doi.org/10.26481/dis.19990625as

Document status and date:

Published: 01/01/1999

DOI:

10.26481/dis.19990625as

Document Version:

Publisher's PDF, also known as Version of record

\section{Please check the document version of this publication:}

- A submitted manuscript is the version of the article upon submission and before peer-review. There can be important differences between the submitted version and the official published version of record.

People interested in the research are advised to contact the author for the final version of the publication, or visit the DOI to the publisher's website.

- The final author version and the galley proof are versions of the publication after peer review.

- The final published version features the final layout of the paper including the volume, issue and page numbers.

Link to publication

\footnotetext{
General rights rights.

- You may freely distribute the URL identifying the publication in the public portal. please follow below link for the End User Agreement:

www.umlib.nl/taverne-license

Take down policy

If you believe that this document breaches copyright please contact us at:

repository@maastrichtuniversity.nl

providing details and we will investigate your claim.
}

Copyright and moral rights for the publications made accessible in the public portal are retained by the authors and/or other copyright owners and it is a condition of accessing publications that users recognise and abide by the legal requirements associated with these

- Users may download and print one copy of any publication from the public portal for the purpose of private study or research.

- You may not further distribute the material or use it for any profit-making activity or commercial gain

If the publication is distributed under the terms of Article $25 \mathrm{fa}$ of the Dutch Copyright Act, indicated by the "Taverne" license above, 


\title{
Diet and other risk factors
}

\author{
for prostate cancer
}


CIP-DATA KONINKLIJKE BIBLIOTHEEK, DEN HAAG

(c) Schuurman, Anne Gezina

Diet and other risk factors for prostate cancer / Anne Gezina Schuurman

Thesis Maastricht University. - With summary in Dutch.

ISBN 90-9012-731-3

Subject headings: prostate cancer - diet - environmental factors - incidence - epidemiology

In de drukkosten van dit proefschrift werd bijgedragen door:

Janssen-Cilag B.V., het Voedingscentrum en Bional Pharma BV.

Produktie: PrintPartners Ipskamp, Enschede 


\title{
Diet and other risk factors
}

\author{
for prostate cancer
}

PROEFSCHRIFT

ter verkrijging van de graad van doctor

aan de Universiteit Maastricht te Maastricht,

op gezag van de Rector Magnificus, Prof.dr. A.C. Nieuwenhuijzen Kruseman

volgens het besluit van het College van Dekanen,

in het openbaar te verdedigen op vrijdag 25 juni 1999 om 14.00 uur

door

Anne Gezina Schuurman 


\section{Promotor}

Prof.dr.ir. P.A. van den Brandt

\section{Co-promotor}

Dr.ir. R.A. Bausch-Goldbohm

Beoordelingscommissie

Prof.dr.ir. W.H.M. Saris (voorzitter)

Prof.dr. Ph.E.V.A. van Kerrebroeck

Prof.dr. J.A. Knottnerus

Prof.dr.ir. F.E. van Leeuwen (Vrije Universiteit, Amsterdam)

Prof.dr. F.H. Schröder (Erasmus Universiteit, Rotterdam) 


\section{Contents |}

Introduction

Chapter 1. Prospective epidemiological studies on dietary risk factors for prostate cancer: a review

Chapter 2. Vegetable and fruit consumption and prostate cancer risk: a cohort study in the Netherlands

Chapter 3. A prospective cohort study on retinol, vitamins $\mathrm{C}$ and $\mathrm{E}$, and carotenoids and prostate cancer risk

Chapter 4. Animal products, calcium and protein and prostate cancer risk in the Netherlands Cohort Study

Chapter 5. Intake of energy and fat and prostate cancer risk: results from the Netherlands Cohort Study

Chapter 6. A prospective cohort study on consumption of alcoholic beverages in relation to prostate cancer incidence

Chapter 7. Anthropometry in relation to prostate cancer risk in the Netherlands Cohort Study

Chapter 8. A case-cohort study on prostate cancer risk in relation to family history of prostate cancer

Chapter 9. Socioeconomic status in relation to risk of prostate cancer

Epilogue

Summary

Samenvatting

Dankwoord 



\section{Introduction}

\section{Background}

Prostate cancer is predominantly a disease of the elderly. A diagnosis of prostate cancer is hardly made during the first four decades of life. After age 50, however, a steep increase of prostate cancer incidence with age is apparent (1). In the Netherlands, age-specific incidence rates per 100,000 person years in 1995 were 26.8 at ages 50-54, 185.8 at ages $60-64,628.8$ at ages 70-74, and 1028.0 at ages 80-84 (2). Standardized to the world population, the age-adjusted incidence rate for prostate cancer per 100,000 is 39.6 in the Netherlands (3) and prostate cancer is the second most common cancer among men (2). In general, the incidence rates in Europe vary between 20 up to 50 per 100,000 (3). In the United States, prostate cancer is already the most frequently diagnosed type of cancer among men $(4,5)$. Age-standardized to the world population, the incidence rates in the United States per 100,000 vary between 60 and 110 for whites and between 80 up to 140 for blacks (3). Worldwide, the lowest incidence rates of prostate cancer have been reported from Asian countries. For example, the age-standardized incidence rates from China vary between 0.5 and 2.3 per 100,000 and in Japan the rates vary between 6.7 and 10.9 (3). The large geographical variation in incidence rates of prostate cancer is a remarkable characteristic of the disease. In its latent form, prostate cancer prevalence does not appear to show much international variation, as has been observed from autopsy studies (6-8).

Despite the high incidence rates of prostate cancer in Western countries, the etiology is still largely unknown. The only established risk factors are age and race (9) and also some familial clustering of prostate cancer is likely $(9,10)$. Furthermore, environmental factors are thought to be important in prostate cancer etiology. The marked international variation in incidence rates and the observation of equivalent prevalence of latent prostate tumors in low- and high-risk populations support a role for environmental factors $(5,7,11)$. Also, among migrants from low-risk to high-risk populations increases in incidence are observed $(4,5,7)$. The observations of marked differences in clinical prostate cancer rates worldwide but similar prevalence of latent cancer might implicate that the initiation rate of prostate cancer is similar in low- and high-risk populations, but that the rate of promotion or progression to clinically evident prostate cancer differs between these areas $(8,11)$. One potentially important environmental factor involved in prostate cancer occurrence is diet. Nevertheless, no dietary risk factor for prostate cancer has been clearly identified thus far.

\section{Aims of the study}

In this thesis, associations between several dietary factors, consumption of alcoholic beverages, anthropometry, family history of prostate cancer and socioeconomic status and the incidence of prostate cancer are tested. Broadly stated, the hypotheses underlying these investigations are as follows: 1) environmental factors, specifically dietary factors, are 
associated with prostate cancer risk, and 2) these factors are more strongly related to nonlatent or advanced prostate tumors than to latent tumors. The analyses regarding the associations between the abovementioned potential risk factors and prostate cancer incidence were carried out within the context of the Netherlands Cohort Study on diet and cancer.

Several nondietary potential risk factors for prostate cancer are not addressed in this thesis. For an overview of the association between vasectomy (12-15), occupation (16-19), physical activity $(20,21)$, and smoking $(22-24)$ the reader is referred to other reviews. Results on endogenous hormones as risk factors for prostate cancer have also been reviewed before $(11,25-27)$.

\section{The Netherlands Cohort Study}

In 1986 a large-scale prospective cohort study, the Netherlands Cohort Study on diet and cancer (28), was initiated among 58,279 men (and 62,573 women) aged 55-69 years. The subjects originated from 204 municipal registries throughout the country. All subjects completed a self-administered questionnaire on diet and other potential risk factors for cancer. Incident prostate cancer cases were detected through record linkage with all regional cancer registries in the Netherlands and with a national pathology register. For the analyses presented in this thesis, all incident prostate cancer cases detected during a follow-up period of 6.3 years (September 1986- December 1992) were included ( $n=704)$. The case-cohort approach $(29,30)$ was used to analyse the relationships between the potential risk factors and prostate cancer risk.

\section{Outline of the thesis}

Results from a literature study on prospective studies investigating dietary and anthropometric risk factors for prostate cancer are described first (chapter 1). Thereafter, our findings regarding possible associations between incidence of prostate cancer and intake of vegetables and fruit (chapter 2), retinol, vitamins C, E and carotenoids (chapter 3), animal products, calcium and protein (chapter 4 ), energy, fat and fatty acids (chapter 5 ), alcohol (chapter 6), anthropometry (chapter 7), family history of prostate cancer (chapter 8), and socioeconomic status (chapter 9 ) are presented. Finally, the findings described in this thesis are discussed, as well as implications for future research regarding risk factors for prostate cancer.

\section{References}

1. Garraway WM, Alexander FE. Prostate disease: epidemiology, natural history and demographic shifts. Br J Urol 1997;79 Suppl 2:3-8.

2. Visser O, Coebergh JWW, Schouten LJ, et al. Incidence of cancer in the Netherlands, 1995. Utrecht: Vereniging van Integrale Kankercentra, 1998. 
3. Parkin DM, Whelan SL, Ferlay J, et al. Cancer incidence in five continents. Volume VII. Lyon: IARC scientific publication no. 143, 1997.

4. Kolonel LN. Nutrition and prostate cancer. Cancer Causes Control 1996;7:83-94.

5. Fair WR, Fleshner NE, Heston W. Cancer of the prostate: a nutritional disease? Urology 1997; 50:840-8.

6. Boyle P, Maisonneuve P, Napalkov P. Incidence of prostate cancer will double by the year 2030 : the argument for. Eur Urol 1996;29:3-9.

7. Giles G, Ireland P. Diet, nutrition and prostate cancer. Int J Cancer 1997; Suppl 10:13-7.

8. Pienta KJ, Esper PS. Risk factors for prostate cancer. Ann Intern Med 1993;118:793-803.

9. Key T. Risk factors for prostate cancer. Cancer Surv 1995;23:63-77.

10. Carter BS, Steinberg GD, Beaty TH, et al. Familial risk factors for prostate cancer. Cancer Surv 1991;11:5-13.

11. Nomura AM, Kolonel LN. Prostate cancer: a current perspective. Epidemiol Rev 1991;13:200-27.

12. DerSimonian R, Clemens J, Spirtas R, et al. Vasectomy and prostate cancer risk: methodological review of the evidence. J Clin Epidemiol 1993;46:163-72.

13. Guess HA. Is vasectomy a risk factor for prostate cancer? Eur J Cancer 1993;29a:1055-60.

14. Pollack AE. Vasectomy and prostate cancer. Adv Contracept 1993;9:181-6.

15. Bernal Delgado E, Latour Perez J, Pradas Arnal F, et al. The association between vasectomy and prostate cancer: a systematic review of the literature. Fertil Steril 1998;70:191-200.

16. Keller Byrne JE, Khuder SA, Schaub EA. Meta-analyses of prostate cancer and farming. Am J Ind Med 1997;31:580-6.

17. Van der Gulden JW, Kolk JJ, Verbeek AL. Prostate cancer and work environment. J Occup Med $1992 ; 34: 402-9$.

18. Van der Gulden JW, Vogelzang PF. Farmers at risk for prostate cancer. Br J Urol 1996;77:6-14.

19. Van der Gulden JW. Metal workers and repairmen at risk for prostate cancer: a review. Prostate 1997;30:107-16.

20. McTiernan A, Ulrich C, Slate S, et al. Physical activity and cancer etiology: associations and mechanisms. Cancer Causes Control 1998;9:487-509.

21. Oliveria SA, Lee IM. Is exercise beneficial in the prevention of prostate cancer? Sports Med 1997;23:271-8.

22. Lumey LH. Prostate cancer and smoking: a review of case-control and cohort studies. Prostate 1996;29:249-60.

23. Matzkin H, Soloway MS. Cigarette smoking: a review of possible associations with benign prostatic hyperplasia and prostate cancer. Prostate 1993;22:277-90.

24. Van der Gulden JW, Verbeek AL, Kolk JJ. Smoking and drinking habits in relation to prostate cancer. Br J Urol 1993;73:382-9.

25. Wilding G. Endocrine control of prostate cancer. Cancer Surv 1995;23:43-62.

26. Isaacs JT. Role of androgens in prostatic cancer. Vitam Horm 1994;49:433-502.

27. Montie JE, Pienta KJ. Review of the role of androgenic hormones in the epidemiology of benign prostatic hyperplasia and prostate cancer. Urology 1994;43:892-9.

28. Van den Brandt PA, Goldbohm RA, Van 't Veer P, et al. A large-scale prospective cohort study on diet and cancer in The Netherlands. J Clin Epidemiol 1990;43:285-95.

29. Prentice RL. A case-cohort design for epidemiologic cohort studies and disease prevention trials. Biometrika 1986;73:1-11.

30. Self SG, Prentice RL. Asymptotic distribution theory and efficiency results for case-cohort studies. Ann Stat 1988;16:64-81. 



\title{
Chapter 1
}

\section{Prospective epidemiological studies on}

\section{dietary risk factors for prostate cancer:}

\section{a review}

\author{
Agnes G. Schuurman ${ }^{1}$ \\ Piet A. van den Brandt' \\ R. Alexandra Goldbohm ${ }^{2}$
}

\begin{abstract}
Prostate cancer is one of the most frequent cancer sites in Western societies. Dietary factors are among the potential risk factors for this disease. In this overview prospective epidemiological studies published between 1966 and July 1998 on potential dietary risk factors for prostate cancer are reviewed. Factors included in this review are vegetables, fruit, meat, fish, milk, dairy products, eggs, coffee, tea, vitamins, fat, fatty acids, selenium and alcohol. In addition, results on anthropometric measures are also included. Almost without exception, results on potential risk factors are inconclusive. Drawbacks of the reviewed studies include limited exposure data, a small number of prostate cancer cases, and no or limited control for potential confounding factors. Furthermore, only a few studies investigated potential risk factors separately for latent and nonlatent or advanced prostate tumors. Whether there are different etiologic factors for latent and nonlatent prostate tumors remains therefore unknown. Future studies on dietary risk factors for prostate cancer need a comprehensive dietary assessment, information on several other potential confounding factors, and a large number of cases, offering the ability to also evaluate tumor subgroups.
\end{abstract}

\footnotetext{
'Dept. of Epidemiology, Maastricht University, Maastricht

${ }^{2}$ Dept. of Consumer Research \& Epidemiology, TNO Nutrition and Research Institute, Zeist
} 


\section{Introduction}

Prostatic cancer is presently one of the most frequently occurring forms of cancer in Western countries. In Europe, as well as in the United States (US) and Canada, the ageadjusted incidence is increasing (1). Annual age-adjusted clinical prostate cancer incidence rates of approximately 1 per 100,000 are found in China while in the US for blacks rates up to 102 per 100,000 are found. Rates for whites in the US vary from about 45 up to 65 per 100,000 . In Western Europe most incidence rates are around 20-30 per 100,000 although also some variation exists (2). Mortality rates have not changed markedly during this century (1). In contrast to clinical prostate cancer incidence which shows a noteworthy geographical variation, latent prostate carcinomas seem to be equally distributed across areas with high and low total prostate cancer incidence rates (3-5).

Age and race are established risk factors for prostate cancer (6). Whether prostate cancer is familial has not been dissolved completely, but several studies noted familial aggregation of prostate cancer and therefore Carter et al. $(7,8)$ conclude that there is evidence for familial risk factors for prostate cancer. Besides age, race and familial risk factors, environmental factors are thought to play a role in prostate cancer etiology because of the substantial variation in incidence rates worldwide. Environmental and genetic factors could also explain some of the differences in incidence rates between blacks and whites, but also hormonal factors might play a role $(9,10)$.

Dietary factors are among the environmental factors which may be important in prostate cancer etiology. Since 1980 a large number of reviews on prostate cancer have been published in which also dietary factors were described $(4,5,9,11-20)$. However, in the majority of these reviews potential dietary risk factors were only briefly addressed, not all published studies on a specific risk factor were included, or a small selection of potential dietary risk factors was evaluated $(4,5,9,11,13,16-18,20)$. Therefore, from these reviews no strong conclusions with respect to any of the investigated dietary risk factors could be drawn. There were only four reviews in which dietary factors were more extensively addressed $(12,14,15,19)$. One of these reviews was published some 10 years ago and, therefore, cannot be regarded as reviewing the state of the knowledge on dietary risk factors for prostate cancer (19). The other three reviews did not specifically address methodological aspects of the different studies included in the review and also only broad categories of different dietary foods were evaluated. Therefore, our review will both discuss methodological qualities of the different studies and results on several individual foods or nutrients. Because of the availability of a large number of prospective epidemiological studies and because prospective studies are less prone to bias compared with case-control studies, only these type of studies are included. 
Table 1: Descriptive characteristics of published prospective intervention studies on dietary risk factors for prostate cancer, ordered according to year of baseline measurement.

\begin{tabular}{|c|c|c|c|c|c|c|c|c|}
\hline $\begin{array}{l}\text { Country (ref) } \\
\text { Year of } \\
\text { publication }\end{array}$ & Baseline & $\begin{array}{l}\text { Cohort size } \\
\text { (age range) }{ }^{1}\end{array}$ & $\begin{array}{l}\text { Years of } \\
\text { follow-up }\end{array}$ & $\begin{array}{l}\text { Number of } \\
\text { cases } \\
(I \text { or } D)^{2}\end{array}$ & Design & Intervention & Placebo & Notes \\
\hline $\begin{array}{l}\text { USA (21) } \\
1996\end{array}$ & 1982 & $\begin{array}{l}22,071 \\
(40-84)\end{array}$ & 12 & 1047 (I\&D) & $\begin{array}{l}\text { two-by-two } \\
\text { factorial design }\end{array}$ & $\begin{array}{l}\beta \text {-carotene: } 50 \mathrm{mg} \\
\text { on alternate days }\end{array}$ & yes & physicians \\
\hline $\begin{array}{l}\text { USA (22) } \\
1998\end{array}$ & 1983 & $\begin{array}{l}974 \\
(63)^{3}\end{array}$ & 6.5 & $48(I)$ & $\begin{array}{l}\text { block } \\
\text { randomization by } \\
\text { time \& clinic }\end{array}$ & selenium $0.2 \mathrm{~g}$ daily & yes & $\begin{array}{l}\text { patients with } \\
\text { previous skin } \\
\text { cancer }\end{array}$ \\
\hline $\begin{array}{l}\text { Finland (23) } \\
1998\end{array}$ & $1985-1988$ & $\begin{array}{l}29,133 \\
(50-69) \\
\end{array}$ & $5-8$ & $246(1)$ & $\begin{array}{l}\text { two-by-two } \\
\text { factorial design }\end{array}$ & $\begin{array}{l}\alpha \text {-tocopherol: } 50 \mathrm{mg} \text { daily } \\
\beta \text {-carotene: } 20 \mathrm{mg} \text { daily }\end{array}$ & yes & smokers \\
\hline $\begin{array}{l}\text { USA (24) } \\
1996\end{array}$ & 1988 & $\begin{array}{l}18,314 \\
(58)^{3}\end{array}$ & 4 & $300(1)$ & $\begin{array}{l}\text { partly two-by-two } \\
\text { factorial design; } \\
\text { partly } 1: 1\end{array}$ & $\begin{array}{l}\text { B-carotene } 30 \mathrm{mg} \text { in } \\
\text { combination with } 25000 \\
\text { IU vitamin A daily }\end{array}$ & yes & $\begin{array}{l}\text { subjects at } \\
\text { high risk for } \\
\text { lung cancer }\end{array}$ \\
\hline
\end{tabular}

${ }^{1}$ Age range of the study population; ${ }^{2}$ I are incident cases, $\mathrm{D}$ are deceased cases; ${ }^{3}$ Mean age. 


\section{Methods}

The literature for this review was sought with MEDLINE, the computerized database from the Index Medicus. The keywords used were EPIDEMIOLOGY, ETIOLOGY, DIET, RISK FACTOR, COHORT, and STUDY, all in combination with PROSTATIC NEOPLASMS. Furthermore, references in the selected publications were checked to find other relevant publications not included in the MEDLINE search. Studies included in this review are prospective analytical epidemiological studies published between 1966, the earliest year covered by MEDLINE, and July 1998. Only those studies in which dietary intake was measured by blood samples or questionnaires or interviews, are included. Dietary factors that are described include vegetables, fruit, meat, fish, milk and dairy products, eggs, coffee, tea, vitamins, fat, fatty acids, selenium and alcohol. In addition, prospective studies on anthropometric measures are also reviewed. All individual dietary items with their original names as mentioned in the reports or measures of anthropometry that were investigated in the studies are listed in the tables. Items were considered to be associated with a decrease or increase in prostate cancer risk when the relative risk estimate for the highest vs lowest exposure category was below 0.8 (decrease) or above 1.2 (increase). Furthermore, all statistically significant findings are indicated in the tables by means of an asterix (*). All RRs in the tables refer to the highest vs lowest exposure category as mentioned in the cited study, unless otherwise indicated. After reviewing and discussing the results, implications for future research on dietary risk factors in relation to prostate cancer risk will be discussed.

\section{Results}

A total of four intervention studies (21-24) were identified and their descriptive characteristics are displayed in table 1. All trials were randomized and placebo-controlled; one trial was conducted in Finland (23) and the other three in the USA $(21,22,24)$.

A total of 34 cohort studies were found; 15 of these cohort studies (25-47) made use of blood samples to measure certain dietary factors (table 2) and 19 studies used questionnaires or interviews (48-69) to measure dietary risk factors (table 3 ). In general, the baseline measurement in most of the cohort studies was before 1980. The range in cohort size is very large, varying from $974(22)$ to 450,279 men (65). There are several studies with a total number of prostate cancer cases less than $60(22,25,32-35,37,38,40,42$, 58 ). The largest number of cases to date is a total of 1,748 (65). Endpoints used in different studies were both incidence and mortality. The majority of studies that used a questionnaire to measure dietary factors, did not mention whether the questionnaire was validated or not. Only in the Health Professionals Follow-Up Study (66-69), in the cohortbased part of the Alpha-Tocopherol Beta-Carotene Cancer Prevention Study (ATBC Study) (47) and in a Norwegian study (61) it is mentioned that the utilized questionnaire was 
Table 2: Descriptive characteristics of published prospective cohort studies on prostate cancer and dietary and anthropometric risk factors measured by blood samples only or in combination with questionnaires/interviews, ordered according to year of baseline measurement.

\begin{tabular}{|c|c|c|c|c|c|c|c|c|}
\hline $\begin{array}{l}\text { Country (ref) } \\
\text { Year of } \\
\text { publication }\end{array}$ & $\begin{array}{l}\text { Baseline } \\
\text { measurement }\end{array}$ & $\begin{array}{l}\text { Cohort size } \\
\text { (age range) }{ }^{1}\end{array}$ & $\begin{array}{l}\text { Years of } \\
\text { follow-up }\end{array}$ & $\begin{array}{l}\text { Number of } \\
\text { cases } \\
(I \text { or D })^{2}\end{array}$ & $\begin{array}{l}\text { Exposure } \\
\text { measurement }\end{array}$ & $\begin{array}{l}\text { Investigated exposure } \\
\text { variables }\end{array}$ & $\begin{array}{l}\text { Number of } \\
\text { items on diet } \\
\text { (alcohol) }\end{array}$ & $\begin{array}{l}\text { Validation } \\
\text { dietary } \\
\text { questionnaire }\end{array}$ \\
\hline $\begin{array}{l}\text { USA (25) } \\
1981\end{array}$ & $1960-1962$ & $\begin{array}{l}3,102 \\
(>40)\end{array}$ & $12-14$ & $8(I \& D)$ & blood sample & vitamins & - & - \\
\hline $\begin{array}{l}\text { USA }(26,27) \\
1993-1995\end{array}$ & $1964-1971$ & $\begin{array}{l}250,000^{3} \\
(38-81)\end{array}$ & $1-23$ & $181(\mathrm{l})$ & blood sample & vitamins & - & - \\
\hline $\begin{array}{l}\text { USA (32) } \\
1984\end{array}$ & $1967-1969$ & $?$ & $10-12$ & 14 (I\&D) & blood sample & vitamins & - & - \\
\hline $\begin{array}{l}\text { Finland }(33,34) \\
1988-1990\end{array}$ & $1968-1972$ & $\begin{array}{l}36,265^{3} \\
(15-99)\end{array}$ & $6-10$ & $32(1)$ & $\begin{array}{l}\text { blood sample; } \\
\text { questionnaire }\end{array}$ & vitamins & $\mathrm{NDQ}^{5}$ & - \\
\hline $\begin{array}{l}\text { USA (36) } \\
1990\end{array}$ & $1971-1975$ & $\begin{array}{l}2,440 \\
(>50)\end{array}$ & 10 & 84 (I\&D) & $\begin{array}{l}\text { blood sample; } \\
\text { questionnaire; } \\
\text { examination }\end{array}$ & vitamins & $\begin{array}{l}\text { NDQ } \\
\text { (unknown) }\end{array}$ & - \\
\hline $\begin{array}{l}\text { USA (37) } \\
1988\end{array}$ & $1972-1976$ & $\begin{array}{l}6,167 \\
(?)\end{array}$ & $0-10$ & $13(1)$ & blood sample & vitamins, selenium & - & - \\
\hline $\begin{array}{l}\text { USA (38) } \\
1991\end{array}$ & $1972-1976$ & $\begin{array}{l}8,825 \\
(>30)\end{array}$ & 8.5 & 6 (D) & $\begin{array}{l}\text { blood sample; } \\
\text { interview }\end{array}$ & vitamins, selenium & $N^{2} Q^{5}$ & - \\
\hline
\end{tabular}


Table 2 continued

\begin{tabular}{|c|c|c|c|c|c|c|c|c|}
\hline $\begin{array}{l}\text { Country (ref) } \\
\text { Year of } \\
\text { publication }\end{array}$ & $\begin{array}{l}\text { Baseline } \\
\text { measurement }\end{array}$ & $\begin{array}{l}\text { Cohort size } \\
\text { (age range) }\end{array}$ & $\begin{array}{l}\text { Years of } \\
\text { follow-up }\end{array}$ & $\begin{array}{l}\text { Number of } \\
\text { cases } \\
(\operatorname{lor} D)^{2}\end{array}$ & $\begin{array}{l}\text { Exposure } \\
\text { measurement }\end{array}$ & $\begin{array}{l}\text { Investigated exposure } \\
\text { variables }\end{array}$ & $\begin{array}{l}\text { Number of } \\
\text { items on diet } \\
\text { (alcohol) }\end{array}$ & $\begin{array}{l}\text { Validation } \\
\text { dietary } \\
\text { questionnaire }\end{array}$ \\
\hline $\begin{array}{l}\text { Sweden (39) } \\
1994\end{array}$ & $1972-1978$ & $\begin{array}{l}53,242 \\
(20-55)\end{array}$ & 16.3 & $220(I)$ & $\begin{array}{l}\text { blood sample; } \\
\text { questionnaire; } \\
\text { examination }\end{array}$ & fatty acids, anthropometry & $\mathrm{NDQ}^{5}$ & - \\
\hline $\begin{array}{l}\text { USA (40) } \\
1984\end{array}$ & $1973-1974$ & $\begin{array}{l}4,480 \\
(30-69)\end{array}$ & 5 & $11(I)$ & blood sample & vitamins & - & - \\
\hline $\begin{array}{l}\text { Norway (41) } \\
1997\end{array}$ & $1973-1994$ & $\begin{array}{l}? \\
(50)\end{array}$ & $0.4-19.2$ & $141(I)$ & blood sample & fat, fatty acids & - & - \\
\hline $\begin{array}{l}\text { USA }(42,43) \\
1990-1996\end{array}$ & 1974 & $\begin{array}{l}25,802 \\
(?)\end{array}$ & $12 ?$ & $43-103(I)$ & blood sample & vitamins, fatty acids & - & - \\
\hline $\begin{array}{l}\text { USA (44-46) } \\
1994-1997\end{array}$ & 1982 & $\begin{array}{l}22,071 \\
(40-84)\end{array}$ & $6-12$ & $120-1,047^{4}(I)$ & $\begin{array}{l}\text { blood sample; } \\
\text { questionnaire }\end{array}$ & $\begin{array}{l}\text { meat, dairy, vitamins, } \\
\text { fatty acids, anthropometry }\end{array}$ & $\begin{array}{l}\text { (unknown) } \\
\text { (unknown) }\end{array}$ & unknown \\
\hline $\begin{array}{l}\text { Finland (47) } \\
1998\end{array}$ & $1985-1993$ & $\begin{array}{l}29,133 \\
(50-69)\end{array}$ & 7 & $317(I)$ & $\begin{array}{l}\text { blood sample; } \\
\mathrm{FFQ}^{5}\end{array}$ & vitamins, selenium & 203 & yes \\
\hline
\end{tabular}

${ }^{1}$ Age range of the study population; ${ }^{2}$ I are incident cases, $D$ are deceased cases; ${ }^{3}$ Only a total of men and women is given; ${ }^{4}$ Number of cases depending on exposure under study; ${ }^{5} \mathrm{FFQ}=$ food frequency questionnaire, $\mathrm{NDQ}=$ no dietary questionnaire. 
Table 3: Descriptive characteristics of published prospective cohort studies on dietary risk factors measured by questionnaires or interviews and on anthropometric risk factors for prostate cancer, ordered according to year of baseline measurement.

\begin{tabular}{|c|c|c|c|c|c|c|c|c|}
\hline $\begin{array}{l}\text { Country (ref) } \\
\text { Year of } \\
\text { publication }\end{array}$ & $\begin{array}{l}\text { Baseline } \\
\text { measurement }\end{array}$ & $\begin{array}{l}\text { Cohort size } \\
\text { (age range) })^{1}\end{array}$ & $\begin{array}{l}\text { Years of } \\
\text { follow-up }\end{array}$ & $\begin{array}{l}\text { Number of } \\
\text { cases } \\
(1 \text { or D })^{2}\end{array}$ & $\begin{array}{l}\text { Exposure } \\
\text { measurement }\end{array}$ & $\begin{array}{l}\text { Investigated exposure } \\
\text { variables }\end{array}$ & $\begin{array}{l}\text { Number of items } \\
\text { on diet } \\
\text { (alcohol) } \\
\end{array}$ & $\begin{array}{l}\text { Validation } \\
\text { dietary } \\
\text { questionnaire } \\
\end{array}$ \\
\hline $\begin{array}{l}\text { USA (48) } \\
1974\end{array}$ & $1880-1916$ & $\begin{array}{l}18,000 \\
\text { (college } \\
\text { attendents) }\end{array}$ & $?$ & 268 (D) & measurement & anthropometry & - & - \\
\hline $\begin{array}{l}\text { USA (49) } \\
1985\end{array}$ & $1916-1950$ & $\begin{array}{l}51,477 \\
\text { (college } \\
\text { attendents) }\end{array}$ & $16-50$ & $243(I \& D)$ & $\begin{array}{l}\text { questionnaire; } \\
\text { examination }\end{array}$ & $\begin{array}{l}\text { alcohol, } \\
\text { anthropometry }\end{array}$ & (unknown) & unknown \\
\hline $\begin{array}{l}\text { Denmark (50) } \\
1994\end{array}$ & $1954-1987$ & $\begin{array}{l}15,214 \\
(?)\end{array}$ & 12.9 & $91(\mathrm{I})$ & interview & alcohol & & \\
\hline $\begin{array}{l}\text { USA (51) } \\
1996\end{array}$ & $1957-1958$ & $\begin{array}{l}1,899 \\
(40-55)\end{array}$ & 30 & 132 (I\&D) & $\begin{array}{l}\text { interview; } \\
\text { questionnaire; } \\
\text { dietary history }\end{array}$ & vitamins & 195 & unknown \\
\hline $\begin{array}{l}\text { USA (52) } \\
1986\end{array}$ & 1959 & $\begin{array}{l}336,442 \\
(?)\end{array}$ & 12 & $?$ (D) & questionnaire & anthropometry & - & - \\
\hline $\begin{array}{l}\text { USA (53) } \\
1984\end{array}$ & 1960 & $\begin{array}{l}6,763 \\
(>60) \\
\end{array}$ & 21 & 99 (D) & questionnaire & $\begin{array}{l}\text { vegetables, fruits, meat, } \\
\text { milk, eggs, anthropometry }\end{array}$ & $14 ?$ & unknown \\
\hline $\begin{array}{l}\text { Japan }(54) \\
1990\end{array}$ & 1965 & $\begin{array}{l}122,261 \\
(>40)\end{array}$ & 17 & $183(D)$ & interview & $\begin{array}{l}\text { vegetables, meat, milk, } \\
\text { eggs, alcohol }\end{array}$ & $\begin{array}{l}7 \\
(2) \\
\end{array}$ & unknown \\
\hline $\begin{array}{l}\text { USA (55) } \\
1990\end{array}$ & 1966 & $\begin{array}{l}17,633 \\
(>35)\end{array}$ & 20 & 149 (D) & $\begin{array}{l}\text { mailed } \\
\text { questionnaire }\end{array}$ & $\begin{array}{l}\text { vegetables, fruits, meat, } \\
\text { milk, fish, eggs, coffee, } \\
\text { alcohol }\end{array}$ & $\begin{array}{l}35 \\
(2 ?)\end{array}$ & unknown \\
\hline $\begin{array}{l}\text { Sweden (56) } \\
1996\end{array}$ & $1967-1970$ & $\begin{array}{l}9,152 \\
(42-81)\end{array}$ & 22 & 406 (?) & questionnaire & $\begin{array}{l}\text { vegetables, fruits, meat, } \\
\text { fish, milk, eggs, coffee, } \\
\text { alcohol }\end{array}$ & $\begin{array}{l}10 \\
(4)\end{array}$ & unknown \\
\hline
\end{tabular}


Table 3 continued

\begin{tabular}{|c|c|c|c|c|c|c|c|c|}
\hline $\begin{array}{l}\text { Country (ref) } \\
\text { Year of } \\
\text { publication }\end{array}$ & $\begin{array}{l}\text { Baseline } \\
\text { measurement }\end{array}$ & $\begin{array}{l}\text { Cohort size } \\
\text { (age range) }\end{array}$ & $\begin{array}{l}\text { Years of } \\
\text { follow-up }\end{array}$ & $\begin{array}{l}\text { Number of } \\
\text { cases } \\
(\text { I or D })^{2}\end{array}$ & $\begin{array}{l}\text { Exposure } \\
\text { measurement }\end{array}$ & $\begin{array}{l}\text { Investigated exposure } \\
\text { variables }\end{array}$ & $\begin{array}{l}\text { Number of items } \\
\text { on diet } \\
\text { (alcohol) }\end{array}$ & $\begin{array}{l}\text { Validation } \\
\text { dietary } \\
\text { questionnaire }\end{array}$ \\
\hline $\begin{array}{l}\text { Sweden (57) } \\
1997\end{array}$ & $1971-1975$ & $\begin{array}{l}135,006 \\
(<30-\geq 60)\end{array}$ & 20 & $2,368(I \& D)$ & $\begin{array}{l}\text { questionnaire; } \\
\text { measurement }\end{array}$ & anthropometry & - & - \\
\hline $\begin{array}{l}\text { USA (58) } \\
1989\end{array}$ & $1972-1974$ & $\begin{array}{l}1,776 \\
(50-84)\end{array}$ & 14 & $54(\mathrm{l})$ & $\begin{array}{l}\text { interview; } \\
\text { examination }\end{array}$ & $\begin{array}{l}\text { milk, eggs, } \\
\text { anthropometry }\end{array}$ & 2 & unknown \\
\hline $\begin{array}{l}\text { USA (59) } \\
1994\end{array}$ & $1975-1980$ & $\begin{array}{l}20,316 \\
(>45)\end{array}$ & 14 & $198(l)$ & $\begin{array}{l}\text { interview; } \\
\text { questionnaire }\end{array}$ & $\begin{array}{l}\text { vegetables, fruits, meat, } \\
\text { fish, milk, eggs, coffee, } \\
\text { alcohol, anthropometry }\end{array}$ & 13 & no \\
\hline $\begin{array}{l}\text { USA (60) } \\
1989\end{array}$ & 1976 & $\begin{array}{l}14,000 \\
(>25)\end{array}$ & 6 & $180(\mathrm{l})$ & questionnaire & $\begin{array}{l}\text { vegetables, fruits, alcohol, } \\
\text { meats, milk, fish, eggs }\end{array}$ & unknown & unknown \\
\hline $\begin{array}{l}\text { Norway (61) } \\
1997\end{array}$ & $1977-1983$ & $\begin{array}{l}25,708 \\
(16-56)\end{array}$ & 12.4 & $72(I)$ & $\mathrm{FFQ}^{3}$ & $\begin{array}{l}\text { meat, fish, milk, eggs, } \\
\text { fat, anthropometry }\end{array}$ & 80 & yes \\
\hline $\begin{array}{l}\text { USA (62) } \\
1994\end{array}$ & $1978-1985$ & $\begin{array}{l}43,432 \\
(>30)\end{array}$ & 4.6 & $238(I)$ & questionnaire & alcohol & (unknown) $^{5}$ & unknown ${ }^{4}$ \\
\hline $\begin{array}{l}\text { USA (63) } \\
1992\end{array}$ & $1981-1985$ & $\begin{array}{l}11,577 \\
(>60)\end{array}$ & 8 & $208(1)$ & questionnaire & $\begin{array}{l}\text { vegetables, fruits, } \\
\text { vitamins }\end{array}$ & 59 & unknown \\
\hline $\begin{array}{l}\text { USA (64) } \\
1997\end{array}$ & 1982 & $\begin{array}{l}1,050 \\
(>65) \\
\end{array}$ & 11 & $71(1)$ & interview & alcohol, anthropometry & (unknown) & unknown \\
\hline $\begin{array}{l}\text { USA (65) } \\
1997\end{array}$ & 1982 & $\begin{array}{l}450,279 \\
(>30)\end{array}$ & 9 & $1,748(D)$ & questionnaire & vegetables & unknown & unknown \\
\hline $\begin{array}{l}\text { USA (66-69) } \\
1993-1998\end{array}$ & 1986 & $\begin{array}{l}51,529 \\
(40-75)\end{array}$ & $6-8$ & $\begin{array}{l}300-1369^{6} \\
(I \& D)\end{array}$ & $\mathrm{FFQ}^{3}$ & $\begin{array}{l}\text { vegetables, fruits, meat, } \\
\text { milk, eggs, fat, fatty acids, } \\
\text { vitamins, anthropometry }\end{array}$ & 131 & yes \\
\hline
\end{tabular}

${ }^{1}$ Age range of the study population; ${ }^{2}$ I are incident cases, $\mathrm{D}$ are deceased cases; ${ }^{3} \mathrm{FFQ}=$ food frequency questionnaire; ${ }^{4} \mathrm{Data}$ compared closely to data from 7-day recall; ${ }^{5}$ Questions on current and past consumption, number of drinks consumed per day, and the type of alcoholic beverage; ${ }^{6}$ Number of cases depending on exposure under study. 
validated. These studies also had the most extensive questionnaires on diet. Other studies used questionnaires more limited in size.

In tables 4-7 results from intervention studies and cohort studies on dietary risk factors for prostate cancer are displayed. Table 4 shows results from the four trials on $\beta$-carotene, retinol, vitamin E and selenium. In the ATBC Study (23) and the Physicians' Health Study (21) no effect of supplementation with $\beta$-carotene was observed and in the Beta-Carotene and Retinol Efficacy Trial (CARET) no effect of supplementation with $\beta$-carotene and retinol was found (24). Significant decreased risks were found for supplementation with vitamin $E$ in the ATBC Study (23) and for selenium in the Nutritional Prevention of Cancer Trial (22).

Table 4: Results on nutrients in relation to risk of prostate cancer from prospective intervention studies.

\begin{tabular}{|c|c|c|c|c|}
\hline \multirow[t]{2}{*}{ Exposure } & \multicolumn{2}{|l|}{ Effect estimate $<0.8$} & \multicolumn{2}{|c|}{ Effect estimate 0.8-1.2 } \\
\hline & Item & Effect estimate (ref) $^{1}$ & Item & Effect estimate (ref) ${ }^{\prime}$ \\
\hline Vitamins & vitamin E (suppl.) & $0.64^{*}(23)$ & $\begin{array}{c}\beta \text {-carotene (suppl.) } \\
\beta \text {-carotene + retinol } \\
\text { (suppl.) }\end{array}$ & $\begin{array}{l}1.20(23), N^{2}(21) \\
1.01(24)\end{array}$ \\
\hline
\end{tabular}

Selenium selenium (suppl.) $\quad 0.37^{*}(22)$

${ }^{1}$ Effect estimates for highest versus lowest exposure category, asterix (*) denotes statistically significant finding; ${ }^{2} \mathrm{NS}=$ not significant.

Results on vitamins and selenium from cohort studies using blood samples (table 5) or questionnaires (table 6) were mostly inconsistent. From the studies shown in table 5, some found decreased risks for serum levels of vitamin $A(36)$ or retinol $(38,43)$, some found no association for levels of retinol $(32)$ or carotenes $(35,43)$ and some found increased risks for serum retinol levels $(33,35,37,40)$ or carotene levels $(33,40)$. In questionnaire-based studies mostly null associations were found for vitamin $A(55,65)$, retinol $(55)$ or carotenes $(51,55,63,68)$. In one study a significant increase in risk was observed for intake of retinol (68). In two cohort studies investigating serum levels of vitamin $E$ decreased associations were indicated $(34,40)$ and in two other studies no associations were observed $(43,47)$. Vitamin $\mathrm{E}$ intake based on questionnaire measurement also showed no association with prostate cancer risk in two studies $(63,68)$. Serum levels of selenium were associated with a decreased prostate cancer risk in two cohort studies $(37,38)$ and in one cohort study no association was observed (47).

Other carotenoids or vitamins investigated in cohort studies include lycopene, and vitamins $\mathrm{C}$ and $\mathrm{D}$. Lycopene showed an inverse association with prostate cancer risk in both a serum-based (43) and a questionnaire-based (68) study. For vitamin $C$ serum levels no 
Table 5: Results on nutrients in relation to risk of prostate cancer from prospective cohort studies using blood samples for exposure measurement.

\begin{tabular}{|c|c|c|c|c|c|c|}
\hline Exposure & \multicolumn{2}{|l|}{ Effect estimate $<0.8$} & \multicolumn{2}{|l|}{ Effect estimate 0.8-1.2 } & \multicolumn{2}{|l|}{ Effect estimate $>1.2$} \\
\hline Vitamins & $\begin{array}{l}\text { vitamin } A \\
\text { retinol } \\
\text { lycopene } \\
\text { vitamin } D(1,25-D) \\
\text { vitamin } E\end{array}$ & $\begin{array}{l}0.4^{*}(36) \\
0.40(43), \mathrm{CL}^{2}(38) \\
0.50(43) \\
\mathrm{CL}^{* 2}(27) \\
0.60(34), \mathrm{CL}^{2}(40)\end{array}$ & $\begin{array}{l}\text { retinol } \\
\text { carotenes } \\
\beta \text {-carotene } \\
\text { vitamin C } \\
\text { vitamin D (25-D) } \\
\text { vitamin D (1,25-D) } \\
\text { vitamin E } \\
\text { vitamin E (suppl.) }\end{array}$ & $\begin{array}{l}\operatorname{NS}^{2}(32) \\
0.92(35) \\
1.08(43) \\
0.93(35) \\
0.92(45), \mathrm{CS}^{2}(27) \\
0.88(45) \\
\mathrm{NS}^{2}(47), 1.00(43) \\
\mathrm{NS}^{2}(47)\end{array}$ & $\begin{array}{l}\text { retinol } \\
\text { carotenoids } \\
\beta \text {-carotene }\end{array}$ & $\begin{array}{l}1.48(35), 1.4(33), \\
3.0(37), \mathrm{CH}^{2}(40) \\
\mathrm{CH}^{2}(40) \\
5.0^{*}(33)\end{array}$ \\
\hline Selenium & selenium & $\mathrm{CL}^{2}(38), 0.3(37)$ & selenium & $\mathrm{NS}^{2}(47)$ & & \\
\hline Fat & $\begin{array}{l}\text { n-6 pufa } \\
\text { stearic acid } \\
\text { linoleic acid } \\
\text { arachidic acid } \\
\text { docosanoic acid } \\
\text { docosapentaenoic } \\
\quad \text { acid } \\
\text { tetracosanoic acid } \\
\text { tetracosenoic acid }\end{array}$ & $\begin{array}{l}0.7(41) \\
0.35(46) \\
0.62(46) \\
0.7(41) \\
0.7(41) \\
\\
0.7(41) \\
0.5^{*}(41) \\
0.7(41)\end{array}$ & $\begin{array}{l}\text { total fat } \\
\text { total fatty acids } \\
\text { saturated fat } \\
\text { unsaturated fat } \\
\text { polyunsaturated fat } \\
\mathrm{n}-6 \text { fatty acids } \\
\mathrm{n}-3 \text { fatty acids } \\
\mathrm{n}-3 \text { pufa } \\
\text { linoleic acid } \\
\text { palmitic acid } \\
\text { eicosapentaenoic acid } \\
\text { eicosenoic acid } \\
\text { eicosadienoic acid } \\
\text { dihomo-v-linoleic acid } \\
\text { arachidonic acid } \\
\text { eicosapentaenoic acid } \\
\text { docosahexaenoic acid }\end{array}$ & $\begin{array}{l}0.87(30) \\
1.1(41), 1.05^{3}(39) \\
1.00(30) \\
1.09(30) \\
1.1(41) \\
\mathrm{NA}^{2}(42) \\
\mathrm{NA}^{2}(42) \\
1.1(41) \\
0.9(41) \\
0.90(46) \\
0.87(46) \\
1.2(41) \\
1.0(41) \\
1.1(41) \\
0.8(41) \\
1.2(41) \\
1.0(41)\end{array}$ & $\begin{array}{l}\text { saturated fat } \\
\text { monounsaturated fat } \\
\alpha \text {-linolenic acid } \\
\text { oleic acid } \\
\text { arachidonic acid } \\
\text { myristic acid } \\
\text { palmitic acid } \\
\text { palmitoleic acid } \\
\text { stearic acid }\end{array}$ & $\begin{array}{l}1.6(41) \\
1.3(41) \\
2.0^{*}(41), 2.14(46) \\
1.8^{*}(41), 1.50(46) \\
1.36(46) \\
1.8^{*}(41) \\
2.3^{*}(41) \\
2.8^{*}(41) \\
1.3(41)\end{array}$ \\
\hline
\end{tabular}

${ }^{1}$ Effect estimates for highest versus lowest exposure category, asterix ( $\left.{ }^{*}\right)$ denotes statistically significant finding; ${ }^{2} \mathrm{CL}=$ cases lower level than controls, NS=not significantly associated, CS=cases similar level than controls, $\mathrm{CH}=$ cases higher level than controls, NA=not associated; ${ }^{3}$ Triglycerides per mmol/iter. 
Table 6: Results on nutrients in relation to risk of prostate cancer from prospective cohort studies using questionnaires or interviews for exposure measurement.

\begin{tabular}{|c|c|c|c|c|c|c|}
\hline \multirow[t]{2}{*}{ Exposure } & \multicolumn{2}{|c|}{ Effect estimate $<0.8$} & \multicolumn{2}{|c|}{ Effect estimate 0.8-1.2 } & \multicolumn{2}{|l|}{ Effect estimate $>1.2$} \\
\hline & Item & Effect estimate (ref) ${ }^{1}$ & Item & Effect estimate (ref) $^{1}$ & Item & Effect estimate (ref) \\
\hline Vitamins & lycopene & $0.79 *(68)$ & $\begin{array}{l}\text { vitamin } A \\
\text { vitamin } A \text { (suppl.) } \\
\text { retinol } \\
\alpha \text {-carotene } \\
\beta \text {-carotene } \\
\beta \text {-cryptoxanthin } \\
\text { lutein } \\
\text { vitamin } C \\
\text { vitamin } C \text { (suppl.) } \\
\text { vitamin } E \\
\text { vitamin } E \text { (suppl.) }\end{array}$ & $\begin{array}{l}1.13(68), 1.1(55) \\
1.13(63) \\
1.2(55) \\
1.09(68) \\
1.05(68), 1.04(51), \\
1.09(63), 0.9(55) \\
0.94(68) \\
1.10(68) \\
1.09(68), 0.96(63) \\
1.00(63) \\
0.94(68) \\
1.00(63)\end{array}$ & $\begin{array}{l}\text { retinol } \\
\text { vitamin C }\end{array}$ & $\begin{array}{l}1.32^{*}(68) \\
1.30(51)\end{array}$ \\
\hline Fat & saturated fat & $0.7(61)$ & $\begin{array}{l}\text { saturated fat } \\
\text { linoleic acid }\end{array}$ & $\begin{array}{l}0.84(69) \\
0.88(69)\end{array}$ & $\begin{array}{l}\text { total fat } \\
\text { monounsaturated fat } \\
\text { polyunsaturated fat } \\
\text { animal fat } \\
\alpha \text {-linolenic acid }\end{array}$ & $\begin{array}{l}1.32(69), 1.3(61) \\
1.4(61), 1.86(69) \\
1.4(61) \\
1.35(60) \\
1.25(69)\end{array}$ \\
\hline
\end{tabular}

'Effect estimates for highest versus lowest exposure category, asterix (") denotes statistically significant finding. 
association was observed (35) and in two studies using questionnaires also no associations were found $(63,68)$. In one study an increased association was indicated (51). Vitamin $D$ metabolite levels $(1,25-D)$ measured in blood samples showed either an inverse association (27) or no association (45). For levels of 25-D no associations were apparent $(27,45)$.

Results on fat and fatty acids are also shown in tables 5 and 6 . Total fat or total fatty acids were not associated with risk of prostate cancer in serum-based studies $(30,39,41)$ but from questionnaire-based studies positive associations were suggested $(61,69)$. Saturated fat showed one null association (30) and one positive association (41) from serum-based studies and an inverse (61), and a null association (69) from questionnaire-based studies. For different categorizations of unsaturated fat mostly null associatons were observed in serum-based studies $(30,41,42)$, nevertheless, an inverse association was found for $n-6$ pufa (41) and a positive association was observed for monounsaturated fat (41). In two questionnaire-based studies increased risks were indicated for intake of monounsaturated fat $(61,69)$ and polyunsaturated fat $(61)$. Linoleic acid and $\alpha$-linolenic acid are two fatty acids which have most frequently been investigated with respect to risk of prostate cancer. For linoleic acid an inverse (46) and a null association (41) from serum-based studies have been reported and from questionnaire-based studies a null association was observed (69). Linolenic acid showed increased prostate cancer risks from both serum-based $(41,46)$ and questionnaire-based studies (69). In two serum-based studies several other fatty acids were investigated $(41,46)$ but consistent associations were not observed.

Table 7 summarizes results on foods and alcohol; exposure measurement in all studies is based on questionnaires or interviews. Consumption of total vegetables showed inverse associations $(55,65)$ as well as null associations $(63,68)$. Furthermore, inverse associations were observed for consumption of green salads $(60)$, tomatoes $(60,68)$ and beans, lentils and peas combined (60) and positive associations were observed for consumption of cruciferous vegetables (55), fried vegetables (30), cooked and raw spinach (68). Several other (grouped) vegetables were investigated for which no associations with prostate cancer risk were indicated. Overall consumption of fruit showed mostly a null association with risk of prostate cancer $(53,55,60,63,68)$, but in one study an increased risk was observed (30). For other items on fruit mostly no associations were observed, only for consumption of raisins, dates and other dried fruit a decreased prostate cancer risk was suggested (60).

In two studies overall meat consumption was not related to prostate cancer risk $(30,55)$ but in one study an increased risk was observed (54) and in another study a decreased risk was observed (61). For consumption of several types of meat either no association or positive associations were observed. Consumption of fish was positively associated with 
prostate cancer risk in two cohort studies $(30,60)$, inversely in one study (54) and not associated in four other prospective studies $(55,56,59,61)$.

Consumption of milk or other dairy products was either not associated with risk of prostate cancer or positively associated. Positive associations were suggested for consumption of milk $(53,59)$, skim milk (61), cheese (53), butter, margarine and cheese combined (30), and icecream (30). In six cohort studies consumption of eggs was not significantly related to prostate cancer risk $(55,56,58,59,61,68)$. A positive association, nevertheless, was suggested in two cohort studies $(30,53)$ and an inverse association in one cohort study (60).

Coffee consumption was investigated in four cohort studies $(30,55,56,59)$ but only in one study an association with risk of prostate cancer was observed, which was positive (56). In one study no association was found for black tea and for green tea a borderline significant increase in risk was noted (30). Exclusion of latent cases in one of the studies did not change the results.

Nine cohort studies were identified in which alcohol consumption in relation to risk of prostate cancer was investigated. Overall consumption of alcohol was mostly not associated with risk of prostate cancer $(30,56,59,62,64)$ but in one study a decreased risk was observed $(60)$ and in two cohort studies increased risks were noted $(50,54)$. Specific types of alcolic beverages were mostly not associated with risk of prostate cancer $(54,55,56)$ but for consumption of spirits (56) and shochu (54) decreased and increased associations, respectively, were observed.

Table 8 presents results from prospective cohort studies on anthropometric variables in relation to risk of prostate cancer. In four studies a significant positive association between height and prostate cancer risk was observed $(44,57,59,67)$. In five other studies there was no association $(39,48,49,62,64)$. Weight showed either null associations $(48,59,62)$ or positive associations $(29,52,53,57,64)$. Body mass index (BMI) has been investigated most frequently. Although several studies showed no association between BMI and prostate cancer risk $(57,58,60,62,70)$, positive associations were found in about an equal number of studies $(31,39,56,61,64)$. Some other measures of body fat distribution were investigated with equivocal findings. Studies on BMI at earlier ages are too few to draw conclusions yet $(49,64,70)$.

Only a few of all prospective studies investigated latent and nonlatent or advanced prostate tumors separately $(27,30,41,46,59,64,67-69,71)$. Although for some risk factors, e.g. vitamin D (27), total fat, monounsaturated fat and $\alpha$-linolenic acid (69), and BMI (64) associations were reported to be stronger for advanced or aggressive prostate tumors, for 
Table 7: Results on foods and alcohol in relation to risk of prostate cancer from prospective epidemiological studies using questionnaires or interviews for exposure measurement.

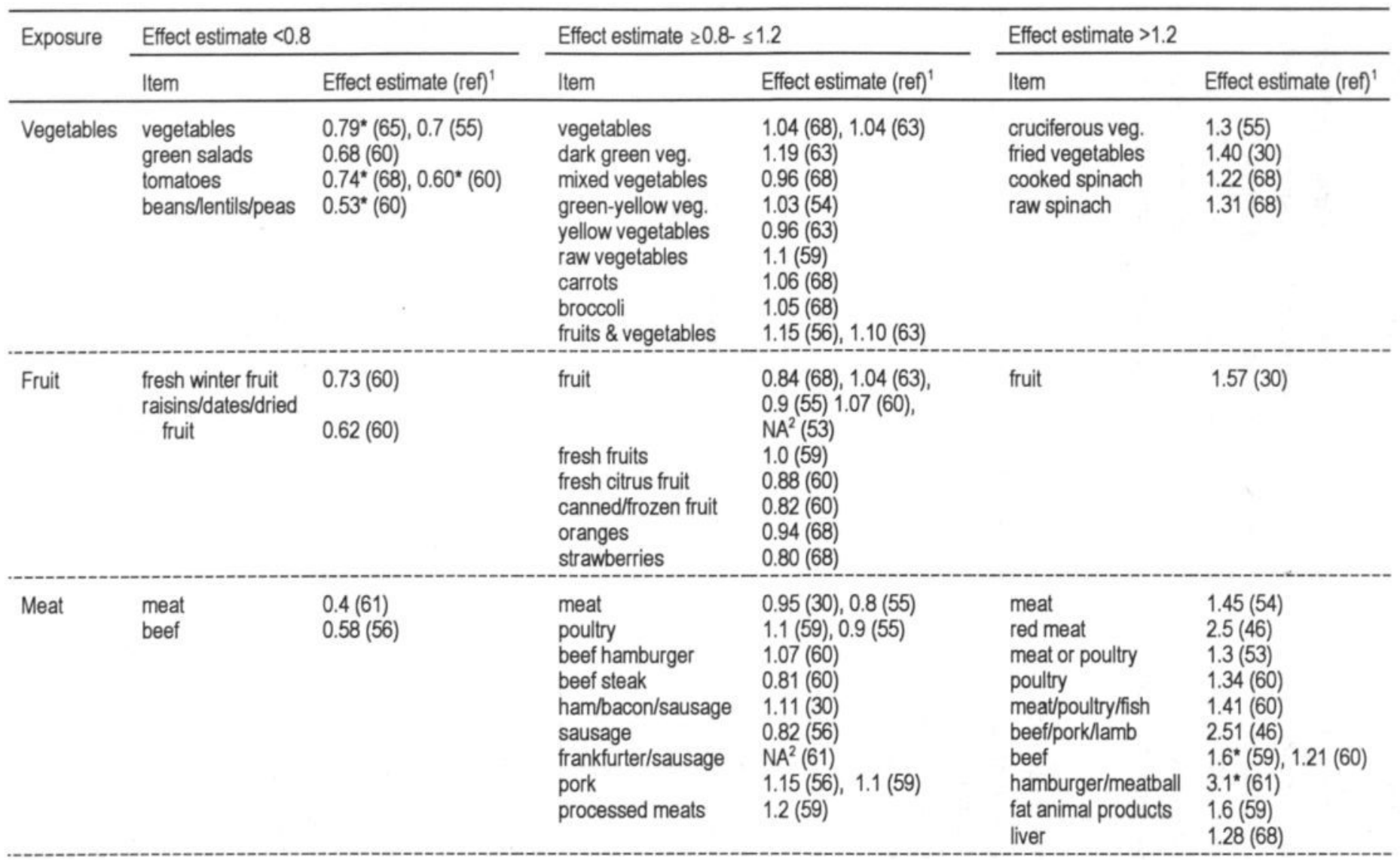


Table 7 continued

\begin{tabular}{|c|c|c|c|c|c|c|}
\hline \multirow[t]{2}{*}{ Exposure } & \multicolumn{2}{|c|}{ Effect estimate $<0.8$} & \multicolumn{2}{|c|}{ Effect estimate $\geq 0.8-\leq 1.2$} & \multicolumn{2}{|l|}{ Effect estimate $>1.2$} \\
\hline & Item & Effect estimate (ref) ${ }^{1}$ & Item & Effect estimate (ref) ${ }^{1}$ & Item & Effect estimate (ref) $)^{1}$ \\
\hline Fish & fish & $0.54(54)$ & fish & $\begin{array}{l}0.99(56), \mathrm{NA}^{2}(61) \\
1.2(59), 0.8(55)\end{array}$ & fish & $1.22(30), 1.57(60)$ \\
\hline $\begin{array}{l}\text { Milk, } \\
\text { dairy }\end{array}$ & & . & $\begin{array}{l}\text { milk } \\
\text { whole milk } \\
\text { dairy }\end{array}$ & $\begin{array}{l}\mathrm{NA}^{2}(68), 1.00(30) \\
0.84(56), 1.08(54) \\
0.80(60), 0.9^{3}(58) \\
N^{2}(46), 1.0(55)\end{array}$ & $\begin{array}{l}\text { milk } \\
\text { skim vs whole milk } \\
\text { cheese } \\
\text { butter/margarin/ } \\
\quad \text { cheese } \\
\text { icecream }\end{array}$ & $\begin{array}{l}1.4(59), 1.5(53) \\
2.2^{*}(61) \\
1.4(53) \\
1.47(30) \\
1.31(30)\end{array}$ \\
\hline Eggs & eggs & $0.76(60)$ & eggs & $\begin{array}{l}\mathrm{NA}^{2}(61,68), 0.85(56) \\
1.1(59), 0.9(55) \\
1.0^{4}(58)\end{array}$ & eggs & $1.57(30), 1.3(53)$ \\
\hline $\begin{array}{l}\text { Coffee, } \\
\text { tea }\end{array}$ & & & $\begin{array}{l}\text { coffee } \\
\text { black tea }\end{array}$ & $\begin{array}{l}0.92(30), 1.1(59) \\
1.0(55) \\
0.83(30)\end{array}$ & $\begin{array}{l}\text { coffee } \\
\text { green tea }\end{array}$ & $\begin{array}{l}1.91(56) \\
1.47^{*}(30)\end{array}$ \\
\hline Alcohol & $\begin{array}{l}\text { alcohol } \\
\text { spirits }\end{array}$ & $\begin{array}{l}0.71(60) \\
0.78(56)\end{array}$ & $\begin{array}{l}\text { alcohol } \\
\text { lifetime ethanol } \\
\text { beer } \\
\text { wine } \\
\text { liquor }\end{array}$ & $\begin{array}{l}1.0(64), 1.09(30), \\
0.89(56), 1.0(62) \\
1.1(59) \\
0.84(56), 0.94(54), \\
1.2(55) \\
1.18(56) \\
1.0(55)\end{array}$ & $\begin{array}{l}\text { alcohol } \\
\text { alcohol abusers } \\
\text { shochu }\end{array}$ & $\begin{array}{l}1.38(54) \\
1.4^{*}(50) \\
2.34^{*}(54)\end{array}$ \\
\hline
\end{tabular}

'Effect estimates for highest versus lowest exposure category, asterix ( $\left.{ }^{*}\right)$ denotes statistically significant finding; ${ }^{2} \mathrm{NA}=$ not associated; ${ }^{3} \mathrm{Per}$ cup per day; ${ }^{4} \mathrm{Per}$ egg per week. 
other risk factors like carotenoids (68), fried vegetables and fruit (30), beef and high-fat animal products (59), and milk and eggs (30) associations in subgroups based on tumor characterization were reported to be similar.

\section{Discussion}

From earlier reviews it is concluded that results from case-control studies on risk factors for prostate cancer are inconclusive $(12,14)$. In this review, only prospective studies on risk factors for prostate cancer have been summarized, and data from these studies also lead to the conclusion of inconsistent results. At most, we can state that there is some evidence that certain dietary factors could be protective (e.g. vitamin E, selenium) or are associated with an increase in prostate cancer risk (e.g. height), but convincing evidence is lacking.

Chance variation might be one of the reasons for the largely inconsistent findings.

Furthermore, we used only published literature in the English language. If certain risk factors were evaluated in different studies but not published because no association was observed, this could have influenced our results. However, results that were mentioned in the results or discussion section of articles without giving effect estimates, were also included in this review. Furthermore, given the high incidence of prostate cancer and the largely unknown etiology of the disease, any findings on possible risk factors are likely to result in publication. The chance of missing published papers seems very small, because we not only used different keywords, but also checked the references within the reports we found through Medline.

Methodological drawbacks are also important in explaining the largely inconsistent findings. A major methodological shortcoming in the majority of the cited studies is the very limited measurement of dietary exposure. Crude dietary exposure information gathered with questionnaires or interviews could have resulted in misclassification and, consequently, in biased results. Furthermore, only in the reports of Hartman et al. (47) and Giovannucci et al. $(68,69)$ the validation of the questionnaire has been described. In one other study it is mentioned that the questionnaire was not validated (59). In all other questionnaire or interview based studies the validity of the measures that were used to estimate dietary intake has not been described. Several studies used blood samples to measure nutrients and these studies were summarized separately. Certainly, random misclassification of exposure could also have resulted in an underestimation of effect in these studies.

Another consequence of the limited exposure measurement in the majority of studies is that several possible risk factors have only briefly been investigated. For example, different types of individual vegetables and fruit have not been investigated thus far. Also, data on individual types of alcoholic beverages is lacking. Furthermore, if individual dietary foods or nutrients have been addressed, this has mostly been done by a limited number of studies. 
Table 8: Results from prospective epidemiological studies on anthropometry in relation to risk of prostate cancer.

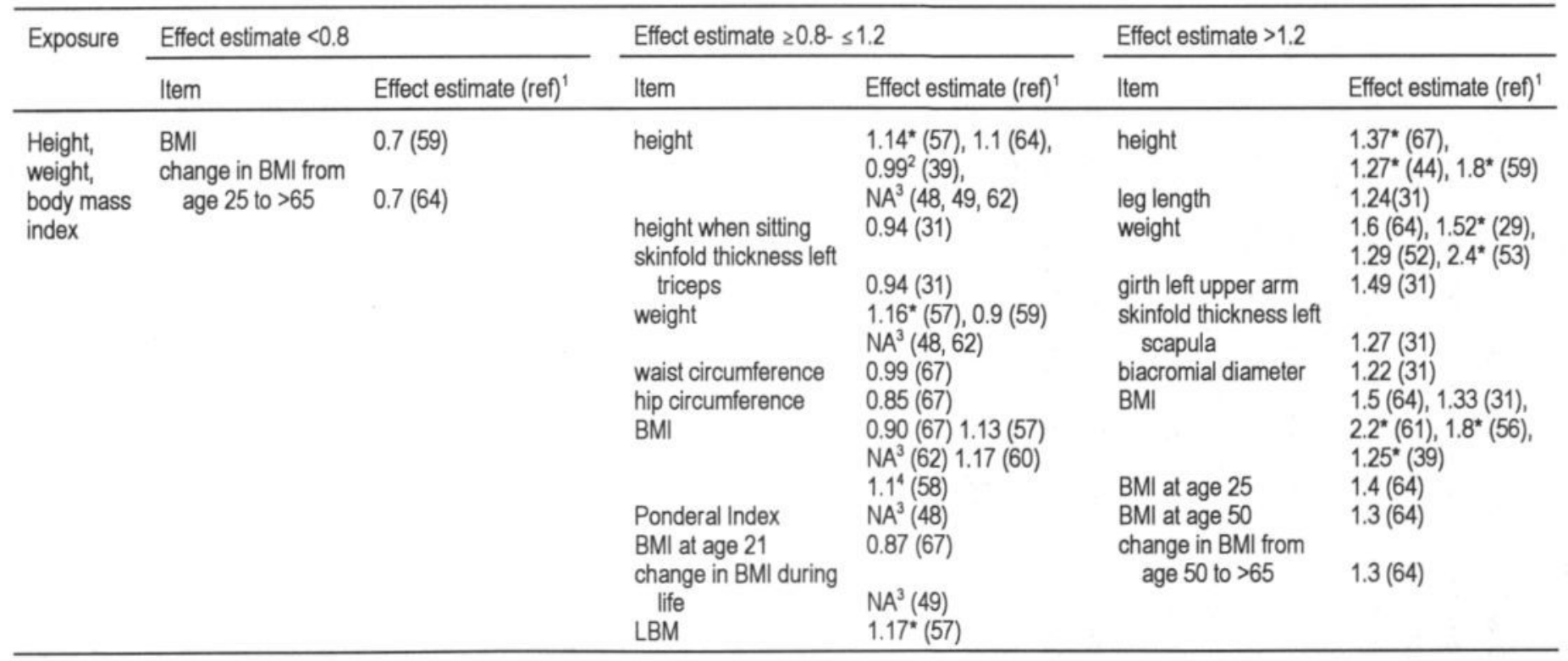

${ }^{1}$ Effect estimates for highest versus lowest exposure category, asterix ( $\left.{ }^{*}\right)$ denotes statistically significant finding; ${ }^{2} \mathrm{Per} 10 \mathrm{~cm} ;{ }^{3} \mathrm{NA}=\mathrm{not}$ associated; ${ }^{4} \mathrm{Per} 2.92 \mathrm{~kg} / \mathrm{m}^{2}$. 
Therefore, consistency in results is hardly evaluable and findings need replication from other well-designed prospective studies.

Another important drawback which must also be considered in interpreting results from earlier studies is that there are only a few studies in which a reasonable number of prostate cancer cases could be investigated. For example, only a few prospective studies included more than 400 cases $(44,57,65,67,68)$ and there were various studies in which less than 35 cases were included $(25,32-35,37,38,40)$. Additionally, in some studies prostate cancer incidence was used as an endpoint while in other studies prostate cancer mortality or a combination of both incidence and mortality was the endpoint of study. In general, incidence is a more appropriate endpoint. If prognosis is related to a certain exposure factor, selection bias might have been present in studies with mortality as an endpoint.

Bias by confounding is another possibility that may explain the diverse results from previous studies. As was concluded from Table 1, almost none of the prospective studies had an extensive dietary assessment. Therefore, controlling for potential confounding by other than the investigated dietary factor was mostly not possible and also information on nondietary potential risk factors was often not available.

Finally, the hypothesis that latent and clinically apparent or advanced or aggressive prostate tumors might have a different etiology has not been investigated in the majority of earlier prospective epidemiological studies. Therefore, it is too early to draw conclusions. This issue also deserves attention in future epidemiological studies on prostate cancer etiology.

In summary, several potential risk factors for prostate cancer have already been investigated in prospective epidemiological studies but there is hardly any consistency in results. These inconsistencies can largely be explained by limited exposure data, a small number of prostate cancer cases, and no or limited control for potential confounding factors. Future research on dietary risk factors for prostate cancer should be based on an extensive exposure measurement which also includes information on nondietary risk factors, making control for confounding from dietary as well as nondietary risk factors possible. Furthermore, a reasonable number of cases should be available so that also subgroup analyses can be performed.

\section{References}

1. Boyle P, Maisonneuve P, Napalkov P. Geographical and temporal patterns of incidence and mortality from prostate cancer. Urology 1995;46:47-55.

2. Parkin DM, Muir CS, Whelan SL, et al. Cancer incidence in five continents. Lyon: IARC Scientific Publications, 1992.

3. Coffey DS. Prostate cancer. An overview of an increasing dilemma. Cancer 1993;71:880-6.

4. Pienta KJ, Esper PS. Risk factors for prostate cancer. Ann Intern Med 1993;118:793-803. 
5. Zaridze DG, Boyle P. Cancer of the prostate: epidemiology and aetiology. Br J Urol 1987;59:493502.

6. Ross RK, Henderson BE. Do diet and androgens alter prostate cancer risk via a common etiologic pathway? J Natl Cancer Inst 1994;86:252-4.

7. Carter BS, Steinberg GD, Beaty TH, et al. Familial risk factors for prostate cancer. Cancer Surv 1991;11:5-13.

8. Carter BS, Bova GS, Beaty TH, et al. Hereditary prostate cancer: epidemiologic and clinical features. J Urol 1993;150:797-802.

9. Nomura AM, Kolonel LN. Prostate cancer: a current perspective. Epidemiol Rev 1991;13:200-27.

10. Ross RK, Shimizu H, Paganini Hill A, et al. Case-control studies of prostate cancer in blacks and whites in southern California. J Natl Cancer Inst 1987;78:869-74.

11. Ekman P, Pan Y, Li C, et al. Environmental and genetic factors: a possible link with prostate cancer. Br J Urol 1997;79 Suppl 2:35-41.

12. Giles G, Ireland P. Diet, nutrition and prostate cancer. Int J Cancer 1997;Suppl 10:13-7.

13. Mettlin C. Recent developments in the epidemiology of prostate cancer. Eur J Cancer 1997;33:340-7.

14. Kolonel LN. Nutrition and prostate cancer. Cancer Causes Control 1996;7:83-94.

15. Key T. Risk factors for prostate cancer. Cancer Surv 1995;23:63-77.

16. Boyle P, Zaridze DG. Risk factors for prostate and testicular cancer. Eur J Cancer 1993;29a:1048-55.

17. Morra MN, Das S. Prostate cancer. Epidemiology and etiology. In: Das S, Crawford ED, eds. Cancer of the prostate. New York: Dekker, 1993:1-12.

18. Meikle AW, Smith JA, Jr. Epidemiology of prostate cancer. Urol Clin North Am 1990;17:709-18.

19. Bosland MC. The etiopathogenesis of prostatic cancer with special reference to environmental factors. Adv Cancer Res 1988;51:1-106.

20. Schuman LM, Mandel JS. Epidemiology of prostatic cancer in blacks. Prev Med 1980;9:630-49.

21. Hennekens $\mathrm{CH}$, Buring JE, Manson JE, et al. Lack of effect of long-term supplementation with beta carotene on the incidence of malignant neoplasms and cardiovascular disease. $\mathrm{N} \mathrm{Engl} \mathrm{J}$ Med 1996;334:1145-9.

22. Clark LC, Dalkin B, Krongrad A, et al. Decreased incidence of prostate cancer with selenium supplementation: results of a double -blind cancer prevention trial. Br J Urol 1998;81:730-4.

23. Heinonen OP, Albanes D, Virtamo J, et al. Prostate cancer and supplementation with alphatocopherol and beta-carotene: incidence and mortality in a controlled trial. J Natl Cancer Inst 1998;90:440-6.

24. Omenn GS, Goodman GE, Thornquist MD, et al. Risk factors for lung cancer and for intervention effects in CARET, the Beta-Carotene and Retinol Efficacy Trial. J Natl Cancer Inst 1996;88:1550-9.

25. Kark JD, Smith $A H$, Switzer BR, et al. Serum vitamin A (retinol) and cancer incidence in Evans County, Georgia. J Natl Cancer Inst 1981;66:7-16.

26. Corder EH, Friedman GD, Vogelman JH, et al. Seasonal variation in vitamin D, vitamin Dbinding protein, and dehydroepiandrosterone: risk of prostate cancer in black and white men. Cancer Epidemiol Biomarkers Prev 1995;4:655-9.

27. Corder EH, Guess HA, Hulka BS, et al. Vitamin D and prostate cancer: a prediagnostic study with stored sera. Cancer Epidemiol Biomarkers Prev 1993;2:467-72.

28. Nomura AM, Stemmermann GN, Lee J, et al. Serum micronutrients and prostate cancer in Japanese Americans in Hawaii. Cancer Epidemiol Biomarkers Prev 1997;6:487-91.

29. Chyou PH, Nomura AM, Stemmermann GN. A prospective study of weight, body mass index and other anthropometric measurements in relation to site-specific cancers. Int J Cancer 1994;57:313-7.

30. Severson RK, Nomura AM, Grove JS, et al. A prospective study of demographics, diet, and prostate cancer among men of Japanese ancestry in Hawaii. Cancer Res 1989;49:1857-60.

31. Severson RK, Grove JS, Nomura AM, et al. Body mass and prostatic cancer: a prospective study. British Medical Journal 1988;297:713-5.

32. Peleg I, Heyden S, Knowles M, et al. Serum retinol and risk of subsequent cancer: extension of the Evans County, Georgia, study. J Natl Cancer Inst 1984;73:1455-8.

33. Knekt P, Aromaa A, Maatela J, et al. Serum vitamin A and subsequent risk of cancer: cancer incidence follow-up of the Finnish Mobile Clinic Health Examination Survey. Am J Epidemiol 1990;132:857-70. 
34. Knekt P, Aromaa A, Maatela J, et al. Serum vitamin E and risk of cancer among Finnish men during a 10-year follow-up. Am J Epidemiol 1988;127:28-41.

35. Eichholzer M, Stahelin HB, Gey KF, et al. Prediction of male cancer mortality by plasma levels of interacting vitamins: 17-year follow-up of the prospective Basel study. Int J Cancer 1996;66:145-50.

36. Reichman ME, Hayes RB, Ziegler RG, et al. Serum vitamin A and subsequent development of prostate cancer in the first National Health and Nutrition Examination Survey Epidemiologic Follow-up Study. Cancer Res 1990;50:2311-5.

37. Coates RJ, Weiss NS, Daling JR, et al. Serum levels of selenium and retinol and the subsequent risk of cancer. Am J Epidemiol 1988;128:515-23.

38. Criqui $\mathrm{MH}$, Bangdiwala S, Goodman DS, et al. Selenium, retinol, retinol-binding protein, and uric acid. Associations with cancer mortality in a population-based prospectivecase-control study. Ann Epidemiol 1991;1:385-93.

39. Thune I, Lund E. Physical activity and the risk of prostate and testicular cancer: a cohort study of 53,000 Norwegian men. Cancer Causes Control 1994:5:549-56.

40. Willett WC, Polk BF, Underwood BA, et al. Relation of serum vitamins $A$ and $E$ and carotenoids to the risk of cancer. N Engl J Med 1984;310:430-4.

41. Harvei S, Bjerve KS, Tretli S, et al. Prediagnostic level of fatty acids in serum phospholipids: omega-3 and omega-6 fatty acids and the risk of prostate cancer. Int J Cancer 1997;71:545-51.

42. Alberg AJ, Kafonek S, Huang HY, et al. Fatty acid levels and the subsequent development of prostate cancer. Proc Am Assoc Cancer Res 1996;37:281.

43. Hsing AW, Comstock GW, Abbey H, et al. Serologic precursors of cancer. Retinol, carotenoids, and tocopherol and risk of prostate cancer. J Natl Cancer Inst 1990;82:941-6.

44. Hebert PR, Ajani U, Cook NR, et al. Adult height and incidence of cancer in male physicians (United States). Cancer Causes Control 1997;8:591-7.

45. Gann $\mathrm{PH}, \mathrm{Ma} \mathrm{J}$, Hennekens $\mathrm{CH}$, et al. Circulating vitamin $\mathrm{D}$ metabolites in relation to subsequent development of prostate cancer. Cancer Epidemiol Biomarkers Prev 1996;5:121-6.

46. Gann PH, Hennekens $\mathrm{CH}$, Sacks FM, et al. Prospective study of plasma fatty acids and risk of prostate cancer. J Natl Cancer Inst 1994;86:281-6.

47. Hartman TJ, Albanes D, Peitinen $P$, et al. The association between baseline vitamin $E$, selenium, and prostate cancer in the Alpha-Tocopherol, Beta-Carotene Prevention Study. Cancer Epidemiol Biomarker Prev 1998;7:335-40.

48. Greenwald P, Damon A, Kirmss V, et al. Physical and demographic features of men before developing cancer of the prostate. J Natl Cancer Inst 1974;53:341-6.

49. Whittemore AS, Paffenbarger RS, Jr., Anderson K, et al. Early precursors of site-specific cancers in college men and women. J Natl Cancer Inst 1985;74:43-51.

50. Tonnesen $\mathrm{H}$, Moller $\mathrm{H}$, Andersen JR, et al. Cancer morbidity in alcohol abusers. $\mathrm{Br} \mathrm{J}$ Cancer 1994;69:327-32.

51. Daviglus ML, Dyer AR, Persky V, et al. Dietary beta-carotene, vitamin C, and risk of prostate cancer: results from the Western Electric Study. Epidemiology 1996;7:472-7.

52. Garfinkel L. Overweight and mortality. Cancer 1986;58:1826-9.

53. Snowdon DA, Phillips RL, Choi W. Diet, obesity, and risk of fatal prostate cancer. Am J Epidemiol 1984;120:244-50.

54. Hirayama T. Life-style and mortality. A large-scale census-based cohort study in Japan. Basel: Karger, 1990.

55. Hsing AW, McLaughlin JK, Schuman LM, et al. Diet, tobacco use, and fatal prostate cancer: results from the Lutheran Brotherhood Cohort Study. Cancer Res 1990;50:6836-40.

56. Gronberg H, Damber L, Damber JE. Total food consumption and body mass index in relation to prostate cancer risk: a case-control study in Sweden with prospectively collected exposure data. J Urol 1996;155:969-74.

57. Andersson SO, Wolk A, Bergstrom R, et al. Body size and prostate cancer: a 20-year follow-up study among 135006 Swedish construction workers. J Natl Cancer Inst 1997;89:385-9.

58. Thompson MM, Garland C, Barrett-Connor E, et al. Heart disease risk factors, diabetes, and prostatic cancer in an adult community. Am J Epidemiol 1989;129:511-7.

59. Le Marchand L, Kolonel LN, Wilkens LR, et al. Animal fat consumption and prostate cancer: a prospective study in Hawaii. Epidemiology 1994;5:276-82.

60. Mills PK, Beeson WL, Phillips RL, et al. Cohort study of diet, lifestyle, and prostate cancer in Adventist men. Cancer 1989;64:598-604. 
61. Veierod MB, Laake P, Thelle DS. Dietary fat intake and risk of prostate cancer: a prospective study of 25,708 Norwegian men. Int J Cancer 1997;73:634-8.

62. Hiatt RA, Armstrong MA, Klatsky AL, et al. Alcohol consumption, smoking, and other risk factors and prostate cancer in a large health plan cohort in California (United States). Cancer Causes Control 1994;5:66-72.

63. Shibata A, Paganini Hill A, Ross RK, et al. Intake of vegetables, fruits, beta-carotene, vitamin C and vitamin supplements and cancer incidence among the elderly: a prospective study. $\mathrm{Br} \mathrm{J}$ Cancer 1992;66:673-9.

64. Cerhan JR, Torner JC, Lynch CF, et al. Association of smoking, body mass, and physical activity with risk of prostate cancer in the lowa 65+ Rural Health Study (United States). Cancer Causes Control 1997;8:229-38.

65. Rodriguez C, Tatham LM, Thun MJ, et al. Smoking and fatal prostate cancer in a large cohort of adult men. Am J Epidemiol 1997;145:466-75.

66. Giovannucci E, Rimm EB, Wolk A, et al. Calcium and fructose intake in relation to risk of prostate cancer. Cancer Res 1998;58:442-7.

67. Giovannucci E, Rimm EB, Stampfer MJ, et al. Height, body weight, and risk of prostate cancer. Cancer Epidemiol Biomarkers Prev 1997;6:557-63.

68. Giovannucci E, Ascherio A, Rimm EB, et al. Intake of carotenoids and retinol in relation to risk of prostate cancer. J Natl Cancer Inst 1995;87:1767-76.

69. Giovannucci E, Rimm EB, Colditz GA, et al. A prospective study of dietary fat and risk of prostate cancer. J Natl Cancer Inst 1993;85:1571-9.

70. Giovannucci E, Rimm EB, Stampfer MJ, et al. Height, body weight, and risk of prostate cancer. Cancer Epidemiol Biomarkers Prev 1997;6:557-63.

71. Hsing AW, Comstock GW. Serological precursors of cancer: serum hormones and risk of subsequent prostate cancer. Cancer Epidemiol Biomarkers Prev 1993;2:27-32. 



\title{
Chapter 2
}

\section{Vegetable and fruit consumption and}

\section{prostate cancer risk: a cohort study in the}

\section{Netherlands ${ }^{1}$}

\author{
Agnes G. Schuurman ${ }^{2}$ - R. Alexandra Goldbohm ${ }^{3}$ \\ Elisabeth Dorant ${ }^{2}$ - Piet A. van den Brandt ${ }^{2}$
}

\section{Abstract}

The association between 21 vegetables and eight fruits and prostate cancer risk was assessed in the Netherlands Cohort Study among 58,279 men aged 55-69 years at baseline in 1986. After 6.3 years of follow-up 610 cases with complete vegetable data and 642 cases with complete fruit data were available for analysis. In multivariate case-cohort analyses, the following Rate Ratios [RRs] (95\% Confidence Interval [95\% Cl]) for vegetable consumption were found (comparing highest vs lowest quintile): total vegetables, 0.80 (0.57-1.12); prepared vegetables, 0.85 (0.61-1.19); raw vegetables, 0.96 (0.69-1.34). For vegetables categorized in botanical groups no associations were found except for consumption of pulses ( $R R=0.71(0.51-0.98)$, test for trend $p$-value 0.01$)$. The RRs for total fruit and citrus fruit were $1.31(0.96-1.79)$ and $1.27(0.93-1.73)$, respectively; the corresponding p-values for the trend tests were 0.02 and 0.01 , respectively. In a continuous model, no association for total fruit was observed. Individual vegetables and fruits were evaluated as continuous variables ( $\mathrm{g} / \mathrm{day}$ ). Nonsignificant inverse associations (RRs per increment of $25 \mathrm{~g} /$ day) were found for consumption of kale ( $R R=0.74)$, raw endive $(R R=0.72)$, mandarins $(R R=0.75)$ and raisins or other dried fruit $(R R=0.49)$. Observed positive associations were significant for consumption of leek $(R R=1.38)$ and oranges $(R R=1.07)$ and nonsignificant for sweet peppers $(R R=1.60)$ and mushrooms $(R R=1.49)$. Results in subgroups of cases were more or less consistent with the overall results. From our study we cannot conclude that vegetable consumption is important in prostate cancer etiology, but for certain vegetables or fruits an association can neither be excluded.

\footnotetext{
${ }^{1}$ Published in Cancer Epidemiology Biomarkers \& Prevention 1998; 7: 673-80

${ }^{2}$ Dept. of Epidemiology, Maastricht University, Maastricht

${ }^{3}$ Dept. of Consumer Research \& Epidemiology, TNO Nutrition and Food Research Institute, Zeist
} 


\section{Introduction}

Although prostate cancer is one of the types of cancer with a high incidence in Western countries, the etiology is largely unknown. In a recent review (1) it was concluded that environmental risk factors, including diet, may play an important role in the etiology of this disease. Among dietary factors, not only meat consumption and fat intake have been evaluated frequently but also vegetable and fruit consumption. Vegetable and fruit consumption may be protective against cancer because of the anticarcinogenic agents in these foods. Some potentially anticarcinogenic substances are carotenoids, vitamins $\mathrm{C}$ and E, selenium, glucosinolates and indoles, flavonoids, protease inhibitors, and allium compounds and some possible mechanisms of action are induction of detoxification enzymes, inhibition of nitrosamine formation, alteration of hormone metabolism, and antioxidant effects $(2,3)$. Up to 1998 , we identified ten cohort studies (4-13) and 13 casecontrol studies (14-26) in which consumption of vegetables or fruit in relation to prostate cancer risk was evaluated. Many different vegetable groups or individual vegetables have been investigated, but thus far results are not conclusive. In the majority of these earlier studies no extensive measurement of vegetable and fruit consumption was made and no or only limited adjustment for potential confounding factors was employed. Therefore, we further explored the possible association between vegetable and fruit consumption and prostate cancer risk in the Netherlands Cohort Study (NLCS) which was specifically designed to investigate the relationship between diet and cancer. Besides the extensive assessment of the usual diet, information on other risk factors for cancer is also available, offering a possibility to control for dietary as well as nondietary factors in multivariate analyses. Moreover, also subgroup analyses on tumor differentiation grade and tumor size could be performed to investigate the hypothesis (1) that clinically apparent tumors might have a different etiology than latent tumors.

\section{Methods}

The cohort study

The study design has been described elsewhere (27). In brief, the NLCS was initiated in September 1986 . The male cohort consists of 58,279 men who completed a questionnaire on usual diet, lifestyle, personal and family history of cancer, other risk factors for cancer, and demographic data. The study population originated from 204 municipal population registries throughout the country. For reasons of efficiency in data processing and analysis, the case-cohort approach $(28,29)$ was used. In a case-cohort approach, cases are derived from the entire cohort (providing numerator information for calculation of cancer incidence rates), while accumulated person years at risk in the total cohort are estimated from a random sample (subcohort) from the cohort (providing denominator information for the rates). In contrast to nested case-control sampling, this subcohort can be used for multiple disease endpoints. The subcohort $(n=1688)$ was sampled directly after identification of all cohort members and has been followed up biennially for vital status information. Follow-up 
for incidence of prostate cancer was established by computerized record linkage with all nine cancer registries in The Netherlands, and with the Dutch national data base of pathology reports (PALGA) (30). No subcohort members were lost to follow-up and completeness of follow-up of cancer was at least 96 percent (31). After a follow-up period of 6.3 years (September 1986-December 1992), 704 incident, microscopically or histologically confirmed, primary prostate cancer cases were detected.

\section{The questionnaire}

The self-administered questionnaire has been described elsewhere (32). Usual consumption of food and beverages during the year preceding the start of the study was assessed with a 150-item semiquantitative food frequency questionnaire. Participants were asked to report their frequency of consumption of 12 prepared vegetables, five raw vegetables and eight fruits (see also Table 1). Categories ranged from 'never or less than once per month' to '3-7 times per week' (vegetables) or '6-7 times per week' (fruits). For onions, tomatoes, sweet peppers, and mushrooms participants were asked to report the number they usually ate per week (onions, tomatoes) or month (sweet peppers, mushrooms [in boxes of $250 \mathrm{~g}$ ]). Frequency of vegetable consumption was asked separately for summer and winter, from which a combined consumption frequency was calculated. For string beans and endive, portion sizes were asked which were used as indicators to calculate portion sizes of the other vegetables, according to a vegetable-specific algorithm. For fruits, subjects were asked to indicate how many pieces they ate each time. Frequency of consumption and portion size of tomato juice and processed orange/grapefruit juice was also asked. Mean daily vegetable and fruit consumption (in $\mathrm{g} / \mathrm{day}$ ) was calculated by multiplying consumption frequency, number of portions per occasion and portion size. Standard sizes were assumed for each fruit. The questionnaire has been validated against a 9-day diet record; the Spearman correlation coefficient for total vegetable consumption was 0.4 and for total fruit consumption this estimate was $0.6(32)$.

\section{Data analysis}

Questionnaire data were key-entered twice and processed for all incident cases in the cohort and for all subcohort members in a manner blinded with respect to case/subcohort status. This was done in order to minimize observer bias in coding and interpretation of the data. Subjects who reported a history of cancer other than skin cancer at baseline, were excluded. Furthermore, according to criteria published before (32), subjects with incomplete or inconsistent dietary data were excluded; 642 men with prostate cancer and 1525 male subcohort members remained for analysis on fruit consumption. In addition, for vegetables we computed an error index based on the consistency of responses on vegetable questions. When this error index exceeded a certain value, i.e., more than three errors, subjects were excluded for all analyses regarding consumption of vegetables. Therefore, data analysis regarding consumption of vegetables was based on 610 cases and 1456 
Table 1: Description of daily vegetable and fruit consumption in prostate cancer cases and subcohort members, Netherlands Cohort Study (1986-1992).

\begin{tabular}{|c|c|c|c|c|}
\hline \multirow[t]{2}{*}{ Vegetable/fruit consumption (g/day) } & \multicolumn{2}{|c|}{ Cases } & \multicolumn{2}{|c|}{ Subcohort } \\
\hline & mean & SD & mean & SD \\
\hline Vegetables & $n=610$ & & $n=1456$ & \\
\hline Total vegetables & 183.3 & 69.6 & 187.1 & 76.3 \\
\hline Prepared vegetables & 147.0 & 59.8 & 150.8 & 63.1 \\
\hline Raw vegetables & 36.2 & 28.7 & 36.2 & 29.0 \\
\hline Pulses $^{1}$ & 33.0 & 22.7 & 34.7 & 23.0 \\
\hline String/french beans & 20.0 & 15.3 & 20.5 & 15.3 \\
\hline Broad beans & 4.5 & 7.0 & 4.7 & 7.2 \\
\hline Brassicas & 31.5 & 19.7 & 32.7 & 20.3 \\
\hline Cauliflower & 14.3 & 10.3 & 14.6 & 11.1 \\
\hline Cabbage (white/green) & 6.7 & 9.1 & 7.2 & 8.2 \\
\hline Kale & 3.1 & 3.3 & 3.3 & 3.4 \\
\hline Brussels sprouts & 7.4 & 6.7 & 7.7 & 6.7 \\
\hline Leafy vegetables prepared & 21.6 & 15.2 & 21.6 & 16.0 \\
\hline Endive prepared & 12.0 & 10.2 & 12.0 & 10.8 \\
\hline Spinach & 9.5 & 8.7 & 9.6 & 8.9 \\
\hline Leafy vegetables raw & 9.7 & 8.3 & 9.9 & 9.2 \\
\hline Endive raw & 2.1 & 4.1 & 2.4 & 4.9 \\
\hline Lettuce & 7.5 & 6.5 & 7.6 & 6.7 \\
\hline Alliums & 27.6 & 24.4 & 28.5 & 24.2 \\
\hline Leek & 9.2 & 13.6 & 8.5 & 10.9 \\
\hline Onions & 18.4 & 17.2 & 20.1 & 19.0 \\
\hline \multicolumn{5}{|l|}{ Other vegetables } \\
\hline Carrots prepared & 8.4 & 7.0 & 9.0 & 8.9 \\
\hline Carrots raw & 2.2 & 9.4 & 2.1 & 7.8 \\
\hline Sauerkraut & 5.8 & 5.8 & 5.9 & 5.5 \\
\hline Red beets & 7.5 & 7.2 & 7.7 & 8.7 \\
\hline Sweet peppers & 2.5 & 4.3 & 2.5 & 4.0 \\
\hline Mushrooms & 3.2 & 3.9 & 3.2 & 3.9 \\
\hline Tomatoes & 19.7 & 20.7 & 19.5 & 20.1 \\
\hline Tomato juice & 2.8 & 16.0 & 1.9 & 13.5 \\
\hline Gherkins & 1.7 & 4.7 & 1.9 & 8.1 \\
\hline Rhubarb & 2.1 & 4.9 & 2.2 & 5.7 \\
\hline Fruit & $n=642$ & & $n=1525$ & \\
\hline Total fruit & 165.6 & 112.6 & 154.4 & 111.8 \\
\hline Citrus fruit & 72.7 & 74.1 & 64.8 & 69.8 \\
\hline Oranges & 49.8 & 56.3 & 40.6 & 51.5 \\
\hline Mandarins & 3.3 & 6.6 & 3.8 & 7.2 \\
\hline Grapefruit & 7.8 & 26.4 & 6.6 & 21.7 \\
\hline Processed orange/grapefruit juice & 11.8 & 30.9 & 13.8 & 38.2 \\
\hline Grapes & 4.2 & 8.6 & 3.9 & 8.5 \\
\hline Apples \& pears & 68.0 & 70.7 & 67.4 & 74.6 \\
\hline Bananas & 13.1 & 27.9 & 12.9 & 25.0 \\
\hline Strawberries & 6.8 & 8.3 & 6.8 & 7.8 \\
\hline Raisins/other dried fruit & 0.6 & 2.3 & 0.7 & 3.2 \\
\hline
\end{tabular}

${ }^{1}$ Dried seeds were also included. 
subcohort members.

Mean intake levels ( $\mathrm{g} /$ day) of vegetables and fruits and other characteristics were compared between prostate cancer cases and male subcohort members. Furthermore, the mean intakes of total vegetable and total fruit were compared in categories of potential confounding factors and tested with analysis of variance. Variables that were considered as potential confounders were age, a family history of prostate cancer, socioeconomic status, fruit consumption (for analyses regarding vegetables) and vegetable consumption (for analyses regarding fruits). Total energy and total fat intake were not considered as potential confounding factors because no association with prostate cancer risk was observed (data not shown). Rate Ratios (RRs) and 95\% confidence intervals (95\% Cl) were computed using the GLIM statistical package (33). Exponentially distributed survival times were assumed in the follow-up period. Since standard software was not available, specific macros were developed in GLIM to account for the additional variance introduced by using the subcohort instead of the entire cohort (34). Tests for trend were based on likelihood ratio tests and two-sided $\mathrm{P}$-values are used throughout this report. We first evaluated combined vegetable and fruit consumption, total vegetables, prepared and raw vegetables, vegetables categorized in botanical groups, total fruit, and citrus fruit, after categorizing subjects into quintile levels of consumption. Age-adjusted as well as multivariate-adjusted analyses were done. In addition, cases detected during the first and the first two years of follow-up were excluded from analyses to evaluate whether preclinical symptoms might have influenced results. Second, vegetables and fruits were evaluated as continuous variables (g/day) and multivariate RRs were expressed per increment of $25 \mathrm{~g} /$ day, corresponding to a consumption frequency of a vegetable of approximately once per week. In order to assess the independent contribution of each specific vegetable or fruit on prostate cancer risk, total vegetable or total fruit consumption was added to the multivariate model. Analyses were also done for continuous variables in subgroups of cases, based on differentiation grade and size of the tumor, and for latent and nonlatent tumors. The differentiation grade and tumor size were unknown for $8.7 \%$ and $22.8 \%$ of all cases, respectively. Latent and nonlatent prostate tumors were defined based on information from pathology reports that have been obtained from PALGA. Prostate cancer cases detected incidentally during transurethral prostate resections were coded latent. Cases detected during surgical procedures used in case of suspected prostate cancer (biopsy, radical prostatectomy) were coded nonlatent (35). If available, more than one pathology report per subject was used. $38.8 \%$ of all cases could not be grouped according to latency.

\section{Results}

In Table 1 mean daily consumption of total vegetables, vegetables combined into botanical groups, total fruit, citrus fruit and all individual vegetables and fruits is presented for cases and subcohort members. Total and prepared vegetable consumption was slightly lower 
among cases compared to subcohort members. Onion consumption was slightly lower and leek consumption was higher among cases compared to subcohort members. For the other vegetable groups or individual vegetables no large differences in mean daily consumption were observed. Total fruit, citrus fruit, orange and grapefruit consumption was higher for cases than for subcohort members. No large differences in consumption of other fruit items between cases and subcohort members were found. Comparison of the distribution of potential confounding factors showed that cases were somewhat older and more highly educated than subcohort members and more often had a positive family history of prostate cancer (data not shown).

Mean vegetable and fruit consumption was also compared across categories of potential confounding factors. Total vegetable consumption was significantly lower for subjects with a positive family history of prostate cancer and significantly higher for subjects with the highest fruit consumption. Total fruit consumption varied slightly over categories of socioeconomic status but increased with age. A significantly increased total fruit consumption was found for subjects with a positive family history of prostate cancer, and for subjects with the highest vegetable consumption (data not shown).

RRs for categories of grouped of vegetables and fruit are presented in Table 2. Overall, age-adjusted and multivariate adjusted RRs were similar. Vegetable and fruit consumption combined showed no association with prostate cancer risk. The RR for the highest versus the lowest quintile of consumption was 1.05 ( $95 \% \mathrm{Cl}: 0.76-1.45)$. Total vegetable consumption was neither associated with prostate cancer risk ( $R R=0.80,95 \% \mathrm{Cl}$ : 0.57-1.12 for the highest vs the lowest quintile of consumption). Also for prepared and raw vegetables no associations were found (RRs of 0.85 and 0.96 , respectively, for the same contrast). When the botanical groups were evaluated, RRs for pulses and brassicas were below unity but only for pulses there was a significantly decreasing trend in risk with increasing consumption $(p=0.01)$. Only the RR in the highest quintile of consumption of pulses was significant ( $R R=0.71,95 \% \mathrm{Cl}: 0.51-0.98)$. In the other botanical groups no clear associations were seen. For both total fruit consumption and citrus fruit consumption a significant positive trend in risk was found ( $p$-values of 0.02 and 0.01 , respectively). The RR for total fruit consumption (highest vs the lowest quintile) was 1.31 (95\% Cl: 0.96-1.79) and for citrus fruit the estimate was $1.27(95 \% \mathrm{Cl}: 0.93-1.73)$. Exclusion of the first or the first two years of follow-up did not essentially change the results (data not shown).

Expressed as an increment of $25 \mathrm{~g} /$ day, the $\mathrm{RR}(95 \% \mathrm{Cl})$ for vegetables and fruit combined was $1.00(0.98-1.02)$ (Table 3 ). For total vegetable consumption the estimate was 0.98 (0.95-1.02). In contrast to the findings for total fruit evaluated as a categorized variable, fruit evaluated as a continuous variable showed no association with prostate cancer risk (RR=1.01, 95\% Cl: 0.99-1.04). Also displayed in Table 3 are RRs (per $25 \mathrm{~g}$ increment) for 
Table 2: Rate Ratios (RR) and 95\% Confidence Intervals (Cl) for prostate cancer according to vegetable and fruit consumption, Netherlands Cohort Study (1986-1992).

\begin{tabular}{|c|c|c|c|c|c|}
\hline \multirow[b]{2}{*}{$\begin{array}{l}\text { Vegetable/fruit } \\
\text { (g/day in quintiles) }\end{array}$} & \multirow[b]{2}{*}{$\begin{array}{l}\text { Median } \\
\text { intake in } \\
\text { subcohort }\end{array}$} & \multicolumn{2}{|l|}{ Age-adjusted } & \multicolumn{2}{|c|}{ Multivariate adjusted } \\
\hline & & $\begin{array}{l}\text { No of cases/ } \\
\text { Person years } \\
\text { in subcohort }\end{array}$ & $\mathrm{RR}(95 \% \mathrm{Cl})$ & $\begin{array}{l}\text { No of casesl } \\
\text { Person years } \\
\text { in subcohort }\end{array}$ & $\mathrm{RR}(95 \% \mathrm{Cl})$ \\
\hline
\end{tabular}

Vegetables \& fruit

combined

$\begin{array}{lll}1 \text { (low) } & 177.7 & 107 / 1756 \\ 2 & 257.1 & 123 / 1696 \\ 3 & 319.0 & 121 / 1784 \\ 4 & 392.9 & 136 / 1731 \\ 5 \text { (high) } & 519.0 & 123 / 1748\end{array}$

Total vegetables

$\begin{array}{lll}1 \text { (low) } & 100.0 & 117 / 1725 \\ 2 & 144.0 & 126 / 1765 \\ 3 & 175.0 & 127 / 1743 \\ 4 & 214.0 & 145 / 1777 \\ 5 \text { (high) } & 285.0 & 95 / 1705\end{array}$

Prepared vegetables

1 (low)
2
3
4
5 (high)

79.0

115.0

143.0

174.0

234.0

Raw vegetables

1 (low)
2
3
4
5 (high)

$\begin{array}{rr}7.0 & 125 / 1861 \\ 19.0 & 108 / 1673 \\ 30.0 & 118 / 1752 \\ 44.0 & 144 / 1722 \\ 73.0 & 115 / 1707\end{array}$

(1)

Pulses
1 (low)
2
3
4
5 (high)

11.0

22.0

30.0

40.0

62.3

$\begin{array}{ll}1.00 & 107 / 1744 \\ 1.10(0.80-1.53) & 120 / 1674 \\ 1.08(0.78-1.50) & 121 / 1772 \\ 1.19(0.86-1.64) & 135 / 1725 \\ 1.05(0.76-1.45) & 123 / 1741 \\ \text { P-trend } 0.56 & \end{array}$

\subsection{0}

$1.07(0.78-1.46)$

$1.12(0.82-1.54)$

$1.27(0.93-1.74)$

$0.82(0.59-1.14)$

P-trend 0.61

\subsection{0}

$1.04(0.76-1.42)$

$1.19(0.87-1.62)$

$1.11(0.81-1.53)$

$0.85(0.61-1.18)$

P-trend 0.40

\subsection{0}

$0.94(0.68-1.29)$

$1.03(0.75-1.41)$

$1.19(0.88-1.62)$

$1.04(0.76-1.42)$

P-trend 0.26

\subsection{0}

$0.90(0.67-1.21)$

$0.75(0.55-1.04)$

$0.92(0.67-1.25)$

$0.69(0.51-0.95)$

P-trend 0.01

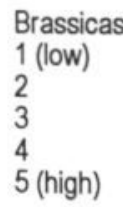

10.7

21.0

29.0

40.0

58.3
$146 / 1936$
$130 / 1682$
$102 / 1620$
$129 / 1809$
$103 / 1669$
1.00

$0.97(0.72-1.31)$

$0.81(0.59-1.11)$

$0.88(0.65-1.19)$

$0.80(0.58-1.10)$

P-trend 0.06
$145 / 1936$

$\begin{array}{ll}116 / 1719 & 1.00^{1.3} \\ 125 / 1749 & 1.06(0.77-1.46) \\ 126 / 1730 & 1.08(0.78-1.49) \\ 145 / 1764 & 1.28(0.94-1.75) \\ 94 / 1693 & 0.80(0.57-1.12) \\ & \text { P-trend } 0.51\end{array}$

$117 / 1753$

$126 / 1720$

$138 / 1743$

$123 / 1740$

$102 / 1699$

$125 / 1848$

$107 / 1661$

$117 / 1740$

$142 / 1722$

$115 / 1685$

$147 / 1750$

$139 / 1900$

$100 / 1639$

$121 / 1639$

99/1727

$130 / 1669$

$101 / 1598$

$127 / 1796$

103/1656
$1.00^{1,2}$

$1.08(0.78-1.50)$

$1.07(0.77-1.48)$

$1.16(0.84-1.60)$

$1.05(0.76-1.45)$

$\mathrm{P}$-trend 0.58

$1.00^{1,3}$

$1.03(0.74-1.41)$

$1.19(0.87-1.64)$

$1.13(0.82-1.56)$

$0.85(0.61-1.19)$

P-trend 0.46

$1.00^{1,3}$

$0.89(0.64-1.23)$

$0.97(0.71-1.34)$

$1.11(0.81-1.51)$

$0.96(0.69-1.34)$

P-trend 0.61

$1.00^{1,3}$

$0.92(0.68-1.24)$

$0.77(0.55-1.06)$

0.93 (0.68-1.27)

$0.71(0.51-0.98)$

P-trend 0.01

$1.00^{1,3}$

$0.98(0.72-1.32)$

$0.81(0.59-1.12)$

$0.87(0.64-1.18)$

$0.82(0.59-1.12)$

$\mathrm{P}$-trend 0.06 
Table 3: Rate Ratios (RR) and 95\% Confidence Intervals (Cl) for prostate cancer for continuous variables of vegetable and fruit consumption, Netherlands Cohort Study (1986-1992).

\begin{tabular}{|c|c|c|}
\hline Vegetable/fruit (g/day) & $\begin{array}{l}\mathrm{RR}^{1}(95 \% \mathrm{Cl}) \\
\text { per } 25 \mathrm{~g}\end{array}$ & $\begin{array}{l}\operatorname{RR}^{2}(95 \% \mathrm{Cl}) \\
\text { per } 25 \mathrm{~g}\end{array}$ \\
\hline Vegetables and fruit combined & $1.00(0.98-1.02)^{3}$ & \\
\hline Total vegetables & $0.98(0.95-1.02)$ & \\
\hline Total fruit & $1.01(0.99-1.04)$ & \\
\hline \multicolumn{3}{|l|}{ Individual vegetable items } \\
\hline String/french beans & $0.94(0.80-1.12)$ & $0.98(0.81-1.20)$ \\
\hline Broad beans & $0.90(0.63-1.30)$ & $0.95(0.65-1.38)$ \\
\hline Cauliflower & $0.90(0.71-1.14)$ & $0.94(0.73-1.23)$ \\
\hline Cabbage (white/green) & $0.88(0.64-1.21)$ & $0.94(0.66-1.35)$ \\
\hline Kale & $0.67(0.31-1.42)$ & $0.74(0.33-1.64)$ \\
\hline Brussels sprouts & $0.81(0.55-1.21)$ & $0.87(0.56-1.36)$ \\
\hline Endive prepared & $0.89(0.71-1.12)$ & $0.93(0.72-1.13)$ \\
\hline Spinach & $1.03(0.78-1.36)$ & $1.12(0.82-1.52)$ \\
\hline Endive raw & $0.69(0.40-1.18)$ & $0.72(0.41-1.25)$ \\
\hline Lettuce & $0.99(0.67-1.46)$ & $1.06(0.71-1.59)$ \\
\hline Leek & $1.23(0.99-1.54)$ & $1.38(1.08-1.76)$ \\
\hline Onions & $0.92(0.80-1.05)$ & $0.93(0.79-1.10)$ \\
\hline Carrots prepared & $0.83(0.60-1.13)$ & $0.87(0.61-1.23)$ \\
\hline Carrots raw & $1.04(0.76-1.42)$ & $1.08(0.78-1.49)$ \\
\hline Sauerkraut & $1.01(0.64-1.59)$ & $1.15(0.69-1.91)$ \\
\hline Red beets & $0.89(0.65-1.23)$ & $0.95(0.67-1.35)$ \\
\hline Sweet peppers & $1.35(0.72-2.56)$ & $1.60(0.82-3.12)$ \\
\hline Mushrooms prepared & $1.33(0.67-2.62)$ & $1.49(0.74-3.01)$ \\
\hline Tomatoes & $1.00(0.88-1.14)$ & $1.05(0.90-1.22)$ \\
\hline Tomato juice & $1.11(0.96-1.29)$ & $1.12(0.96-1.29)$ \\
\hline Gherkins & $0.89(0.61-1.28)$ & $0.92(0.64-1.32)$ \\
\hline Rhubarb & $0.90(0.55-1.47)$ & $0.92(0.56-1.51)$ \\
\hline \multicolumn{3}{|l|}{ Individual fruit items } \\
\hline Oranges & $1.06(1.02-1.11)$ & $1.07(1.01-1.14)$ \\
\hline Mandarins & $0.79(0.54-1.17)$ & $0.75(0.50-1.11)$ \\
\hline Grapefruit & $1.03(0.93-1.15)$ & $1.01(0.90-1.13)$ \\
\hline Processed orange/grapefruit juice & $0.96(0.89-1.03)$ & $0.96(0.89-1.03)$ \\
\hline Grapes & $1.10(0.83-1.44)$ & $1.04(0.78-1.39)$ \\
\hline Apples \& pears & $0.99(0.96-1.03)$ & $0.95(0.90-0.99)$ \\
\hline Bananas & $1.02(0.92-1.12)$ & $1.00(0.91-1.11)$ \\
\hline Strawberries & $0.94(0.69-1.29)$ & $0.89(0.65-1.24)$ \\
\hline Raisins/other dried fruit & $0.52(0.20-1.39)$ & $0.49(0.18-1.32)$ \\
\hline
\end{tabular}

'Adjusted for age, family history of prostate cancer, socioeconomic status, and total fruit consumption (for vegetable items) or total vegetable consumption (for fruit items); ${ }^{2}$ Adjusted for age, family history of prostate cancer, socioeconomic status, total fruit and total vegetable consumption; ${ }^{3}$ Adjusted for age, family history of prostate cancer, and socioeconomic status. 
Furthermore, we excluded subjects who appeared not to have correctly understood how to fill in the questions on vegetable consumption; those subjects were defined by an extreme score on an error index. In the NLCS validation study, the correlation coefficient for total vegetable consumption was $0.4(32)$, which is quite low, but comparable to the figure reported for other prospective studies (37-39). One possible reason for the low correlation may be the relative lack of true contrast in the frequency of total vegetable consumption in the NLCS. Most subjects are accustomed to a diet including one hot meal per day, which almost always includes vegetables. Due to individual preferences, however, contrast in consumption frequency of many specific vegetables is much higher. As can be seen in Table 3, the median intake in the highest quintile of, for example, pulses, is more than five times higher than the median intake in the lowest quintile. Also for Brassicas there is about a fivefold difference between the median intake in the highest and lowest consumption quintile. For individual vegetables the range in consumption is even higher because very often subjects in the lowest consumption quintile are nonconsumers of the specific vegetable. Therefore a smaller measurement error and a higher correlation is to be expected for specific vegetable items. It was not possible to assess the validity for specific vegetables in the NLCS validation study, since 9 days of dietary record are not sufficient to estimate consumption frequency of specific vegetables. In our validation study, the correlation coefficient for fruit consumption was 0.60 which may implicate that there is less measurement error regarding fruit consumption in the NLCS. For total fruit consumption, the range of difference between highest and lowest consumption quintile is about 252 grams, which is not low, and, as for vegetables, the range in consumption of specific fruits is determined by individual preferences and should therefore also be large enough. Misclassification of both vegetable and fruit consumption is likely to be nondifferential, thus leading to an underestimation of the strength of association.

Another explanation that has to be considered in the interpretation of our results is that unmeasured or unknown factors may have caused residual confounding. We considered, however, most of the factors that have been implied in prostate cancer etiology and factors showing an association with prostate cancer risk in our study were included into the multivariate model. Thus, total energy and fat intake were not included into the multivariate model. When we performed some analyses with these factors additionally in the multivariate model, risk estimates did not change. Therefore, factors other than energy or fat intake could be responsible for residual confounding. Preclinical symptoms are not likely to have influenced our results because after exclusion of cases detected in the first and in the first two years of follow-up results were similar to results including all cases. Finally, chance will have played a role in our findings, in particular because of the multiple comparisons that were made. 
Table 4: Rate Ratios (RRs) and 95\% Confidence Intervals (Cl) of prostate cancer for continuous variables of vegetable and fruit consumption in subgroups on differentiation grade, Netherlands Cohort Study (1986-1992).

\begin{tabular}{|c|c|c|c|}
\hline & $\begin{array}{l}\text { Well differentiated } \\
(n=181)\end{array}$ & $\begin{array}{l}\text { Moderately } \\
\text { differentiated } \\
(n=217)\end{array}$ & $\begin{array}{l}\text { Poorly or } \\
\text { undifferentiated } \\
(n=153)\end{array}$ \\
\hline Vegetable/fruit & $\begin{array}{l}\mathrm{RR}^{1}(95 \% \mathrm{Cl}) \\
\text { per } 25 \mathrm{~g}\end{array}$ & $\begin{array}{l}\mathrm{RR}^{1}(95 \% \mathrm{Cl}) \\
\text { per } 25 \mathrm{~g}\end{array}$ & $\begin{array}{l}\mathrm{RR}^{1}(95 \% \mathrm{Cl}) \\
\text { per } 25 \mathrm{~g}\end{array}$ \\
\hline Vegetables and fruit combined ${ }^{2}$ & $1.00(0.97-1.03)$ & $1.00(0.98-1.02)$ & $1.00(0.98-1.03)$ \\
\hline Total vegetables $^{3}$ & $0.99(0.93-1.04)$ & $0.96(0.91-1.01)$ & $0.99(0.94-1.05)$ \\
\hline Prepared vegetables & $0.89(0.75-1.06)$ & $0.97(0.82-1.15)$ & $1.08(0.89-1.31)$ \\
\hline Raw vegetables & $1.12(0.94-1.34)$ & $1.03(0.87-1.22)$ & $0.93(0.76-1.13)$ \\
\hline Pulses & $0.93(0.76-1.15)$ & $0.88(0.72-1.08)$ & $1.07(0.87-1.32)$ \\
\hline Brassicas & $0.95(0.73-1.24)$ & $0.88(0.68-1.13)$ & $0.99(0.75-1.30)$ \\
\hline Leafy vegetables prepared & $0.88(0.65-1.19)$ & $1.11(0.85-1.46)$ & $1.13(0.83-1.52)$ \\
\hline Leafy vegetables raw & $1.23(0.81-1.87)$ & $0.78(0.49-1.23)$ & $0.89(0.54-1.47)$ \\
\hline \multirow[t]{2}{*}{ Alliums } & $0.92(0.75-1.15)$ & $1.06(0.87-1.29)$ & $1.11(0.89-1.37)$ \\
\hline & $n=191$ & $n=229$ & $n=160$ \\
\hline Total fruit ${ }^{4}$ & $1.00(0.97-1.04)$ & $1.03(1.00-1.06)$ & $1.02(0.99-1.06)$ \\
\hline Citrus fruit & $1.01(0.94-1.07)$ & $1.02(0.96-1.08)$ & $1.02(0.96-1.09)$ \\
\hline
\end{tabular}

${ }^{1}$ Adjusted for age, family history of prostate cancer, socioeconomic status, total fruit consumption and total vegetable consumption; ${ }^{2}$ Not adjusted for total vegetable and total fruit consumption; ${ }^{3}$ Not adjusted for total vegetable consumption; ${ }^{4}$ Not adjusted for total fruit consumption.

There were only four other cohort studies on prostate cancer in which total vegetable consumption was investigated. In three studies, as in our study, no clear associations were observed $(8,9,11)$ and in the other cohort study a decreased risk was found (13). In one case-control study total vegetables showed no association (20) and in three case-control studies in which 'vegetables' were investigated also no clear associations were noted ( 19 , 22,25 ). We found no association for prepared vegetables but in one case-control study a decreased risk was noted (26). As in our study, raw vegetables showed no association in one cohort study (10). For consumption of pulses, we found a statistically significant inverse trend in risk. Beans, lentils and peas combined were also negatively associated with prostate cancer risk in another cohort study (5) and two case-control studies $(14,26)$, but this was not supported by another case-control study reporting no association (24). All the estimates for vegetables of the brassica genus were below unity in our study, but not significant, and there was no clear trend in risk. In three other studies cruciferous vegetables showed no clear associations with prostate cancer risk $(8,15,20)$, but in two case-control studies cabbage was inversely associated with prostate cancer risk $(14,21)$. For prepared and raw leafy vegetables and alliums we found no increase or decrease in risk. For individual vegetables, evaluated as continuous variables, inverse associations were found for consumption of kale and raw endive, and positive associations were noted 
for consumption of leek, sweet peppers and mushrooms. Only the RR for leek was statistically significant. In other studies different (groups of) vegetables have been evaluated and no associations were shown for consumption of green or yellow vegetables $(7,9)$, dark green (leafy) vegetables $(9,20,26)$, 'other' vegetables $(4)$, 'mixed' vegetables (11), tomatoes $(20,26)$, carrots $(11,20,22-24)$, onions $(26)$, spinach $(11,18)$, broccoli $(11)$, cauliflower (14), bracken fern (19) and rutabaga (14). In some studies positive associations were noted for consumption of fried vegetables (6) and mushrooms (19), and protective associations were noted for consumption of dark green vegetables for men aged less than 70 years $(20)$, leafy green vegetables $(24)$, tomatoes $(5,11,14)$, carrots $(14,18,21,26)$, and spinach $(19,21)$.

Because so many different vegetables were evaluated, and studies were carried out in various populations with different eating habits, the interpretation of results from these studies are hampered. In addition, studies differ in the level and range of exposure, thus leading to results that are not directly comparable. These drawbacks not only apply to studies on prostate cancer risk in relation to vegetable consumption but also in relation to fruit consumption (discussed below). Other drawbacks are that endpoints in previous studies were either incidence or mortality and, as a consequence, consistency in results is difficult to evaluate. Also, several epidemiological studies are hampered by the fact that no extensive measurement of consumption of vegetables and fruit was made. Therefore, no complete evaluation of vegetables and fruit was possible and for those vegetables and fruit that were included, a random misclassification bias may have occurred which led to an underestimation of effect. Another drawback is that because in several studies only limited adjustment was employed, results in these studies might have been influenced by confounding. Finally, in none of the previous studies the independent effect of individual vegetables or fruits was assessed by including total vegetable or total fruit consumption into the multivariate model.

When quintiles of total fruit and citrus fruit consumption were evaluated in our cohort study, we observed significant positive trends in risk, but in a continuous model no association with total fruit consumption was found. In most other cohort studies no clear associations were found for total fruit $(4,5,8,9,11)$ and fresh citrus fruit (5). Total fruit consumption was positively associated with prostate cancer in one cohort study (6) and one case-control study (25) and also for citrus fruit a positive association was noted in a case-control study (26). Null associations have been reported for consumption of canned or frozen fruit (5), fresh winter fruit (5), noncitrus fruit (26) or 'other' fresh fruit $(5,10)$. In one case-control study fresh fruit consumption was negatively associated with prostate cancer risk, but only for men aged 70 years and older (22). Except for mandarins and raisins, which were inversely associated with prostate cancer risk in the NLCS, no strong associations for individual fruits were found. There is only one other study in which consumption of raisins 
and other dried fruit was evaluated and in this cohort study also an inverse association was observed (5). Other individual fruits that have been evaluated are oranges (11), strawberries (11), pumpkin or mangoes and papaya (20). Only for papaya a positive association with prostate cancer risk was observed in men aged 70 years and older. In two cohort studies consumption of vegetables and fruit combined showed no associations with prostate cancer risk $(9,12)$, and this was confirmed in our study.

It has been suggested before that latent and nonlatent or aggressive prostate tumors might have a different etiology (1). The RRs for groups of vegetables and fruits did not differ to a large extent between the different subgroups in our study. In one other study in which only carrots were evaluated it was mentioned that a distinction in localized and advanced prostate tumors displayed results similar to overall results (23). Thus far, there have been no other studies regarding vegetable and fruit consumption and prostate cancer risk in which subgroup analyses based on tumor characterization were conducted.

In conclusion, for most vegetables thus far no consistent associations with prostate cancer risk have been observed. Moreover, in most studies, including the present one, vegetable consumption seemed not to be associated with prostate cancer risk. However, different vegetables have been evaluated in different studies which makes a comparison between studies difficult. We found some indication of a protective effect of consumption of pulses, kale and raw endive and of a positive association between consumption of leek, sweet peppers and mushrooms and prostate cancer risk. These results, however, need to be confirmed in other studies. For fruit, similar conclusions can be drawn. We found a positive trend in risk for total fruit consumption and citrus fruit consumption, but this has mostly not been reported from other studies. In a continuous model, fruit consumption showed no association with prostate cancer risk. Results from our study regarding individual fruits were not very convincing. Nevertheless, there was a tendency for a protective effect of consumption of raisins and other dried fruit. Because this effect was also reported in another study, more studies on a possible effect of raisins are warranted. Our results indicate no different association for latent and nonlatent or more advanced prostate tumors.

\section{Acknowledgements}

We are indebted to the participants of this study and further wish to thank the regional cancer registries (IKA, IKL, IKMN, IKN, IKO, IKR, IKST, IKW, IKZ), and the Dutch national data base of pathology (PALGA); A. Volovics for statistical advice; S. van de Crommert, J. Nelissen, H. Brants, M. Moll, W. van Dijk, C. Sloot, P. Florax and A. Pisters for assistance; and $\mathrm{H}$. van Montfort, R. Schmeitz, T. van Montfort, and M. de Leeuw for programming and statistical assistance. 


\section{References}

1. Kolonel LN. Nutrition and prostate cancer. Cancer Causes Control 1996;7:83-94.

2. Steinmetz KA, Potter JD. Vegetables, fruit, and cancer. II. Mechanisms. Cancer Causes Control 1991;2:427-42.

3. Steinmetz KA, Potter JD. Vegetables, fruit, and cancer prevention: a review. J Am Diet Assoc 1996;96:1027-39.

4. Snowdon DA, Phillips RL, Choi W. Diet, obesity, and risk of fatal prostate cancer. Am J Epidemiol 1984;120:244-50.

5. Mills PK, Beeson WL, Phillips RL, et al. Cohort study of diet, lifestyle, and prostate cancer in Adventist men. Cancer 1989;64:598-604.

6. Severson RK, Nomura AM, Grove JS, et al. A prospective study of demographics, diet, and prostate cancer among men of Japanese ancestry in Hawaii. Cancer Res 1989;49:1857-60.

7. Hirayama T. Life-style and mortality. A large-scale census-based cohort study in Japan. Basel: Karger, 1990.

8. Hsing AW, McLaughlin JK, Schuman LM, et al. Diet, tobacco use, and fatal prostate cancer: results from the Lutheran Brotherhood Cohort Study. Cancer Res 1990;50:6836-40.

9. Shibata A, Paganini Hill A, Ross RK, et al. Intake of vegetables, fruits, beta-carotene, vitamin C and vitamin supplements and cancer incidence among the elderly: a prospective study. $\mathrm{Br} J$ Cancer 1992;66:673-9.

10. Le Marchand L, Kolonel LN, Wilkens LR, et al. Animal fat consumption and prostate cancer: a prospective study in Hawaii. Epidemiology 1994;5:276-82.

11. Giovannucci E, Ascherio A, Rimm EB, et al. Intake of carotenoids and retinol in relation to risk of prostate cancer. J Natl Cancer Inst 1995;87:1767-76.

12. Gronberg H, Damber L, Damber JE. Total food consumption and body mass index in relation to prostate cancer risk: a case-control study in Sweden with prospectively collected exposure data. J Urol 1996;155:969-74.

13. Rodriguez C, Tatham LM, Thun MJ, et al. Smoking and fatal prostate cancer in a large cohort of adult men. Am J Epidemiol 1997;145:466-75.

14. Schuman LM, Mandel JS, Radke A, et al. Some selected features of the epidemiology of prostatic cancer: Minneapolis-St. Paul, Minnesota case-control study, 1976-1979. In: Magnus K, ed. Trends in cancer incidence: causes and practical implications. Washington: Hemisphere Publishiong corporation, 1982:345-54.

15. Graham S, Haughey B, Marshall J, et al. Diet in the epidemiology of carcinoma of the prostate gland. J Natl Cancer Inst 1983;70:687-92.

16. Mishina $\mathrm{T}$, Watanabe $\mathrm{H}$, Araki $\mathrm{H}$, et al. Epidemiological study of prostatic cancer by matched-pair analysis. Prostate 1985;6:423-36.

17. Talamini R, La Vecchia C, Decarli A, et al. Nutrition, social factors and prostatic cancer in a Northern Italian population. Br J Cancer 1986;53:817-21.

18. Ross RK, Shimizu H, Paganini Hill A, et al. Case-control studies of prostate cancer in blacks and whites in southern California. J Natl Cancer Inst 1987;78:869-74.

19. Oishi K, Okada K, Yoshida O, et al. A case-control study of prostatic cancer with reference to dietary habits. Prostate 1988;12:179-90.

20. Le Marchand L, Hankin JH, Kolonel LN, et al. Vegetable and fruit consumption in relation to prostate cancer risk in Hawaii: a reevaluation of the effect of dietary beta-carotene. Am J Epidemiol 1991;133:215-9.

21. Walker AR, Walker BF, Tsotetsi NG, et al. Case-control study of prostate cancer in black patients in Soweto, South Africa. Br J Cancer 1992;65:438-41.

22. Talamini R, Franceschi S, La Vecchia C, et al. Diet and prostatic cancer: a case-control study in northern Italy. Nutr Cancer 1992;18:277-86.

23. Andersson SO, Baron J, Wolk A, et al. Early life risk factors for prostate cancer: a populationbased case-control study in Sweden. Cancer Epidemiol Biomarkers Prev 1995;4:187-92.

24. Ewings P, Bowie C. A case-control study of cancer of the prostate in Somerset and east Devon. Br J Cancer 1996;74:661-6.

25. De Stefani E, Fierro L, Barrios E, et al. Tobacco, alcohol, diet and risk of prostate cancer. Tumori 1995;81:315-20.

26. Key TJ, Silcocks PB, Davey GK, et al. A case-control study of diet and prostate cancer. Br J Cancer 1997;76:678-87. 
27. Van den Brandt PA, Goldbohm RA, Van 't Veer P, et al. A large-scale prospective cohort study on diet and cancer in The Netherlands. J Clin Epidemiol 1990;43:285-95.

28. Prentice RL. A case-cohort design for epidemiologic cohort studies and disease prevention trials. Biometrika 1986;73:1-11.

29. Self SG, Prentice RL. Asymptotic distribution theory and efficiency results for case-cohort studies. Ann Stat 1988;16:64-81.

30. Van den Brandt PA, Schouten LJ, Goldbohm RA, et al. Development of a record linkage protocol for use in the Dutch Cancer Registry for Epidemiological Research. Int J Epidemiol 1990;19:5538.

31. Goldbohm RA, Van den Brandt PA, Dorant E. Estimation of the coverage of Dutch municipalities by cancer registries and PALGA based on hospital discharge data. Tijdschr Soc Gezondheidsz 1994;72:80-4.

32. Goldbohm RA, Van den Brandt PA, Brants HAM, et al. Validation of a dietary questionnaire used in a large-scale prospective cohort study on diet and cancer. Eur J Clin Nutr 1994;48:253-65.

33. Baker J. GLIM 3.77 Reference Manual. Oxford: Numerical Algorithms Group, 1985.

34. Volovics A, van den Brandt PA. Methods for the analyses of case-cohort studies. Biom J 1997;2:195-214.

35. Boyle $P$, Maisonneuve $P$, Napalkov $P$. Geographical and temporal patterns of incidence and mortality from prostate cancer. Urology 1995;46:47-55.

36. Van den Brandt PA, Van 't Veer P, Goldbohm RA, et al. A prospective cohort study on dietary fat and the risk of postmenopausal breast cancer. Cancer Res 1993;53:75-82.

37. Ocke MC, Bueno de Mesquita HB, Goddijn HE, et al. The Dutch EPIC food frequency questionnaire. I. Description of the questionnaire, and relative validity and reproducibility for food groups. Int J Epidemiol 1997;26 Supplement:S37-S48.

38. Nes M, Frost Andersen L, Solvoll K, et al. Accuracy of a quantitative food frequency questionnaire applied in elderly Norwegian women. Eur J Clin Nutr 1992;46:809-21.

39. Hankin JH, Wilkens LR, Kolonel LN, et al. Validation of a quantitative diet history method in Hawaii. Am J Epidemiol 1991;133:616-28. 


\title{
Chapter 3
}

\section{A prospective cohort study on retinol,}

\section{vitamins $C$ and $E$, and carotenoids and}

\section{prostate cancer risk'}

\author{
Agnes G. Schuurman ${ }^{2}$ \\ R. Alexandra Goldbohm ${ }^{3}$ \\ Henny A.M. Brants ${ }^{3}$ \\ Piet A. van den Brandt ${ }^{2}$
}

\begin{abstract}
The association between retinol, vitamins $\mathrm{C}$ and $\mathrm{E}$, and carotenoids and prostate cancer risk was investigated in the Netherlands Cohort Study among 58,279 men aged 55-69 years at baseline in 1986. Information on diet was assessed with a 150-item semiquantitative food frequency questionnaire. After 6.3 years of follow-up 642 cases were available for analyses. Multivariate analyses were adjusted for age, family history of prostate cancer, socioeconomic status and alcohol intake. A positive association was observed for intake of $\beta$-cryptoxanthin. RRs in increasing quintiles were 1.00 (ref), 0.94 , $1.01,1.16,1.41 ; p$-trend $<0.01$. For intake of retinol, vitamins $C$ and $E$ and other carotenoids ( $\alpha$-carotene, $\beta$-carotene, lycopene and lutein/zeaxanthin) no effect on overall prostate cancer risk was found. RRs for vitamin supplement use were decreased, but not significantly. Nutrients were also evaluated in subgroups of nondrinkers and drinkers. Among nondrinkers, nonsignificant inverse associations were observed for intake of retinol, $\alpha$-carotene, and $\beta$-carotene. RRs in the highest vs lowest intake quintile were $0.23,0.60$, and 0.76 , respectively. Among drinkers, $\beta$-cryptoxanthin showed a positive association (RR highest vs lowest quintile=1.40). In conclusion, from our study an interaction between vitamins and alcohol consumption is suggested, which needs confirmation.
\end{abstract}

\footnotetext{
Submitted for publication

${ }^{2}$ Dept. of Epidemiology, Maastricht University, Maastricht

${ }^{3}$ Dept. of Consumer Research \& Epidemiology, TNO Nutrition and Food Research Institute, Zeist
} 


\section{Introduction}

Vitamins are thought to play a potentially important role in the prevention of cancer. For example, vitamin A may inhibit tumor promotion, carotenoids and vitamins $\mathrm{C}$ and $\mathrm{E}$ may be protective because of antioxidant effects, and vitamin $\mathrm{C}$ may prevent the formation of carcinogens from precursor compounds (1). In fact, for different types of cancer (e.g. cancers of the stomach, esophagus, lung, oral cavity and pharynx, endometrium, and pancreas) the evidence for a protective effect of consumption of vegetables and fruit is considered to be consistent. However, for prostate cancer the evidence is questionable (2). For several nutrients, results from trials with prostate cancer as one of the endpoints have become available recently. The Finnish Alpha-Tocopherol, Beta-Carotene Cancer Prevention Study (ATBC study), a large chemoprevention trial among male smokers, indicated an adverse effect of $\beta$-carotene on prostate cancer risk. Among nondrinkers, however, $\beta$-carotene supplementation appeared to decrease the risk of prostate cancer. In this same trial, a protective effect of $\alpha$-tocopherol supplementation was observed. Subjects receiving $\alpha$-tocopherol plus $\beta$-carotene had a slight nonsignificant decrease in prostate cancer incidence compared with the placebo group (3). In the Physicians' Health Study among US male physicians $\beta$-carotene supplementation showed no statistically significant effect on prostate cancer risk (4) and in the US Beta-Carotene and Retinol Efficacy Trial among subjects at high risk of developing lung cancer, no effect on prostate cancer incidence of supplementation with $\beta$-carotene or retinol was observed (5). Besides these trials, several observational epidemiological studies have been conducted. Especially retinol and $\beta$-carotene have been investigated for many years now, but results for these and other nutrients are still mostly inconsistent (6). Few studies to date have investigated specific carotenoids besides $\beta$-carotene in prostate cancer etiology $(6,7)$. Nevertheless, prospective studies indicated a decreased association with intake of lycopene (8) and an increased association for serum $\beta$-cryptoxanthin (9) and in one case-control study an increased risk was observed for intake of papaya and it was suggested that $\beta$ cryptoxanthin, a common carotenoid in papaya, may be responsible for this observed association (10).

To further explore a possible association between intake of vitamins and carotenoids and prostate cancer risk, we investigated this within the Netherlands Cohort Study (NLCS) on diet and cancer.

\section{Materials and methods}

\section{The cohort study}

We will only briefly outline the study design because this has been reported in detail elsewhere (11). The NLCS was initiated in September 1986 and includes 58,279 men aged 55-69 years at the beginning of the study. The study population originated from 204 municipal registries throughout the country. All cohort members completed a mailed, self- 
administered questionnaire on dietary habits and other risk factors for cancer. For reasons of efficiency in data processing and analysis, the case-cohort approach $(12,13)$ was used. In a case-cohort approach, cases are derived from the entire cohort (providing numerator information for calculation of cancer incidence rates), while accumulated person years at risk in the total cohort are estimated using a random subcohort sample (providing denominator information for the rates). In contrast to nested case-control sampling, this subcohort can be used for multiple disease endpoints. The subcohort $(n=1,688)$ was sampled directly after identification of all cohort members and has been followed up biennially for vital status information. Follow-up for incidence of prostate cancer was established by computerized record linkage with all nine cancer registries in the Netherlands and with the Dutch national data base of pathology reports (PALGA) (14). No subcohort members were lost to follow-up and completeness of follow-up of cancer has been estimated to be at least 96 percent (15). After a follow-up period of 6.3 years (September 1986-December 1992), 704 incident, microscopically or histologically confirmed, primary prostate cancer cases were detected.

\section{The questionnaire}

The self-administered questionnaire has also been described in detail elsewhere (16). The dietary section of the questionnaire, a 150-item semiquantitative food frequency questionnaire, concentrated on habitual consumption of food and beverages during the year preceding the start of the study. Questionnaire data were key-entered twice and processed for all incident cases in the cohort and for all subcohort members in a standardized manner blinded with respect to case/subcohort status. This was done in order to minimize observer bias in coding and interpretation of the data. Mean daily vitamin intakes were calculated using the computerized Dutch food composition table (17). For carotenoids, a recently developed food composition database was used. Regularly eaten vegetables were comprehensively sampled and analyzed for their carotenoid content and the database was completed with data from the recent literature and information from food manufacturers (18). Information on dietary supplement use was collected using an openended question with space for adding a maximum of four different supplements.

Participants were asked whether they used vitamin tablets, drops or other preparations during five years before baseline. Subjects were categorized in users or nonusers of supplements and supplements containing vitamin A, C or E. The questionnaire was validated against a 9-day diet record. The energy and sex-adjusted Pearson correlation coefficients between the 9-day record and the questionnaire were 0.48 for total vitamin $A$, and 0.55 for vitamin $C(16)$.

\section{Data analysis}

In the subcohort prevalent cancer cases at baseline other than skin cancer were excluded, leaving 1,630 subcohort members for analysis. Furthermore, according to criteria published 
before (16), subjects with incomplete or inconsistent dietary data were excluded; 642 men with prostate cancer and 1,525 male subcohort members remained for analysis.

The distribution of dietary factors and other characteristics was compared between cases and subcohort members. Furthermore, mean intakes of vitamins and carotenoids were compared across categories of potential confounding variables. Variables that were considered as potential confounders were age (continuous), a family history of prostate cancer (no, yes), socioeconomic status (low, medium, high) and alcohol intake from white/fortified wine ( $<15 \mathrm{~g} /$ day, $\geq 15 \mathrm{~g} /$ day) because in previous analyses these factors were associated with prostate cancer risk in the NLCS (data not shown). Total energy and total fat intake were not considered as potential confounding factors because no association with prostate cancer risk was observed (data not shown). The same applies to vegetable and fruit consumption (19). Subjects were categorized according to quintile levels of nutrients, or according to their use of vitamin supplements. Vitamin C intake was categorized into three categories because the validation study showed that quintiles two and three and quintiles four and five of vitamin $C$ intake could not be distinguished (16). Rate ratios (RRs) and 95 percent confidence intervals (95 percent $\mathrm{Cl}$ ) were computed using the GLIM statistical package (20). Exponentially distributed survival times were assumed in the follow-up period. Since standard software was not available, specific macros were developed to account for the additional variance introduced by using the subcohort instead of the entire cohort (21). Tests for trend were based on likelihood ratio tests and two-sided p-values are used throughout this report. Age-adjusted as well as multivariate adjusted analyses were done. Advanced prostate cancer cases (T3-4, M0; TO-4, M1) were evaluated separately to test the hypothesis that diet may be more strongly related to advanced prostate tumors. Furthermore, associations between intake of vitamins and carotenoids and supplement use and risk of prostate cancer were also investigated in subgroups of nondrinkers and drinkers of alcoholic beverages because in the ATBC trial an interaction between $\beta$-carotene supplementation and alcohol consumption was shown. To evaluate whether preclinical disease might have influenced results, cases detected in the first two years of follow-up were exluded in additional analyses.

\section{Results}

The mean daily intake of vitamins is shown in table 1. Mostly, no large differences in intake between cases and subcohort members were observed although vitamin $\mathrm{C}$ intake was somewhat higher among cases. Overall, use of any vitamin supplement was similar between cases and subcohort members. However, use of supplements containing vitamin A, C, or E among cases (3.7, 7.2, and 3.7 percent, respectively) was lower compared to subcohort members $(5.2,8.2$, and 4.8 percent, respectively). Also shown in this table is the distribution of potential confounding factors. Compared to subcohort members, cases are older ( 63.9 vs 61.4 years), more often have a family history of prostate cancer ( $4.4 \mathrm{vs} 2.7$ 
percent) and are more often of a higher socioeconomic status (20.2 vs 17.8 percent).

Table 1: Description of mean daily intake of vitamins, carotenoids and vitamin supplement use and distribution of potential confounding factors, Netherlands Cohort Study (1986-1992).

\begin{tabular}{|c|c|c|c|c|}
\hline \multirow[t]{2}{*}{ Characteristis } & \multicolumn{2}{|c|}{ Cases $(n=642)$} & \multicolumn{2}{|c|}{ Subcohort $(n=1,525)$} \\
\hline & mean & SD & mean & SD \\
\hline \multicolumn{5}{|l|}{ Exposure variables } \\
\hline Retinol (mg) & 0.6 & 0.3 & 0.6 & 0.3 \\
\hline Vitamin C (mg/day) & 102.2 & 43.4 & 98.1 & 41.7 \\
\hline Vitamin E (mg/day) & 14.4 & 6.4 & 14.7 & 6.6 \\
\hline$\alpha$-carotene (mg/day) & 0.6 & 0.5 & 0.7 & 0.6 \\
\hline$\beta$-carotene (mg/day) & 2.9 & 1.3 & 3.0 & 1.6 \\
\hline$\beta$-cryptoxanthin (mg/day) & 0.2 & 0.2 & 0.2 & 0.2 \\
\hline Lycopene (mg/day) & 1.1 & 2.3 & 1.0 & 1.6 \\
\hline Lutein/zeaxanthin (mg/day) & 2.5 & 1.1 & 2.6 & 1.1 \\
\hline Any vitamin supplement use (\% yes) & 22.9 & & 22.4 & \\
\hline Use of supplements containing vitamin $\mathrm{A}$ (\% yes) & 3.7 & & 5.2 & \\
\hline Use of supplements containing vitamin $\mathrm{C}$ (\% yes) & 7.2 & & 8.2 & \\
\hline Use of supplements containing vitamin $E$ (\% yes) & 3.7 & & 4.8 & \\
\hline \multicolumn{5}{|l|}{ Potential confounding factors } \\
\hline Age (years) & 63.9 & 3.8 & 61.4 & 4.2 \\
\hline Family history ( $\%$ yes) & 4.4 & & 2.7 & \\
\hline Socioeconomic status (\% high) & 20.2 & & 17.8 & \\
\hline Alcohol from white/fortified wines (g/day) ${ }^{1}$ & 3.0 & 6.6 & 2.3 & 5.3 \\
\hline
\end{tabular}

${ }^{1}$ Nondrinking cases $(n=101)$ and nondrinking subcohort members $(n=231)$ not included.

Furthermore, among drinking cases alcohol intake from white wine and fortified wines was higher than among drinking subcohort members ( $3.0 \mathrm{vs} 2.3 \mathrm{~g} /$ day). When we evaluated the intake of vitamins across categories of potential confounding factors, the mean intakes of retinol, vitamin $\mathrm{E}, \alpha$-carotene, $\beta$-carotene, and lutein and zeaxanthin did not differ between categories of age, socioeconomic status, family history of prostate cancer and alcohol intake. The intake of vitamin $C$ and $\beta$-cryptoxanthin increased with age and the intake of vitamin $\mathrm{C}$ and lycopene increased with socioeconomic status. Finally, subjects with the lowest socioeconomic status had the lowest intake of $\beta$-cryptoxanthin, and subjects in the medium category had the highest intake (data not shown).

RRs for intake of retinol, vitamins $C$ and $E$, and carotenoids are shown in table 2, for all cases as well as for advanced cases separately. No associations were observed between intake of retinol, and vitamins $C$ and $E$ and overall risk of prostate cancer. Also for advanced cases no clear associations were observed. For intake of $\alpha$-carotene, all estimated RRs were below unity. The RR for the highest versus lowest quintile of intake 
was 0.85 (95 percent $\mathrm{Cl}$ 0.62-1.17), but no trend in risk was noted for overall prostate cancer risk ( $p$-trend=0.29). When advanced cases were evaluated separately, the RR for the same contrast was 0.64 (95 percent $\mathrm{Cl} 0.39-1.06$ ) and the trend test was of borderline significance $(p=0.07)$. For $\beta$-cryptoxanthin, a positive trend in risk was observed $(p<0.01)$. Only in the highest quintile of intake a significant increased risk was found $(R R=1.41,95$ percent $\mathrm{Cl}$ 1.03-1.92). For advanced cases only, the positive trend in risk was still significant ( $p$-trend=0.01) and the estimate in the highest intake quintile was of borderline significance ( $R R=1.56,95$ percent $\mathrm{Cl} 0.99-2.44)$. For other individual carotenoids no associations were noted.

Table 2: Rate ratios and $95 \%$ confidence intervals for prostate cancer according to quintiles of intake of retinol, vitamins C and E, and carotenoids, Netherlands Cohort Study (1986-1992).

\begin{tabular}{|c|c|c|c|c|c|c|}
\hline Exposure & Q1 ${ }^{1}$ & Q2 & Q3 & Q4 & Q5 & $\begin{array}{l}\mathrm{P} \text { for } \\
\text { trend }\end{array}$ \\
\hline Retinol (mg/day) $)^{2}$ & 0.3 & 0.4 & 0.6 & 0.7 & 1.0 & \\
\hline Cases/person years & $138 / 1807$ & $147 / 1841$ & $115 / 1831$ & $123 / 1821$ & $119 / 1821$ & \\
\hline $\operatorname{RR}(95 \% \mathrm{Cl})^{3}$ & 1.00 & $1.06(0.78-1.42)$ & $0.89(0.65-1.22)$ & $0.98(0.72-1.33)$ & $0.93(0.69-1.27)$ & 0.44 \\
\hline $\operatorname{RR}(95 \% \mathrm{Cl})^{4}$ & 1.00 & $1.08(0.80-1.46)$ & $0.86(0.62-1.18)$ & $0.98(0.72-1.34)$ & $0.96(0.70-1.32)$ & 0.49 \\
\hline Advanced cases $(n)^{5}$ & 46 & 53 & 34 & 42 & 35 & \\
\hline $\operatorname{RR}(95 \% \mathrm{CI})^{4}$ & 1.00 & $1.16(0.75-1.79)$ & $0.76(0.47-1.23)$ & $0.99(0.63-1.57)$ & $0.86(0.53-1.38)$ & 0.33 \\
\hline Vitamin C (mg/day) $)^{2}$ & 52.5 & 82.3 & 128.3 & & & \\
\hline Cases/person years & $109 / 1816$ & $245 / 3645$ & $288 / 3662$ & & & \\
\hline $\operatorname{RR}(95 \% \mathrm{CI})^{3}$ & 1.00 & $1.10(0.83-1.45)$ & $1.22(0.93-1.61)$ & & & 0.06 \\
\hline $\operatorname{RR}(95 \% \mathrm{Cl})^{4}$ & 1.00 & $1.06(0.80-1.40)$ & $1.15(0.87-1.52)$ & & & 0.19 \\
\hline Advanced cases $(n)^{5}$ & 33 & 84 & 93 & & & \\
\hline $\operatorname{RR}(95 \% \mathrm{CI})^{4}$ & 1.00 & $1.19(0.77-1.84)$ & $1.24(0.81-1.91)$ & & & 0.32 \\
\hline Vitamin E (mg/day) $)^{2}$ & 7.1 & 10.4 & 13.5 & 17.3 & 23.6 & \\
\hline Cases/person years & $128 / 1769$ & $126 / 1854$ & $149 / 1845$ & $126 / 1820$ & $113 / 1835$ & \\
\hline $\operatorname{RR}(95 \% \mathrm{Cl})^{3}$ & 1.00 & $1.05(0.77-1.43)$ & $1.20(0.88-1.62)$ & $0.99(0.72-1.34)$ & $0.95(0.69-1.31)$ & 0.60 \\
\hline $\operatorname{RR}(95 \% \mathrm{CI})^{4}$ & 1.00 & $1.05(0.77-1.44)$ & $1.14(0.84-1.54)$ & $0.94(0.69-1.29)$ & $0.94(0.68-1.29)$ & 0.42 \\
\hline Advanced cases $(n)^{5}$ & 48 & 43 & 37 & 39 & 43 & \\
\hline $\operatorname{RR}(95 \% \mathrm{CI})^{4}$ & 1.00 & $0.96(0.61-1.51)$ & $0.77(0.49-1.23)$ & $0.81(0.51-1.29)$ & $0.96(0.61-1.50)$ & 0.57 \\
\hline \multicolumn{7}{|l|}{$\alpha$-carotene $(\mathrm{mg} / \text { day })^{2}$} \\
\hline Cases/person years & 0.2 & 0.4 & 0.6 & 0.8 & 1.3 & \\
\hline $\mathrm{RR}(95 \% \mathrm{Cl})^{3}$ & $134 / 1800$ & $136 / 1839$ & $126 / 1819$ & $132 / 1830$ & $114 / 1834$ & \\
\hline $\operatorname{RR}(95 \% \mathrm{Cl})^{4}$ & 1.00 & $0.95(0.70-1.29)$ & $0.92(0.67-1.25)$ & $0.97(0.71-1.31)$ & $0.85(0.62-1.16)$ & 0.29 \\
\hline Advanced cases $(n)^{5}$ & 1.00 & $0.95(0.69-1.29)$ & $0.91(0.67-1.25)$ & $0.96(0.71-1.31)$ & $0.85(0.62-1.17)$ & 0.29 \\
\hline \multirow[t]{2}{*}{$\operatorname{RR}(95 \% \mathrm{Cl})^{4}$} & 44 & 49 & 44 & 44 & 29 & \\
\hline & 1.00 & $1.04(0.67-1.63)$ & $0.96(0.61-1.52)$ & $0.94(0.60-1.49)$ & $0.64(0.39-1.06)$ & 0.07 \\
\hline$\beta$-carotene $(\mathrm{mg} / \text { day })^{2}$ & 1.5 & 2.1 & 2.7 & 3.4 & 4.7 & \\
\hline Cases/person years & $119 / 1801$ & $148 / 1840$ & $130 / 1819$ & $120 / 1818$ & $125 / 1844$ & \\
\hline $\operatorname{RR}(95 \% \mathrm{Cl})^{3}$ & 1.00 & $1.19(0.88-1.62)$ & $1.12(0.82-1.54)$ & $0.97(0.71-1.33)$ & $1.07(0.78-1.47)$ & 0.77 \\
\hline $\operatorname{RR}(95 \% \mathrm{CI})^{4}$ & 1.00 & $1.19(0.87-1.62)$ & $1.11(0.81-1.53)$ & $0.95(0.69-1.31)$ & $1.09(0.79-1.49)$ & 0.79 \\
\hline Advanced cases $(n)^{5}$ & 36 & 51 & 47 & 41 & 35 & \\
\hline $\operatorname{RR}(95 \% \mathrm{CI})^{4}$ & 1.00 & $1.34(0.84-2.14)$ & $1.30(0.81-2.09)$ & $1.07(0.66-1.74)$ & $0.97(0.59-1.60)$ & 0.54 \\
\hline
\end{tabular}


Table 2 continued

\begin{tabular}{|c|c|c|c|c|c|c|}
\hline Exposure & Q1 ${ }^{1}$ & Q2 & Q3 & Q4 & Q5 & $\begin{array}{l}\mathrm{P} \text { for } \\
\text { trend }\end{array}$ \\
\hline \multicolumn{7}{|l|}{$\beta$-cryptoxanthin } \\
\hline$(\mathrm{mg} / \text { day })^{2}$ & 0.012 & 0.045 & 0.1 & 0.2 & 0.4 & \\
\hline Cases/person years & $112 / 1826$ & $105 / 1833$ & $115 / 1830$ & $136 / 1810$ & $174 / 1824$ & \\
\hline RR $(95 \% \mathrm{Cl})^{3}$ & 1.00 & $0.96(0.70-1.34)$ & $1.02(0.74-1.41)$ & $1.18(0.86-1.61)$ & $1.45(1.07-1.96)$ & $<0.01$ \\
\hline $\operatorname{RR}(95 \% \mathrm{CI})^{4}$ & 1.00 & $0.94(0.68-1.32)$ & $1.01(0.73-1.40)$ & $1.16(0.85-1.60)$ & $1.41(1.03-1.92)$ & $<0.01$ \\
\hline Advanced cases $(n)^{5}$ & 36 & 32 & 35 & 44 & 63 & \\
\hline $\operatorname{RR}(95 \% \mathrm{Cl})^{4}$ & 1.00 & $0.87(0.52-1.45)$ & $0.91(0.55-1.51)$ & $1.15(0.71-1.85)$ & $1.56(0.99-2.44)$ & 0.01 \\
\hline Lycopene $(\mathrm{mg} / \text { day })^{2}$ & 0.1 & 0.4 & 0.7 & 1.1 & 2.0 & \\
\hline Cases/person years & $128 / 1825$ & $104 / 1841$ & $150 / 1824$ & $134 / 1822$ & $126 / 1810$ & \\
\hline $\operatorname{RR}(95 \% \mathrm{Cl})^{3}$ & 1.00 & $0.81(0.59-1.11)$ & $1.15(0.85-1.55)$ & $1.02(0.75-1.38)$ & $1.03(0.76-1.40)$ & 0.33 \\
\hline $\operatorname{RR}(95 \% \mathrm{Cl})^{4}$ & 1.00 & $0.79(0.57-1.09)$ & $1.08(0.80-1.47)$ & $0.99(0.72-1.36)$ & $0.98(0.71-1.34)$ & 0.58 \\
\hline Advanced cases $(n)^{5}$ & 42 & 35 & 49 & 43 & 41 & \\
\hline $\operatorname{RR}(95 \% \mathrm{CI})^{4}$ & 1.00 & $0.80(0.49-1.31)$ & $1.09(0.69-1.71)$ & $0.94(0.59-1.50)$ & $0.92(0.57-1.47)$ & 0.96 \\
\hline \multicolumn{7}{|l|}{ Lutein/zeaxanthin } \\
\hline$(\mathrm{mg} / \text { day })^{2}$ & 1.4 & 1.9 & 2.4 & 2.9 & 3.9 & \\
\hline Cases/person years & $138 / 1812$ & $123 / 1800$ & $123 / 1843$ & $139 / 1843$ & $119 / 1824$ & \\
\hline $\operatorname{RR}(95 \% \mathrm{Cl})^{3}$ & 1.00 & $0.95(0.70-1.30)$ & $0.86(0.63-1.17)$ & $1.07(0.79-1.44)$ & $0.91(0.67-1.24)$ & 0.79 \\
\hline $\operatorname{RR}(95 \% \mathrm{Cl})^{4}$ & 1.00 & $0.91(0.67-1.25)$ & $0.86(0.63-1.17)$ & $1.05(0.77-1.43)$ & $0.91(0.66-1.24)$ & 0.85 \\
\hline Advanced cases $(n)^{5}$ & 40 & 40 & 35 & 52 & 43 & \\
\hline RR $(95 \% \mathrm{Cl})^{4}$ & 1.00 & $1.01(0.63-1.63)$ & $0.84(0.51-1.37)$ & $1.34(0.85-2.11)$ & $1.16(0.73-1.85)$ & 0.22 \\
\hline
\end{tabular}

${ }^{1}$ Reference category; ${ }^{2}$ Median intake (subcohort) in category; ${ }^{3}$ Adjusted for age; ${ }^{4}$ Adjusted for age, family history of prostate cancer, socioeconomic status, and alcohol from white or fortified wine; ${ }^{5} \mathrm{~T} 3-4, \mathrm{M} 0, \mathrm{~T} 0-4, \mathrm{M} 1$.

Table 3 shows the results for vitamin supplement use. For use of supplements containing vitamin $A$, vitamin $C$ or supplements containing vitamin $E$, all estimated $R R$ s were below unity, although not statistically significant. The RRs ( 95 percent $\mathrm{CI}$ ) for users versus nonusers were $0.65(0.40-1.07), 0.80(0.55-1.17)$ and $0.70(0.42-1.15)$, respectively. The estimates in the subgroup of advanced cases were similar to the estimated RRs for overall prostate cancer risk. After exclusion of cases detected in the first two years of follow-up risk estimates were similar to those presented in tables 2 and 3 (data not shown).

We also evaluated vitamin intake among nondrinkers and drinkers separately (table 4). Among nondrinkers, a decreased risk was observed for intake of retinol. The estimate for the highest vs lowest intake quintile was 0.23 with a 95 percent $\mathrm{Cl}$ of 0.08 to 0.61 and the $p$-value for the trend test was $<0.001$. Also for intake of $\alpha$-carotene and $\beta$-carotene inverse associatons were observed among nondrinking subjects. Risk estimates (95 percent $\mathrm{Cl}$ ) for the same contrast were $0.60(0.28-1.26)$ and $0.76(0.36-1.61)$, respectively. Lycopene intake showed decreased RRs in quintiles $2-4$, but in the fifth quintile a RR of 0.90 was observed. No clear associations were found for intake of vitamins $C$ and $E, \beta$-cryptoxanthin, and lutein and zeaxanthin among nondrinkers. Among drinking subjects, mostly no associations with prostate cancer risk were observed. Only for intake of $\beta$-cryptoxanthin a 
significant positive association was noted (RR highest vs lowest intake quintile was 1.43, 95 percent $\mathrm{Cl} 1.01-2.01$ ), and the trend test was also statistically significant ( $p$-value <0.01). Vitamin supplement use did not show clearly different associations with prostate cancer risk among drinkers and nondrinkers. As for the overall analyses, inverse associations were indicated.

Table 3: Rate ratios and 95\% confidence intervals for prostate cancer according to quintiles of intake of supplements, Netherlands Cohort Study (1986-1992).

\begin{tabular}{|c|c|c|}
\hline Exposure & $\mathrm{No}^{1}$ & Yes \\
\hline \multicolumn{3}{|l|}{ Any vitamin supplement } \\
\hline Cases/person years & $495 / 7085$ & $147 / 2037$ \\
\hline $\operatorname{RR}(95 \% \mathrm{CI})^{2}$ & 1.00 & $0.95(0.75-1.20)$ \\
\hline $\operatorname{RR}(95 \% \mathrm{Cl})^{3}$ & 1.00 & $0.93(0.73-1.18)$ \\
\hline Advanced cases $(n)^{4}$ & 167 & 43 \\
\hline $\operatorname{RR}(95 \% \mathrm{Cl})^{3}$ & 1.00 & $0.79(0.55-1.14)$ \\
\hline \multicolumn{3}{|l|}{ Vitamin A supplement } \\
\hline Cases/person years & $618 / 8642$ & $24 / 480$ \\
\hline $\operatorname{RR}(95 \% \mathrm{CI})^{2}$ & 1.00 & $0.65(0.40-1.07)$ \\
\hline $\operatorname{RR}(95 \% \mathrm{Cl})^{3}$ & 1.00 & $0.65(0.40-1.07)$ \\
\hline Advanced cases $(n)^{4}$ & 202 & 8 \\
\hline $\operatorname{RR}(95 \% \mathrm{Cl})^{3}$ & 1.00 & $0.62(0.29-1.32)$ \\
\hline \multicolumn{3}{|l|}{ Vitamin C supplement } \\
\hline Cases/person years & $596 / 8381$ & $46 / 741$ \\
\hline $\operatorname{RR}(95 \% \mathrm{Cl})^{2}$ & 1.00 & $0.83(0.57-1.20)$ \\
\hline $\operatorname{RR}(95 \% \mathrm{Cl})^{3}$ & 1.00 & $0.80(0.55-1.17)$ \\
\hline Advanced cases $(n)^{4}$ & 197 & 13 \\
\hline $\operatorname{RR}(95 \% \mathrm{CI})^{3}$ & 1.00 & $0.64(0.35-1.18)$ \\
\hline \multicolumn{3}{|l|}{ Vitamin E supplement } \\
\hline Cases/person years & $618 / 8688$ & $24 / 434$ \\
\hline $\operatorname{RR}(95 \% \mathrm{Cl})^{2}$ & 1.00 & $0.71(0.43-1.16)$ \\
\hline $\mathrm{RR}(95 \% \mathrm{Cl})^{3}$ & 1.00 & $0.70(0.42-1.15)$ \\
\hline Advanced cases $(n)^{4}$ & 202 & 8 \\
\hline $\operatorname{RR}(95 \% \mathrm{Cl})^{3}$ & 1.00 & $0.70(0.33-1.49)$ \\
\hline
\end{tabular}

${ }^{1}$ Reference category; ${ }^{2}$ Adjusted for age; ${ }^{3}$ Adjusted for age, family history of prostate cancer, socioeconomic status, and alcohol from white or fortified wine; ${ }^{4}$ T3-4, MO, TO-4, M1.

\section{Discussion}

Among nondrinking subjects, we found inverse associations for intake of retinol, $\alpha$ carotene, and $\beta$-carotene in relation to risk of prostate cancer. Among drinkers, intake of $\beta$ cryptoxanthin was positively associated with prostate cancer risk. In the total group of prostate cancers a positive association was also noted for intake of $\beta$-cryptoxanthin but for the total group of cases few other associations were observed. Users of vitamin $A, C$ and $E$ containing supplements showed nonsignificantly decreased risks, also in subgroups of 
drinkers and nondrinkers, for users of any vitamin supplements this was less clear. We found no indication that vitamins or carotenoids are more strongly related to advanced prostate tumors.

One important strength of the NLCS and other prospective studies is that exposure was assessed before the diagnosis of cancer. Therefore, recall bias is not likely to have influenced our results. Furthermore, selection bias is also unlikely because of the high completeness of follow-up of cases and subcohort members $(15,22)$. Another strength is that the consumption of vegetables and fruits, which contribute most to the intake of vitamins, was extensively measured in the NLCS, using a validated semi-quantitative food frequency questionnaire. Furthermore, also the assessment of intake of vitamin supplements was shown to be reasonably well in our study (23). The large number of prostate cancer cases in the NLCS is also an important strength. Besides overall analyses with relatively high power, we were also able to investigate different subgroups based on tumor characterization (advanced cases) or other characteristics of our study population (nondrinkers vs drinkers). There are also some limitations to our study. For example, misclassification of exposure might have occurred. However, from our validation study it was concluded that the questionnaire could satisfactorily rank subjects according to the intake of a number of macro- and micronutrients (16). If misclassification has occurred, we expect this to be nondifferential and risk estimates are most likely biased towards the null value. Another potential limitation is that we cannot exclude that residual confounding has influenced our results. Finally, also chance may have played a role in our findings.

The ATBC Study, a randomized placebo-controlled trial among 29,000 male Finnish smokers, was the first in which was reported that vitamin intake in relation to prostate cancer risk differed between drinking and nondrinking subjects. In this trial supplementation with $\beta$-carotene decreased the risk of prostate cancer by 32 percent among nondrinkers. Among drinkers, divided in tertiles, risk was increased by 25,42 and 40 percent, respectively (3). In our study, also inverse associations were observed among nondrinkers whereas among drinkers mostly no associations were noted. Thus far, for several vitamins and carotenoids inconsistencies in results from several studies exist (discussed below). If an interaction between vitamin or carotenoid intake and alcohol consumption exists, different proportions of drinkers and nondrinkers in previous studies may explain the inconsistent results observed thus far. In the NLCS, a lower intake of several nutrients among drinkers of alcoholic beverages compared to nondrinkers could not explain our findings (data not shown). We do, however, not have an obvious biological explanation for a potential interaction effect between vitamins or carotenoids and alcohol in prostate cancer etiology. Therefore, mechanistic research is warranted in addition to epidemiological studies. 
Table 4: Rate ratios (RR) and 95\% confidence intervals (Cl) for prostate cancer according to intake of vitamins, carotenoids and vitamin supplement use, in subgroups of nondrinkers and drinkers, Netherlands Cohort Study (1986-1992).

\begin{tabular}{|c|c|c|c|c|}
\hline \multirow[t]{2}{*}{ Exposure } & \multicolumn{2}{|l|}{ Nondrinkers } & \multicolumn{2}{|l|}{ Drinkers } \\
\hline & $\begin{array}{l}\text { Cases/ Person } \\
\text { years in } \\
\text { subcohort }\end{array}$ & $\mathrm{RR}^{1}(95 \% \mathrm{Cl})$ & $\begin{array}{l}\text { Cases/Person } \\
\text { years in } \\
\text { subcohort }\end{array}$ & $\mathrm{RR}^{1}(95 \% \mathrm{Cl})$ \\
\hline \multicolumn{5}{|l|}{ Retinol } \\
\hline $1(\text { low })^{2}$ & $30 / 283$ & 1.00 & $108 / 1499$ & 1.00 \\
\hline & $31 / 256$ & $1.37(0.68-2.73)$ & $115 / 1561$ & $0.98(0.70-1.37)$ \\
\hline 3 & $17 / 292$ & $0.65(0.31-1.38)$ & $95 / 1508$ & $0.89(0.63-1.26)$ \\
\hline 4 & $16 / 258$ & $0.69(0.32-1.50)$ & $105 / 1534$ & $1.02(0.73-1.43)$ \\
\hline 5 (high) & $6 / 254$ & $0.23(0.08-0.61)$ & $109 / 1520$ & $1.11(0.79-1.56)$ \\
\hline & & P-trend $<0.001$ & & P-trend 0.41 \\
\hline \multicolumn{5}{|l|}{ Vitamin C } \\
\hline $1(\mathrm{low})^{2}$ & $17 / 282$ & 1.00 & $91 / 1493$ & 1.00 \\
\hline 2 & $35 / 513$ & $1.05(0.52-2.13)$ & $207 / 3049$ & $1.06(0.78-1.45)$ \\
\hline 3 (high) & $48 / 548$ & $1.36(0.69-2.68)$ & $234 / 3080$ & $1.13(0.83-1.53)$ \\
\hline & & P-trend 0.21 & & P-trend 0.31 \\
\hline \multicolumn{5}{|l|}{ Vitamin E } \\
\hline $1(\mathrm{low})^{2}$ & $22 / 332$ & 1.00 & $106 / 1401$ & 1.00 \\
\hline 2 & $17 / 256$ & $0.88(0.40-1.92)$ & $108 / 1560$ & $1.11(0.79-1.56)$ \\
\hline 3 & $21 / 271$ & $1.18(0.56-2.49)$ & $123 / 1547$ & $1.14(0.82-1.60)$ \\
\hline 4 & $21 / 269$ & $1.27(0.60-2.65)$ & $102 / 1544$ & $0.91(0.65-1.29)$ \\
\hline 5 (high) & $19 / 215$ & $1.31(0.60-2.83)$ & $93 / 1569$ & $0.91(0.64-1.29)$ \\
\hline & & P-trend 0.22 & & P-trend 0.23 \\
\hline \multicolumn{5}{|c|}{$\alpha$-carotene } \\
\hline $1(\mathrm{low})^{2}$ & $28 / 301$ & 1.00 & $103 / 1458$ & 1.00 \\
\hline 2 & $23 / 264$ & $0.78(0.38-1.60)$ & $110 / 1542$ & $0.99(0.70-1.39)$ \\
\hline 3 & $17 / 249$ & $0.71(0.34-1.50)$ & $108 / 1526$ & $0.97(0.69-1.37)$ \\
\hline 4 & $14 / 232$ & $0.66(0.30-1.46)$ & $117 / 1579$ & $1.02(0.72-1.42)$ \\
\hline 5 (high) & $18 / 297$ & $0.60(0.28-1.26)$ & $94 / 1517$ & $0.91(0.64-1.29)$ \\
\hline & & P-trend 0.08 & & P-trend 0.62 \\
\hline \multicolumn{5}{|c|}{$\beta$-carotene } \\
\hline $1(\mathrm{low})^{2}$ & $28 / 339$ & 1.00 & $89 / 1427$ & 1.00 \\
\hline 2 & $23 / 251$ & $1.03(0.51-2.11)$ & $124 / 1549$ & $1.25(0.89-1.77)$ \\
\hline 3 & $18 / 228$ & $0.97(0.46-2.07)$ & $109 / 1560$ & $1.13(0.79-1.60)$ \\
\hline 4 & $14 / 247$ & $0.65(0.29-1.42)$ & $103 / 1540$ & $1.02(0.71-1.45)$ \\
\hline 5 (high) & $17 / 278$ & $0.76(0.36-1.61)$ & $107 / 1545$ & $1.15(0.81-1.63)$ \\
\hline & & P-trend 0.17 & & P-trend 0.93 \\
\hline \multicolumn{5}{|c|}{ B-cryptoxanthin } \\
\hline $1(\text { low })^{2}$ & $22 / 312$ & 1.00 & $86 / 1457$ & 1.00 \\
\hline 2 & $17 / 221$ & $1.17(0.52-2.62)$ & $87 / 1581$ & $0.94(0.65-1.35)$ \\
\hline 3 & $13 / 294$ & $0.66(0.29-1.48)$ & $101 / 1506$ & $1.09(0.76-1.57)$ \\
\hline 4 & $22 / 246$ & $1.11(0.52-2.35)$ & $112 / 1537$ & $1.20(0.84-1.71)$ \\
\hline \multirow[t]{2}{*}{5 (high) } & $26 / 270$ & $1.40(0.68-2.91)$ & $146 / 1541$ & $1.43(1.01-2.01)$ \\
\hline & & P-trend 0.31 & & P-trend $<0.01$ \\
\hline
\end{tabular}


Table 4 continued

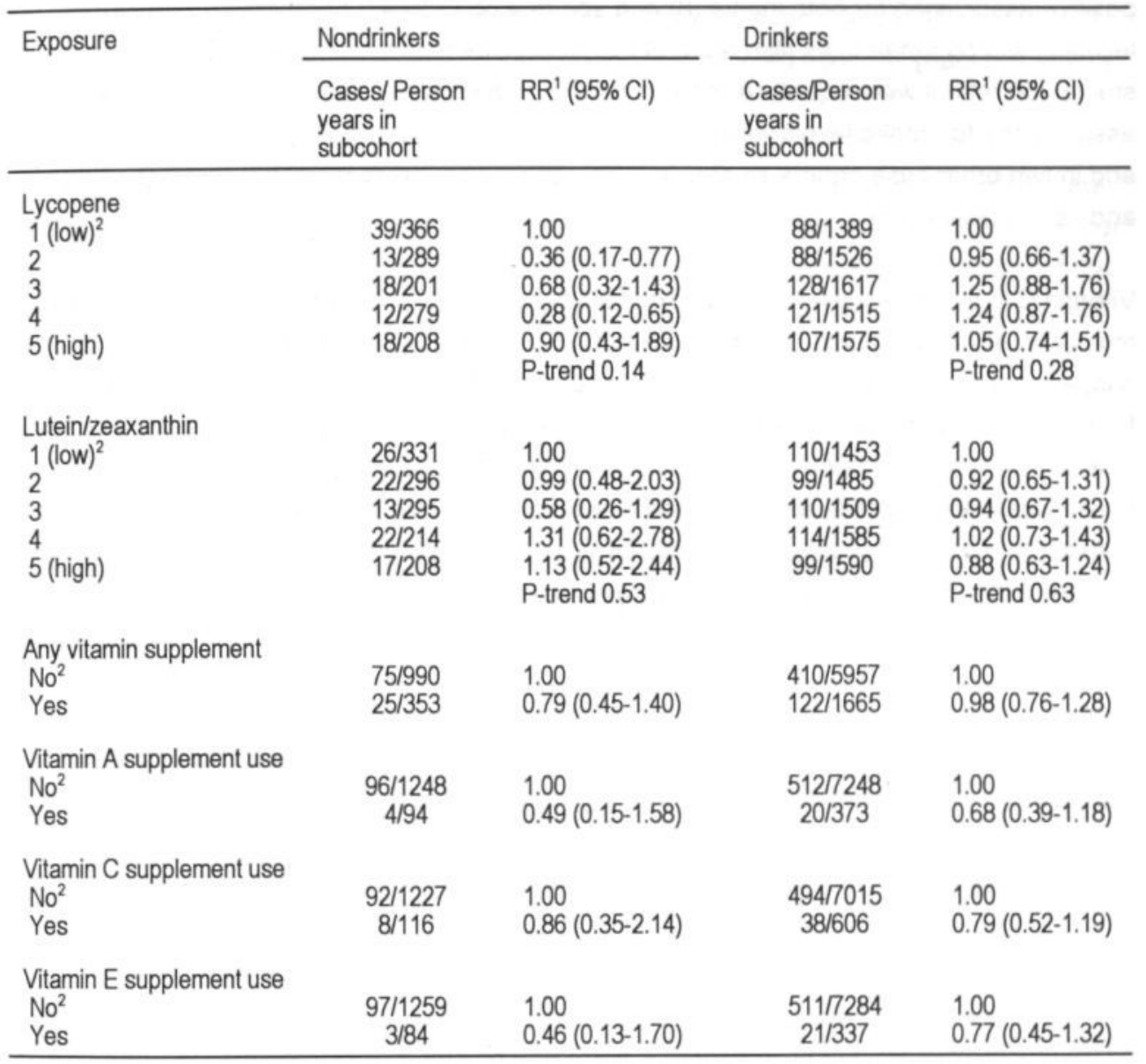

${ }^{1}$ Adjusted for age, family history of prostate cancer, and socioeconomic status; ${ }^{2}$ Reference category.

Vitamin A is involved in cell differentiation and since lack of differentiation is a feature of cancer cells, a protective effect vitamin A on cancer development may be expected (1). Retinol is the physiologically active form of vitamin A, and retinoids may act as suppressing agents retarding neoplasia development, or as inhibitors of tumor promotion (1). In our study, protective effects of supplements containing vitamin A were suggestive. In three previous prospective studies no association for vitamin $A$ intake $(8,24)$ or vitamin $A$ supplements (25) was shown. In one cohort study protective effects were indicated for serum levels of vitamin A (26). Case-control studies on vitamin A in relation to prostate cancer risk have also shown equivocal findings (10, 27-37). In our study we found no association between intake of retinol and overall prostate cancer risk but among nondrinkers a strong inverse association was observed. Other cohort studies found no 
association for intake $(24)$ or serum levels $(9,38)$, but several cohort studies indicated a positive association for both intake (8) and serum levels (39-41) of retinol and for serum levels in two cohort studies also a protective effect was observed $(42,43)$. Case-control studies on retinol were equally diverse in results. In two case-control studies increased associations for intake levels were only observed for cases aged 70 years or older $(44,45)$, and in two other case-control studies inverse associations were indicated for intake (29) and serum levels (46).

Vitamin $C$ is mostly known for its antioxidant capacity $(1,47)$. For prostate cancer, however, mostly no effect of vitamin C intake levels $(8,25)$, serum levels (39), or vitamin C supplements (25) was observed, and also in the NLCS no association was apparent. Only for supplements containing vitamin $\mathrm{C}$ a slight nonsignificant decrease in risk was observed. One cohort study indicated an increased risk only in the highest quartile of intake, no trend in risk was observed (48). Most case-control studies reported null associations for vitamin C in relation to risk of prostate cancer $(28,29,31,35,36,44,49-52)$. In two case-control studies, estimated risks suggested a positive association between vitamin $\mathrm{C}$ intake and prostate cancer risk $(30,37)$.

The antioxidative property of vitamin E might be a mechanism by which (prostate) cancer incidence is reduced $(3,53)$. Also, an enhancement of immune functions might be a pathway (3). In the ATBC-trial, a 32 percent decrease (95 percent $\mathrm{Cl}-47$ to -12 percent) in prostate cancer incidence was observed for subjects receiving $\alpha$-tocopherol compared with those not receiving it (3). In the NLCS, however, no effect of dietary intake of vitamin E was found but subjects taking supplements containing vitamin $E$ showed nonsignificant decreased risks. No associations were shown in other cohort studies using intake $(8,25)$ or serum levels $(9,42,54,55)$ or vitamin E supplements (25). Also in a cohort analysis of the ATBC Study between baseline vitamin $E$ from the diet and serum vitamin $E$ ( $\alpha$-tocopherol) and prostate cancer risk no associations were apparent (53). In two case-control studies an inverse association has been shown for vitamin $E$, but only in the highest category of intake (50) or serum level (46). In other case-control studies no clear alteration in risk was noted $(29,49,56)$.

Beta-carotene has long been known for its antioxidative properties and is the most investigated carotenoid in prostate cancer etiology. Also, via its conversion to vitamin A or via an enhancement of immunologic function a protective effect of this carotenoid may be explained (1). In the NLCS, no clear associations emerged for intake of $\beta$-carotene and overall prostate cancer risk. In one out of the three chemopreventive trials, an adverse effect of $\beta$-carotene was observed (3), in the other two trials $\beta$-carotene showed no effect on prostate cancer risk $(4,5)$. In five other cohort studies, intake $(8,24,25,48)$ or serum levels (42) of $\beta$-carotene were also not associated with risk of prostate cancer. In two cohort 
studies an increased risk was observed for serum levels $(9,40)$. Case-control studies were also inconsistent, varying from no association $(29,33,45)$ to inverse associations $(32,57)$, also for serum levels (46), and positive associations only for men aged 70 years $(44,45)$ or 68 years $(30)$ and older.

Few studies have evaluated specific carotenoids besides $\beta$-carotene in relation to prostate cancer occurrence. For intake of $\beta$-cryptoxanthin a positive association was observed in our study. In one cohort study, also a positive association was found (for serum levels), but the trend test was not significant in that study (9) while in another prospective cohort study no association for intake of $\beta$-cryptoxanthin was noted (8). In a case-control study in Hawaii (10) a positive association was noted for consumption of papaya, and $\beta$-cryptoxanthin is a common carotenoid in papaya (7). Further research into this issue is warranted. A significant inverse trend in risk was observed for intake of lycopene in the Health Professionals Follow-up Study (8), but in another study no association was observed for serum levels (9). In two nested case-control studies, serum lycopene levels were also inversely related to prostate cancer risk, but nonsignificantly and no trend in risk was observed $(42,54)$. A role of lycopene in prostate cancer carcinogenesis is not inconceivable because lycopene is an efficient scavenger of singlet oxygen $(8,58)$. Comparable to our results, in two other studies with prospectively collected exposure data, intake ( 8 ) and serum levels (9) of both $\alpha$-carotene and lutein were found not to be related to prostate cancer risk.

Inverse associations for users of vitamin supplements were suggestive but statistically nonsignificant in our study. Since it has been shown that vitamin supplement users have cancer-related behaviours that are different from non-users of vitamin supplements (59), confounding might explain some of our findings regarding vitamin supplement use. For example, in the United States supplement users have been shown to have had a prostatespecific antigen test twice as likely as nonusers, to take regularly aspirin, more often exercise, and eat more vegetables and fruit and less fat (59). However, during our followup period prostate-specific antigen testing was not a common screening routine in the Netherlands and therefore we should not expect a confounding effect of this factor. Moreover, if supplement users more often had a prostate-specific antigen test an increased risk of prostate cancer would be expected, while we observed a decrease in risk. In our study no associations between consumption of vegetables and fruit and risk of prostate cancer was shown (19) and also for fat intake no clear associations emerged, therefore, we do not expect a confounding effect of these dietary factors. Furthermore, residual confounding by aspirin use or physical activity cannot be excluded but since these factors are not known to be strong risk factors for prostate cancer a large confounding effect is not suspected. 
In summary, associations between vitamins and carotenoids and risk of overall prostate cancer were not clearly indicated in our study. Nevertheless, for intake of retinol, $\alpha$ carotene and $\beta$-carotene a protective effect was suggested among nondrinking subjects.

\section{Acknowledgements}

We are indebted to the participants of this study and further wish to thank the regional cancer registries (IKA, IKL, IKMN, IKN, IKO, IKR, IKST, IKW, IKZ), and the Dutch national data base of pathology (PALGA); Dr. A. Volovics for statistical advice; S. van de Crommert, J. Nelissen, C. de Zwart, M. Moll, W. van Dijk, P. Florax and A. Pisters for assistance; and H. van Montfort, R. Schmeitz, T. van Montfort, and M. de Leeuw for programming and statistical assistance.

\section{References}

1. Steinmetz KA, Potter JD. Vegetables, fruit, and cancer. II. Mechanisms. Cancer Causes Control $1991 ; 2: 427-42$.

2. Steinmetz KA, Potter JD. Vegetables, fruit, and cancer prevention: a review. J Am Diet Assoc 1996;96:1027-39.

3. Heinonen OP, Albanes D, Virtamo J, et al. Prostate cancer and supplementation with alphatocopherol and beta-carotene: incidence and mortality in a controlled trial. J Natl Cancer Inst 1998;90:440-6.

4. Hennekens $\mathrm{CH}$, Buring JE, Manson JE, et al. Lack of effect of long-term supplementation with beta carotene on the incidence of malignant neoplasms and cardiovascular disease. N Engl J Med 1996;334:1145-9.

5. Omenn GS, Goodman GE, Thornquist MD, et al. Risk factors for lung cancer and for intervention effects in CARET, the Beta-Carotene and Retinol Efficacy Trial. J Natl Cancer Inst 1996;88:1550-9.

6. Giles G, Ireland P. Diet, nutrition and prostate cancer. Int J Cancer 1997;Suppl 10:13-7.

7. Kolonel LN. Nutrition and prostate cancer. Cancer Causes Control 1996;7:83-94.

8. Giovannucci E, Ascherio A, Rimm EB, et al. Intake of carotenoids and retinol in relation to risk of prostate cancer. J Natl Cancer Inst 1995;87:1767-76.

9. Nomura AM, Stemmermann GN, Lee J, et al. Serum micronutrients and prostate cancer in Japanese Americans in Hawaii. Cancer Epidemiol Biomarkers Prev 1997;6:487-91.

10. Kolonel LN, Hankin JH, Yoshizawa CN. Vitamin A and prostate cancer in elderly men: enhancement of risk. Cancer Res 1987;47:2982-5.

11. Van den Brandt PA, Goldbohm RA, Van 't Veer P, et al. A large-scale prospective cohort study on diet and cancer in The Netherlands. J Clin Epidemiol 1990;43:285-95.

12. Prentice RL. A case-cohort design for epidemiologic cohort studies and disease prevention trials. Biometrika 1986;73:1-11.

13. Self SG, Prentice RL. Asymptotic distribution theory and efficiency results for case-cohort studies. Ann Stat 1988;16:64-81.

14. Van den Brandt PA, Schouten LJ, Goldbohm RA, et al. Development of a record linkage protocol for use in the Dutch Cancer Registry for Epidemiological Research. Int J Epidemiol 1990;19:5538.

15. Goldbohm RA, Van den Brandt PA, Dorant E. Estimation of the coverage of Dutch municipalities by cancer registries and PALGA based on hospital discharge data. Tijdschr Soc Gezondheidsz 1994:72:80-4.

16. Goldbohm RA, Van den Brandt PA, Brants HAM, et al. Validation of a dietary questionnaire used in a large-scale prospective cohort study on diet and cancer. Eur J Clin Nutr 1994;48:253-65.

17. Voorlichtingsbureau voor de voeding. Nevo table: Dutch Food Composition Table 1986-1987. The Hague, 1986.

18. Goldbohm RA, Brants HAM, Hulshof KFAM, et al. The contribution of various foods to intake of vitamin A and carotenoids in the Netherlands. Int J Vit Res 1998;(in press). 
19. Schuurman AG, Goldbohm RA, Dorant E, et al. Vegetable and fruit consumption and prostate cancer risk: a cohort study in the Netherlands. Cancer Epidemiol Biom Prev 1998;7:673-80.

20. Baker J. GLIM 3.77 Reference Manual. Oxford: Numerical Algorithms Group, 1985.

21. Volovics A, van den Brandt PA. Methods for the analyses of case-cohort studies. Biom J 1997;2:195-214.

22. Van den Brandt PA, Van 't Veer P, Goldbohm RA, et al. A prospective cohort study on dietary fat and the risk of postmenopausal breast cancer. Cancer Res 1993;53:75-82.

23. Dorant E, van den Brandt PA, Goldbohm RA, et al. Agreement between interview data and a self-administered questionnaire on dietary supplement use. Eur J Clin Nutr 1994;48:180-8.

24. Hsing AW, McLaughlin JK, Schuman LM, et al. Diet, tobacco use, and fatal prostate cancer: results from the Lutheran Brotherhood Cohort Study. Cancer Res 1990;50:6836-40.

25. Shibata A, Paganini Hill A, Ross RK, et al. Intake of vegetables, fruits, beta-carotene, vitamin C and vitamin supplements and cancer incidence among the elderly: a prospective study. $\mathrm{Br} J$ Cancer 1992;66:673-9.

26. Reichman ME, Hayes RB, Ziegler RG, et al. Serum vitamin A and subsequent development of prostate cancer in the first National Health and Nutrition Examination Survey Epidemiologic Follow-up Study. Cancer Res 1990;50:2311-5.

27. Andersson SO, Wolk A, Bergstrom R, et al. Energy, nutrient intake and prostate cancer risk: a population-based case-control study in Sweden. Int J Cancer 1996;68:716-22.

28. Ghadirian P, Lacroix A, Maisonneuve $P$, et al. Nutritional factors and prostate cancer: a casecontrol study of French Canadians in Montreal, Canada. Cancer Causes Control 1996;7:428-36.

29. Rohan TE, Howe GR, Burch JD, et al. Dietary factors and risk of prostate cancer: a case-control study in Ontario, Canada. Cancer Causes Control 1995;6:145-54.

30. West DW, Slattery ML, Robison LM, et al. Adult dietary intake and prostate cancer risk in Utah: a case-control study with special emphasis on aggressive tumors. Cancer Causes Control $1991 ; 2: 85-94$.

31. Fincham SM, Hill GB, Hanson J, et al. Epidemiology of prostatic cancer: a case-control study. Prostate 1990;17:189-206.

32. Ohno Y, Yoshida O, Oishi K, et al. Dietary beta-carotene and cancer of the prostate: a casecontrol study in Kyoto, Japan. Cancer Res 1988;48:1331-6.

33. Ross RK, Shimizu H, Paganini Hill A, et al. Case-control studies of prostate cancer in blacks and whites in southern California. J Natl Cancer Inst 1987;78:869-74.

34. Middleton B, Byers T, Marshall J, et al. Dietary vitamin A and cancer--a multisite case-control study. Nutr Cancer 1986;8:107-16.

35. Heshmat MY, Kaul L, Kovi J, et al. Nutrition and prostate cancer: a case-control study. Prostate 1985;6:7-17.

36. Bravo MP, Castellanos E, del Rey Calero J. Dietary factors and prostatic cancer. Urol Int 1991;46:163-6.

37. Graham S, Haughey B, Marshall J, et al. Diet in the epidemiology of carcinoma of the prostate gland. J Natl Cancer Inst 1983;70:687-92.

38. Peleg I, Heyden S, Knowles M, et al. Serum retinol and risk of subsequent cancer: extension of the Evans County, Georgia, study. J Natl Cancer Inst 1984;73:1455-8.

39. Eichholzer M, Stahelin HB, Gey KF, et al. Prediction of male cancer mortality by plasma levels of interacting vitamins: 17-year follow-up of the prospective Basel study. Int J Cancer 1996;66:145-50.

40. Knekt $P$, Aromaa A, Maatela J, et al. Serum vitamin A and subsequent risk of cancer: cancer incidence follow-up of the Finnish Mobile Clinic Health Examination Survey. Am J Epidemiol 1990;132:857-70.

41. Coates RJ, Weiss NS, Daling JR, et al. Serum levels of selenium and retinol and the subsequent risk of cancer. Am J Epidemiol 1988;128:515-23.

42. Hsing AW, Comstock GW, Abbey H, et al. Serologic precursors of cancer. Retinol, carotenoids, and tocopherol and risk of prostate cancer. J Natl Cancer Inst 1990;82:941-6.

43. Criqui $\mathrm{MH}$, Bangdiwala S, Goodman DS, et al. Selenium, retinol, retinol-binding protein, and uric acid. Associations with cancer mortality in a population-based prospectivecase-control study.

Ann Epidemiol 1991;1:385-93.

44. Kolonel LN, Yoshizawa CN, Hankin JH. Diet and prostatic cancer: a case-control study in Hawaii. Am J Epidemiol 1988;127:999-1012. 
45. Talamini R, Franceschi S, La Vecchia C, et al. Diet and prostatic cancer: a case-control study in northern Italy. Nutr Cancer 1992;18:277-86.

46. Hayes RB, Bogdanovicz JF, Schroeder FH, et al. Serum retinol and prostate cancer. Cancer 1988;62:2021-6.

47. Fair WR, Fleshner NE, Heston W. Cancer of the prostate: a nutritional disease? Urology 1997:50:840-8.

48. Daviglus ML, Dyer AR, Persky V, et al. Dietary beta-carotene, vitamin C, and risk of prostate cancer: results from the Western Electric Study. Epidemiology 1996;7:472-7.

49. Key TJ, Silcocks PB, Davey GK, et al. A case-control study of diet and prostate cancer. Br J Cancer 1997;76:678-87.

50. Vlajinac HD, Marinkovic JM, Ilic MD, et al. Diet and prostate cancer: a case-control study. Eur J Cancer 1997;33:101-7.

51. Oishi K, Okada K, Yoshida O, et al. A case-control study of prostatic cancer with reference to dietary habits. Prostate 1988;12:179-90.

52. Kaul L, Heshmat MY, Kovi J, et al. The role of diet in prostate cancer. Nutr Cancer 1987;9:123-8.

53. Hartman TJ, Albanes D, Peitinen P, et al. The association between baseline vitamin E, selenium, and prostate cancer in the Alpha-Tocopherol, Beta-Carotene Prevention Study. Cancer Epidemiol Biomarker Prev 1998;7:335-40.

54. Comstock GW, Helzlsouer KJ, Bush TL. Prediagnostic serum levels of carotenoids and vitamin $\mathrm{E}$ as related to subsequent cancer in Washington County, Maryland. Am J Clin Nutr 1991; $53: 260$ s-4s.

55. Willett WC, Polk BF, Underwood BA, et al. Relation of serum vitamins A and $E$ and carotenoids to the risk of cancer. N Engl J Med 1984;310:430-4.

56. Knekt $P$, Aromaa A, Maatela J, et al. Serum vitamin $E$ and risk of cancer among Finnish men during a 10-year follow-up. Am J Epidemiol 1988;127:28-41.

57. Mettlin C, Selenskas S, Natarajan N, et al. Beta-carotene and animal fats and their relationship to prostate cancer risk. A case-control study. Cancer 1989;64:605-12.

58. Clinton SK, Emenhiser C, Schwartz SJ, et al. cis-trans lycopene isomers, carotenoids, and retinol in the human prostate. Cancer Epidemiol Biomarkers Prev 1996;5:823-33.

59. Patterson RE, Neuhouser ML, White E, et al. Cancer-related behavior of vitamin supplement users. Cancer Epidemiol Biomarkers Prev 1998;7:79-81. 


\title{
Chapter 4
}

\section{Animal products, calcium and protein and}

\section{prostate cancer risk in the Netherlands}

\section{Cohort Study ${ }^{1}$}

\author{
Agnes G. Schuurman ${ }^{2}$ \\ Piet A. van den Brandt ${ }^{2}$ \\ Elisabeth Dorant ${ }^{2}$ \\ R. Alexandra Goldbohm ${ }^{3}$
}

\begin{abstract}
Prostate cancer risk in relation to consumption of animal products, and intake of calcium and protein was investigated in the Netherlands Cohort Study. At baseline in 1986, 58,279 men aged 55-69 years completed a self-administered 150-item food frequency questionnaire and a questionnaire on other risk factors for cancer. After 6.3 years of followup, 642 prostate cancer cases were available for analysis. In multivariate case-cohort analyses adjusted for age, family history of prostate cancer and socioeconomic status, no associations were found for consumption of fresh meat, fish, cheese and eggs. Positive trends in risk were found for consumption of cured meat and milk products ( $p$-values 0.04 and 0.02 , respectively). For calcium and protein intake, no associations were observed. The hypothesis that dietary factors might be more strongly related to advanced prostate tumors could not be confirmed in our study. We conclude that, in this study, animal products are not strongly related to prostate cancer risk.
\end{abstract}

\footnotetext{
${ }^{1}$ Accepted by British Journal of Cancer

${ }^{2}$ Dept. of Epidemiology, Maastricht University, Maastricht

${ }^{3}$ Dept. of Consumer Research \& Epidemiology, TNO Nutrition and Food Research Institute, Zeist
} 


\section{Introduction}

Remarkable geographic variation exists as regards clinical prostate cancer incidence. Annual age-adjusted incidence rates of approximately 1 per 100,000 are found in China while in the US rates up to 102 per 100,000 are found for blacks. Rates for whites in the US vary from about 45 to 65 per 100,000. In Western Europe most incidence rates are around 20-30 per 100,000 although also some variation exists (1). The prevalence of latent prostatic carcinomas is estimated to be similar in areas with high and with low total prostate cancer incidence rates $(2,3)$. Because of these variations in incidence rates worldwide, environmental factors, particularly dietary factors, are supposed to be related to risk of prostate cancer (4). Consumption of animal products like meat, fish, milk, dairy products and eggs differs between countries with high and low prostate cancer incidence rates and may, therefore, be an explanation for the observed differences in incidence rates.

Results from several cohort (5-14) and case-control studies (15-28) are available on consumption of animal products and prostate cancer risk. However, the role of animal products remains unclear since contradictory results from both types of studies have been reported.

A potential effect of animal products on prostate cancer risk is often explained by the fat contained in the product $(3,29-31)$. Increased fat intake might lead to increased testosterone levels and this might, eventually, lead to increased cell division and activation of proto-oncogenes and deactivation of tumor suppressor genes (32). However, there is no conclusive evidence to the role of fat in prostate cancer etiology (31). Therefore, other hypotheses on the mechanism of action are also plausible. For example, it has been proposed that $1,25(\mathrm{OH})_{2} \mathrm{D}$ levels, which is a vitamin $\mathrm{D}$ metabolite, are protective against prostate cancer $(33,34)$ and intake of calcium, for which dairy products are a major dietary source, may increase prostate cancer risk by suppressing $1,25(\mathrm{OH})_{2} \mathrm{D}$ levels (35). Finally, another possibility is that meat may get burned at high temperatures and heterocyclic amines are produced which are mutagenic and may be carcinogenic (36).

Several authors suggest that dietary factors may play a greater role in accelerating tumor growth than in initiating cancer $(4,29,31)$ but thus far it is not clear whether this is true for animal products. We further investigated animal products consumption as well as calcium intake in relation to prostate cancer risk in the Netherlands Cohort Study (NLCS). To evaluate the effect of a diet containing mostly animal foods or mostly plant-based foods, the intake of protein (total, animal and vegetable) was also evaluated in this study.

\section{Materials and methods}

\section{The cohort}

The study design has been described in detail elsewhere (37). In brief, the NLCS was initiated in September 1986 . The male cohort consists of 58,279 men aged $55-69$ years 
who completed a self-administered questionnaire on usual diet, and other risk factors for cancer. The case-cohort approach (38) was used for data processing and analysis. In a case-cohort approach, cases are derived from the entire cohort (providing numerator information for calculation of cancer incidence rates), while accumulated person years at risk in the total cohort are estimated using a random subcohort sample (providing denominator information for the rates). The male subcohort was sampled directly after identification of the total cohort and includes 1,688 men. The method of cancer follow-up has also been described previously (39). In short, incident prostate cancer cases were detected by computerized record linkage with all nine cancer registries in The Netherlands, and with the Dutch national data base of pathology reports (PALGA). The subcohort has been followed up biennially for vital status information. Completeness of cancer follow-up was at least 96 percent (40) and follow-up of person years in the subcohort was complete. After a follow-up period of 6.3 years (September 1986-December 1992), 704 incident, microscopically confirmed, primary prostate cancer cases were detected. During this period, systematic screening for prostate cancer was not used in the Netherlands.

\section{The questionnaire}

Usual consumption of food and beverages during the year preceding the start of the study was assessed with a 150-item semiquantitative food frequency questionnaire (41).

Participants were asked to report their frequency of consumption of 14 different individual fresh meat items (several cuts of beef and pork, minced meat, chicken, liver, other meat), fish, 14 milk and milk items (whole, low-fat and skimmed milk, cream, buttermilk, chocolate milk, dry curd, whole and skimmed yogurt, other items), and eggs. For fresh meat items, participants also had to indicate their usual amount of consumption in grams (as bought, i.e., based on raw meat). For four cured meat items (boiled ham, bacon, lean meat products including smoked beef, and 'other sliced cold meats') and two cheese items (fat cheese and low-fat cheese), subjects had to indicate how many slices of bread they ate with the particular product on it. For other items, subjects had to indicate the consumption amount in natural or household units (e.g. glass). Mean daily consumption (g/day) of the items was calculated by multiplying frequency of consumption by amount of consumption with standard portion sizes for the items that were asked in natural or household units. Calcium and protein intake were computed using the computerized Dutch food composition table (42). The questionnaire has been validated against a 9-day diet record. For the exposures under study the Spearman correlation coefficients betweeen questionnaire and the dietary record were as follows: fresh meat 0.46 , cured meat 0.54 ; milk and milk products 0.60 ; cheese 0.61 ; fish 0.53 ; eggs 0.61 . The Pearson correlation coefficient (energy and sexadjusted) for calcium was 0.62 and for total protein, vegetable protein and animal protein the estimates were $0.59,0.68$ and 0.64 , respectively (41). 


\section{Data analysis}

In the subcohort, prevalent cases other than skin cancer were excluded, leaving 1630 subcohort members for analysis. Furthermore, according to criteria published before (41), subjects with incomplete or inconsistent dietary data were excluded; 642 men with prostate cancer and 1525 male subcohort members remained for analysis.

Intake of calcium and protein was adjusted for energy by regression analysis (43). Mean intake levels of the different exposure variables and other characteristics were compared between prostate cancer cases and male subcohort members. Furthermore, mean intakes of fresh meat, fish, cured meat, milk and milk products, cheese, eggs, calcium and protein were compared in categories of potential confounders. Variables that were considered as potential confounders were age, a family history of prostate cancer, and socioeconomic status. Total energy and total fat intake were not considered as potential confounding factors because no association with prostate cancer risk was observed in our study (data not shown). The same applies to vegetable and fruit consumption (44). Energy was, however, included in the analyses for calcium and protein, whereas total protein was included in the analyses of animal and vegetable protein to assess the substitution effects of the two sources of protein. Rate ratios (RRs) and $95 \%$ confidence intervals $(95 \% \mathrm{Cl})$ were computed for quintiles or categories of exposure variables, as well as for continuous variables, using the GLIM statistical package (45). Exponentially distributed survival times were assumed in the follow-up period. Since standard software was not available, specific macros were developed to account for the additional variance introduced by using the subcohort instead of the entire cohort (46). Tests for trend were based on likelihood ratio tests. Throughout this report two-sided P-values are used. Age-adjusted and multivariate analyses were conducted. In order to evaluate the independent contribution of each specific type of fresh meat, cured meat, and dairy items analyses were done with the inclusion of total fresh meat, total cured meat, and total dairy consumption, respectively, in the multivariate models. Furthermore, analyses were done for localized (TO-2, MO) and advanced (T3-4, M0; T0-4, M1) prostate cancer cases separately. This classification is based on the TNM staging system. To evaluate whether preclinical symptoms may have influenced results, additional analyses with exclusion of cases detected during the first two years of follow-up were conducted.

\section{Results}

The mean intake of fresh meat, fish, cured meat, milk and milk products, cheese, eggs, calcium and protein among cases and subcohort members is shown in Table 1. Mean intake of none of these food products differed markedly between cases and subcohort members. The distribution of potential confounding factors is also shown in this table. Cases are older than subcohort members and more often have a positive family history of prostate cancer. Furthermore, cases more often have a high socioeconomic status 
compared to subcohort members. Consumption of cured meat was highest among the youngest men and protein intake was highest among men aged 60-64 years. Men in the lowest category of socioeconomic status consumed more fresh meat, cured meat and eggs, and less cheese. Men with a positive family history of prostate cancer consumed more calcium than men without such a family history. Mean consumption of animal products or protein intake differed not between subjects with and without a family history of prostate cancer (data not shown).

Table 1: Description of mean daily intake of animal products, protein and calcium and other characteristics in prostate cancer cases and subcohort members, Netherlands Cohort Study (1986-1992).

\begin{tabular}{|c|c|c|c|c|}
\hline \multirow[b]{2}{*}{ Characteristics } & \multicolumn{2}{|c|}{ Cases $(n=642)$} & \multicolumn{2}{|c|}{$\begin{array}{l}\text { Subcohort } \\
(n=1525)\end{array}$} \\
\hline & mean & SD & mean & SD \\
\hline \multicolumn{5}{|l|}{ Exposure variables ( $g /$ day) } \\
\hline Fresh meat and poultry ${ }^{1}$ & 102.9 & 39.6 & 105.2 & 43.1 \\
\hline Fish & 15.0 & 17.2 & 14.2 & 16.0 \\
\hline Cured meat ${ }^{2}$ & 15.2 & 15.0 & 15.7 & 17.3 \\
\hline Milk and milk products ${ }^{3}$ & 307.1 & 190.1 & 308.0 & 215.0 \\
\hline Cheese $^{4}$ & 23.0 & 18.7 & 22.8 & 19.4 \\
\hline Eggs & 16.5 & 12.1 & 17.1 & 12.5 \\
\hline Calcium (mg/day) $)^{5}$ & 951.7 & 274.7 & 943.7 & 292.4 \\
\hline Total protein 5 & 75.3 & 10.9 & 75.4 & 11.4 \\
\hline Vegetable protein ${ }^{5}$ & 27.6 & 6.0 & 27.9 & 6.0 \\
\hline Animal protein ${ }^{5}$ & 48.2 & 11.1 & 48.1 & 11.8 \\
\hline \multicolumn{5}{|l|}{ Potential confounding variables } \\
\hline Age (years) & 63.9 & 3.8 & 61.4 & 4.2 \\
\hline Family history of prostate cancer (\%yes) & 4.4 & & 2.7 & \\
\hline \multicolumn{5}{|l|}{ Highest educational level $(\%)^{6}$} \\
\hline low & 44.4 & & 46.8 & \\
\hline medium & 34.6 & & 34.8 & \\
\hline high & 20.2 & & 17.8 & \\
\hline
\end{tabular}

${ }^{1}$ This includes beef, pork, minced meat (beef \& pork), poultry, liver, and 'other meat' (raw weight); ${ }^{2}$ This includes boiled ham, bacon, lean meat products (including smoked beef), and 'other sliced cold meats' (several types of sausages); ${ }^{3}$ This includes fermented milk products, and nonfermented milk products; ${ }^{4}$ This includes fat cheese, and low-fat cheese; ${ }^{5}$ Energy-adjusted; ${ }^{6}$ There was missing information for $0.8 \%$ (cases) and $0.7 \%$ (subcohort members); low is defined as primary school with/without lower level vocational education, medium as secondary school or medium level vocational education, high as university or higher level vocational education.

RRs for quintile or categorized variables for clusters of food items are shown in Table 2. For total fresh meat and fish consumption no associations with prostate cancer were observed. For both total cured meat and milk and milk products a positive trend in risk was observed (p-values for trend test were 0.04 and 0.02 , respectively). The RRs $(95 \% \mathrm{Cl})$ were 1.37 (1.00-1.89) for cured meat and $1.12(0.81-1.56)$ for milk and milk products for the highest vs 
lowest quintile of consumption. Only the RR in the fourth quintile of consumption of milk and milk products was significantly increased $(R R=1.63,95 \% \mathrm{Cl}: 1.20-2.20)$. In the age-adjusted analysis, consumption of cheese showed a positive trend in risk $(p=0.04)$, this $p$-value was 0.09 in the multivariate analysis. The RR for the highest vs the lowest category of consumption was 1.21 (95\% Cl: 0.87-1.70). Egg consumption showed no association with prostate cancer risk. After exclusion of cases diagnosed in the first two years of follow-up, RRs were virtually the same.

Table 2: Rate ratios (RRs) and 95\% confidence intervals (95\% Cl) for prostate cancer according to quintiles or categories of consumption of meat, fish, processed meat, milk and dairy, cheese, and eggs, Netherlands Cohort Study (1986-1992).

\begin{tabular}{|c|c|c|c|c|c|c|}
\hline Exposure & Q1' & Q2 & Q3 & Q4 & Q5 & $\begin{array}{l}\mathrm{P} \text { for } \\
\text { trend }\end{array}$ \\
\hline \multicolumn{7}{|l|}{ Fresh meat and poultry } \\
\hline Median intake $e^{2}$ & 56 & 85 & 102 & 123 & 158 & \\
\hline Cases/Person years & $128 / 1820$ & $138 / 1919$ & $144 / 1787$ & $121 / 1766$ & $111 / 1830$ & \\
\hline $\operatorname{RR}(95 \% \mathrm{Cl})^{3}$ & 1.00 & $1.08(0.80-1.46)$ & $1.23(0.91-1.67)$ & $1.05(0.77-1.43)$ & $1.01(0.73-1.39$ & 0.98 \\
\hline $\operatorname{RR}(95 \% \mathrm{CI})^{4}$ & 1.00 & $1.08(0.79-1.47)$ & $1.27(0.93-1.73)$ & $1.12(0.82-1.53)$ & $1.07(0.77-1.47)$ & 0.52 \\
\hline \multicolumn{7}{|l|}{ Fish } \\
\hline Median intake $e^{2.5}$ & 0 & 5 & 14 & 32 & & \\
\hline Cases/Person years & $162 / 2238$ & $135 / 2115$ & $119 / 1874$ & $226 / 2895$ & & \\
\hline $\operatorname{RR}(95 \% \mathrm{Cl})^{3}$ & 1.00 & $0.85(0.64-1.13)$ & $0.95(0.70-1.28)$ & $1.06(0.82-1.37)$ & & 0.32 \\
\hline $\operatorname{RR}(95 \% \mathrm{CI})^{4}$ & 1.00 & $0.83(0.62-1.11)$ & $0.95(0.70-1.29)$ & $1.03(0.80-1.34)$ & & 0.41 \\
\hline \multicolumn{7}{|l|}{ Cured meat } \\
\hline Median intake ${ }^{2}$ & 0 & 5 & 11 & 19 & 36 & \\
\hline Cases/Person years & $118 / 1849$ & $137 / 1907$ & $140 / 1703$ & $124 / 1880$ & $123 / 1783$ & \\
\hline $\operatorname{RR}(95 \% \mathrm{Cl})^{3}$ & 1.00 & $1.18(0.87-1.61)$ & $1.46(1.07-1.99)$ & $1.14(0.84-1.57)$ & $1.32(0.96-1.81)$ & 0.07 \\
\hline $\operatorname{RR}(95 \% \mathrm{Cl})^{4}$ & 1.00 & $1.22(0.90-1.67)$ & $1.50(1.09-2.06)$ & $1.18(0.86-1.62)$ & $1.37(1.00-1.89)$ & 0.04 \\
\hline \multicolumn{7}{|l|}{ Milk and milk products } \\
\hline Median intake $e^{2}$ & 74 & 179 & 271 & 376 & 566 & \\
\hline Cases/Person years & $114 / 1860$ & $112 / 1835$ & $132 / 1803$ & $172 / 1824$ & $112 / 1800$ & \\
\hline $\operatorname{RR}(95 \% \mathrm{Cl})^{3}$ & 1.00 & $1.08(0.79-1.49)$ & $1.22(0.89-1.67)$ & $1.60(1.19-2.17)$ & $1.09(0.79-1.50)$ & 0.03 \\
\hline $\operatorname{RR}(95 \% \mathrm{Cl})^{4}$ & 1.00 & $1.11(0.80-1.53)$ & $1.25(0.91-1.71)$ & $1.63(1.20-2.20)$ & $1.12(0.81-1.56)$ & 0.02 \\
\hline \multicolumn{7}{|l|}{ Cheese } \\
\hline Median intake $e^{2}$ & 2 & 13 & 19 & 27 & 43 & \\
\hline Cases/Person years & $140 / 2261$ & $121 / 1620$ & $119 / 1607$ & $175 / 2371$ & $87 / 1264$ & \\
\hline $\operatorname{RR}(95 \% \mathrm{Cl})^{3}$ & 1.00 & $1.29(0.95-1.74)$ & $1.16(0.86-1.58)$ & $1.34(1.01-1.77)$ & $1.26(0.90-1.76)$ & 0.04 \\
\hline $\operatorname{RR}(95 \% \mathrm{Cl})^{4}$ & 1.00 & $1.27(0.94-1.73)$ & $1.15(0.84-1.56)$ & $1.28(0.97-1.70)$ & $1.21(0.87-1.70)$ & 0.09 \\
\hline \multicolumn{7}{|l|}{ Eggs } \\
\hline Median intake $e^{2.5}$ & 5 & 14 & 29 & & & \\
\hline Cases/Person years & $197 / 2530$ & $208 / 3243$ & $237 / 3349$ & & & \\
\hline $\operatorname{RR}(95 \% \mathrm{Cl})^{3}$ & 1.00 & $0.90(0.70-1.15)$ & $0.96(0.76-1.22)$ & & & 0.72 \\
\hline $\operatorname{RR}(95 \% \mathrm{Cl})^{4}$ & 1.00 & $0.89(0.69-1.14)$ & $0.96(0.75-1.22)$ & & & 0.71 \\
\hline
\end{tabular}

'Reference category; ${ }^{2}$ Median intake ( $g /$ day) in subcohort; cutpoints fresh meat and poultry $73,93,108$, 137; fish $0,10,20$; cured meat $2,8,14,25$; milk and milk products $139,220,321,460$; cheese $7,14,21,37$; eggs $7,14{ }^{3}$ Adjusted for age; ${ }^{4}$ Adjusted for age, family history of prostate cancer, and socioeconomic status; ${ }^{5}$ Categories instead of quintiles. 
Table 3 shows results for animal products evaluated as continuous variables, for all tumors and separately for localized and advanced prostate tumors. Within the cluster of fresh meat and poultry items, none of the continuous variables was clearly associated with risk of prostate cancer. Also in subgroups of localized and advanced prostate tumors mostly no association existed. Only for consumption of liver an inverse association with advanced prostate tumors was observed (RR per $5 \mathrm{~g}$ increment $=0.79,95 \% \mathrm{Cl}: 0.63-0.99$ ). An item on horsemeat, lamb and mutton and an item on consumption of veal were included in the other meat category. The RR $(95 \% \mathrm{Cl})$ per $5 \mathrm{~g}$ for consumption of horsemeat, lamb and mutton was 1.11 (1.02-1.21) and $1.07(0.99-1.15)$ for consumption of veal (data not shown). Total fish and total cured meat consumption were not associated with overall prostate cancer risk, nor with risk of localized and advanced tumors. Evaluated as continuous variables, none of the individual cured meat items was strongly related to prostate cancer risk. Nevertheless, in categorized analyses a positive trend in risk was noted for consumption of 'other sliced cold meats' ( $p$-value trend test $=0.02$ ). For the highest vs the lowest consumption category a RR of 1.37 (95\% Cl: 1.03-1.83) was found in the multivariate analysis. This increase in risk was only found in the subgroup of localized prostate tumors (RR for the same contrast=1.44, 95\% Cl: 0.95-2.20) and not for advanced prostate tumors (data not shown). Fermented whole milk showed a borderline significant inverse association with overall prostate cancer risk (RR per $50 \mathrm{~g}=0.87,95 \% \mathrm{Cl}: 0.76-1.00$ ), and also for advanced tumors an inverse association was suggested (RR per $50 \mathrm{~g}=0.84,95 \% \mathrm{Cl}: 0.66-1.05)$. For none of the individual milk items except consumption of whole yogurt, associations with prostate cancer risk were observed. In the continuous model, the RR for consumption of whole yogurt per $50 \mathrm{~g}$ increment was $0.88(95 \% \mathrm{Cl}: 0.76-1.01)$. Cheese consumption showed no association with overall prostate cancer risk, but was positively associated with localized prostate tumors (RR per $20 \mathrm{~g}=1.20,95 \% \mathrm{Cl}$ : 1.06-1.37). Finally, consumption of eggs was inversely associated with advanced prostate tumors (RR per $20 \mathrm{~g}=0.70,95 \% \mathrm{Cl}$ : 0.53-0.93).

The results for calcium and protein intake are shown in Table 4. For intake of calcium and total protein no associations with prostate cancer risk were noted. Controlling for total protein, intake of vegetable protein showed RRs below one in all four categories, but none of the RRs was statistically significant. All RRs for intake of animal protein were above one. Only the RR in the fourth quintile of intake was statistically significant (RR=1.52, 95\% Cl: 1.01-2.30). For both sources of protein intake, no trend in risk was found. We also evaluated calcium and protein intake in subgroups of localized and advanced prostate tumors. As for the animal products, there was no clear tendency for stronger associations with advanced prostate tumors.

\section{Discussion}

Overall consumption of fresh meat and poultry, fish, cheese and eggs showed no association with prostate cancer risk in the NLCS. The observed positive trend in risk for 
quintiles of total cured meat consumption could be explained by a positive association with consumption of 'other sliced cold meats'. For most clusters of milk items, or individual milk items no strong associations were observed, but consumption of whole yogurt might be associated with a decreased prostate cancer risk. Intake of calcium and protein was not associated with risk of prostate cancer in our study. Finally, we found no clear evidence for a stronger association of various products with advanced prostate cancer.

Table 3: Rate ratios (RRs) and $95 \%$ confidence intervals ( $95 \% \mathrm{Cl}$ ) for prostate cancer for continuous variables of consumption of animal products, for all cases and separately for localized (TO-2, MO) and advanced (T3-4, M0; TO-4, M1) tumors, Netherlands Cohort Study (1986-1992).

\begin{tabular}{|c|c|c|c|c|c|}
\hline \multirow[t]{2}{*}{ Exposure } & $\begin{array}{l}\text { Intake in } \\
\text { subcohort } \\
\text { (g/day) }\end{array}$ & \multirow[t]{2}{*}{$\begin{array}{l}\text { Incre- } \\
\text { ment }\end{array}$} & \multirow{2}{*}{$\begin{array}{l}\begin{array}{l}\text { All tumors } \\
(n=642)\end{array} \\
\operatorname{RR}(95 \% \mathrm{Cl})^{1}\end{array}$} & \multirow{2}{*}{$\begin{array}{l}\text { Localized } \\
\text { tumors }(n=226) \\
\operatorname{RR}(95 \% \mathrm{Cl})^{1}\end{array}$} & \multirow{2}{*}{$\begin{array}{l}\text { Advanced } \\
\text { tumors }(n=213) \\
\operatorname{RR}(95 \% \mathrm{Cl})^{1}\end{array}$} \\
\hline & Mean (SD) & & & & \\
\hline Fresh meat and poultry & $105.2(43.1)$ & 25 & $1.00(0.86-1.16)$ & $0.99(0.91-1.08)$ & $1.00(0.91-1.09)$ \\
\hline beef $^{2}$ & $27.4(23.6)$ & 25 & $1.00(0.89-1.12)$ & $0.95(0.80-1.12)$ & $0.92(0.77-1.10)$ \\
\hline pork $^{2}$ & $40.6(31.1)$ & 25 & $1.06(0.96-1.18)$ & $1.16(1.00-1.34)$ & $1.06(0.91-1.23)$ \\
\hline minced meat (beef\&pork) ${ }^{2}$ & $20.0(19.0)$ & 25 & $0.86(0.74-1.01)$ & $0.84(0.66-1.07)$ & $0.90(0.71-1.14)$ \\
\hline chicken ${ }^{2}$ & $13.4(15.0)$ & 25 & $1.00(0.84-1.18)$ & $0.89(0.68-1.16)$ & $1.11(0.87-1.42)$ \\
\hline liver $^{2}$ & $2.1(4.7)$ & 5 & $0.92(0.82-1.04)$ & $0.99(0.85-1.17)$ & $0.79(0.63-0.99)$ \\
\hline other meat ${ }^{2}$ & $2.8(6.0)$ & 5 & $1.06(0.99-1.15)$ & $1.04(0.93-1.16)$ & $1.09(0.98-1.21)$ \\
\hline Fish & $14.2(16.0)$ & 25 & $1.06(0.91-1.22)$ & $0.91(0.73-1.15)$ & $1.08(0.87-1.33)$ \\
\hline Cured meat & $15.7(17.3)$ & 15 & $1.03(0.94-1.12)$ & $1.03(0.91-1.17)$ & $1.00(0.88-1.14)$ \\
\hline boiled ham ${ }^{3}$ & $5.4(8.1)$ & 15 & $0.94(0.73-1.21)$ & $1.00(0.69-1.45)$ & $0.95(0.64-1.40)$ \\
\hline bacon $^{3}$ & $2.0(5.1)$ & 15 & $0.80(0.57-1.13)$ & $0.79(0.47-1.33)$ & $1.04(0.66-1.65)$ \\
\hline lean meat products ${ }^{3}$ & $2.4(5.4)$ & 15 & $0.93(0.68-1.27)$ & $0.78(0.48-1.29)$ & $1.01(0.63-1.60)$ \\
\hline other sliced cold meat ${ }^{3}$ & $6.0(10.2)$ & 15 & $1.18(0.96-1.44)$ & $1.22(0.90-1.65)$ & $1.01(0.74-1.39)$ \\
\hline Milk and milk products & $308.0(215.0)$ & 50 & $1.00(0.98-1.03)$ & $1.01(0.98-1.05)$ & $0.99(0.95-1.03)$ \\
\hline whole milk, fermented ${ }^{4}$ & $15.9(40.1)$ & 50 & $0.87(0.76-1.00)$ & $0.96(0.79-1.15)$ & $0.84(0.66-1.05)$ \\
\hline low-fat milk, fermented ${ }^{4}$ & $68.4(107.5)$ & 50 & $1.01(0.96-1.07)$ & $1.01(0.94-1.09)$ & $1.03(0.95-1.11)$ \\
\hline whole milk ${ }^{4}$ & $136.0(164.4)$ & 50 & $1.00(0.96-1.03)$ & $0.97(0.92-1.03)$ & $1.00(0.95-1.06)$ \\
\hline low-fat milk ${ }^{4}$ & $87.8(139.4)$ & 50 & $1.01(0.97-1.05)$ & $1.03(0.97-1.09)$ & $0.99(0.93-1.06)$ \\
\hline Cheese & $22.8(19.4)$ & 20 & $1.02(0.93-1.13)$ & $1.20(1.06-1.37)$ & $0.92(0.78-1.08)$ \\
\hline cheese $^{5}$ & $21.1(18.6)$ & 20 & $0.99(0.76-1.30)$ & $0.94(0.68-1.29)$ & $1.05(0.66-1.68)$ \\
\hline low-fat cheese ${ }^{5}$ & $1.7(7.6)$ & 20 & $1.01(0.77-1.32)$ & $1.07(0.78-1.47)$ & $0.95(0.60-1.52)$ \\
\hline Eggs & $17.1(12.5)$ & 20 & $0.95(0.81-1.11)$ & $0.99(0.78-1.24)$ & $0.70(0.53-0.93)$ \\
\hline
\end{tabular}

'Adjusted for age, family history of prostate cancer, and socioeconomic status; ${ }^{2}$ Additional adjustment for consumption of total fresh meat and poultry; ${ }^{3}$ Additional adjustment for consumption of total cured meat; ${ }^{4}$ Additional adjustment for consumption of total milk and milk products; ${ }^{5}$ Additional adjustment for consumption of total cheese. 
Table 4: Rate ratios (RRs) and $95 \%$ confidence intervals (95\% Cl) for prostate cancer according to quintiles of intake of energy-adjusted calcium and energy-adjusted protein, for all cases and separately for localized (TO-2, MO) and advanced (T3-4, M0; T0-4, M1) prostate tumors, Netherlands Cohort Study, (1986-1992).

\begin{tabular}{|c|c|c|c|c|c|c|}
\hline Exposure & Q1 ${ }^{1}$ & Q2 & Q3 & Q4 & Q5 & $\begin{array}{l}\mathrm{P} \text { for } \\
\text { trend }\end{array}$ \\
\hline \multicolumn{7}{|l|}{ Calcium } \\
\hline Median intake mg/day ${ }^{2}$ & 602 & 780 & 911 & 1064 & 1329 & \\
\hline Cases/Person years & $120 / 1821$ & $126 / 1845$ & $127 / 1840$ & $140 / 1817$ & $129 / 1800$ & \\
\hline $\operatorname{RR}(95 \% \mathrm{CI})^{3}$ & 1.00 & $1.07(0.79-1.47)$ & $1.03(0.75-1.41)$ & $1.20(0.88-1.64)$ & $1.07(0.79-1.47)$ & 0.36 \\
\hline $\operatorname{RR}(95 \% \mathrm{Cl})^{4}$ & 1.00 & $1.10(0.80-1.51)$ & $1.04(0.76-1.42)$ & $1.21(0.89-1.66)$ & $1.09(0.79-1.50)$ & 0.34 \\
\hline Localized tumors (n) & 47 & 30 & 45 & 46 & 56 & \\
\hline $\operatorname{RR}(95 \% \mathrm{CI})^{4}$ & 1.00 & $0.69(0.42-1.13)$ & $0.96(0.61-1.50)$ & $1.04(0.67-1.63)$ & $1.21(0.79-1.86)$ & 0.10 \\
\hline Advanced tumors ( $n$ ) & 44 & 46 & 37 & 46 & 37 & \\
\hline $\operatorname{RR}(95 \% \mathrm{Cl})^{4}$ & 1.00 & $1.08(0.69-1.70)$ & $0.79(0.49-1.27)$ & $1.06(0.67-1.66)$ & $0.83(0.52-1.34)$ & 0.45 \\
\hline \multicolumn{7}{|l|}{ Total protein } \\
\hline Median intake; g/day ${ }^{2}$ & 62 & 69 & 75 & 81 & 90 & \\
\hline Cases/Person years & $128 / 1839$ & $121 / 1836$ & $134 / 1821$ & $135 / 1792$ & $124 / 1834$ & \\
\hline $\operatorname{RR}(95 \% \mathrm{Cl})^{3}$ & 1.00 & $1.03(0.75-1.41)$ & $1.10(0.81-1.50)$ & $1.31(0.96-1.79)$ & $1.09(0.80-1.48)$ & 0.15 \\
\hline $\operatorname{RR}(95 \% \mathrm{Cl})^{4}$ & 1.00 & $1.04(0.76-1.43)$ & $1.12(0.82-1.53)$ & $1.35(0.98-1.84)$ & $1.10(0.81-1.51)$ & 0.11 \\
\hline Localized tumors (n) & 51 & 34 & 40 & 49 & 50 & \\
\hline $\operatorname{RR}(95 \% \mathrm{CI})^{4}$ & 1.00 & $0.76(0.47-1.22)$ & $0.87(0.55-1.38)$ & $1.27(0.82-1.96)$ & $1.13(0.73-1.74)$ & 0.13 \\
\hline Advanced tumors ( $n$ ) & 46 & 43 & 48 & 38 & 35 & \\
\hline $\operatorname{RR}(95 \% \mathrm{Cl})^{4}$ & 1.00 & $1.04(0.66-1.64)$ & $1.08(0.69-1.69)$ & $1.02(0.64-1.64)$ & $0.83(0.51-1.33)$ & 0.49 \\
\hline \multicolumn{7}{|l|}{ Vegetable protein } \\
\hline Median intake; g/day ${ }^{2}$ & 22 & 25 & 27 & 30 & 35 & \\
\hline Cases/Person years & $143 / 1827$ & $129 / 1833$ & $139 / 1813$ & $110 / 1812$ & $121 / 1839$ & \\
\hline $\operatorname{RR}(95 \% \mathrm{CI})^{3}$ & 1.00 & $0.87(0.64-1.18)$ & $0.99(0.74-1.34)$ & $0.83(0.61-1.13)$ & $0.92(0.67-1.24)$ & 0.43 \\
\hline $\operatorname{RR}(95 \% \mathrm{Cl})^{5}$ & 1.00 & $0.86(0.63-1.17)$ & $1.00(0.74-1.36)$ & $0.83(0.61-1.14)$ & $0.90(0.66-1.23)$ & 0.37 \\
\hline Localized tumors (n) & 53 & 46 & 42 & 35 & 48 & \\
\hline $\operatorname{RR}(95 \% \mathrm{CI})^{5}$ & 1.00 & $0.86(0.55-1.33)$ & $0.85(0.54-1.33)$ & $0.73(0.46-1.17)$ & $0.96(0.62-1.48)$ & 0.63 \\
\hline Advanced tumors ( $n$ ) & 38 & 43 & 57 & 30 & 42 & \\
\hline $\operatorname{RR}(95 \% \mathrm{Cl})^{5}$ & 1.00 & $1.08(0.67-1.74)$ & $1.55(0.98-2.44)$ & $0.85(0.51-1.43)$ & $1.19(0.74-1.92)$ & 0.81 \\
\hline \multicolumn{7}{|l|}{ Animal protein } \\
\hline Median intake; $g /$ day $^{2}$ & 34 & 42 & 47 & 53 & 64 & \\
\hline Cases/Person years & $112 / 1825$ & $137 / 1843$ & $121 / 1819$ & $150 / 1812$ & $122 / 1823$ & \\
\hline $\operatorname{RR}(95 \% \mathrm{Cl})^{3}$ & 1.00 & $1.21(0.88-1.65)$ & $1.11(0.81-1.53)$ & $1.42(1.04-1.93)$ & $1.16(0.84-1.59)$ & 0.11 \\
\hline $\mathrm{RR}(95 \% \mathrm{Cl})^{5}$ & 1.00 & $1.29(0.92-1.81)$ & $1.16(0.80-1.68)$ & $1.52(1.01-2.30)$ & $1.32(0.76-2.29)$ & 0.09 \\
\hline Localized tumors (n) & 44 & 40 & 44 & 45 & 51 & \\
\hline $\operatorname{RR}(95 \% \mathrm{Cl})^{5}$ & 1.00 & $0.94(0.57-1.55)$ & $1.08(0.64-1.83)$ & $1.13(0.62-2.05)$ & $1.26(0.58-2.75)$ & 0.44 \\
\hline Advanced tumors ( $n$ ) & 43 & 49 & 41 & 47 & 30 & \\
\hline $\operatorname{RR}(95 \% \mathrm{Cl})^{5}$ & 1.00 & $1.21(0.75-1.95)$ & $0.96(0.56-1.65)$ & $1.11(0.61-2.04)$ & $0.71(0.31-1.63)$ & 0.61 \\
\hline
\end{tabular}

${ }^{1}$ Reference category; ${ }^{2}$ Median intake in subcohort; cutpoints calcium 709, 848, 984, 1164; total protein 66, 72, 77,84 ; vegetable protein $23,26,29,32$; animal protein $38,45,50,58 ;{ }^{3}$ Adjusted for age; ${ }^{4}$ Adjusted for age, family history of prostate cancer, socioeconomic status, and total energy intake; ${ }^{5}$ Adjusted for age, family history of prostate cancer, socioeconomic status, total energy intake, and total protein intake.

The NLCS is a prospective cohort study specifically designed to evaluate the relation between diet and cancer. An important strength of prospective studies is that recall bias is avoided because of the prospective nature of these studies. Selection bias is also not likely 
to have taken place because of the high completeness of follow-up of subcohort members $(40,47)$. A 150-item semi-quantitative food frequency questionnaire was used to estimate the usual consumption of fresh meat and poultry, fish, cured meat, milk and milk products, cheese and eggs during the year preceding the start of the study. The questionnaire was validated against a 9-day dietary record. Based on the Spearman correlation coefficients we conclude that our exposure variables were reasonably well measured. In addition, these correlation coefficients may be underestimated because many of the record data were coded as ingredients from recipes or mixed dishes as opposed to the questionnaire data, which were coded as food product. Consequently, the division between food groups was not always clear, resulting in lower correlations (41). Misclassification of subjects according to their exposure status is possible, but expected to be nondifferential. To prevent substantial misclassification of subjects with respect to exposure status, subjects with incomplete or inconsistent data were excluded, according to criteria published before (41). Besides a validation study, five annually repeated measurements of the food frequency questionnaire were conducted. From the results it was concluded that the single measurement of diet in the NLCS can characterize dietary habits for a period of at least five years (48). This is further supported by the fact that our study population consists of older subjects (aged 55-69 years) with relatively stable dietary habits (37).

Data gathered with our questionnaire allowed us to take other dietary and nondietary risk factors for prostate cancer into account in multivariate analyses. Although our final multivariate model was also somewhat restricted, we considered several potential confounding factors and only those factors associated with prostate cancer risk in our study were included in the model. Certainly, unmeasured or still unknown other factors may have caused residual confounding. Results after exclusion of cases detected in the first two years of follow-up were similar to results including all prostate cancer cases. Therefore, preclinical disease are not likely to have influenced our results. Finally, chance will have played a role in our study, in particular because of the multiple associations that were studied.

Only a minority of previous cohort $(5,13,49)$ and case-control studies $(21,24,25)$ had a more or less comprehensive measurement of dietary habits. Therefore, (random) misclassification of exposure may have affected results in earlier studies. Furthermore, results from most other studies were based on substantially less cases than the total number of cases in our study. There were only two cohort studies with more than 400 cases $(13,14,49)$ and only three case-control studies with more than 300 cases $(16,21,28)$. Consistency in results between studies is also hampered by the fact that endpoints in previous studies were either incidence or mortality. Deceased prostate cancer cases may not adequately reflect the source population of total prostate cancer cases. Finally, limited adjustment for confounding factors may have influenced results in different studies. 
Total meat consumption or consumption of specific types of meat were not clearly associated with prostate cancer risk in several other cohort studies $(5-7,10,13)$ and casecontrol studies $(15,24,25,28)$. However, positive associations were also observed, in cohort studies for consumption of meat (9), high fat animal products and beef (12), beef, pork and lamb $(11,49)$, and for meat, poultry and fish (6) and in case-control studies for consumption of meat $(17,18,23)$, lamb and pork (22) and meat and fish combined (16). In other cohort studies inverse associations were suggested for consumption of beef (14), and bacon or side pork (15), and in case-control studies for consumption of poultry or chicken $(15,19)$ and liver (27).

As in our study, intake of fish was overall not associated with prostate cancer risk in cohort studies $(7,10,12,14)$, but also a positive (6) and an inverse association (9) have been reported. From case-control studies positive $(25)$, inverse $(15,27,28)$ and null associations (24) have been indicated.

One cohort study reported on processed meats in relation to prostate cancer risk and in this study no association was found (12). Our data suggested a positive association between consumption of 'other sliced cold meats' and prostate cancer risk. Although 'other sliced cold meats' were not defined further in our questionnaire, several types of sausages are frequently consumed in the Netherlands and these products are most likely to account for the observed association.

In most cohort studies intake of milk or other dairy products was not clearly associated with prostate cancer risk (6-10, 12-14), only in one cohort study a positive association was reported (5). From case-control studies on milk or dairy products, however, positive associations were more frequently reported $(17,18,21,24)$, although in this type of study also null associations have been found $(15,25,26)$. To our knowledge, an (inverse) association between fermented milk products and prostate cancer risk has not been reported elsewhere. Nevertheless, an inverse association has been reported for other hormone-related cancers (50).

Consumption of cheese (5) and cheese in combination with butter and margarine (7) were associated with a modest increase in risk in two cohort studies. In two case-control studies no associations were found $(24,25)$. Egg consumption was not associated with prostate cancer risk in all $(5,6,8,10,12-14)$ but one cohort study, in which a positive association was indicated (7). Results from case-control studies were more diverse, varying from a suggestive inverse association (26), and null associations $(15,24,25)$ to positive associations $(19,23)$.

In some studies the exposure variables were evaluated separately for localized and regional or distant, or advanced prostate tumors $(12,13,25)$. We also evaluated risk factors 
separately for localized and advanced tumors, but in our study some 30 percent of all cases could not be classified because of missing information on tumor characterization. The results from our or other studies do not uniformly point at stronger associations between the exposure variables and advanced prostate tumors. Because the number of studies in which subgroup analyses based on tumor characterization is low, definite conclusions cannot be drawn yet.

From the results of the NLCS and from the overview of results from other studies we can conclude that, thus far, there is no convincing evidence for an important role of the consumption of fresh meat, fish, cured meat, milk and milk products, cheese and eggs in prostate cancer etiology. It has to be mentioned, however, that even the lower tail of the distribution of consumption of animal products in the NLCS and in most of the other studies represents a higher consumption than the average consumption level in countries with low prostate cancer incidence rates. Therefore, the possibility that at much lower levels consumption of animal products is important in prostate cancer etiology cannot be ruled out.

In our study we could not confirm a positive association between calcium intake and prostate cancer risk, which has recently been proposed (35). Furthermore, also for animal and vegetable protein associations with prostate cancer risk were not clear. More studies are needed to investigate the suggested role of calcium intake in prostate cancer etiology. Other studies should also evaluate whether a diet based on animal foods might be positively associated with prostate cancer risk and whether plant-based foods might be protective. In future studies, long follow-up periods with repeated extensive measurements of diet could be helpful in evaluating whether diet is involved in prostate cancer progression or whether diet has an effect relatively early in carcinogenesis. Finally, also mechanistic research is warranted.

\section{Acknowledgements}

We are indebted to the participants of this study and further wish to thank the regional cancer registries (IKA, IKL, IKMN, IKN, IKO, IKR, IKST, IKW, IKZ), and the Dutch national data base of pathology (PALGA); A. Volovics for statistical advice; S. van de Crommert, J. Nelissen, H. Brants, M. Moll, W. van Dijk, P. Florax and A. Pisters for assistance; and H. van Montfort, R. Schmeitz, T. van Montfort, and M. de Leeuw for programming and statistical assistance.

\section{References}

1. Parkin DM, Muir CS, Whelan SL, et al. Cancer incidence in five continents. Lyon: IARC Scientific Publications, 1992.

2. Boyle P, Maisonneuve P, Napalkov P. Geographical and temporal patterns of incidence and mortality from prostate cancer. Urology 1995;46:47-55.

3. Pienta KJ, Esper PS. Risk factors for prostate cancer. Ann Intern Med 1993;118:793-803.

4. Mettlin C. Recent developments in the epidemiology of prostate cancer. Eur $\mathrm{J}$ Cancer 1997;33:340-7. 
5. Snowdon DA, Phillips RL, Choi W. Diet, obesity, and risk of fatal prostate cancer. Am J Epidemiol 1984;120:244-50.

6. Mills PK, Beeson WL, Phillips RL, et al. Cohort study of diet, lifestyle, and prostate cancer in Adventist men. Cancer 1989;64:598-604.

6. Severson RK, Nomura AM, Grove JS, et al. A prospective study of demographics, diet, and prostate cancer among men of Japanese ancestry in Hawaii. Cancer Res 1989;49:1857-60.

8. Thompson MM, Garland C, Barrett-Connor E, et al. Heart disease risk factors, diabetes, and prostatic cancer in an adult community. Am J Epidemiol 1989;129:511-7.

9. Hirayama T. Life-style and mortality. A large-scale census-based cohort study in Japan. Basel: Karger, 1990.

10. Hsing AW, McLaughlin JK, Schuman LM, et al. Diet, tobacco use, and fatal prostate cancer: results from the Lutheran Brotherhood Cohort Study. Cancer Res 1990;50:6836-40.

11. Gann $\mathrm{PH}, \mathrm{Hennekens} \mathrm{CH}$, Sacks FM, et al. Prospective study of plasma fatty acids and risk of prostate cancer. J Natl Cancer Inst 1994;86:281-6.

12. Le Marchand L, Kolonel LN, Wilkens LR, et al. Animal fat consumption and prostate cancer: a prospective study in Hawaii. Epidemiology 1994;5:276-82.

13. Giovannucci E, Ascherio A, Rimm EB, et al. Intake of carotenoids and retinol in relation to risk of prostate cancer. J Natl Cancer Inst 1995;87:1767-76.

14. Gronberg H, Damber L, Damber JE. Total food consumption and body mass index in relation to prostate cancer risk: a case-control study in Sweden with prospectively collected exposure data. J Urol 1996;155:969-74.

15. Schuman LM, Mandel JS, Radke A, et al. Some selected features of the epidemiology of prostatic cancer: Minneapolis-St. Paul, Minnesota case-control study, 1976-1979. In: Magnus K, ed. Trends in cancer incidence: causes and practical implications. Washington: Hemisphere Publishiong corporation, 1982:345-54.

16. Graham S, Haughey B, Marshall J, et al. Diet in the epidemiology of carcinoma of the prostate gland. J Natl Cancer Inst 1983;70:687-92.

17. Mishina $\mathrm{T}$, Watanabe $\mathrm{H}$, Araki $\mathrm{H}$, et al. Epidemiological study of prostatic cancer by matched-pair analysis. Prostate 1985;6:423-36.

18. Talamini R, La Vecchia C, Decarli A, et al. Nutrition, social factors and prostatic cancer in a Northern Italian population. Br J Cancer 1986;53:817-21.

19. Ross RK, Shimizu H, Paganini Hill A, et al. Case-control studies of prostate cancer in blacks and whites in southern California. J Natl Cancer Inst 1987;78:869-74.

20. Oishi K, Okada K, Yoshida O, et al. A case-control study of prostatic cancer with reference to dietary habits. Prostate 1988;12:179-90.

21. Mettlin C, Selenskas S, Natarajan N, et al. Beta-carotene and animal fats and their relationship to prostate cancer risk. A case-control study. Cancer 1989;64:605-12.

22. Bravo MP, Castellanos E, del Rey Calero J. Dietary factors and prostatic cancer. Urol Int 1991;46:163-6.

23. Walker AR, Walker BF, Tsotetsi NG, et al. Case-control study of prostate cancer in black patients in Soweto, South Africa. Br J Cancer 1992;65:438-41.

24. Talamini R, Franceschi S, La Vecchia C, et al. Diet and prostatic cancer: a case-control study in northern Italy. Nutr Cancer 1992;18:277-86.

25. Andersson SO, Baron J, Wolk A, et al. Early life risk factors for prostate cancer: a populationbased case-control study in Sweden. Cancer Epidemiol Biomarkers Prev 1995;4:187-92.

26. Ewings $P$, Bowie $C$. A case-control study of cancer of the prostate in Somerset and east Devon. Br J Cancer 1996;74:661-6.

27. Pawlega J, Rachtan J, Dyba T. Dietary factors and risk of prostate cancer in Poland. Results of case-control study. Neoplasma 1996;43:61-3.

28. Key TJ, Silcocks PB, Davey GK, et al. A case-control study of diet and prostate cancer. Br J Cancer 1997;76:678-87.

29. Kolonel LN. Nutrition and prostate cancer. Cancer Causes Control 1996;7:83-94.

30. Boyle P, Zaridze DG. Risk factors for prostate and testicular cancer. Eur J Cancer 1993;29a:1048-55.

31. Giles G, Ireland P. Diet, nutrition and prostate cancer. Int J Cancer 1997; Suppl 10:13-7.

32. Ross RK, Henderson BE. Do diet and androgens alter prostate cancer risk via a common etiologic pathway? J Natl Cancer Inst 1994;86:252-4. 
33. Corder EH, Guess HA, Hulka BS, et al. Vitamin D and prostate cancer: a prediagnostic study with stored sera. Cancer Epidemiol Biomarkers Prev 1993;2:467-72.

34. Corder EH, Friedman GD, Vogelman JH, et al. Seasonal variation in vitamin D, vitamin Dbinding protein, and dehydroepiandrosterone: risk of prostate cancer in black and white men. Cancer Epidemiol Biomarkers Prev 1995;4:655-9.

35. Giovannucci E, Rimm EB, Wolk A, et al. Calcium and fructose intake in relation to risk of prostate cancer. Cancer Res 1998;58:442-7.

36. Felton JS, Malfatti MA, Knize MG, et al. Health risks of heterocyclic amines. Mutat Res 1997; $376: 37-41$

37. Van den Brandt PA, Goldbohm RA, Van 't Veer P, et al. A large-scale prospective cohort study on diet and cancer in The Netherlands. J Clin Epidemiol 1990;43:285-95.

38. Prentice RL. A case-cohort design for epidemiologic cohort studies and disease prevention trials. Biometrika 1986;73:1-11.

39. Van den Brandt PA, Schouten LJ, Goldbohm RA, et al. Development of a record linkage protocol for use in the Dutch Cancer Registry for Epidemiological Research. Int J Epidemiol 1990;19:5538.

40. Goldbohm RA, Van den Brandt PA, Dorant E. Estimation of the coverage of Dutch municipalities by cancer registries and PALGA based on hospital discharge data. Tijdschr Soc Gezondheidsz $1994 ; 72: 80-4$

41. Goldbohm RA, Van den Brandt PA, Brants HAM, et al. Validation of a dietary questionnaire used in a large-scale prospective cohort study on diet and cancer. Eur J Clin Nutr 1994;48:253-65.

42. Voorlichtingsbureau voor de Voeding. Nevo table: Dutch Food Composition Table 1986-1987. The Hague, 1986.

43. Willett $W$. Implications of total energy intake for epidemiologic analyses. In: Willett W, ed. Nutritional epidemiology. New York: Oxford University Press, 1990:245-71.

44. Schuurman AG, Goldbohm RA, Dorant E, et al. Vegetable and fruit consumption and prostate cancer risk: a cohort study in the Netherlands. Cancer Epidemiol Biom Prev 1998;7:673-80.

45. Baker J. GLIM 3.77 Reference Manual. Oxford: Numerical Algorithms Group, 1985.

46. Volovics A, van den Brandt PA. Methods for the analyses of case-cohort studies. Biom J 1997;2:195-214.

47. Van den Brandt PA, Van 't Veer P, Goldbohm RA, et al. A prospective cohort study on dietary fat and the risk of postmenopausal breast cancer. Cancer Res 1993;53:75-82.

48. Goldbohm RA, Van 't Veer P, Van den Brandt PA, et al. Reproducibility of a food frequency questionnaire and stability of dietary habits determined from five annually repeated measurements. Eur J Clin Nutr 1995;49:420-9.

49. Giovannucci E, Rimm EB, Colditz GA, et al. A prospective study of dietary fat and risk of prostate cancer. J Natl Cancer Inst 1993;85:1571-9.

50. Van 't Veer P, Dekker JM, Lamers JW, et al. Consumption of fermented milk products and breast cancer: a case-control study in The Netherlands. Cancer Res 1989;49:4020-3. 


\section{Chapter 5}

\section{Intake of energy and fat and prostate cancer}

\section{risk: results from the Netherlands Cohort}

\section{Study ${ }^{1}$}

Agnes G. Schuurman ${ }^{2}$ - Piet A. van den Brandt ${ }^{2}$

Elisabeth Dorant ${ }^{2}$ - Henny A.M. Brants ${ }^{3}$

R. Alexandra Goldbohm ${ }^{3}$

\section{Abstract}

The role of energy and fat intake as risk factors for prostate cancer is still questionable. Therefore, this was evaluated within the Netherlands Cohort Study. The cohort consists of 58,279 men aged 55-69 years at baseline in 1986; after 6.3 years of follow-up, 642 incident prostate cancer cases were available for analysis. Intake of energy, fat, and separate fatty acids were measured by means of a self-administered questionnaire; fat intake was adjusted for energy by regression analysis. The case-cohort method was used to calculate rate ratios (RR). Analyses were done for all prostate cancer cases together, and for case subgroups (latent vs nonlatent; localized vs advanced). No associations were found in multivariate analyses between prostate cancer and intake of energy, total fat, total saturated fatty acids, and total trans unsaturated fatty acids (RR highest vs lowest quintile: $0.99,1.10,1.19,0.99$, respectively). Oleic acid intake showed a nonsignificant positive association ( $R R=1.38,95 \% \mathrm{Cl}: 0.88-2.19)$. Also in subgroup analyses positive associations were observed for intake of oleic acid. Intake of linoleic acid ( $R R=0.78,95 \% \mathrm{Cl}: 0.56-1.09$ ) and linolenic acid ( $R R=0.76 .95 \% \mathrm{Cl}: 0.66-1.04)$ showed nonsignificantly decreased risks; only for linolenic acid these associations persisted in subgroup analyses. No associations were found for intake of arachidonic acid, eicosapentaenoic acid and docosahexaenoic acid. These data suggest that some specific fatty acids might be involved in prostate cancer occurrence, although chance findings cannot be excluded.

\footnotetext{
${ }^{1}$ Provisionally accepted by Cancer

${ }^{2}$ Dept. of Epidemiology, Maastricht University, Maastricht

${ }^{3}$ Dept. of Consumer Research \& Epidemiology, TNO Nutrition and Food Research Institute, Zeist
} 


\section{Introduction}

Prostate cancer incidence as well as mortality are increasing (1). In many Western countries, prostate cancer is one of the most frequently occurring types of cancer among men. Because clinical prostate cancer shows a noteworthy geographical variation in incidence compared to latent prostate cancer, environmental risk factors, among which are energy and fat intake, are thought to play an important role in the etiology of clinical prostate cancer (2-5).

The relationship between fat intake and prostate cancer risk was summarized in several reviews on (dietary) risk factors for prostate cancer (2-6). From these reviews it is mostly concluded that fat intake is positively related to prostate cancer risk. However, these conclusions are not only based on fat intake per se, but also on results regarding consumption of meat, milk and dairy. In one of the reviews it is concluded that there is no conclusive evidence to the role of fat in prostate cancer etiology (2). Furthermore, specific fatty acids have been investigated in few studies (7-14). Nevertheless, in some studies a positive association between $\alpha$-linolenic acid $(9,10,12)$ and oleic acid $(10,12)$ and risk of prostate cancer was shown. It has been proposed that clinically apparent or advanced prostate tumors might have a different etiology than latent tumors. Only a minority of all studies on fat and prostate cancer risk examined fat intake for latent and nonlatent or localized and advanced tumors separately $(9,10,13,15-17)$, with diverse results.

Underlying biological mechanisms explaining a possible effect of fat intake on prostate cancer risk are not clear but some mechanisms have been proposed. Increased fat intake might lead to increased testosterone levels and this might, eventually, lead to increased cell division and activation of proto-oncogenes and deactivation of tumor suppressor genes (18). A role of specific fatty acids in prostate tumor occurrence is biologically plausible since essential fatty acids are a source of metabolic energy, and are required for membrane structure and for the synthesis of intermediate compounds important for cellular metabolism (19). Linoleic acid and linolenic acid are both precursors for eicosanoid production and eicosanoids have been shown to be related to tumor development, including cell proliferation, immune response, invasion, and metastasis $(10,20)$. In vitro, linoleic acid has been shown to stimulate growth of some but not all prostate cell lines $(19,20)$ and the same counts for linolenic acid (19). For docosahexaenoic acid and eicosapentaenoic acid growth inhibitory effects have been reported (20) but at low concentrations eicosapentaenoic acid has also been reported to stimulate tumor promotion (19). Finally, another potential mechanism to explain an effect of fatty acids may be free radical formation resulting from oxidation of fatty acids $(9,10)$.

In this article we present our findings regarding fat intake and prostate cancer risk from the Netherlands Cohort Study (NLCS) which was specifically designed to examine diet in 
relation to cancer. Findings are also presented with respect to latent and nonlatent, and localized and advanced prostate tumors.

\section{Methods}

\section{The cohort}

The study design has been described elsewhere (21). In brief, the NLCS was initiated in September 1986 . The male cohort consists of 58,279 men aged 55-69 years who completed a self-administered questionnaire on usual diet, and other risk factors for cancer. Subjects originated from 204 municipal population registries throughout the country. For reasons of efficiency in data processing and analysis, the case-cohort approach (22) was used. In a case-cohort approach, cases are derived from the entire cohort (providing numerator information for calculation of cancer incidence rates), whereas accumulated person years at risk in the total cohort are estimated using a random male subcohort sample (providing denominator information for the rates). In contrast to nested case-control sampling, this subcohort can be used for multiple disease endpoints. The male subcohort was sampled directly after identification of the total cohort and includes 1,688 men: The method of cancer follow-up has also been described previously (23). In short, incident primary prostate cancer cases were detected by computerized record linkage with all nine cancer registries in the Netherlands, and with the Dutch national data base of pathology reports (PALGA). The subcohort has been followed up biennially for vital status information. No subcohort members were lost to follow-up and completeness of follow-up of cancer was at least 96 percent (24). After a follow-up period of 6.3 years (September 1986-December 1992), 704 incident, microscopically confirmed, primary prostate cancer cases were detected.

\section{The questionnaire}

The self-administered questionnaire has been described elsewhere (25). Usual consumption of food and beverages during the year preceding the start of the study was assessed with a 150-item semiquantitative food frequency questionnaire. Among the principal nutrients of interest were energy and fat intake. Questionnaire data were keyentered twice and processed for all incident cases in the cohort and for all subcohort members in a manner blinded with respect to case/subcohort status. This was done in order to minimize observer bias in coding and interpretation of the data. Mean daily nutrient intakes were calculated using the computerized Dutch food composition table (26). Intake of specific fatty acids was based on a food compostion database with specific fatty acids, including trans fatty acids, derived from the TRANSFAIR study (27). For this database, the hundred foods that contributed most to fat intake in the Dutch dietary pattern were sampled and analyzed as methyl esters of the fatty acids present in the foods. In the database, total fat includes triglycerides and other lipids such as phospholipids and sterols. The percentage of triglycerides in total fat is assumed to be on average 93 percent, but varies across food 
sources. In the database for the NLCS, the concentrations of fatty acids were based on the concentrations before 1995, when changes in the trans content of manufactured products such as margarines led to a decrease in intake of trans fatty acids.

\section{Data analysis}

In the subcohort prevalent cancer cases at baseline other than skin cancer were excluded, leaving 1,630 subcohort members for analysis. Furthermore, according to criteria published before (25), subjects with incomplete or inconsistent dietary data were excluded; 642 men with prostate cancer and 1525 male subcohort members remained for analysis.

Exposure variables included in the present analysis are intake of total energy, total fat, total fatty acids, saturated fattty acids, mono and polyunsaturated fatty acids, trans unsaturated fatty acids, cis unsaturated fatty acids, palmitic acid, stearic acid, oleic acid, linoleic acid, linolenic acid, arachidonic acid, eicosapentaenoic acid, and docosahexaenoic acid. Fat intake was adjusted for energy by regression analysis (28). Mean intake levels of exposure variables and other characteristics were compared between prostate cancer cases and male subcohort members. Furthermore, mean intakes of total energy and total fat intake were compared in categories of potential confounders. Rate ratios (RR) and 95\% confidence intervals $(95 \% \mathrm{Cl})$ were computed for quintiles of energy and fat intake, as well as for continuous variables of intake, using the GLIM statistical package (29). Exponentially distributed survival times were assumed in the follow-up period. Since standard software was not available, specific macros were developed to account for the additional variance introduced by using the subcohort instead of the entire cohort (30). Throughout this report two-sided $\mathrm{P}$-values are used; trend tests for quintile ranks were based on likelihood ratio tests. Age-adjusted and multivariate analyses were conducted. Variables that were considered as potential confounders were age, family history of prostate cancer, and socioeconomic status. For all energy-adjusted variables energy intake was also included into the multivariate model, in conformity with the method described by Willett (28). In addition, in order to assess the independent contribution of saturated fatty acids, mono and polyunsaturated fatty acids and each specific fatty acid, total energy-adjusted fat intake was also included in the multivariate model. Vegetable and fruit consumption and intake of vitamin $\mathrm{E}$ were not considered as potential confounding factors because no association with prostate cancer risk was observed (31). In additional analyses, cases detected during the first two years of follow-up were excluded to evaluate whether preclinical disease may have influenced results.

\section{Subgroup analyses}

Separate analyses were done for latent and nonlatent tumors, for continuous variables of exposure. The subgroups were constructed based on information about surgical procedures mentioned in the pathology reports that have been obtained from PALGA. Tumors that were 
detected as a consequence of transurethral prostate resections, usually performed for problems associated with Benign Prostatic Hyperplasia (BPH), were coded latent. Nonlatent tumors were those tumors that were detected as a consequence of procedures used in case of suspected cancer (biopsy, radical prostatectomy). Cases were excluded from these subgroup analyses when this additional information was unknown or unclear (38.2\%).

Because population screening for prostate cancer was not instituted before 1992 in the Netherlands, we assumed there were no tumors detected by screening in the 6.3 years of follow-up. Analyses were also done for localized prostate tumors (TO-2, MO: no evidence of primary tumor [TO], clinically inapparent tumor [T1], or tumor confined within the prostate [T2], no distant metastasis [MO]) and advanced prostate tumors (T3-4, MO; TO-4, M1: tumor

Table 1: Description of mean energy and energy-adjusted fat intake and distribution of potential confounding variables in prostate cancer cases and male subcohort members, Netherlands Cohort Study (19861992).

\begin{tabular}{|c|c|c|c|c|}
\hline \multirow[b]{2}{*}{ Characteristics } & \multicolumn{2}{|c|}{ Cases $(n=642)$} & \multicolumn{2}{|c|}{ Subcohort ( $n=1525)$} \\
\hline & mean & SD & mean & SD \\
\hline \multicolumn{5}{|l|}{ Exposure variables ( $g /$ day) } \\
\hline Energy intake (kcal/day) & 2115 & 487 & 2157 & 513 \\
\hline Total fat ${ }^{1}$ & 94.1 & 13.3 & 93.6 & 14.4 \\
\hline Total fatty acids ${ }^{2}$ & 87.5 & 12.8 & 87.0 & 13.8 \\
\hline Total saturated fatty acids & 36.9 & 8.5 & 36.3 & 8.4 \\
\hline Total monounsaturated fatty acids & 28.5 & 5.1 & 28.3 & 5.2 \\
\hline Total polyunsaturated fatty acids & 20.2 & 7.7 & 20.5 & 8.2 \\
\hline Total trans unsaturated fatty acids & 3.3 & 1.4 & 3.3 & 1.3 \\
\hline Total cis unsaturated fatty acids & 45.4 & 9.6 & 45.6 & 10.1 \\
\hline Palmitic acid & 18.6 & 3.7 & 18.4 & 3.8 \\
\hline Stearic acid & 8.3 & 1.4 & 8.2 & 1.6 \\
\hline Oleic acid & 21.7 & 4.4 & 21.6 & 4.3 \\
\hline Linoleic acid & 18.0 & 7.7 & 18.2 & 8.1 \\
\hline Linolenic acid & 1.3 & 0.6 & 1.4 & 0.6 \\
\hline Arachidonic acid & 0.11 & 0.04 & 0.11 & 0.05 \\
\hline Eicosapentaenoic acid & 0.05 & 0.06 & 0.04 & 0.05 \\
\hline Docosahexaenoic acid & 0.09 & 0.09 & 0.08 & 0.08 \\
\hline \multicolumn{5}{|l|}{ - } \\
\hline \multicolumn{5}{|l|}{ Potential confounding variables } \\
\hline Age (years) & 63.9 & 3.8 & 61.4 & 4.2 \\
\hline Family history of prostate cancer (\% yes) & 4.4 & & 2.7 & \\
\hline \multicolumn{5}{|l|}{ Highest educational level $(\%)^{3}$} \\
\hline low & 44.7 & & 47.1 & \\
\hline medium & 34.9 & & 35.0 & \\
\hline high & 20.4 & & 17.9 & \\
\hline
\end{tabular}

${ }^{1}$ Includes other lipids such as phospholipids; ${ }^{2}$ Includes about 2 percent unidentified fatty acids; ${ }^{3}$ Low is defined as primary school with/without lower level vocational education, medium as secondary school or medium level vocational education, high as university or higher level vocational education. 
extending through prostatic capsule [T3], fixed tumor or tumor invading adjacent structures other than seminal vesicles [T4], no distant metastasis [MO]; any tumor [T0-4] with distant metastasis [M1]), based on the TNM classification system (32). Of all cases, $31.6 \%$ could not be categorized in localized or advanced tumors.

\section{Results}

In Table 1 the mean intake of energy and energy-adjusted fat intake among cases and subcohort members is shown. The mean energy intake was somewhat lower among cases compared to subcohort members. Overall, mean fat intake did not differ to a large extent between cases and subcohort members. Also shown in this table is the distribution of potential confounding factors. Cases are older than subcohort members, they more often have a positive family history of prostate cancer and are more highly educated than subcohort members. Comparing total energy and fat intake across categories of potential confounding factors showed that total energy intake was highest at younger ages and in the lowest category of socioeconomic status. Total fat intake did not differ across categories of potential confounding factors (data not shown).

Age-adjusted and multivariate adjusted RRs for prostate cancer according to total energy and total fat intake, as well as grouped fatty acids are summarized in table 2 . Multivariate adjusted RRs were similar to age-adjusted risk estimates. No associations were observed for intake of total energy, total fat, total fatty acids, saturated fatty acids and trans unsaturated fatty acids. A nonsignificant slightly increased risk was noted for intake of monounsaturated fatty acids (RR highest vs lowest quintile=1.32, 95\% Cl: 0.82-2.12). Nonsignificant inverse associations were indicated for intake of polyunsaturated fatty acids $(\mathrm{RR}=0.78,95 \% \mathrm{Cl}: 0.56-1.10)$ and intake of cis unsaturated fatty acids ( $\mathrm{RR}=0.80,95 \% \mathrm{Cl}$ : $0.54-1.20)$. When cis unsaturated fatty acids were separated in monounsaturated and polyunsaturated cis fatty acids, the RR comparing highest vs lowest quintile for cis monounsaturated fatty acids was somewhat increased $(R R=1.34,95 \% \mathrm{Cl}: 0.84-2.14)$, while the RR for cis polyunsaturated fatty acids was slightly decreased $(R R=0.77,95 \% \mathrm{Cl}: 0.55-$ 1.08). However, both estimates were not significant and there was no trend in risk (data not shown).

In Table 3 the RRs for the intake of specific fatty acids in relation to prostate cancer risk are shown. Again, age-adjusted and multivariate adjusted RRs were very similar. For most individual fatty acids no clear associations with prostate cancer were observed. Only for intake of oleic acid, a nonsignificant slightly increased risk was observed $(R R=1.38)$ but there was no trend in risk. In the highest intake quintiles, both for intake of linoleic acid and linolenic acid nonsignificant decreased risks were observed (RRs of 0.78 and 0.76 , respectively) but the trend test was not significant in both instances. Exclusion of cases detected during the first two years of follow-up did not change the results presented in tables 2 and 3 (data not shown). 
Table 2: Rate ratios (RR) and $95 \%$ confidence intervals $(95 \% \mathrm{Cl})$ for prostate cancer according to quintiles of intake of energy, and energy-adjusted fat, Netherlands Cohort Study (1986-1992).

\begin{tabular}{|c|c|c|c|c|c|c|}
\hline Exposure & $\mathrm{Q} 1^{1}$ & Q2 & Q3 & Q4 & Q5 & $\begin{array}{l}\mathrm{P} \text { for } \\
\text { trend }\end{array}$ \\
\hline \multicolumn{7}{|l|}{ Energy intake } \\
\hline Median intake ${ }^{2}$ & 1541 & 1870 & 2117 & 2377 & 2803 & \\
\hline Cases/Person years & 133/1804 & $141 / 1803$ & 129/1831 & $135 / 1836$ & $104 / 1848$ & \\
\hline $\mathrm{RR}^{3}(95 \% \mathrm{Cl})$ & 1.00 & $1.08(0.80-1.46)$ & $0.97(0.72-1.32)$ & $1.08(0.80-1.46)$ & $0.98(0.71-1.36)$ & 0.94 \\
\hline $\mathrm{RR}^{4}(95 \% \mathrm{Cl})$ & 1.00 & $1.05(0.78-1.43)$ & $0.95(0.70-1.30)$ & $1.04(0.77-1.41)$ & $0.99(0.72-1.37)$ & 0.93 \\
\hline \multicolumn{7}{|c|}{ 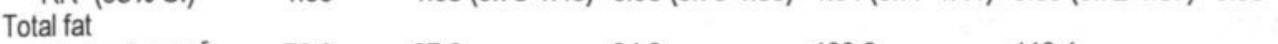 } \\
\hline Median intake ${ }^{5}$ & 76.0 & 87.2 & 94.0 & 100.3 & 110.4 & \\
\hline Cases/Person years & $114 / 1804$ & $139 / 1828$ & $132 / 1853$ & $132 / 1806$ & $125 / 1831$ & \\
\hline $\mathrm{RR}^{3}(95 \% \mathrm{Cl})$ & 1.00 & $1.24(0.91-1.69)$ & $1.12(0.82-1.54)$ & $1.10(0.81-1.51)$ & $1.11(0.81-1.52)$ & 0.81 \\
\hline $\mathrm{RR}^{6}(95 \% \mathrm{Cl})$ & 1.00 & $1.22(0.89-1.67)$ & $1.10(0.80-1.51)$ & $1.10(0.80-1.51)$ & $1.10(0.80-1.52)$ & 0.78 \\
\hline \multicolumn{7}{|l|}{ Total fatty acids } \\
\hline Median intake ${ }^{5}$ & 70.1 & 80.9 & 87.3 & 93.5 & 103.5 & \\
\hline Cases/Person years & $110 / 1804$ & $146 / 1820$ & $127 / 1864$ & $133 / 1812$ & $126 / 1822$ & \\
\hline $\operatorname{RR}^{3}(95 \% \mathrm{Cl})$ & 1.00 & $1.36(1.00-1.86)$ & $1.07(0.78-1.47)$ & $1.14(0.84-1.57)$ & $1.15(0.84-1.58)$ & 0.77 \\
\hline $\mathrm{RR}^{6}(95 \% \mathrm{Cl})$ & 1.00 & $1.32(0.97-1.82)$ & $1.04(0.76-1.44)$ & $1.13(0.82-1.56)$ & $1.14(0.83-1.57)$ & 0.77 \\
\hline \multicolumn{7}{|l|}{ Saturated fatty acids } \\
\hline Median intake $e^{5}$ & 26.4 & 31.7 & 35.5 & 40.0 & 47.5 & \\
\hline Cases/Person years & $129 / 1814$ & $115 / 1822$ & $128 / 1812$ & $103 / 1864$ & $167 / 1809$ & \\
\hline $\operatorname{RR}^{3}(95 \% \mathrm{Cl})$ & 1.00 & $0.91(0.67-1.25)$ & $0.96(0.71-1.31)$ & $0.75(0.54-1.03)$ & $1.23(0.91-1.65)$ & 0.27 \\
\hline $\mathrm{RR}^{7}(95 \% \mathrm{Cl})$ & 1.00 & $0.88(0.63-1.24)$ & $0.93(0.65-1.32)$ & $0.75(0.51-1.08)$ & $1.19(0.80-1.76)$ & 0.43 \\
\hline \multicolumn{7}{|c|}{$\begin{array}{l}\text { Monounsaturated fatty } \\
\text { acids }\end{array}$} \\
\hline Median intake & 22.3 & 25.8 & 28.2 & 30.6 & 34.3 & \\
\hline Cases/Person years & $120 / 1780$ & $133 / 1846$ & $144 / 1849$ & $117 / 1827$ & $128 / 1821$ & \\
\hline $\mathrm{RR}^{3}(95 \% \mathrm{Cl})$ & 1.00 & $1.16(0.85-1.59)$ & $1.26(0.93-1.71)$ & $1.00(0.73-1.37)$ & $1.22(0.89-1.67)$ & 0.39 \\
\hline $\mathrm{RR}^{7}(95 \% \mathrm{Cl})$ & 1.00 & $1.22(0.87-1.71)$ & $1.30(0.90-1.88)$ & $1.07(0.72-1.60)$ & $1.32(0.82-2.12)$ & 0.48 \\
\hline \multicolumn{7}{|l|}{$\begin{array}{l}\text { Polyunsaturated fatty } \\
\text { acids }\end{array}$} \\
\hline Median intake ${ }^{5}$ & 11.0 & 15.9 & 19.8 & 24.1 & 31.1 & \\
\hline Cases/Person years & $135 / 1807$ & $101 / 1833$ & $150 / 1819$ & $142 / 1843$ & $114 / 1821$ & \\
\hline $\mathrm{RR}^{3}(95 \% \mathrm{Cl})$ & 1.00 & $0.71(0.52-0.98)$ & $1.14(0.85-1.54)$ & $1.01(0.75-1.37)$ & $0.80(0.58-1.09)$ & 0.71 \\
\hline $\mathrm{RR}^{7}(95 \% \mathrm{Cl})$ & 1.00 & $0.73(0.53-1.01)$ & $1.15(0.84-1.56)$ & $1.00(0.73-1.37)$ & $0.78(0.56-1.10)$ & 0.52 \\
\hline \multicolumn{7}{|c|}{$\begin{array}{l}\text { Trans unsaturated fatty } \\
\text { acids }\end{array}$} \\
\hline Median intake ${ }^{5}$ & 1.9 & 2.6 & 3.2 & 3.7 & 4.7 & \\
\hline Cases/Person years & $119 / 1795$ & $136 / 1824$ & $135 / 1830$ & $136 / 1829$ & $116 / 1844$ & \\
\hline $\mathrm{RR}^{3}(95 \% \mathrm{Cl})$ & 1.00 & $1.22(0.89-1.66)$ & $1.18(0.86-1.60)$ & $1.13(0.83-1.54)$ & $1.01(0.73-1.39)$ & 0.87 \\
\hline $\mathrm{RR}^{7}(95 \% \mathrm{Cl})$ & 1.00 & $1.25(0.90-1.72)$ & $1.20(0.86-1.65)$ & $1.12(0.80-1.55)$ & $0.99(0.70-1.40)$ & 0.72 \\
\hline \multicolumn{7}{|l|}{$\begin{array}{l}\text { Cis unsaturated fatty } \\
\text { acids }\end{array}$} \\
\hline Median intake ${ }^{5}$ & 34.2 & 40.2 & 45.0 & 51.1 & 58.1 & \\
\hline Cases/Person years & $135 / 1821$ & $122 / 1814$ & $127 / 1812$ & $142 / 1847$ & $116 / 1829$ & \\
\hline $\operatorname{RR}^{3}(95 \% \mathrm{Cl})$ & 1.00 & $0.93(0.69-1.27)$ & $1.00(0.74-1.37)$ & $1.03(0.76-1.39)$ & $0.89(0.65-1.22)$ & 0.67 \\
\hline $\mathrm{RR}^{7}(95 \% \mathrm{Cl})$ & 1.00 & $0.90(0.65-1.24)$ & $0.94(0.67-1.32)$ & $0.96(0.68-1.35)$ & $0.80(0.54-1.20)$ & 0.34 \\
\hline
\end{tabular}

${ }^{1}$ Reference category; ${ }^{2}$ Median intake (kcal/day) in subcohort; ${ }^{3}$ Adjusted for age; ${ }^{4}$ Adjusted for age, family history of prostate cancer, and socioeconomic status; ${ }^{5}$ Median intake (g/day) in subcohort; ${ }^{6}$ Adjusted for age, family history of prostate cancer, socioeconomic status, and total energy intake; ${ }^{7}$ Adjusted for age, family history of prostate cancer, socioeconomic status, total energy intake, and total energy-adjusted fat intake. 
In Table 4, results from multivariate analyses for continuous variables of energy and fat intake are presented for all prostate cancer cases, and separately for latent, nonlatent, localized and advanced tumors. For most exposure variables, no clear associations were observed in the different subgroups and, overall, associations were mostly similar in subgroups of latent and nonlatent and localized and advanced tumor subgroups. Nonsignificant increased risk estimates were found for intake of monounsaturated fatty acids and latent and nonlatent tumors and for oleic acid in association with all four tumor subgroups. Inverse associations were observed in subgroups of latent, nonlatent and localized tumors for intake of linolenic acid.

\section{Discussion}

In the NLCS we found no association between intake of energy, total fat, total fatty acids, saturated fatty acids, and trans unsaturated fatty acids and overall prostate cancer risk. For specific fatty acids, a positive association with prostate cancer risk was indicated for oleic acid intake, also in subgroup analyses. An inverse association was indicated for intake of linoleic acid and linolenic acid. The trend test for linolenic acid intake was significant in the age-adjusted analysis. Results in subgroups were less clear.

Before discussing the results in relation with other studies, some remarks about the NLCS are relevant. Loss to follow-up is the primary source of potential selection bias in prospective cohort studies. Given the high completeness of follow-up of the cases and subcohort person years in the $\operatorname{NLCS}(24,33)$ selection bias is unlikely. In the case of prostate cancer, symptoms of prostate cancer (e.g. urethral obstruction) are unlikely to cause a change in dietary fat intake. Nevertheless, we conducted analyses after exclusion of cases diagnosed in the first two years of follow-up, and the results were similar to our overall results.

The questionnaire has been validated against a 9-day diet record. Crude and energy-sexadjusted (in parentheses) Pearson correlation coefficients between the dietary record and the questionnaire were as follows: energy, 0.74 ; total fat, $0.72(0.52)$; saturated fat, 0.73 (0.58); polyunsaturated fat, $0.73(0.75)(25)$. From this validation study we conclude that fat intake was reasonably well measured in our self-administered semiquantitative questionnaire. The correlation coefficient of 0.52 for total fat intake is most likely a consequence of the relatively homogeneous dietary fat intake in our study population. For polyunsaturated fat intake, however, the range in intake is much higher and the correlation coefficient from our validation study was 0.75 . To prevent substantial misclassification, we excluded subjects with incomplete or inconsistent data. A possible misclassification of fat intake is likely to be nondifferential, thus leading to a bias towards the null value. Besides a validation study, five annually repeated measurements of the food frequency questionnaire were conducted. From the results it was concluded that the single measurement of intake of 
Table 3: Rate ratios (RR) and $95 \%$ confidence intervals (95\% Cl) for prostate cancer according to quintiles of intake of specific energy-adjusted fatty acids, Netherlands Cohort Study (1986-1992).

\begin{tabular}{|c|c|c|c|c|c|c|}
\hline Exposure & $\mathrm{Q} 1^{1}$ & Q2 & Q3 & Q4 & Q5 & $\begin{array}{l}\mathrm{P} \text { for } \\
\text { trend }\end{array}$ \\
\hline \multicolumn{7}{|l|}{ Palmitic acid } \\
\hline Median intake ${ }^{2}$ & 13.9 & 16.5 & 18.3 & 20.2 & 23.2 & \\
\hline Cases/Person years & $110 / 1802$ & $136 / 1816$ & $128 / 1834$ & $137 / 1860$ & $131 / 1811$ & \\
\hline $\mathrm{RR}^{3}(95 \% \mathrm{Cl})$ & 1.00 & $1.38(1.01-1.90)$ & $1.14(0.83-1.56)$ & $1.19(0.87-1.63)$ & $1.16(0.85-1.60)$ & 0.62 \\
\hline $\mathrm{RR}^{4}(95 \% \mathrm{Cl})$ & 1.00 & $1.37(0.98-1.91)$ & $1.14(0.80-1.62)$ & $1.20(0.83-1.74)$ & $1.14(0.75-1.74)$ & 0.79 \\
\hline \multicolumn{7}{|c|}{ 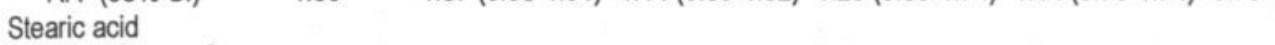 } \\
\hline Median intake ${ }^{2}$ & 6.4 & 7.4 & 8.2 & 8.9 & 10.1 & \\
\hline Cases/Person years & $105 / 1804$ & $133 / 1831$ & $140 / 1810$ & $133 / 1854$ & $131 / 1823$ & \\
\hline $\mathrm{RR}^{3}(95 \% \mathrm{Cl})$ & 1.00 & $1.15(0.84-1.59)$ & $1.28(0.94-1.76)$ & $1.06(0.77-1.45)$ & $1.17(0.85-1.61)$ & 0.49 \\
\hline $\mathrm{RR}^{4}(95 \% \mathrm{Cl})$ & 1.00 & $1.18(0.84-1.67)$ & $1.35(0.93-1.94)$ & $1.12(0.75-1.66)$ & $1.23(0.78-1.94)$ & 0.57 \\
\hline \multicolumn{7}{|l|}{ Oleic acid } \\
\hline Median intake ${ }^{2}$ & 16.8 & 19.6 & 21.5 & 23.4 & 26.3 & \\
\hline Cases/Person years & $113 / 1795$ & $152 / 1829$ & $131 / 1864$ & $118 / 1807$ & $128 / 1827$ & \\
\hline $\mathrm{RR}^{3}(95 \% \mathrm{Cl})$ & 1.00 & $1.45(1.06-1.97)$ & $1.18(0.86-1.62)$ & $1.10(0.80-1.52)$ & $1.30(0.94-1.78)$ & 0.45 \\
\hline $\mathrm{RR}^{4}(95 \% \mathrm{Cl})$ & 1.00 & $1.47(1.05-2.06)$ & $1.23(0.85-1.79)$ & $1.17(0.78-1.76)$ & $1.38(0.88-2.19)$ & 0.48 \\
\hline \multicolumn{7}{|l|}{ Linoleic acid } \\
\hline Median intake ${ }^{2}$ & 9.0 & 13.6 & 17.1 & 21.4 & 28.8 & \\
\hline Cases/Person years & $135 / 1813$ & $101 / 1824$ & $144 / 1824$ & $144 / 1836$ & $118 / 1825$ & \\
\hline $\mathrm{RR}^{3}(95 \% \mathrm{Cl})$ & 1.00 & $0.69(0.50-0.95)$ & $1.05(0.78-1.42)$ & $1.06(0.78-1.43)$ & $0.80(0.58-1.09)$ & 0.89 \\
\hline $\mathrm{RR}^{4}(95 \% \mathrm{Cl})$ & 1.00 & $0.71(0.51-0.98)$ & $1.04(0.77-1.42)$ & $1.05(0.77-1.44)$ & $0.78(0.56-1.09)$ & 0.68 \\
\hline \multicolumn{7}{|l|}{ Linolenic acid } \\
\hline Median intake ${ }^{2}$ & 0.7 & 1.1 & 1.3 & 1.7 & 2.1 & \\
\hline Cases/Person years & $154 / 1802$ & $126 / 1820$ & $125 / 1808$ & $123 / 1838$ & $114 / 1855$ & \\
\hline $\mathrm{RR}^{3}(95 \% \mathrm{Cl})$ & 1.00 & $0.80(0.59-1.08)$ & $0.82(0.61-1.11)$ & $0.80(0.59-1.08)$ & $0.76(0.56-1.03)$ & 0.04 \\
\hline $\mathrm{RR}^{4}(95 \% \mathrm{Cl})$ & 1.00 & $0.76(0.55-1.05)$ & $0.82(0.60-1.13)$ & $0.80(0.59-1.10)$ & $0.76(0.66-1.04)$ & 0.09 \\
\hline \multicolumn{7}{|l|}{ Arachidonic acid } \\
\hline Median intake ${ }^{2}$ & 0.06 & 0.09 & 0.11 & 0.13 & 0.17 & \\
\hline Cases/Person years & $113 / 1781$ & $133 / 1849$ & $151 / 1879$ & $113 / 1783$ & $132 / 1830$ & \\
\hline $\mathrm{RR}^{3}(95 \% \mathrm{Cl})$ & 1.00 & $1.23(0.90-1.69)$ & $1.38(1.01-1.88)$ & $1.10(0.80-1.53)$ & $1.20(0.87-1.64)$ & 0.40 \\
\hline $\mathrm{RR}^{4}(95 \% \mathrm{Cl})$ & 1.00 & $1.21(0.88-1.66)$ & $1.37(1.00-1.87)$ & $1.11(0.80-1.54)$ & $1.20(0.87-1.66)$ & 0.30 \\
\hline \multicolumn{7}{|c|}{ Eicosapentaenoic acid } \\
\hline Median intake ${ }^{2}$ & 0.00 & 0.01 & 0.03 & 0.05 & 0.10 & \\
\hline Cases/Person years & $135 / 1918$ & $102 / 1853$ & $125 / 1790$ & $138 / 1771$ & $142 / 1790$ & \\
\hline $\mathrm{RR}^{3}(95 \% \mathrm{Cl})$ & 1.00 & $0.69(0.50-0.95)$ & $0.94(0.69-1.28)$ & $1.06(0.79-1.44)$ & $1.01(0.75-1.37)$ & 0.11 \\
\hline $\mathrm{RR}^{4}(95 \% \mathrm{Cl})$ & 1.00 & $0.66(0.47-0.91)$ & $0.92(0.67-1.27)$ & $1.05(0.77-1.44)$ & $1.00(0.73-1.35)$ & 0.10 \\
\hline \multicolumn{7}{|c|}{ Docosahexaenoic acid } \\
\hline Median intake $e^{2}$ & 0.01 & 0.03 & 0.06 & 0.09 & 0.18 & \\
\hline Cases/Person years & $124 / 1846$ & $111 / 1834$ & $128 / 1811$ & $139 / 1836$ & $140 / 1796$ & \\
\hline $\mathrm{RR}^{3}(95 \% \mathrm{Cl})$ & 1.00 & $0.82(0.60-1.13)$ & $1.01(0.74-1.38)$ & $1.07(0.79-1.46)$ & $1.05(0.77-1.42)$ & 0.19 \\
\hline $\mathrm{RR}^{4}(95 \% \mathrm{Cl})$ & 1.00 & $0.81(0.58-1.11)$ & $1.00(0.73-1.38)$ & $1.09(0.80-1.49)$ & $1.03(0.75-1.40)$ & 0.19 \\
\hline
\end{tabular}

${ }^{1}$ Reference category; ${ }^{2}$ Median intake (g/day) in subcohort; ${ }^{3}$ Adjusted for age; ${ }^{4}$ Adjusted for age, family history of prostate cancer, socioeconomic status, total energy intake and total energy-adjusted fat intake. 
Table 4: Rate ratios (RR) and $95 \%$ confidence intervals $(95 \% \mathrm{Cl})$ per $10 \mathrm{~g}$ increment for prostate cancer according to intake of energy and energy-adjusted fat, for all cases and in subgroups based on tumor characterization, Netherlands Cohort Study (1986-1992).

\begin{tabular}{|c|c|c|c|c|c|}
\hline \multirow[t]{2}{*}{ Exposure } & \multirow{2}{*}{$\frac{\text { All tumors }}{(n=642)}$} & \multicolumn{2}{|l|}{ Tumor subgroups } & \multicolumn{2}{|l|}{ Tumor subgroups } \\
\hline & & $\begin{array}{l}\text { Latent tumors } \\
(n=115)\end{array}$ & $\begin{array}{l}\text { Nonlatent tumors } \\
(n=282)\end{array}$ & $\begin{array}{l}\text { Localized } \\
(n=226)\end{array}$ & $\begin{array}{l}\text { Advanced } \\
(n=213)\end{array}$ \\
\hline \multicolumn{6}{|l|}{ Energy intake } \\
\hline $\mathrm{RR}^{1.2}(95 \% \mathrm{Cl})$ & $1.00(0.98-1.02)$ & $1.01(0.97-1.05)$ & $1.00(0.97-1.02)$ & $1.03(1.00-1.06)$ & $0.99(0.96-1.02)$ \\
\hline \multicolumn{6}{|l|}{ Total fat } \\
\hline $\mathrm{RR}^{3}(95 \% \mathrm{Cl})$ & $1.02(0.95-1.09)$ & $1.07(0.93-1.22)$ & $1.00(0.91-1.10)$ & $1.03(0.93-1.14)$ & $1.00(0.90-1.11)$ \\
\hline \multicolumn{6}{|l|}{ Total fatty acids } \\
\hline $\mathrm{RR}^{3}(95 \% \mathrm{Cl})$ & $1.02(0.95-1.10)$ & $1.08(0.93-1.24)$ & $1.00(0.91-1.10)$ & $1.03(0.93-1.15)$ & $1.01(0.90-1.12)$ \\
\hline \multicolumn{6}{|l|}{ Saturated fatty acids } \\
\hline $\mathrm{RR}^{4}(95 \% \mathrm{Cl})$ & $1.09(0.92-1.28)$ & $1.02(0.72-1.43)$ & $1.06(0.84-1.33)$ & $1.08(0.86-1.36)$ & $1.02(0.80-1.31)$ \\
\hline \multicolumn{6}{|c|}{ Monounsaturated fatty acids } \\
\hline $\mathrm{RR}^{4}(95 \% \mathrm{Cl})$ & $1.25(0.89-1.75)$ & $1.45(0.76-2.75)$ & $1.30(0.84-2.02)$ & $1.12(0.70-1.80)$ & $1.23(0.74-2.03)$ \\
\hline \multicolumn{5}{|c|}{ Polyunsaturated fatty acids } & $0.98(0.80-1.19)$ \\
\hline \multicolumn{6}{|c|}{ Trans unsaturated fatty acids } \\
\hline $\mathrm{RR}^{4}(95 \% \mathrm{Cl})$ & $1.06(0.48-2.33)$ & $0.99(0.22-4.55)$ & $1.11(0.39-3.14)$ & $0.93(0.30-2.86)$ & $0.76(0.21-2.71)$ \\
\hline $\begin{array}{l}\text { Cis unsaturated fatt } \\
\qquad \operatorname{RR}^{4}(95 \% \mathrm{Cl})\end{array}$ & $0.94(0.82-1.08)$ & $0.96(0.74-1.26)$ & $0.97(0.81-1.16)$ & $0.94(0.78-1.14)$ & $1.02(0.83-1.25)$ \\
\hline \multicolumn{6}{|l|}{ Palmitic acid } \\
\hline $\mathrm{RR}^{4}(95 \% \mathrm{Cl})$ & $1.17(0.79-1.75)$ & $1.34(0.61-2.92)$ & $0.99(0.59-1.68)$ & $1.07(0.61-1.89)$ & $1.09(0.60-2.00)$ \\
\hline \multicolumn{6}{|l|}{ Stearic acid } \\
\hline $\mathrm{RR}^{4}(95 \% \mathrm{Cl})$ & $1.06(0.37-3.01)$ & $1.52(0.20-11.62)$ & $0.66(0.17-2.60)$ & $0.74(0.17-3.18)$ & $0.92(0.19-4.45)$ \\
\hline \multicolumn{6}{|l|}{ Oleic acid } \\
\hline $\mathrm{RR}^{4}(95 \% \mathrm{Cl})$ & $1.32(0.90-1.91)$ & $1.50(0.75-3.02)$ & $1.43(0.88-2.34)$ & $1.22(0.72-2.08)$ & $1.43(0.82-2.50)$ \\
\hline
\end{tabular}


Table 4 continued

\begin{tabular}{|c|c|c|c|c|c|}
\hline \multirow[t]{2}{*}{ Exposure } & \multirow{2}{*}{$\begin{array}{l}\text { All tumors } \\
(n=642)\end{array}$} & \multicolumn{2}{|l|}{ Tumor subgroups } & \multicolumn{2}{|l|}{ Tumor subgroups } \\
\hline & & $\begin{array}{l}\text { Latent tumors } \\
(n=115)\end{array}$ & $\begin{array}{l}\text { Nonlatent tumors } \\
(n=282)\end{array}$ & $\begin{array}{l}\text { Localized } \\
(n=226)\end{array}$ & $\begin{array}{l}\text { Advanced } \\
(n=213)\end{array}$ \\
\hline \multicolumn{6}{|l|}{ Linoleic acid } \\
\hline $\mathrm{RR}^{4}(95 \% \mathrm{Cl})$ & $0.92(0.81-1.05)$ & $0.92(0.71-1.19)$ & $0.94(0.79-1.12)$ & $0.94(0.78-1.13)$ & $0.98(0.80-1.19)$ \\
\hline \multicolumn{6}{|l|}{ Linolenic acid } \\
\hline $\mathrm{RR}^{4}(95 \% \mathrm{Cl})$ & $0.22(0.04-1.36)$ & $0.26(0.00-9.20)$ & $0.20(0.02-2.31)$ & $0.14(0.00-1.93)$ & $1.12(0.08-16.18)$ \\
\hline \multicolumn{6}{|l|}{ Arachidonic acid } \\
\hline $\mathrm{RR}^{4,5}(95 \% \mathrm{Cl})$ & $1.06(0.85-1.32)$ & $0.79(0.50-1.24)$ & $1.04(0.77-1.39)$ & $0.90(0.65-1.25)$ & $1.11(0.80-1.54)$ \\
\hline \multicolumn{6}{|l|}{ Eicosapentaenoic acid } \\
\hline $\mathrm{RR}^{4,5}(95 \% \mathrm{Cl})$ & $1.15(0.96-1.38)$ & $1.14(0.80-1.62)$ & $1.02(0.80-1.32)$ & $0.97(0.73-1.29)$ & $1.11(0.84-1.45)$ \\
\hline \multicolumn{6}{|l|}{ Docosahexaenoic acid } \\
\hline $\mathrm{RR}^{4,5}(95 \% \mathrm{Cl})$ & $1.08(0.96-1.21)$ & $1.08(0.86-1.36)$ & $1.00(0.85-1.17)$ & $0.95(0.79-1.15)$ & $1.09(0.92-1.29)$ \\
\hline
\end{tabular}

${ }^{1}$ Adjusted for age, family history of prostate cancer, and socioeconomic status; ${ }^{2} \mathrm{RR}$ per increment of $100 \mathrm{kcal} ;{ }^{3}$ Adjusted for age, family history of prostate cancer, socioeconomic status, and total energy intake; ${ }^{4}$ Adjusted for age, family history of prostate cancer, socioeconomic status, total energy intake, and total energy-adjusted fat intake; ${ }^{5} \mathrm{RR}$ per increment of $0.1 \mathrm{~g}$. 
diet in the NLCS can characterize dietary habits for a period of at least five years (34).

Furthermore, our study population consists of older subjects (aged 55-69 years) which were chosen because, in general, they show more stable dietary habits than younger individuals (21). Nevertheless, if diet in early adulthood might be important in prostate cancer etiology, our results may not reflect these effects.

Finally, residual confounding cannot be excluded and it is also important to note that multiple comparisons were made in our study. Therefore, although the power of the NLCS, based on 642 cases and 1525 subcohort members, was large, chance will have played a role in our findings and one needs to be stringent in interpreting the data.

Some remarks about other studies on energy and fat intake and prostate cancer risk are also in place. First, most evidence on fat intake in relation to prostate cancer risk comes from case-control studies $(7,8,13-17,35-45)$, there are only six cohort studies on the topic $(9-12,46,47)$. In general, case-control studies are more prone to bias than cohort studies. Second, there were only a few cohort studies $(9,10,12)$ and case-control studies $(13,15$, $16,37,43,44)$ that extensively evaluated the role of energy and fat intake. Other studies had limited exposure information. In addition, there was only a minority of studies in which energy intake was taken into account in evaluating fat intake $(9,13,15,16,43-45)$. Third, in several studies only limited adjustment for other possible confounders was made and residual confounding may have influenced results. Finally, evidence from earlier studies on fat in relation to prostate cancer risk is mostly based on a number of cases that was less than the 642 cases used in our study. To date, the largest cohort study on fat intake in relation to prostate cancer risk comprised 300 cases (9).

For intake of energy, total fatty acids, saturated fatty acids, and mono- and polyunsaturated fatty acids, no strong associations with overall risk of prostate cancer were observed in our study. In several other studies also no associations were reported for energy (44-46), total fat $(9,12,13,15,17,37-39,42,45,46)$, saturated fat $(9,13,45,46)$, unsaturated fat $(37$, $46)$, monounsaturated fat $(12,13,16,45)$ and polyunsaturated fat $(12,13,16,43,45)$. Nevertheless, also positive associations have been reported for energy $(13,15,43)$, total fat $(16,35,36,40,41)$, saturated fat $(12,15,16,37)$, monounsaturated $(9,15)$, and polyunsaturated fat $(15,44)$ and inverse association for energy $(39)$, total fat $(43,44)$, saturated fat $(43,44)$, and monounsaturated fat $(43,44)$.

The principal saturated fatty acids in the diet are palmitic and stearic acid for which we found no clear associations. In previous studies, for serum levels of palmitic acid, both no association (10) and a positive association (12) were reported and for serum levels of stearic acid, both a null association (12) and an inverse association (10) were observed. For oleic acid, the principal monounsaturated fatty acid in the diet, we observed a positive 
association. Positive associations have been reported before for serum levels of oleic acid $(10,12)$, but not for intake levels $(7,8)$. Our results indicated an inverse association between prostate cancer risk and intake of linoleic and linolenic acid. The suggested inverse association between prostate cancer risk and linoleic acid intake gains support from one other cohort study using serum levels (10), but in some other studies associations were less clear $(9,12,13)$, or even positive (14). From other studies on linolenic acid mostly increased estimates have been reported $(10,12,14)$, sometimes only for advanced tumors (9) and in one study no association was found (13). Finally, we found no clear associations for intake of arachidonic acid, eicosapentaenoic acid, and docosahexaenoic acid. From other studies also no clear or strong associations for these fatty acids have been reported $(9,10,12,14)$.

For none of our exposure variables of interest, except for intake of oleic acid, we found a stronger association with nonlatent or advanced prostate tumors. Our results, however, need to be interpreted carefully, because a considerable proportion of cases could not be classified into tumor subgroups. In two case-control studies also no evidence was found that fat intake is more strongly related to risk of advanced tumors than to overall prostate cancer risk $(12,13)$. Furthermore, in some other studies it was found that excluding focal microscopic cancers (10), or diffuse latent cancers (17) did not change results. However, in one cohort study total fat intake and intake of $\alpha$-linolenic acid were positively associated with advanced tumors, and not with all tumors (9). In one case-control study only saturated fat intake showed a stronger positive association with advanced tumors than with all prostate tumors (16), and in another case-control study fat intake was consistently stronger associated with aggressive prostate tumors, only for men aged 68 years and older (15). Thus far, conclusions regarding fat intake being particularly associated with advanced or aggressive prostate tumors seem preliminary.

In conclusion, from our study we found no evidence for a strong association between energy or fat intake, or intake of a number of specific fatty acids and prostate cancer risk. However, there was a suggestion for a positive association for intake of oleic acid and an inverse association for intake of linoleic acid and linolenic acid. Findings from other studies are very diverse, also with respect to nonlatent or advanced prostate tumors. More studies with extensive exposure information are needed to clarify the role of specific fatty acids in prostate cancer etiology.

\section{Acknowledgements}

We are indebted to the participants of this study and further wish to thank the regional cancer registries (IKA, IKL, IKMN, IKN, IKO, IKR, IKST, IKW, IKZ), the Dutch national data base of pathology (PALGA); V. Zambon for advice on coding tumors according to latency; A. Volovics for statistical advice; S. van de Crommert, J. Nelissen, C. de Zwart, P. Florax, 
W. van Dijk, C. Sloot, and A. Pisters for assistance; and H. van Montfort, R. Schmeitz, T. van Montfort, and M. de Leeuw for programming and statistical assistance.

\section{References}

1. Boyle P, Maisonneuve P, Napalkov P. Geographical and temporal patterns of incidence and mortality from prostate cancer. Urology 1995;46:47-55.

2. Giles G, Ireland P. Diet, nutrition and prostate cancer. Int J Cancer 1997; Suppl 10:13-17.

3. Kolonel LN. Nutrition and prostate cancer. Cancer Causes Control 1996;7:83-94.

4. Pienta KJ, Esper PS. Risk factors for prostate cancer. Ann Intern Med 1993;118:793-803.

5. Boyle P, Zaridze DG. Risk factors for prostate and testicular cancer. Eur J Cancer 1993;29a:1048-55.

6. World Cancer Research Fund/American Institute for Cancer Research. Food, nutrition, and the prevention of cancer: a global perspective. Washington: American Institute for Cancer Research, 1997.

7. Heshmat MY, Kaul L, Kovi J, et al. Nutrition and prostate cancer: a case-control study. Prostate 1985;6:7-17.

8. Kaul L, Heshmat MY, Kovi J, et al. The role of diet in prostate cancer. Nutr Cancer 1987;9:123-8.

9. Giovannucci E, Rimm EB, Colditz GA, et al. A prospective study of dietary fat and risk of prostate cancer. J Natl Cancer Inst 1993;85:1571-9.

10. Gann PH, Hennekens $\mathrm{CH}$, Sacks FM, et al. Prospective study of plasma fatty acids and risk of prostate cancer. J Natl Cancer Inst 1994;86:281-6.

11. Alberg AJ, Kafonek S, Huang HY, et al. Fatty acid levels and the subsequent development of prostate cancer. Proc Am Assoc Cancer Res 1996;37:281.

12. Harvei S, Bjerve KS, Tretli S, et al. Prediagnostic level of fatty acids in serum phospholipids: omega-3 and omega-6 fatty acids and the risk of prostate cancer. Int J Cancer 1997;71:545-51.

13. Andersson SO, Wolk A, Bergstrom R, et al. Energy, nutrient intake and prostate cancer risk: a population-based ease-control study in Sweden. Int J Cancer 1996;68:716-22.

14. Godley PA, Campbell MK, Gallagher $P$, et al. Biomarkers of essential fatty acid consumption and risk of prostatic carcinoma. Cancer Epidemiol Biomarkers Prev 1996;5:889-95.

15. West DW, Slattery ML, Robison LM, et al. Adult dietary intake and prostate cancer risk in Utah: a case-control study with special emphasis on aggressive tumors. Cancer Causes Control $1991 ; 2: 85-94$.

16. Whittemore AS, Kolonel LN, Wu AH, et al. Prostate cancer in relation to diet, physical activity, and body size in blacks, whites, and Asians in the United States and Canada. J Natl Cancer Inst 1995;87:652-61.

17. Ohno Y, Yoshida O, Oishi K, et al. Dietary beta-carotene and cancer of the prostate: a casecontrol study in Kyoto, Japan. Cancer Res 1988;48:1331-6.

18. Ross RK, Henderson BE. Do diet and androgens alter prostate cancer risk via a common etiologic pathway? J Natl Cancer Inst 1994;86:252-4.

19. Pandalai PK, Pilat MJ, Yamazaki K, et al. The effects of omega- 3 and omega- 6 fatty acids on in vitro prostate cancer growth. Anticancer Res 1996;16:815-20.

20. Rose DP, Connolly JM. Effects of fatty acids and eicosanoid synthesis inhibitors on the growth of two human prostate cancer cell lines. Prostate 1991;18:243-54.

21. Van den Brandt PA, Goldbohm RA, Van 't Veer P, et al. A large-scale prospective cohort study on diet and cancer in The Netherlands. J Clin Epidemiol 1990;43:285-95. 
22. Prentice RL. A case-cohort design for epidemiologic cohort studies and disease prevention trials. Biometrika 1986;73:1-11.

23. Van den Brandt PA, Schouten LJ, Goldbohm RA, et al. Development of a record linkage protocol for use in the Dutch Cancer Registry for Epidemiological Research. Int J Epidemiol 1990;19:5538.

24. Goldbohm RA, Van den Brandt PA, Dorant E. Estimation of the coverage of Dutch municipalities by cancer registries and PALGA based on hospital discharge data. Tijdschr Soc Gezondheidsz 1994;72:80-4.

25. Goldbohm RA, Van den Brandt PA, Brants HAM, et al. Validation of a dietary questionnaire used in a large-scale prospective cohort study on diet and cancer. Eur J Clin Nutr 1994;48:253-65.

26. Voorlichtingsbureau voor de Voeding. Nevo table: Dutch Food Composition Table 1986-1987. The Hague, 1986.

27. Van Poppel G, Van Erp-Baart M-A, Leth T, et al. Trans fatty acids in foods in Europe: the TRANSFAIR study. J Food Composition Anal 1998;11:112-36.

28. Willett $W$. Implications of total energy intake for epidemiologic analyses. In: Willett W, ed. Nutritional epidemiology. New York: Oxford University Press, 1990:245-71.

29. Baker J. GLIM 3.77 Reference Manual. Oxford: Numerical Algorithms Group, 1985.

30. Volovics A, van den Brandt PA. Methods for the analyses of case-cohort studies. Biom J 1997;2:195-214.

31. Schuurman AG, Goldbohm RA, Dorant E, et al. Vegetable and fruit consumption and prostate cancer risk: a cohort study in the Netherlands. Cancer Epidemiol Biom Prev 1998;7:673-80.

32. Murphy GP, Lawrence W, Lenhard RE. American Cancer Society textbook of clinical oncology (2nd edition): American Cancer Society, 1995.

33. Van den Brandt PA, Van 't Veer P, Goldbohm RA, et al. A prospective cohort study on dietary fat and the risk of postmenopausal breast cancer. Cancer Res 1993;53:75-82.

34. Goldbohm RA, Van 't Veer P, Van den Brandt PA, et al. Reproducibility of a food frequency questionnaire and stability of dietary habits determined from five annually repeated measurements. Eur J Clin Nutr 1995;49:420-9.

35. Graham S, Haughey B, Marshall J, et al. Diet in the epidemiology of carcinoma of the prostate gland. J Natl Cancer Inst 1983;70:687-92.

36. Ross RK, Shimizu H, Paganini Hill A, et al.. Case-control studies of prostate cancer in blacks and whites in southern California. J Natl Cancer Inst 1987;78:869-74.

37. Kolonel LN, Yoshizawa CN, Hankin JH. Diet and prostatic cancer: a case-control study in Hawaii. Am J Epidemiol 1988;127:999-1012.

38. Mettlin C, Selenskas S, Natarajan N, et al. Beta-carotene and animal fats and their relationship to prostate cancer risk. A case-control study. Cancer 1989;64:605-12.

39. Fincham SM, Hill GB, Hanson J, et al. Epidemiology of prostatic cancer: a case-control study. Prostate 1990;17:189-206.

40. Bravo MP, Castellanos E, del Rey Calero J. Dietary factors and prostatic cancer. Urol Int 1991;46:163-6.

41. Walker AR, Walker BF, Tsotetsi NG, et al. Case-control study of prostate cancer in black patients in Soweto, South Africa. Br J Cancer 1992;65:438-41.

42. Talamini R, Franceschi S, La Vecchia C, et al. Diet and prostatic cancer: a case-control study in northern Italy. Nutr Cancer 1992;18:277-86. 
43. Rohan TE, Howe GR, Burch JD, et al. Dietary factors and risk of prostate cancer: a case-control study in Ontario, Canada. Cancer Causes Control 1995;6:145-54.

44. Ghadirian P, Lacroix A, Maisonneuve $P$, et al. Nutritional factors and prostate cancer: a casecontrol study of French Canadians in Montreal, Canada. Cancer Causes Control 1996;7:428-36.

45. Key TJ, Silcocks PB, Davey GK, et al. A case-control study of diet and prostate cancer. Br J Cancer 1997;76:678-87.

46. Severson RK, Nomura AM, Grove JS, et al. A prospective study of demographics, diet, and prostate cancer among men of Japanese ancestry in Hawaii. Cancer Res 1989;49:1857-60.

47. Mills PK, Beeson WL, Phillips RL, et al. Cohort study of diet, lifestyle, and prostate cancer in Adventist men. Cancer 1989;64:598-604. 


\title{
Chapter 6
}

\section{A prospective cohort study on consumption}

\section{of alcoholic beverages in relation to prostate}

\section{cancer incidence ${ }^{1}$}

Agnes G. Schuurman ${ }^{2}$

R. Alexandra Goldbohm ${ }^{3}$

Piet A. van den Brandt ${ }^{2}$

\begin{abstract}
Alcohol consumption in relation to prostate cancer incidence was examined within the Netherlands Cohort Study. At baseline in 1986, 58,279 men aged 55-69 years completed a self-administered questionnaire on diet, consumption of alcoholic beverages and other risk factors for cancer. For data processing and analyses, the case-cohort approach was used. After 6.3 years of follow-up, 680 incident primary prostate cancer cases were available for analysis. In multivariate analyses adjusted for age, socioeconomic status and family history of prostate cancer, no association between total alcohol consumption, alcohol intake from beer and liquor and prostate cancer risk was found. When different types of wine were evaluated, increased associations were found for alcohol from white wine and fortified wines compared to nondrinkers, but not for red wine. The RRs $(95 \% \mathrm{Cl})$ in the intake category of $\geq 15 \mathrm{~g} /$ day were 3.25 (1.15-9.21) and 2.32 (1.16-4.67), respectively, after additional adjustment for total alcohol intake. There was, however, no significant trend in risk. Alcohol intake was more strongly related with localized than with advanced prostate tumors. Our results do not support an important role for alcohol in prostate cancer etiology. Nevertheless, for specific types of alcoholic beverages, particularly wines, a positive association was suggested which needs examination in further studies.
\end{abstract}

\footnotetext{
${ }^{1}$ Provisionally accepted by Cancer Causes \& Control

${ }^{2}$ Dept. of Epidemiology, Maastricht University, Maastricht

${ }^{3}$ Dept. of Consumer Research \& Epidemiology, TNO Nutrition and Food Research Institute, Zeist
} 


\section{Introduction}

Not much attention is given to alcohol consumption as a potential risk factor for prostate cancer in most reviews on this disease (1-5). Nevertheless, when we searched the literature, we found at least 14 cohort studies (6-19) and 23 case-control studies (20-42) in which alcohol consumption in relation to prostate cancer risk was investigated. In the majority of these studies, however, no extensive evaluation was made. For example, there were four cohort studies $(6,10,13,14)$ and 10 case-control studies $(21,22,25-27,33,36$, $38,40,41$ ) in which some data on different types of alcoholic beverages was presented. In some studies it was suggested that alcohol consumption might be associated with prostate cancer etiology $(11,13,14,21,22,25,26,36,40)$. There were only three studies in which alcohol consumption was investigated in subgroups of aggressive or advanced prostate tumors $(21,25,27)$. Therefore, data on the hypothesis that environmental factors might be more strongly related to advanced prostate cancer are still sparse as regards consumption of alcohol. We further investigated this relationship in the Netherlands Cohort Study (NLCS) on diet and cancer.

\section{Methods}

\section{The cohort}

The study design has been described elsewhere (43). In brief, the NLCS was initiated in September 1986. The male cohort consists of 58,279 men who completed the questionnaire on usual diet, alcohol consumption, personal and family history of cancer, other risk factors for cancer, and demographic data. The case-cohort approach (44) was used for data processing and analysis: for calculation of cancer incidence rates, the number of cancer cases for the entire cohort was used as the numerator, while person years at risk were estimated using a random male subcohort sample, which was sampled directly after identification of the total cohort. The male subcohort includes 1,688 men. Follow-up for incidence of prostate cancer was established by computerized record linkage with all nine cancer registries in The Netherlands, and with the Dutch national data base of pathology reports (PALGA) (45). The subcohort has been followed up biennially for vital status information. Completeness of follow-up of cancer was at least 96 percent (46) and no subcohort members were lost to follow-up. After a follow-up period of 6.3 years (September 1986-December 1992), 704 incident, microscopically or histologically confirmed, primary prostate cancer cases were detected.

\section{The questionnaire}

The self-administered questionnaire has been described elsewhere (47). Briefly, usual consumption of food and beverages during the year preceding the start of the study was assessed with a 150 -item semiquantitative food frequency questionnaire. Participants were asked to report their frequency of consumption of beer, red wine, white wine, sherry and other fortified wines, liqueurs and liquor (e.g. Dutch gin, brandy and whiskey). Categories 
ranged from 'never or less than once per month' to '6-7 days per week' and information on the number of glasses drunk per consumption day was also requested. Daily alcohol consumption (ethanol in $\mathrm{g} / \mathrm{day}$ ) was calculated using the computerized Dutch food composition table (48). The ethanol contents (per $100 \mathrm{~g}$ ) used were: $4 \mathrm{~g}$ for beer, $10 \mathrm{~g}$ for red and white wine, $14 \mathrm{~g}$ for fortified wines, $17 \mathrm{~g}$ for liqueurs, and $29 \mathrm{~g}$ for liquor. The questionnaire has been validated against a 9-day diet record; the Spearman correlation coefficient for alcoholic beverages was 0.89 for all subjects and 0.85 for users of alcoholic beverages (47).

\section{Data analysis}

Questionnaire data were key-entered twice and processed for all incident cases in the cohort and for all subcohort members in a manner blinded with respect to case/subcohort status. This was done in order to minimize observer bias in coding and interpretation of the data. After excluding prevalent cancer cases other than skin cancer from the subcohort, 1630 men remained for analysis. Furthermore, subjects with incomplete alcohol data were also excluded. Alcohol data were considered incomplete when all questions on consumption frequency of alcoholic beverages were left blank and two questions on alcohol consumption pattern did not indicate that the subject was a nondrinker. These two questions concerned alcohol intake during the past week and five years previously $(49,50)$. The results presented here are based on 680 incident prostate cancer cases and 1591 subcohort members for whom alcohol data were considered complete.

The associations between alcohol consumption and some potential confounding factors for prostate cancer were evaluated among men in the subcohort, by comparing the proportion of men with these risk factors across categories of alcohol consumption. Variables that were considered as potential confounders were age, prostate cancer in first degree relatives (father and brothers), and socioeconomic status. Because in previous analyses no associations were observed between total vegetable and fruit consumption (51) and total energy and fat intake and prostate cancer risk, these factors were not considered as confounding factors. Rate ratios (RRs) and $95 \%$ confidence intervals (95\% CI) were computed using the GLIM statistical package (52). Exponentially distributed survival times were assumed in the follow-up period. Since standard software was not available, specific macros were developed to account for the additional variance introduced by using the subcohort instead of the entire cohort (53). Tests for trend were based on likelihood ratio tests and two-sided P-values are used throughout this report.

Age-adjusted as well as multivariate-adjusted analyses were done for both categorized and continuous variables; in addition to the abovementioned confounding factors, alcohol intake from specific types of alcoholic beverages was also adjusted for total alcohol intake. Cases detected during the first two years of follow-up were additionally excluded from analyses to 
evaluate whether preclinical symptoms might have influenced results. Analyses were also done in case subgroups of localized (TO-2, MO) and advanced (T3-4, MO; TO-4, M1) prostate tumors.

Table 1: Distribution of potential confounding factors for prostate cancer in male subcohort members with complete alcohol consumption data, Netherlands Cohort Study (1986-1992).

\begin{tabular}{|c|c|c|c|}
\hline \multirow[b]{3}{*}{ Potential confounding variable } & \multicolumn{3}{|c|}{ Percentage with risk factor } \\
\hline & \multirow[b]{2}{*}{ Nondrinkers $(n=246)$} & \multicolumn{2}{|c|}{ Drinkers } \\
\hline & & $<15$ g/day $(n=767)$ & $\geq 15 \mathrm{~g} /$ day $(n=578)$ \\
\hline \multicolumn{4}{|l|}{ Age (years) } \\
\hline $55-59$ & 32.9 & 40.2 & 37.5 \\
\hline $60-64$ & 31.7 & 34.6 & 36.0 \\
\hline $65-69$ & 35.4 & 25.3 & 26.5 \\
\hline \multicolumn{4}{|l|}{ Family history of prostate cancer } \\
\hline No & 98.8 & 96.9 & 97.6 \\
\hline Yes & 1.2 & 3.1 & 2.4 \\
\hline \multicolumn{4}{|l|}{ Socioeconomic status } \\
\hline Low & 55.7 & 50.4 & 43.5 \\
\hline Medium & 32.4 & 34.5 & 33.7 \\
\hline High & 11.9 & 15.1 & 22.8 \\
\hline
\end{tabular}

' Low is defined as primary school with/without lower vocational education, medium as secondary school or medium level vocational education, high as university or higher level vocational education.

\section{Results}

The percentages of nondrinkers were 15.5 and 16.2, respectively, for subcohort members and cases. Among drinking men, the mean total alcohol intake (SD) was 17.1 (16.6) $\mathrm{g} /$ day for subcohort members and 17.7 (15.9) g/day for prostate cancer cases. Data on the association between alcohol consumption and some potential confounding factors among subcohort members are shown in Table 1. The proportion of older men was somewhat higher among nondrinkers compared to drinkers. Nondrinkers less often had a positive family history of prostate cancer and more often had a lower socioeconomic status than drinkers.

In Table 2 rate ratios of prostate cancer for both categorized and continuous variables of alcohol intake are shown. Total alcohol consumption was not related to prostate cancer risk in the NLCS. For men consuming $30 \mathrm{~g}$ alcohol per day or more the RR was $1.09(95 \% \mathrm{Cl}$ : 0.77-1.55) compared to men who are nondrinkers. There was also no trend in risk. The RR for intake of alcohol from beer was decreased in the highest intake category (RR for $\geq 30$ g/day vs nondrinkers was $0.47,95 \% \mathrm{Cl}: 0.17-1.30)$. In intermediate categories no 
Table 2: Rate ratios (RRs) and $95 \%$ confidence intervals (95\% Cl) for prostate cancer according to intake of alcohol, Netherlands Cohort Study (1986-1992).

\begin{tabular}{|c|c|c|c|c|}
\hline \multirow[b]{2}{*}{$\begin{array}{l}\text { Alcohol intake } \\
\text { (g/day) }\end{array}$} & \multicolumn{2}{|l|}{ Age-adjusted } & \multicolumn{2}{|c|}{ Multivariate adjusted ${ }^{1}$} \\
\hline & $\begin{array}{l}\text { No of cases/ } \\
\text { personyears in } \\
\text { subcohort }\end{array}$ & $\mathrm{RR}(95 \% \mathrm{Cl})$ & $\begin{array}{l}\text { No of cases/ } \\
\text { personyears in } \\
\text { subcohort }\end{array}$ & $\mathrm{RR}(95 \% \mathrm{Cl})$ \\
\hline Nondrinkers ${ }^{2}$ & $110 / 1440$ & 1.00 & $109 / 1428$ & 1.00 \\
\hline $\begin{array}{c}\text { Total alcohol } \\
0.1-4 \\
5-14 \\
15-29 \\
\geq 30\end{array}$ & $\begin{array}{l}143 / 1947 \\
161 / 2637 \\
162 / 2181 \\
104 / 1324\end{array}$ & $\begin{array}{l}1.13(0.82-1.54) \\
0.95(0.70-1.28) \\
1.08(0.79-1.46) \\
1.19(0.85-1.68) \\
\text { P-trend } 0.37\end{array}$ & $\begin{array}{l}143 / 1931 \\
161 / 2624 \\
161 / 2162 \\
101 / 1324\end{array}$ & $\begin{array}{l}1.11(0.81-1.53) \\
0.92(0.68-1.26) \\
1.05(0.77-1.44) \\
1.09(0.77-1.55) \\
\text { P-trend } 0.74\end{array}$ \\
\hline Continuous, $5 \mathrm{~g}$ increment & & $1.01(0.98-1.04)$ & & $1.00(0.97-1.03)$ \\
\hline $\begin{array}{l}\text { Alcohol from beer } \\
\begin{array}{l}\text { no beer } \\
0.1-4 \\
5-14 \\
15-29 \\
\geq 30\end{array}\end{array}$ & $\begin{array}{l}213 / 2621 \\
220 / 3376 \\
112 / 1594 \\
19 / 329 \\
6 / 170\end{array}$ & $\begin{array}{l}1.12(0.84-1.50) \\
1.00(0.75-1.34) \\
1.16(0.83-1.62) \\
1.09(0.60-2.00) \\
0.51(0.20-1.30) \\
\text { P-trend } 0.76\end{array}$ & $\begin{array}{l}212 / 2608 \\
218 / 3341 \\
111 / 1594 \\
19 / 329 \\
6 / 170\end{array}$ & $\begin{array}{l}1.06(0.78-1.45) \\
0.93(0.68-1.28) \\
1.07(0.74-1.56) \\
1.01(0.52-1.96) \\
0.47(0.17-1.30) \\
\text { P-trend } 0.48\end{array}$ \\
\hline Continuous, $5 \mathrm{~g}$ increment & & $0.97(0.91-1.03)$ & & $0.96(0.89-1.03)$ \\
\hline $\begin{array}{l}\text { Alcohol from wine } \\
\text { no wine } \\
0.1-4 \\
5-14 \\
15-29 \\
\geq 30\end{array}$ & $\begin{array}{l}220 / 3273 \\
199 / 2685 \\
91 / 1421 \\
40 / 575 \\
20 / 135\end{array}$ & $\begin{array}{l}1.04(0.77-1.38) \\
1.08(0.80-1.45) \\
0.97(0.69-1.38) \\
1.15(0.73-1.82) \\
2.32(1.15-4.65) \\
\text { P-trend } 0.12\end{array}$ & $\begin{array}{l}219 / 3239 \\
198 / 2679 \\
90 / 1415 \\
39 / 575 \\
20 / 135\end{array}$ & $\begin{array}{l}1.10(0.80-1.51) \\
1.05(0.77-1.44) \\
0.94(0.64-1.39) \\
1.08(0.65-1.81) \\
2.32(1.02-5.29) \\
\text { P-trend } 0.67\end{array}$ \\
\hline Continuous, $5 \mathrm{~g}$ increment & & $1.06(1.00-1.12)$ & & $1.05(0.97-1.12)$ \\
\hline $\begin{array}{l}\text { Alcohol from liquor } \\
\begin{array}{l}\text { no liquor } \\
0.1-4 \\
5-14 \\
15-29 \\
\geq 30\end{array}\end{array}$ & $\begin{array}{l}172 / 2616 \\
155 / 2211 \\
109 / 1595 \\
94 / 1149 \\
40 / 518\end{array}$ & $\begin{array}{l}1.09(0.80-1.47) \\
1.06(0.78-1.44) \\
1.00(0.72-1.40) \\
1.08(0.76-1.54) \\
1.17(0.73-1.86) \\
\text { P-trend } 0.65\end{array}$ & $\begin{array}{l}172 / 2597 \\
154 / 2208 \\
109 / 1589 \\
92 / 1130 \\
39 / 518\end{array}$ & $\begin{array}{l}1.06(0.77-1.46) \\
1.02(0.74-1.41) \\
0.97(0.67-1.40) \\
1.07(0.69-1.64) \\
1.07(0.56-2.04) \\
\text { P-trend } 0.96\end{array}$ \\
\hline Continuous, $5 \mathrm{~g}$ increment & & $1.01(0.97-1.05)$ & & $1.00(0.94-1.06)$ \\
\hline
\end{tabular}

${ }^{1}$ Adjusted for age, family history of prostate cancer, socioeconomic status, and total alcohol intake; ${ }^{2}$ Reference category; ${ }^{3}$ Not adjusted for total alcohol intake. 
associations were noted. For alcohol from liquor, no clear associations with prostate cancer risk were observed. For intake of alcohol from wine, a significant increased risk was found for the highest vs the lowest intake category ( $R R=2.32,95 \% \mathrm{Cl}: 1.02-5.29)$. In the intermediate intake categories no increased risk was observed. The RR for the continuous variable was 1.05 (95\% $\mathrm{Cl}: 0.97-1.12)$ per $5 \mathrm{~g}$ increment.

In Table 3 alcohol intake is evaluated separately for different types of wine: red wine, white wine, fortified wines and liqueurs. Because of sparse data, the highest intake category comprised men consuming $15 \mathrm{~g}$ alcohol or more. For liqueurs, there were only two exposure categories. No associations with risk of prostate cancer were found for intake of alcohol from red wine and liqueurs. For intake of alcohol from white wine, an increased risk was observed with higher consumption, but only in the highest intake category $(R R=3.25$, $95 \% \mathrm{Cl}: 1.15-9.21)$. Also for intake of alcohol from fortified wines, only in the highest intake category an increased risk was found $(\mathrm{RR}=2.32,95 \% \mathrm{Cl}: 1.16-4.67)$ and no dose-response relationship was observed. Effect estimates for continuous variables were not statistically significant. The results shown in Tables 2 and 3 did not materially change after exclusion of cases detected in the first two years of follow-up (data not shown).

Alcohol intake was also evaluated in subgroups of localized and advanced prostate tumors and the results are shown in Table 4. The two highest categories of alcohol from beer (1529 and $\geq 30 \mathrm{~g} /$ day) were combined to allow for a reasonable number of cases in the subgroup analyses. Furthermore, because the effect of alcohol from white wine and alcohol from fortified wines was similar in the overall analysis, these two sources of alcohol intake were combined in order to attain a reasonable number of cases. The number of cases for alcohol from liqueurs was not sufficient to conduct meaningful subgroup analyses. Overall, alcohol intake showed stronger associations with localized prostate tumors than with advanced prostate tumors. In the subgroup of localized prostate tumors, all RRs for total alcohol intake were above the null value, but only in the intake category of $0.1-4.9 \mathrm{~g} / \mathrm{day}$ a significantly increased risk was found ( $R R=1.65,95 \% \mathrm{Cl}: 1.04-2.62)$. No associations with advanced prostate tumors were found. Alcohol from beer showed no clear associations with risk of either localized or advanced prostate tumors. For alcohol from wine, all RRs were increased in the subgroup of localized prostate tumors. Subjects consuming $\geq \mathbf{3 0 ~ g}$ alcohol per day from wine had a RR of 4.62 (95\% Cl: 1.59-13.44) compared to nondrinkers. Among advanced prostate tumors, only the RR in the highest intake category was increased ( $R R=2.93,95 \% \mathrm{Cl}: 1.01-8.49)$. In both subgroups, however, no trend in risk was observed. Although all RRs were increased for intake of alcohol from liquor in the localized prostate tumors subgroup, all but one RRs were statistically nonsignificant and a doseresponse relationship was not observed ( $p$-trend $=0.08$ ). For advanced prostate tumors no associations with intake of alcohol from liquor were apparent. No trend in risk was found for intake of alcohol from red wine in both subgroups. A borderline significant positive trend in 
risk was observed for the combined intake of alcohol from white wine and fortified wines among localized prostate tumors ( $p$-trend 0.06). Compared to nondrinkers, men with an intake of $\geq 15 \mathrm{~g} /$ day had a RR of $3.60(95 \% \mathrm{Cl}: 1.54-8.44)$. Among the advanced prostate tumor group, the effect estimate for the same contrast was 2.24 (95\% Cl: 0.95-5.24).

Table 3: Rate ratios (RRs) and 95\% confidence intervals (95\% Cl) for prostate cancer according to intake of alcohol, Netherlands Cohort Study (1986-1992).

\begin{tabular}{|c|c|c|c|c|}
\hline \multirow[b]{2}{*}{$\begin{array}{l}\text { Alcohol intake } \\
\text { (g/day) }\end{array}$} & \multicolumn{2}{|l|}{ Age-adjusted } & \multicolumn{2}{|c|}{ Multivariate adjusted ${ }^{1}$} \\
\hline & $\begin{array}{l}\text { No of cases/ } \\
\text { personyears in } \\
\text { subcohort }\end{array}$ & $\mathrm{RR}(95 \% \mathrm{Cl})$ & $\begin{array}{l}\text { No of cases/ } \\
\text { personyears in } \\
\text { subcohort }\end{array}$ & $\mathrm{RR}(95 \% \mathrm{Cl})$ \\
\hline Nondrinkers ${ }^{2}$ & $110 / 1440$ & 1.00 & $109 / 1428$ & 1.00 \\
\hline $\begin{array}{l}\text { Alcohol from red wine } \\
\text { no red wine } \\
0.1-4 \\
5-14 \\
\geq 15\end{array}$ & $\begin{array}{l}349 / 5071 \\
151 / 2178 \\
55 / 602 \\
15 / 239\end{array}$ & $\begin{array}{l}1.04(0.79-1.36) \\
1.05(0.77-1.43) \\
1.44(0.94-2.20) \\
0.95(0.49-1.84) \\
\text { P-trend } 0.21\end{array}$ & $\begin{array}{l}347 / 5030 \\
150 / 2178 \\
54 / 596 \\
15 / 239\end{array}$ & $\begin{array}{l}1.04(0.78-1.40) \\
0.95(0.67-1.34) \\
1.26(0.78-2.02) \\
0.82(0.40-1.70) \\
\text { P-trend } 1.00\end{array}$ \\
\hline Continuous, $5 \mathrm{~g}$ increment & & $1.03(0.94-1.14)$ & & $0.99(0.89-1.11)$ \\
\hline $\begin{array}{l}\text { Alcohol from white wine } \\
\text { no white wine } \\
\begin{array}{l}0.1-4 \\
5-14 \\
\geq 15\end{array}\end{array}$ & $\begin{array}{l}362 / 5274 \\
180 / 2551 \\
20 / 226 \\
8 / 38\end{array}$ & $\begin{array}{l}1.05(0.80-1.37) \\
1.06(0.78-1.43) \\
1.25(0.67-2.33) \\
3.38(1.36-8.45) \\
\text { P-trend } 0.13\end{array}$ & $\begin{array}{l}359 / 5233 \\
180 / 2545 \\
19 / 226 \\
8 / 38\end{array}$ & $\begin{array}{l}1.07(0.80-1.43) \\
1.00(0.72-1.39) \\
1.15(0.60-2.24) \\
3.25(1.15-9.21) \\
\text { P-trend } 0.54\end{array}$ \\
\hline Continuous, $5 \mathrm{~g}$ increment & & $1.24(1.04-1.47)$ & & $1.22(0.99-1.49)$ \\
\hline $\begin{array}{l}\text { Alcohol from fortified wines } \\
\text { no fortified wines } \\
\begin{array}{l}0.1-4 \\
5-14 \\
\geq 15\end{array}\end{array}$ & $\begin{array}{l}411 / 5772 \\
108 / 1599 \\
27 / 557 \\
24 / 161\end{array}$ & $\begin{array}{l}1.09(0.84-1.43) \\
0.97(0.69-1.35) \\
0.74(0.44-1.22) \\
2.46(1.29-4.69) \\
\text { P-trend } 0.53\end{array}$ & $\begin{array}{l}408 / 5731 \\
108 / 1593 \\
26 / 557 \\
24 / 161\end{array}$ & $\begin{array}{l}1.10(0.82-1.47) \\
0.88(0.62-1.26) \\
0.66(0.38-1.13) \\
2.32(1.16-4.67) \\
\text { P-trend } 0.77\end{array}$ \\
\hline Continuous, $5 \mathrm{~g}$ increment & & $1.08(0.98-1.19)$ & & $1.07(0.96-1.19)$ \\
\hline $\begin{array}{l}\text { Alcohol from liqueur } \\
\text { no liqueur } \\
0.1-4 \\
\geq 5\end{array}$ & $\begin{array}{l}511 / 7313 \\
52 / 669 \\
7 / 107\end{array}$ & $\begin{array}{l}1.06(0.81-1.37) \\
1.16(0.76-1.77) \\
1.17(0.46-2.99) \\
\text { P-trend } 0.37\end{array}$ & $\begin{array}{l}507 / 7266 \\
52 / 669 \\
7 / 107\end{array}$ & $\begin{array}{l}1.01(0.75-1.34) \\
1.13(0.74-1.74) \\
1.17(0.46-3.00) \\
\text { P-trend } 0.48\end{array}$ \\
\hline Continuous, $5 \mathrm{~g}$ increment & & $0.91(0.59-1.41)$ & & $0.94(0.61-1.45)$ \\
\hline
\end{tabular}

'Adjusted for age, family history of prostate cancer, socioeconomic status, and total alcohol intake; ${ }^{2}$ Reference category. 
Table 4: Rate ratios (RR) and $95 \%$ confidence intervals $(95 \% \mathrm{Cl})$ for prostate cancer according to alcohol intake in subgroups of localized and advanced prostate tumors, Netherlands Cohort Study (1986-1992).

\begin{tabular}{|c|c|c|c|c|c|}
\hline \multirow[b]{2}{*}{$\begin{array}{l}\text { Alcohol intake } \\
\text { (g/day) }\end{array}$} & \multirow[b]{2}{*}{$\begin{array}{l}\text { Person years } \\
\text { in subcohort }\end{array}$} & \multicolumn{2}{|c|}{$\begin{array}{l}\text { Localized prostate tumors } \\
(\text { (TO-2, MO); } n=247\end{array}$} & \multicolumn{2}{|c|}{$\begin{array}{l}\text { Advanced prostate tumors } \\
(\mathrm{T} 3-4, \mathrm{M} 0 ; \mathrm{TO}-4, \mathrm{M} 1) ; \mathrm{n}=236\end{array}$} \\
\hline & & $\begin{array}{l}\text { No of } \\
\text { cases }\end{array}$ & $\operatorname{RR}(95 \% \mathrm{Cl})^{1}$ & $\begin{array}{l}\text { No of } \\
\text { cases }\end{array}$ & $\operatorname{RR}(95 \% \mathrm{Cl})^{1}$ \\
\hline Nondrinkers ${ }^{2}$ & 1428 & 28 & 1.00 & 34 & 1.00 \\
\hline $\begin{array}{c}\text { Total alcohol } \\
\quad 0.1-4 \\
5-14 \\
15-29 \\
\geq 30\end{array}$ & $\begin{array}{l}1931 \\
2624 \\
2162 \\
1324\end{array}$ & $\begin{array}{l}59 \\
55 \\
61 \\
33\end{array}$ & $\begin{array}{l}1.65(1.04-2.62) \\
1.14(0.72-1.81) \\
1.43(0.91-2.27) \\
1.28(0.76-2.18) \\
\text { P-trend } 0.67\end{array}$ & $\begin{array}{l}44 \\
63 \\
49 \\
35\end{array}$ & $\begin{array}{l}0.99(0.62-1.59) \\
1.06(0.68-1.63) \\
0.93(0.59-1.48) \\
1.09(0.66-1.80) \\
\text { P-trend } 0.94\end{array}$ \\
\hline $\begin{array}{l}\text { Alcohol from beer } \\
\text { no beer } \\
0.1-4 \\
5-14 \\
\geq 15\end{array}$ & $\begin{array}{c}2608 \\
3341 \\
1594 \\
499\end{array}$ & $\begin{array}{c}84 \\
82 \\
35 \\
7\end{array}$ & $\begin{array}{l}1.71(1.05-2.77) \\
1.43(0.88-2.34) \\
1.40(0.78-2.53) \\
0.96(0.36-2.59) \\
\text { P-trend } 1.00\end{array}$ & $\begin{array}{c}63 \\
81 \\
40 \\
7\end{array}$ & $\begin{array}{l}0.99(0.62-1.60) \\
1.07(0.67-1.71) \\
1.22(0.70-2.13) \\
0.72(0.27-1.92) \\
\text { P-trend } 0.65\end{array}$ \\
\hline $\begin{array}{l}\text { Alcohol from wine } \\
\text { no wine } \\
0.1-4 \\
5-14 \\
15-29 \\
\geq 30\end{array}$ & $\begin{array}{c}3239 \\
2679 \\
1415 \\
575 \\
135\end{array}$ & $\begin{array}{c}87 \\
69 \\
33 \\
11 \\
8\end{array}$ & $\begin{array}{l}1.87(1.14-3.07) \\
1.50(0.92-2.46) \\
1.48(0.82-2.68) \\
1.37(0.60-3.12) \\
4.62(1.59-13.44) \\
\text { P-trend } 0.38\end{array}$ & $\begin{array}{c}65 \\
72 \\
32 \\
14 \\
8\end{array}$ & $\begin{array}{l}1.03(0.63-1.67) \\
1.20(0.75-1.92) \\
1.04(0.58-1.85) \\
1.19(0.55-2.54) \\
2.93(1.01-8.49) \\
\text { P-trend } 0.25\end{array}$ \\
\hline $\begin{array}{l}\text { Alcohol from liquor } \\
\text { no liquor } \\
0.1-4 \\
5-14 \\
15-29 \\
\geq 30\end{array}$ & $\begin{array}{c}2597 \\
2208 \\
1589 \\
1130 \\
518\end{array}$ & $\begin{array}{l}57 \\
63 \\
41 \\
33 \\
14\end{array}$ & $\begin{array}{l}1.47(0.89-2.45) \\
1.72(1.05-2.84) \\
1.58(0.89-2.80) \\
1.76(0.90-3.43) \\
1.99(0.75-5.30) \\
\text { P-trend } 0.08\end{array}$ & $\begin{array}{l}58 \\
58 \\
35 \\
25 \\
15\end{array}$ & $\begin{array}{l}1.07(0.66-1.74) \\
1.18(0.73-1.90) \\
0.94(0.53-1.64) \\
0.88(0.45-1.72) \\
1.19(0.47-3.02) \\
\text { P-trend } 0.78\end{array}$ \\
\hline $\begin{array}{l}\text { Alcohol from red wine } \\
\text { no red wine } \\
0.1-4 \\
5-14 \\
\geq 15\end{array}$ & $\begin{array}{c}5030 \\
2178 \\
596 \\
239\end{array}$ & $\begin{array}{c}127 \\
60 \\
16 \\
5\end{array}$ & $\begin{array}{l}1.57(0.98-2.50) \\
1.58(0.94-2.68) \\
1.61(0.77-3.36) \\
1.22(0.40-3.68) \\
\text { P-trend } 0.32\end{array}$ & $\begin{array}{c}116 \\
46 \\
24 \\
5\end{array}$ & $\begin{array}{l}1.13(0.72-1.75) \\
0.91(0.53-1.51) \\
1.68(0.87-3.25) \\
0.84(0.28-2.52) \\
\text { P-trend } 0.70\end{array}$ \\
\hline $\begin{array}{l}\text { Alcohol from whitel } \\
\text { fortified wine } \\
\text { no whitel fortified wine } \\
0.1-4 \\
5-14 \\
\geq 15\end{array}$ & $\begin{array}{c}44210 \\
2804 \\
785 \\
243\end{array}$ & $\begin{array}{c}107 \\
70 \\
19 \\
12\end{array}$ & $\begin{array}{l}1.71(1.06-2.76) \\
1.45(0.88-2.40) \\
1.61(0.82-3.17) \\
3.60(1.54-8.44) \\
\text { P-trend } 0.06\end{array}$ & $\begin{array}{l}87 \\
73 \\
20 \\
11\end{array}$ & $\begin{array}{l}1.04(0.65-1.65) \\
1.13(0.70-1.81) \\
1.21(0.63-2.32) \\
2.24(0.95-5.24) \\
\text { P-trend } 0.12\end{array}$ \\
\hline
\end{tabular}

'Adjusted for age, family history of prostate cancer, socioeconomic status, and total alcohol intake; ${ }^{2}$ Reference category; ${ }^{3}$ Not adjusted for total alcohol intake. 


\section{Discussion}

In this study we found no evidence that total alcohol consumption is related to the risk of developing prostate cancer. However, when specific types of alcohol were investigated, high intakes of alcohol from white wine and fortified wines were associated with increased risks. No clear associations existed between alcohol intake from beer, liquor, red wine, and liqueurs and prostate cancer risk. We found no evidence that consumption of alcohol is more related to advanced prostate tumors. On the contrary, alcohol intake showed mostly positive associations in the subgroup of localized prostate tumors.

An important strength of our study is the prospective design, therefore, recall bias is unlikely. Furthermore, selection bias due to loss to follow-up did not influence our results because of the high completeness of follow-up of cases and subcohort members in the $\operatorname{NLCS}(46,54)$. Another advantage is that the assessment of alcohol consumption in the NLCS allowed us to extensively evaluate a possible association with prostate cancer risk. Not only overall consumption of alcohol, but also different types of alcoholic beverages were investigated. Moreover, consumption of several types of alcoholic beverages was also evaluated within case subgroups based on tumor characterisation. Misclassification of exposure is a possible limitation of our study. However, if misclassification has occurred, this is expected to be nondifferential and risk estimates are most likely biased towards the null value. Abstainers and ex-drinkers were not separated in our study, but were included in our reference category of nondrinkers. Ex-drinkers may differ in prostate cancer risk from abstainers and therefore, our estimated risks might be biased in either direction. Thus far, however, an association between alcohol and prostate cancer has not been established definitely and it is also not known whether or how the timing of alcohol consumption might play a role. Further studies are needed to evaluate this matter. We considered most of the factors that have been implied in prostate cancer etiology and factors showing an association with prostate cancer risk in the NLCS were included into the multivariate model. Thus, total energy and fat intake were not included and also vegetable and fruit consumption were not included. Certainly, confounding by unmeasured or other unknown factors cannot be excluded.

In the majority of cohort $(6-10,12,15-19)$ and case-control studies $(20,23,24,27,29-31$, $33-35,37,39,41,42)$ no association between total alcohol consumption and prostate cancer risk was found and this was confirmed in the NLCS. In one cohort study in Japan, alcohol consumption was positively associated with prostate cancer risk and when specific alcoholic beverages were investigated, a significant positive association for consumption of shochu was noted (14). In another cohort study alcohol abusers developed prostate cancer more often than expected (11). In none of the cohort studies was a decreased risk observed. In case-control studies a few positive associations $(21,25,26)$ as well as one inverse association (22) between total alcohol consumption and prostate cancer risk were noted. 
Although a nonsignificant decreased risk was suggested in the highest intake category of beer in our study, in the other exposure categories no association was found. Other cohort $(6,10,13,14)$ and case-control studies $(25,27,33,36,38,41)$ support a conclusion of no association between consumption of beer and risk of prostate cancer. There was one cohort study in which ex-users of beer showed an increased risk of prostate cancer mortality (13). In three case-control studies beer consumption increased prostate cancer risk $(21,26,40)$ and in two of these studies also a significant trend in risk was reported (21, 26). However, in one of these case-control studies other types of alcohol were also associated with an increased prostate cancer risk and therefore it was concluded that the association was due to alcohol and not due to some components of specific types of beverages (21).

No association was found between red wine and prostate cancer risk within the NLCS, but for consumption of white wine and fortified wines increased risks were observed at high intakes. Only in two other cohort studies wine consumption was evaluated and no associations were noted $(6,10)$. Also in most case-control studies no associations were found $(21,25,27,32,33,38,41)$, although some positive $(26,40)$ and inverse associations (36) were indicated. Men consuming daily white wine or fortified wines might be a quite distinctive socioeconomic group of the highest level. Therefore, residual confounding by socioeconomic status or other factors related to socioeconomic status might be an explanation for our observed associations regarding alcohol intake from white wine and fortified wines. This explanation is further supported by the fact that for intake of alcohol from beer an inverse association was observed in the highest exposure category. Among older subjects, high intake of beer was more common in the lower than in the higher socioeconomic classes.

Consumption of liquor was, as in the NLCS, not associated with prostate cancer risk in most other epidemiological studies $(6,10,13,26-28,33,38,40,41)$. Nevertheless, in three case-control studies a positive association was observed $(21,25,36)$ and there was a significant trend in risk in one of these studies (21).

The biological pathway relating alcohol consumption to prostate cancer risk is largely unknown, but some mechanisms have been proposed to both explain an inverse as well as a positive association between alcohol consumption and prostate cancer risk. A decreased risk has been explained by the fact that ethanol has been found to decrease plasma testosterone levels (55) which might decrease prostate cancer risk $(25,26)$. An increased risk of prostate cancer associated with alcohol consumption has been explained by metabolic activation of environmental nitrosamines by ethanol $(21,26)$. Furthermore, alcohol contains contaminants that may be carcinogenic and the major metabolite of alcohol, acetaldehyde, is also known to be carcinogenic and teratogenic (21). 
Immunodepression might also be a pathway through which tumor growth is stimulated by consumption of alcohol (56). Indirect effects of alcohol consumption on prostate cancer risk could be nutrient displacement, malabsorption, liver effects and related pathology $(21,56)$. A specific hypothesis concerning beer consumption that has been proposed is that the nitrosamine content of the beer in the past might be responsible for an increased risk of prostate cancer (26). Finally, the observed positive associations of high white wine and fortified wine consumption with prostate cancer may be due other unknown potential biological pathways, or due to bias or confounding.

The hypothesis that environmental factors (alcohol consumption) are more strongly related to advanced prostate tumors was not confirmed in this investigation. On the contrary, for different types of alcoholic beverages, observed associations were most pronounced in the subgroup of localized prostate tumors. The stronger associations with localized rather than advanced prostate cancer might suggest a social class effect related to increased medical consumption among men with a higher socioeconomic status. However, this issue was separately investigated in the NLCS and no evidence for this explanation was found (submitted for publication). Results from other studies are also somewhat inconsistent and do not uniformely point into a direction of stronger associations with advanced prostate tumors $(21,25,27)$.

In summary, although total alcohol consumption seems not to be related to prostate cancer risk, a positive effect of high intakes of specific types of alcoholic beverages, i.e. white wine and fortified wines, cannot be excluded. Thus far, however, data from epidemiological studies on these types of wine are sparse. Also because a possible biological pathway by which the observed effect can be explained is unknown, this topic deserves further investigation.

\section{Acknowledgements}

We are indebted to the participants of this study and further wish to thank the regional cancer registries (IKA, IKL, IKMN, IKN, IKO, IKR, IKST, IKW, IKZ), and the Dutch national data base of pathology (PALGA); A. Volovics for statistical advice; S. van de Crommert, J. Nelissen, H. Brants, M. Moll, W. van Dijk, C. Sloot, P. Florax and A. Pisters for assistance; and $\mathrm{H}$. van Montfort, R. Schmeitz, T. van Montfort, and M. de Leeuw for programming and statistical assistance.

\section{References}

1. Giles G, Ireland P. Diet, nutrition and prostate cancer. Int J Cancer 1997; Suppl 10:13-17.

2. Kolonel LN. Nutrition and prostate cancer. Cancer Causes Control 1996;7:83-94.

3. Boyle P, Zaridze DG. Risk factors for prostate and testicular cancer. Eur J Cancer 1993;29a:1048-55.

4. Pienta KJ, Esper PS. Risk factors for prostate cancer. Ann Intern Med 1993;118:793-803.

5. Key T. Risk factors for prostate cancer. Cancer Surv 1995;23:63-77. 
6. Cerhan JR, Torner JC, Lynch CF, et al. Association of smoking, body mass, and physical activity with risk of prostate cancer in the lowa 65+ Rural Health Study (United States). Cancer Causes Control 1997; 8:229-38.

7. Hiatt RA, Armstrong MA, Klatsky AL, et al. Alcohol consumption, smoking, and other risk factors and prostate cancer in a large health plan cohort in California (United States). Cancer Causes Control 1994;5:66-72.

8. Le Marchand L, Kolonel LN, Wilkens LR, et al. Animal fat consumption and prostate cancer: a prospective study in Hawaii. Epidemiology 1994;5:276-82.

9. Severson RK, Nomura AM, Grove JS, et al. A prospective study of demographics, diet, and prostate cancer among men of Japanese ancestry in Hawaii. Cancer Res 1989;49:1857-60.

10. Gronberg H, Damber L, Damber JE. Total food consumption and body mass index in relation to prostate cancer risk: a case-control study in Sweden with prospectively collected exposure data. J Urol 1996;155:969-74.

11. Tonnesen $\mathrm{H}$, Moller $\mathrm{H}$, Andersen $\mathrm{JR}$, et al. Cancer morbidity in alcohol abusers. $\mathrm{Br} \mathrm{J}$ Cancer 1994;69:327-32.

12. Mills PK, Beeson WL, Phillips RL, et al. Cohort study of diet, lifestyle, and prostate cancer in Adventist men. Cancer 1989;64:598-604.

13. Hsing AW, McLaughlin JK, Schuman LM, et al. Diet, tobacco use, and fatal prostate cancer: results from the Lutheran Brotherhood Cohort Study. Cancer Res 1990;50:6836-40.

14. Hirayama T. Life-style and mortality. A large-scale census-based cohort study in Japan. Basel: Karger, 1990.

15. Adami HO, McLaughlin JK, Hsing AW, et al. Alcoholism and cancer risk: a population-based cohort study. Cancer Causes Control 1992;3:419-25.

16. Jensen OM. Cancer morbidity and causes of death among Danish brewery workers. Int J Cancer 1979;23:454-63.

17. Carstensen JM, Bygren LO, Hatschek T. Cancer incidence among Swedish brewery workers. Int J Cancer 1990;45:393-6.

18. Whittemore AS, Paffenbarger RS, Jr., Anderson K, et al. Early precursors of site-specific cancers in college men and women. J Natl Cancer Inst 1985;74:43-51.

19. Hakulinen $T$, Lehtimaki L, Lehtonen $M$, et al. Cancer morbidity among two male cohorts with increased alcohol consumption in Finland. J Natl Cancer Inst 1974;52:1711-4.

20. Key TJ, Silcocks PB, Davey GK, et al. A case-control study of diet and prostate cancer. Br J Cancer 1997;76:678-87.

21. Hayes RB, Brown LM, Schoenberg JB, et al. Alcohol use and prostate cancer risk in US blacks and whites. Am J Epidemiol 1996;143:692-7.

22. Ewings $P$, Bowie C. A case-control study of cancer of the prostate in Somerset and east Devon. Br J Cancer 1996;74:661-6.

23. Whittemore AS, Kolonel LN, Wu AH, et al. Prostate cancer in relation to diet, physical activity, and body size in blacks, whites, and Asians in the United States and Canada. J Natl Cancer Inst 1995;87:652-61.

24. Van der Gulden JW, Verbeek AL, Kolk JJ. Smoking and drinking habits in relation to prostate cancer. Br J Urol 1993;73:382-9.

25. Andersson SO, Baron J, Bergstrom R, et al. Lifestyle factors and prostate cancer risk: a casecontrol study in Sweden. Cancer Epidemiol Biomarkers Prev 1996;5:509-13.

26. De Stefani E, Fierro L, Barrios E, et al. Tobacco, alcohol, diet and risk of prostate cancer. Tumori 1995;81:315-20.

27. Slattery ML, West DW. Smoking, alcohol, coffee, tea, caffeine, and theobromine: risk of prostate cancer in Utah (United States). Cancer Causes Control 1993;4:559-63.

28. Pawlega J, Rachtan J, Dyba T. Dietary factors and risk of prostate cancer in Poland. Results of case-control study. Neoplasma 1996;43:61-3.

29. Honda GD, Bernstein L, Ross RK, et al. Vasectomy, cigarette smoking, and age at first sexual intercourse as risk factors for prostate cancer in middle-aged men. $\mathrm{Br} \mathrm{J}$ Cancer 1988;57:326-31.

30. Yu H, Harris RE, Wynder EL. Case-control study of prostate cancer and socioeconomic factors. Prostate 1988;13:317-25.

31. Ross RK, Shimizu H, Paganini Hill A, et al. Case-control studies of prostate cancer in blacks and whites in southern California. J Natl Cancer Inst 1987;78:869-74.

32. Talamini R, La Vecchia C, Decarli A, et al. Nutrition, social factors and prostatic cancer in a Northern Italian population. Br J Cancer 1986;53:817-21. 
33. Tavani A, Negri E, Franceschi S, et al. Alcohol consumption and risk of prostate cancer. Nutr Cancer 1994;21:24-31.

34. Walker AR, Walker BF, Tsotetsi NG, et al. Case-control study of prostate cancer in black patients in Soweto, South Africa. Br J Cancer 1992;65:438-41.

35. Fincham SM, Hill GB, Hanson J, et al. Epidemiology of prostatic cancer: a case-control study. Prostate 1990;17:189-206.

36. Checkoway H, DiFerdinando G, Hulka BS, et al. Medical, life-style, and occupational risk factors for prostate cancer. Prostate 1987;10:79-88.

37. Mishina $T$, Watanabe $H$, Araki $H$, et al. Epidemiological study of prostatic cancer by matchedpair analysis. Prostate 1985;6:423-36.

38. Jackson MA, Kovi J, Heshmat MY, et al. Characterization of prostatic carcinoma among blacks: a comparison between a low-incidence area, Ibadan, Nigeria, and a high-incidence area, Washington, DC. Prostate 1980;1:185-205.

39. Niijima T, Koiso K. Incidence of prostatic cancer in Japan and Asia. Scand J Urol Nephrol Suppl 1980;55:17-21.

40. Schuman LM, Mandel JS, Radke A, et al. Some selected features of the epidemiology of prostatic cancer: Minneapolis-St. Paul, Minnesota case-control study, 1976-1979. In: Magnus K, ed. Trends in cancer incidence: causes and practical implications. Washington: Hemisphere Publishiong corporation, 1982:345-54.

41. Williams RR, Horm JW. Association of cancer sites with tobacco and alcohol consumption and socioeconomic status of patients: interview study from theThird National Cancer Survey. J Natl Cancer Inst 1977;58:525-47.

42. Wynder EL, Mabuchi K, Whitmore WF, Jr. Epidemiology of cancer of the prostate. Cancer 1971;28:344-60.

43. Van den Brandt PA, Goldbohm RA, Van 't Veer P, et al. A large-scale prospective cohort study on diet and cancer in The Netherlands. J Clin Epidemiol 1990;43:285-95.

44. Prentice RL. A case-cohort design for epidemiologic cohort studies and disease prevention trials. Biometrika 1986;73:1-11.

45. Van den Brandt PA, Schouten LJ, Goldbohm RA, et al. Development of a record linkage protocol for use in the Dutch Cancer Registry for Epidemiological Research. Int J Epidemiol 1990;19:5538.

46. Goldbohm RA, Van den Brandt PA, Dorant E. Estimation of the coverage of Dutch municipalities by cancer registries and PALGA based on hospital discharge data. Tijdschr Soc Gezondheidsz 1994;72:80-4.

47. Goldbohm RA, Van den Brandt PA, Brants HAM, et al. Validation of a dietary questionnaire used in a large-scale prospective cohort study on diet and cancer. Eur J Clin Nutr 1994;48:253-65.

48. Voorlichtingsbureau voor de Voeding. Nevo table: Dutch Food Composition Table 1986-1987. The Hague, 1986.

49. Goldbohm RA, Van den Brandt PA, Van 't Veer P, et al. Prospective study on alcohol consumption and the risk of cancer of the colon and rectum in the Netherlands. Cancer Causes Control 1994;5:95-104.

50. Van den Brandt PA, Goldbohm RA, Van 't Veer P. Alcohol and breast cancer: results from The Netherlands Cohort Study. Am J Epidemiol 1995;141:907-15.

51. Schuurman AG, Goldbohm RA, Dorant E, et al. Vegetable and fruit consumption and prostate cancer risk: a cohort study in the Netherlands. Cancer Epidemiol Biom Prev 1998;7:673-80.

52. Baker J. GLIM 3.77 Reference Manual. Oxford: Numerical Algorithms Group, 1985.

53. Volovics A, van den Brandt PA. Methods for the analyses of case-cohort studies. Biom J 1997;2:195-214.

54. Van den Brandt PA, Van 't Veer P, Goldbohm RA, et al. A prospective cohort study on dietary fat and the risk of postmenopausal breast cancer. Cancer Res 1993;53:75-82.

55. Gordon GG, Altman K, Southren AL, et al. Effect of alcohol (ethanol) administration on sexhormone metabolism in normal men. N Engl J Med 1976;295:793-7.

56. Kune GA, Vitetta L. Alcohol consumption and the etiology of colorectal cancer: a review of the scientific evidence from 1957 to 1991. Nutr Cancer 1992;18:97-111. 


\title{
Chapter 7
}

\section{Anthropometry in relation to prostate cancer}

\section{risk in the Netherlands Cohort Study ${ }^{1}$}

\author{
Agnes G. Schuurman ${ }^{2}$ \\ R. Alexandra Goldbohm ${ }^{3}$ \\ Elisabeth Dorant ${ }^{2}$
}

Piet A. van den Brandt ${ }^{2}$

\begin{abstract}
In the Netherlands Cohort Study we investigated whether anthropometry is associated with prostate cancer risk. At baseline in 1986, 58,279 men aged $55-69$ years completed a selfadministered questionnaire on diet, anthropometry and other risk factors for cancer. After 6.3 years of follow-up, 681 cases were available with complete data on height and weight at baseline and 523 cases for weight at the age of 20 years. Both in age-adjusted and multivariate case-cohort analyses (adjusted for age, family history of prostate cancer, and socioeconomic status), height, body mass index (BMl; $\left.\mathrm{kg} / \mathrm{m}^{2}\right)$, and lean body mass $(\mathrm{kg})$ at baseline were not associated with prostate cancer risk. For BMI at age 20 , the rate ratios (RR) of prostate cancer for men with a BMI at age 20 up to $19,21,23,25$, and $\geq 25$ were 1.00 (ref), 1.06, 1.09, 1.39 and 1.34, respectively ( $p$-trend $=0.02$ ). For gain in BMI from age 20 to cohort baseline age an inverse trend in risk was found ( $p$-trend $=0.03$ ), which did not persist after additional adjustment for $\mathrm{BMI}$ at age 20 (p-trend $=0.07$ ). In subgroup analyses, no clear associations between anthropometry and advanced prostate cancer were found. Our findings suggest that body composition at the young adults age may already exert an effect on later risk of prostate cancer.
\end{abstract}

\footnotetext{
${ }^{1}$ Accepted by American Journal of Epidemiology

${ }^{2}$ Dept. of Epidemiology, Maastricht University, Maastricht

${ }^{3}$ Dept. of Consumer Research \& Epidemiology, TNO Nutrition and Food Research Institute, Zeist
} 


\section{Introduction}

Prostate cancer is one of the most frequently occurring types of cancer in western countries but up to now very little is known about the etiology of the disease. Body composition is one of several possible factors which might be related to prostate cancer risk $(1,2)$. Different epidemiological studies have evaluated this possible relationship but with inconclusive results. For height, weight, as well as body mass index (BMI), mostly positive or null associations have been reported, both in cohort and case-control studies, but also inverse associations have been observed $(1,2)$. A potential role of lean body mass (LBM) in prostate cancer etiology is also still questionable (3-5). One important drawback probably contributing to a, thus far, fairly incomplete picture of anthropometry and prostate cancer is the fact that the majority of previous studies did not extensively evaluate this relationship.

Observed associations between anthropometry and prostate cancer are often explained by an interaction with hormonal levels (androgens), but also mechanisms through insulin or growth factors have been proposed (4-6). A hormonal etiology for prostate cancer seems plausible because the normal growth and functioning of the prostate is influenced by androgens. Increased testosterone has been implicated in prostate cancer carcinogenesis (7) and body mass appears to influence serum androgen concentrations (8-10). Because of the long induction period of cancer a possible effect of body composition on prostate cancer risk might occur in an earlier stage of life. Only six studies $(5,6,11-14)$ reported some results on anthropometric measures early in life or change in anthropometric measures during lifetime in relation to prostate cancer risk. Some findings indeed indicate an early effect of body composition, but data are too sparse to draw strong conclusions.

Here, we report our results on anthropometry and change in anthropometric measures during lifetime in relation to prostate cancer risk from the Netherlands Cohort Study (NLCS).

\section{Materials and methods}

\section{The cohort}

Because the study design has been described before (15) we will only give a brief outline. In September 1986 the NLCS was initiated. At baseline, 58,279 men aged 55-69 years completed a self-administered questionnaire on usual diet, lifestyle, personal and family history of cancer, anthropometry, demographic data, and other risk factors for cancer. The case-cohort approach (16) was used for data processing and analysis. For calculation of incidence rates of prostate cancer, the number of cancer cases diagnosed in the entire cohort was used as the numerator, while person years at risk (denominator) were estimated using a random sample of 1,688 men (subcohort). Follow-up for incident prostate cancer was established by computerized record linkage with all nine cancer registries in The Netherlands, and with the Dutch national data base of pathology reports (PALGA) (17). The subcohort has been followed up biennially for vital status information which involved 
personal mailings and (for nonrespondents) additional contacts with municipal population registries. Completeness of cancer follow-up was at least 96 percent (18) and no subcohort members have been lost to follow-up. After a follow-up period of 6.3 years (September 1986-December 1992), 704 incident, microscopically or histologically confirmed, primary prostate cancer cases were detected.

\section{Data collection and analysis}

Information on height (in $\mathrm{cm}$ ), weight at baseline and weight at age 20 (both in $\mathrm{kg}$ ) was obtained using a self-administered questionnaire. In order to minimize observer bias in coding and interpretation of the data, questionnaire data of all cases and subcohort members were key-entered twice and processed in a manner blinded with respect to case/subcohort status. Baseline $\mathrm{BMI}$ and $\mathrm{BMI}$ at age 20 were calculated using baseline weight and weight at age 20 , respectively, divided by height at baseline squared $\left(\mathrm{kg} / \mathrm{m}^{2}\right)$. Change in BMI from age 20 to baseline was calculated as BMI at baseline minus BMI at age 20. LBM (kg) was calculated as [2.447 - 0.09516 age (years) +0.1074 height $(\mathrm{cm})+0.3362$ weight $(\mathrm{kg})] / 0.732$, as described by, e.g., Willett (19). All subjects with prevalent cancer other than skin cancer were excluded. Furthermore, all men with incomplete data on anthropometric measures at baseline were excluded, leaving 681 cases and 1565 subcohort members for analyses. Regarding BMI at age 20 , complete data were available for 523 cases and 1249 subcohort members.

Mean values of anthropometric and potential confounding variables were compared between cases and subcohort members. Rate ratios (RRs) of prostate cancer and 95 percent confidence intervals (95 percent $\mathrm{Cl}$ ) were computed using the GLIM statistical package (20). Exponentially distributed survival times were assumed in the follow-up period. Since standard software was not available, specific macros were developed to account for the additional variance introduced by using the subcohort instead of the entire cohort (21). Tests for trend were based on likelihood ratio tests; two-sided P-values are used throughout this report. Age-adjusted and multivariate-adjusted analyses were conducted for categorized and continuous anthropometric variables. Variables included in the multivariate analyses were age (continuous), family history of prostate cancer (no, yes), and socioeconomic status (low, medium, high) because these variables were associated with prostate cancer risk in our study. Energy and fat intake were not related to prostate cancer risk in the NLCS and therefore not considered as potential confounding variables. The same applies to vegetable and fruit consumption (22).

In order to evaluate whether results for baseline BMI were biased because of an influence of disease occurrence, we performed analyses with exclusion of cases detected in the first two years of follow-up. In order to investigate the hypothesis that latent and nonlatent or aggressive prostate tumors might have a different etiology subgroup analyses were 
performed for continuous anthropometric variables within case subgroups of localized (TO2, MO) and advanced (T3-4, MO; TO-4, M1) prostate tumors (using the TNM classification); well differentiated, moderately differentiated and poorly and undifferentiated prostate tumors; and of latent and nonlatent tumors. Based on information from the pathology reports that have been obtained from PALGA, prostate cancer cases detected during transurethral prostate resections were coded as latent. Cases detected during surgical procedures used in case of suspected cancer (biopsy, radical prostatectomy) were coded as nonlatent. Cases were excluded from these subgroup analyses when this additional information was unknown or unclear (38.8 percent).

Table 1: Description of anthropometric variables and potential confounders in prostate cancer cases and subcohort members, Netherlands Cohort Study (1986-1992).

\begin{tabular}{|c|c|c|c|c|}
\hline \multirow[t]{2}{*}{ Variables } & \multicolumn{2}{|c|}{ Cases $(n=681)$} & \multicolumn{2}{|c|}{ Subcohort $(n=1565)$} \\
\hline & mean & SD & mean & SD \\
\hline \multicolumn{5}{|l|}{ Anthropometric variables } \\
\hline Height at baseline $(\mathrm{cm})$ & 176.3 & 6.7 & 176.6 & 6.8 \\
\hline Weight at baseline $(\mathrm{kg})$ & 77.8 & 9.2 & 78.0 & 9.8 \\
\hline BMl at baseline $\left(\mathrm{kg} / \mathrm{m}^{2}\right)$ & 25.0 & 2.5 & 25.0 & 2.7 \\
\hline LBM at baseline $(\mathrm{kg})$ & 56.7 & 4.9 & 57.1 & 5.2 \\
\hline Weight at age $20^{\prime}(\mathrm{kg})$ & 68.0 & 8.3 & 67.9 & 8.4 \\
\hline BMI at age $20^{1}\left(\mathrm{~kg} / \mathrm{m}^{2}\right)$ & 21.9 & 2.4 & 21.8 & 2.5 \\
\hline \multicolumn{5}{|l|}{ Potentially confounding variables } \\
\hline Age (years) & 63.8 & 3.8 & 61.4 & 4.2 \\
\hline Positive family history of prostate cancer (\% yes) & 4.3 & & 2.6 & \\
\hline \multicolumn{5}{|l|}{ Highest educational level $\left.\right|^{2}(\%)$} \\
\hline low & 46.3 & & 48.1 & \\
\hline medium & 33.2 & & 33.8 & \\
\hline high & 19.7 & & 17.4 & \\
\hline
\end{tabular}

'Based on 523 cases and 1249 subcohort members; ${ }^{2}$ There was missing information for $0.9 \%$ (cases) and $0.7 \%$ (subcohort members); low is defined as primary school with/without lower level vocational education, medium as secondary school or medium level vocational education, high as university or higher level vocational education.

\section{Results}

In table 1 anthropometric variables are described for cases and subcohort members. The means of all anthropometric variables did not differ to a large extent between cases and subcohort members. Furthermore, when subcohort members with missing information for weight at the age of 20 were compared to subcohort members who had mentioned their weight at the age of 20 years, no differences in mean height were found. However, subcohort members with missing information regarding weight at age 20 had a lower weight and $\mathrm{BMI}$ at baseline $\left(76.4 \mathrm{~kg}\right.$ and $24.6 \mathrm{~kg} / \mathrm{m}^{2}$, respectively) than men with complete information $\left(78.4 \mathrm{~kg}\right.$ and $25.1 \mathrm{~kg} / \mathrm{m}^{2}$, respectively). These differences in mean weight and 
BMI were statistically significant. For cases, subjects with missing information regarding weight at age 20 did not differ on baseline height, weight and BMI from cases who had mentioned their weight at the age of 20 years (data not shown). Also shown in table 1 are some potentially confounding variables. The mean age is somewhat higher among cases (63.8 years) than among controls (61.4 years). Furthermore, cases more often reported a positive family history of prostate cancer (4.3 percent vs 2.6 percent) and are more highly educated than subcohort members.

Table 2: Rate ratios (RR) and $95 \%$ confidence intervals $(\mathrm{Cl})$ for prostate cancer according to anthropometric variables, Netherlands Cohort Study (1986-1992).

\begin{tabular}{|c|c|c|c|c|}
\hline \multirow[b]{2}{*}{$\begin{array}{l}\text { Anthropometric } \\
\text { variables }\end{array}$} & \multicolumn{2}{|l|}{ Age-adjusted } & \multicolumn{2}{|l|}{ Multivariate adjusted } \\
\hline & $\begin{array}{l}\text { No of cases/person } \\
\text { years in subcohort }\end{array}$ & $\mathrm{RR}(95 \% \mathrm{Cl})$ & $\begin{array}{l}\text { No of cases/person } \\
\text { years in subcohort }\end{array}$ & $\mathrm{RR}^{1}(95 \% \mathrm{Cl})$ \\
\hline \multicolumn{5}{|c|}{ Height at baseline $(\mathrm{cm})$} \\
\hline$<170^{2}$ & $100 / 1287$ & 1.00 & $99 / 1262$ & 1.00 \\
\hline $170-175$ & $155 / 2272$ & $0.92(0.67-1.27)$ & $154 / 2259$ & $0.90(0.65-1.24)$ \\
\hline $175-180$ & $214 / 2703$ & $1.12(0.83-1.52)$ & $210 / 2690$ & $1.08(0.79-1.47)$ \\
\hline $180-185$ & $142 / 1888$ & $1.03(0.74-1.43)$ & $142 / 1879$ & $0.98(0.70-1.37)$ \\
\hline $185-190$ & $50 / 913$ & $0.83(0.54-1.26)$ & $50 / 907$ & $0.78(0.51-1.19)$ \\
\hline \multirow[t]{2}{*}{$\geq 190$} & $20 / 307$ & $0.97(0.97-0.53)$ & $20 / 307$ & $0.96(0.52-1.75)$ \\
\hline & & P-trend 0.88 & & P-trend 0.60 \\
\hline \multicolumn{5}{|l|}{ Height continuous, } \\
\hline $5 \mathrm{~cm}$ increment & & $1.00(0.94-1.08)$ & & $0.99(0.92-1.06)$ \\
\hline \multicolumn{5}{|c|}{ BMI at baseline $\left(\mathrm{kg} / \mathrm{m}^{2}\right)$} \\
\hline$<22^{2}$ & $63 / 1047$ & 1.00 & $63 / 1047$ & 1.00 \\
\hline $22-24$ & $167 / 2218$ & $1.21(0.85-1.74)$ & $164 / 2211$ & $1.20(0.84-1.73)$ \\
\hline $24-26$ & $237 / 3012$ & $1.28(0.91-1.80)$ & $236 / 2980$ & $1.35(0.95-1.90)$ \\
\hline $26-28$ & $151 / 1988$ & $1.22(0.84-1.75)$ & $150 / 1976$ & $1.26(0.87-1.83)$ \\
\hline \multirow[t]{2}{*}{$\geq 28$} & $63 / 1106$ & $0.85(0.55-1.29)$ & $62 / 1091$ & $0.89(0.58-1.37)$ \\
\hline & & P-trend 0.38 & & P-trend 0.73 \\
\hline \multicolumn{5}{|l|}{ BMI continuous, } \\
\hline $2 \mathrm{~kg} / \mathrm{m}^{2}$ increment & & $0.98(0.91-1.05)$ & & $1.00(0.92-1.07)$ \\
\hline \multicolumn{5}{|c|}{ LBM at baseline $(\mathrm{kg})$} \\
\hline$<52^{2}$ & $108 / 1367$ & 1.00 & $108 / 1361$ & 1.00 \\
\hline $52-55$ & $148 / 1959$ & $0.99(0.72-1.36)$ & $145 / 1940$ & $0.98(0.71-1.35)$ \\
\hline $55-58$ & $168 / 2150$ & $1.07(0.78-1.46)$ & $166 / 2131$ & $1.07(0.79-1.47)$ \\
\hline $58-61$ & $138 / 1863$ & $1.05(0.76-1.44)$ & $138 / 1851$ & $1.05(0.76-1.45)$ \\
\hline \multirow[t]{2}{*}{$\geq 61$} & $119 / 2031$ & $0.96(0.69-1.33)$ & $118 / 2022$ & $0.95(0.69-1.33)$ \\
\hline & & P-trend 0.92 & & P-trend 0.95 \\
\hline \multicolumn{5}{|l|}{ LBM continuous } \\
\hline $2 \mathrm{~kg}$ increment & & $0.99(0.96-1.03)$ & & $1.00(0.96-1.03)$ \\
\hline
\end{tabular}

${ }^{1}$ RRs adjusted for age, family history of prostate cancer, and socioeconomic status; ${ }^{2}$ Reference category. 
In table 2 age-adjusted as well as multivariate-adjusted RRs of prostate cancer are displayed for baseline height, BMI, and LBM. Both in the age-adjusted and multivariate analyses height was not associated with prostate cancer risk. The RRs for BMI at baseline were slightly (but nonsignificantly) increased in the third and fourth category, but the RR somewhat decreased in the highest category and there was no trend in risk ( $p$-trend = 0.73). For LBM we found no association with prostate cancer risk. Results for BMI and LBM after exclusion of cases detected in the first two years of follow-up were essentially the same (data not shown). We also conducted analyses in which each exposure variable was adjusted for the other exposure variables. The estimated RRs were essentially the same as those presented in table 2 (data not shown).

Table 3: Rate ratios (RR) and $95 \%$ confidence intervals $(\mathrm{Cl})$ for prostate cancer according to anthropometric variables at age 20, Netherlands Cohort Study (1986-1992).

\begin{tabular}{|c|c|c|c|c|}
\hline \multirow[b]{2}{*}{ Anthropometric variables } & \multicolumn{2}{|l|}{ Age-adjusted } & \multicolumn{2}{|c|}{ Multivariate adjusted } \\
\hline & $\begin{array}{l}\text { No of cases/ } \\
\text { person years } \\
\text { in subcohort }\end{array}$ & $\mathrm{RR}(95 \% \mathrm{Cl})$ & $\begin{array}{l}\text { No of cases/ } \\
\text { person years } \\
\text { in subcohort }\end{array}$ & $\operatorname{RR}^{1}(95 \% \mathrm{Cl})$ \\
\hline \multicolumn{5}{|l|}{ BMl at age $20\left(\mathrm{~kg} / \mathrm{m}^{2}\right)$} \\
\hline$<19^{2}$ & $57 / 908$ & 1.00 & $57 / 902$ & 1.00 \\
\hline $19-21$ & $124 / 1909$ & $1.10(0.75-1.62)$ & $122 / 1902$ & $1.06(0.72-1.56)$ \\
\hline $21-23$ & $178 / 2552$ & $1.13(0.79-1.64)$ & $176 / 2536$ & $1.09(0.76-1.58)$ \\
\hline $23-25$ & $119 / 1521$ & $1.34(0.91-1.99)$ & $119 / 1496$ & $1.39(0.93-2.06)$ \\
\hline \multirow[t]{2}{*}{$\geq 25$} & $45 / 598$ & $1.34(0.82-2.20)$ & $44 / 598$ & $1.33(0.81-2.19)$ \\
\hline & & P-trend 0.04 & & P-trend 0.02 \\
\hline \multirow{2}{*}{\multicolumn{5}{|c|}{$\begin{array}{l}\text { BMl at age } 20 \text { continuous, } \\
2 \mathrm{~kg} / \mathrm{m}^{2} \text { increment }\end{array}$}} \\
\hline & & $1.07(0.98-1.17)$ & & $1.08(0.99-1.18)$ \\
\hline \multicolumn{5}{|l|}{$\begin{array}{l}\text { Change in BMI from age } 20 \\
\text { to baseline }\left(\mathrm{kg} / \mathrm{m}^{2}\right)\end{array}$} \\
\hline-9.2 to $<0$ & $47 / 668$ & $1.19(0.77-1.84)$ & $47 / 668$ & $1.19(0.74-1.90)^{3}$ \\
\hline 0 to $+2^{2}$ & $122 / 1876$ & 1.00 & $120 / 1857$ & 1.00 \\
\hline+2 to +4 & $179 / 2104$ & $1.31(0.97-1.76)$ & $176 / 2104$ & $1.32(0.98-1.79)^{3}$ \\
\hline+4 to +6 & $113 / 1537$ & $0.99(0.72-1.37)$ & $113 / 1512$ & $1.04(0.74-1.47)^{3}$ \\
\hline+6 to +8 & $43 / 852$ & $0.78(0.51-1.18)$ & $43 / 852$ & $0.83(0.53-1.31)^{3}$ \\
\hline \multirow[t]{2}{*}{$z+8$} & $19 / 451$ & $0.61(0.35-1.08)$ & $19 / 441$ & $0.67(0.36-1.23)^{3}$ \\
\hline & & P-trend 0.01 & & P-trend $0.07^{4}$ \\
\hline
\end{tabular}

Gain in BMl from age 20 to baseline continuous, $2 \mathrm{~kg} / \mathrm{m}^{2}$ increment

${ }^{1}$ RRs adjusted for age, family history of prostate cancer, and socioeconomic status; ${ }^{2}$ Reference category; ${ }^{3}$ Additional adjustment for $\mathrm{BMI}$ at age $20 ;{ }^{4}$ The test for trend applies to weight gain categories only. 
In table 3, results for BMI at age 20 and gain in BMI from age 20 to cohort baseline age are displayed. For $\mathrm{BMI}$ at age 20 , a significant positive trend in risk ( $\mathrm{p}$-trend $=0.02$ ) was found. Men with a BMI at age 20 of 25 or more had a RR of 1.33 (95 percent $\mathrm{Cl} 0.81-2.19$ ) compared to men with a BMI at age 20 of less than 19. For both subcohort members and cases, 9 percent of all men lost weight. The mean gain in weight (standard deviation) for subcohort members and cases was $+12.1(8.4) \mathrm{kg}$ and $+11.2(7.1) \mathrm{kg}$, respectively. The mean gain in BMI (standard deviation) was $+3.9(2.6) \mathrm{kg} / \mathrm{m}^{2}$ for subcohort members and $+3.6(2.2) \mathrm{kg} / \mathrm{m}^{2}$ for cases. A significantly decreasing trend in risk was observed for an increase in BMI from age 20 to cohort baseline age ( $p$-trend $=0.03$ ), however, after additional adjustment for $\mathrm{BMI}$ at age 20 the trend test was no longer statistically significant ( $p$-trend $=0.07$ ). Only in the two highest categories of gain in BMI nonsignificant decreased RRs were observed ( 0.83 and 0.67 , respectively).

Table 4: Rate ratios (RR) and $95 \%$ confidence intervals (Cl) for prostate cancer according to anthropometric variables in subgroups of localized (TO-2, MO) and advanced (T3-4, M0; TO-4, M1) prostate tumors, Netherlands Cohort Study (1986-1992).

\begin{tabular}{|c|c|c|}
\hline & $\begin{array}{l}\text { Localized tumors } \\
(n=239)\end{array}$ & $\begin{array}{l}\text { Advanced tumors } \\
(n=226)\end{array}$ \\
\hline Anthropometric variables & $\mathrm{RR}^{1}(95 \% \mathrm{Cl})$ & $\mathrm{RR}^{1}(95 \% \mathrm{Cl})$ \\
\hline $\begin{array}{l}\text { Height at baseline continuous, } 5 \\
\mathrm{~cm} \text { increment }\end{array}$ & $0.99(0.89-1.10)$ & $0.98(0.88-1.10)$ \\
\hline $\begin{array}{l}\text { BMl at baseline continuous, } \\
2 \mathrm{~kg} / \mathrm{m}^{2} \text { increment }\end{array}$ & $0.96(0.86-1.06)$ & $1.01(0.90-1.13)$ \\
\hline $\begin{array}{l}\text { LBM at baseline continuous, } \\
2 \mathrm{~kg} \text { increment }\end{array}$ & $0.98(0.93-1.03)$ & $1.00(0.94-1.06)$ \\
\hline $\begin{array}{l}\mathrm{BMl} \text { at age } 20 \text { continuous, } \\
2 \mathrm{~kg} / \mathrm{m}^{2} \text { increment }\end{array}$ & $1.18(1.04-1.35)$ & $1.03(0.91-1.18)$ \\
\hline $\begin{array}{l}\text { Gain in BMI from age } 20 \text { to } \\
\text { baseline continuous, } 2 \mathrm{~kg} / \mathrm{m}^{2} \\
\text { increment }\end{array}$ & $0.87(0.74-1.02)^{2}$ & $0.93(0.80-1.08)^{2}$ \\
\hline
\end{tabular}

${ }^{1}$ Adjusted for age, family history of prostate cancer, and socioeconomic status; ${ }^{2}$ Additional adjustment for BMI at age 20.

In table 4 RRs are displayed for continuous anthropometric variables in case subgroups of localized and advanced prostate tumors. No association was found between height and localized or advanced tumors. Baseline BMI and LBM were also not associated with either localized or advanced prostate tumors. In contrast, for $\mathrm{BMI}$ at age 20 a significant increase in risk of localized prostate tumors was found (RR per increment of $2 \mathrm{~kg} / \mathrm{m}^{2}$ of $1.18,95$ percent $\mathrm{Cl}$ 1.04-1.35). No association between $\mathrm{BMI}$ at age 20 and advanced prostate tumors was shown. The overall negative association between gain in $\mathrm{BMI}$ and prostate 
cancer risk was more pronounced for localized prostate tumors $(R R=0.86,95$ percent $\mathrm{Cl}$ 0.75-0.99 per increment of $2 \mathrm{~kg} / \mathrm{m}^{2}$ ). Table 5 shows continuous anthropometric variables evaluated in case subgroups by differentiation grade of the tumor. Some associations were noted in different subgroups, however, anthropometric measures showed no consistent association with one specific subgroup of prostate cancer tumors. For both latent and nonlatent tumors no clear associations were observed (data not shown).

Table 5: Rate ratios (RR) and $95 \%$ confidence intervals (Cl) for prostate cancer according to anthropometric variables in subgroups on differentiation grade, Netherlands Cohort Study (1986-1992).

\begin{tabular}{|c|c|c|c|}
\hline & $\begin{array}{l}\text { Well differentiated } \\
(n=194)\end{array}$ & $\begin{array}{l}\text { Moderately } \\
\text { differentiated } \\
(n=247)\end{array}$ & $\begin{array}{l}\text { Poorly/ } \\
\text { undifferentiated } \\
(n=174)\end{array}$ \\
\hline Anthropometric variables & $\mathrm{RR}^{1}(95 \% \mathrm{Cl})$ & $\mathrm{RR}^{1}(95 \% \mathrm{Cl})$ & $\mathrm{RR}^{1}(95 \% \mathrm{Cl})$ \\
\hline $\begin{array}{l}\text { Height at baseline continuous, } \\
5 \mathrm{~cm} \text { increment }\end{array}$ & $0.94(0.84-1.06)$ & $0.98(0.89-1.08)$ & $1.07(0.95-1.21)$ \\
\hline $\begin{array}{l}\text { BMl at baseline continuous, } \\
2 \mathrm{~kg} / \mathrm{m}^{2} \text { increment }\end{array}$ & $0.92(0.82-1.04)$ & $1.02(0.93-1.13)$ & $1.01(0.89-1.14)$ \\
\hline $\begin{array}{l}\text { LBM at baseline continuous, } \\
2 \mathrm{~kg} \text { increment }\end{array}$ & $0.94(0.89-1.00)$ & $1.00(0.95-1.06)$ & $1.03(0.97-1.10)$ \\
\hline $\begin{array}{l}\text { BMl at age } 20 \text { continuous, } 2 \mathrm{~kg} / \mathrm{m}^{2} \\
\text { increment }\end{array}$ & $1.09(0.94-1.26)$ & $1.15(1.01-1.31)$ & $0.97(0.83-1.13)$ \\
\hline $\begin{array}{l}\text { Gain in BMI from age } 20 \text { to baseline } \\
\text { continuous, } 2 \mathrm{~kg} / \mathrm{m}^{2} \text { increment }\end{array}$ & $0.77(0.65-0.92)^{2}$ & $0.97(0.83-1.13)^{2}$ & $0.68(0.58-0.81)^{2}$ \\
\hline
\end{tabular}

${ }^{1}$ Adjusted for age, family history of prostate cancer, and socioeconomic status; ${ }^{2}$ Additional adjustment for BMl at age 20 .

\section{Discussion}

In our study we observed no clear associations between height, BMI, and LBM and prostate cancer risk. For BMI at age 20 a significant positive trend in risk was observed. In contrast, for a gain in BMI from age 20 to cohort baseline age, a significant inverse trend in risk was found. After correction for the absolute BMI at the age of 20 the trend test was no longer statistically significant. In subgroup analyses, these observed associations for overall prostate cancer risk were mainly found in the subgroup of localized prostate tumors. We found no evidence that anthropometric variables were more strongly related to advanced prostate tumors, poorly and undifferentiated tumors or nonlatent tumors.

The results from the NLCS are not likely to be influenced by selection bias given the high completeness of follow-up of cases and subcohort person years $(18,23)$. All the anthropometric measures are self-reported and misclassification of exposure is a potential 
source of bias. Weight at age 20 was used to calculate $\mathrm{BMl}$ at age 20 and misclassification of $\mathrm{BMl}$ at age 20 might have occurred, because weight at age 20 is difficult to remember. However, misclassification is expected to be nondifferential and therefore a possible effect on the risk estimates should be towards the null value. When we compared the mean selfreported height and weight at baseline in the subcohort with the mean height and weight of a representative sample of Dutch men aged 50 to 69 years in 1985-88 (24) these measures were comparable. Finally, residual confounding of the effect measures cannot be excluded, although we considered several potential confounding factors.

For 20 percent and 23 percent, respectively, of cases and subcohort members data regarding $\mathrm{BMl}$ at age 20 were missing. Cases with and without information regarding $\mathrm{BMI}$ at age 20 did not differ in baseline anthropometric measures, but subcohort members with missing information had a lower weight and BMl at baseline than subcohort members with complete information. Because of these missing data, our positive association with regard to $\mathrm{BMI}$ at age $\mathbf{2 0}$ needs to be carefully interpreted. One case-control study reported no association between BMI 20 years prior to the interview and prostate cancer (25). In another case-control study risk estimates for prostate cancer were nonsignificantly increased in association with $\mathrm{BMI}$ at age 25 and at age 45 (14). In contrast to these findings, Giovannucci et al. (5) found no association between BMI at age 21 and overall prostate cancer risk, but an inverse association between $\mathrm{BMI}$ at age 21 and advanced prostate cancer risk was reported; The RR for men with a BMI $\geq 26$ versus $<20$ at age 21 was 0.53 . For obesity at ages 5 and 10, based on self-reported assessments using pictograms of body size, a reduced risk was also noted. An explanation that was given for this decreased risk is that if obesity is related to the hormonal milieu, low testosterone and IGF-I levels and higher estrogen levels may lower the risk of prostate cancer. In another cohort study (6) and case-control study (11) no clear associations were seen for BMl at a younger age (20 or 25) and prostate cancer risk. In general, obesity has been reported to be inversely associated with plasma testosterone levels $(5,8-10,26)$ and lower testosterone levels may be related to a lower prostate cancer risk (7). Therefore, the suggested positive association observed in our study is somewhat unexpected. However, obesity also shows an inverse relationship with sex hormone-binding globuline (SHBG), and SHBG is hypothesized to have an inverse association with prostate cancer risk (27). Because SHBG binds to testosterone and lower levels of SHBG may lead to higher levels of bioavailable testosterone, this might be a pathway explaining our observed positive association between BMI at age 20 and prostate cancer risk. Our results which indicated an inverse trend in risk when evaluating gain in BMI from age 20 to cohort baseline age (55-69 years), however, are not in concordance with this hypothesis. Nevertheless, it might be plausible that different hormones or hormone levels are involved at different stages in prostate cancer development. The prostate resides in a multihormonal environment and a number of growth-regulatory pathways with complex interactions are involved in epithelial proliferation (28). The exact role of hormones in the 
development of prostate cancer remains poorly understood (29). Therefore, studies providing inside into possible mechanisms of action of hormones in relation to prostate growth and prostate cancer are needed. In two cohort studies no association between change in BMI from age 25 to cohort baseline age (65+ years) (6) or change in BMI from college years to years following college (13) and prostate cancer risk was found. However, in one of these cohort studies percent change in BMI from age 50 to cohort baseline age $(65+$ years) showed a positive trend in risk ( $p$-trend $=0.04)$, although none of the RRs were statistically significant (6). Obviously, misclassification because of a poor memory of BMI at earlier ages may have influenced results in different studies.

According to the results from one study, it has been suggested that lean body mass may be associated with prostate cancer risk and not the fat tissue. In that study a positive association was observed between the area of muscle in the arm but not with area of fat in the arm, and prostate cancer risk (3). The authors speculated that increased muscle development might reflect overproduction of sex hormones, this being a pathway explaining their observed association. We found no association between estimated LBM and prostate cancer risk and in another case-control study no association between fat-free mass and prostate cancer was observed (30). In a retrospective cohort study among 135,006 Swedish construction workers a significant positive trend $(p$-trend $=0.002)$ in risk was observed between calculated LBM (using the same equation as in our study) and prostate cancer incidence (4). The age-adjusted risk estimate for men with a LBM >62 compared to a LBM $<55$ was 1.17 (95 percent $\mathrm{Cl} 1.04-1.32$ ). A disadvantage of the calculated measure is that the assumption of a constant water proportion in the LBM may not hold. Depending on the state of hydration and the relative components of LBM the proportion of water varies $(4,19)$. Sometimes other measures were used to estimate the distribution of fat in the body. No clear associations were found between waist circumference and prostate cancer risk in three studies $(5,31,32)$. In the Health Professionals Follow-Up Study among 47,781 men an inverse association was noted between hip circumference and prostate cancer. The risk estimate for men in the fifth versus men in the first quintile was 0.85 (95 percent $\mathrm{Cl} 0.68$ 1.06) and the trend test was statistically significant ( $p$-trend $=0.04)(5)$. In one case-control study no clear associations were observed with hip or thigh circumference and biacromial breadth (31). However, in this latter case-control study significant differences between cases and controls were found for the waist to thigh ratio $(p=0.03)$ with the cases having a higher ratio than the controls. This was not confirmed in a later case-control study by the same authors (30). In that study the only anthropometric measures that consistently differed between cases and controls were indexes of upper body robustness, as assessed by biacromial, bideltoid, and biacromial-to-standing height ratio measures (30). In one cohort study the waist to hip ratio was not related to overall prostate cancer risk (5). 
Our results of no association between height and prostate cancer risk are in accordance with results from other cohort studies $(3,6,13,33,34)$ and case-control studies $(14,25,30$ $32,35-42)$. Nevertheless, there were four cohort studies $(4,5,43,44)$ and two case-control studies $(45,46)$ in which positive associations with increasing height were indicated. In three of these studies the trend test was statistically significant $(4,43,44)$. In one casecontrol study the sitting to standing height ratio was significantly higher for cases than for control subjects (31). Previous analyses from our study showed a strong positive association between height and breast cancer risk (47). Because we do not expect the determinants of adult height (e.g. childhood energy intake) to differ largely between men and women in our cohort, the absence of variation in these determinants cannot explain our finding of no association between height and prostate cancer risk. The observed positive association between height and prostate cancer risk in some studies might be explained by the fact that tallness could be the result of higher levels of insulin-like growth factor-I (IGF-I) and testosterone, which might influence prostate cancer risk $(4,5)$. In the Health Professionals Follow-Up Study (5), one of the prospective studies in which a positive association between height and prostate cancer risk was found, an inverse association with preadult obesity was observed. Both attained height and childhood obesity may be related to the preadult hormonal milieu. Because of scarcity of data, more studies on preadult exposures in relation to risk of prostate cancer are needed.

The vast majority of previous epidemiological studies on anthropometry and prostate cancer reported results on indices of body mass index, as an indicator of adiposity. Like in our study, in most cohort studies no clear associations were observed $(3,5,13,33,43,48,49)$. However, in four cohort studies positive associations were indicated $(4,6,34,50)$. Casecontrol studies mostly reported null associations $(25,30-32,36-40,51-56)$, but also positive associations were observed $(12,35,45,46)$. Because of the inverse association between obesity and plasma testosterone levels $(5,8-10,26)$ one should expect BMI to be inversely related to risk of prostate cancer. However, the inverse association between $\mathrm{BMI}$ and SHBG, as described before, might explain the positive associations observed in some studies. Inconsistencies in reported results can partly be explained by the fact that the evaluated range in BMI differed between the various studies. Another important drawback of several of the published studies is that only correction for age was reported $(3,4,12,13$, $25,33,34,45,46,49,51-54,56)$. Also, in several case-control studies only a comparison of mean BMI between cases and controls was reported and no risk estimates were computed $(31,32,36-40)$. Furthermore, if BMI in case-control studies was measured at the time of diagnosis, disease may have affected this measure, leading to biased results.

Finally, we found no evidence of anthropometric measures being more strongly associated with advanced, poorly and undifferentiated, or nonlatent prostate tumors. There were only a few other studies $(5,6,11,25,43)$ in which case subgroups were evaluated. Results 
between these studies were not very consistent and do not permit definitive conclusions.

In conclusion, our results indicate an effect of early BMI (BMI at age 20) and change in BMI from age 20 to baseline age. Thus far, evidence for an effect of early weight and weight gain during lifetime is too limited to draw conclusions yet, and more research is warranted, also to reveal potential mechanisms. Furthermore, the effect of timing of changes in anthropometric meausures during lifetime also need attention in future studies on anthropometry and prostate cancer risk. We found no association between height, BMI and LBM at baseline and risk of prostate cancer.

\section{Acknowledgements}

We thank the regional cancer registries (IKA, IKL, IKMN, IKN, IKO, IKR, IKST, IKW, IKZ), and the Dutch national data base of pathology (PALGA) for providing incidence data; $\mathrm{Dr}$. A. Volovics for statistical advice; S. van de Crommert, J. Nelissen, H. Brants, C. de Zwart, M. Moll, W. van Dijk, C. Sloot, P. Florax and A. Pisters for assistance; and H. van Montfort, R. Schmeitz, T. van Montfort, and M. de Leeuw for programming and statistical assistance.

\section{References}

1. Giles G, Ireland P. Diet, nutrition and prostate cancer. Int J Cancer 1997; Suppl 10:13-7.

2. Kolonel LN. Nutrition and prostate cancer. Cancer Causes Control 1996;7:83-94.

3. Severson RK, Grove JS, Nomura AM, et al. Body mass and prostatic cancer: a prospective study. British Medical Journal 1988;297:713-5.

4. Andersson SO, Wolk A, Bergstrom R, et al. Body size and prostate cancer: a 20-year follow-up study among 135006 Swedish construction workers. J Natl Cancer Inst 1997;89:385-9.

5. Giovannucci E, Rimm EB, Stampfer MJ, et al. Height, body weight, and risk of prostate cancer. Cancer Epidemiol Biomarkers Prev 1997;6:557-63.

6. Cerhan JR, Torner JC, Lynch CF, et al. Association of smoking, body mass, and physical activity with risk of prostate cancer in the lowa 65+ Rural Health Study (United States). Cancer Causes Control 1997;8:229-38.

7. Ross RK, Henderson BE. Do diet and androgens alter prostate cancer risk via a common etiologic pathway? J Natl Cancer Inst 1994;86:252-4.

8. Dai WS, Kuller LH, LaPorte RE, et al. The epidemiology of plasma testosterone levels in middleaged men. Am J Epidemiol 1981;114:804-16.

9. Vermeulen A, Kaufman JM, Giagulli VA. Influence of some biological indexes on sex hormonebinding globulin and androgen levels in aging or obese males. J Clin Endocrinol Metab 1996;81:1821-6.

10. Wu AH, Whittemore AS, Kolonel LN, et al. Serum androgens and sex hormone-binding globulins in relation to lifestyle factors in older African-American, white, and Asian men in the United States and Canada. Cancer Epidemiol Biomarkers Prev 1995;4:735-41.

11. Andersson SO, Baron J, Wolk A, et al. Early life risk factors for prostate cancer: a populationbased case-control study in Sweden. Cancer Epidemiol Biomarkers Prev 1995;4:187-92.

12. Ilic M, Vlajinac $\mathrm{H}$, Marinkovic $\mathrm{J}$. Case-control study of risk factors for prostate cancer. $\mathrm{Br} \mathrm{J}$ Cancer 1996;74:1682-6.

13. Whittemore AS, Paffenbarger RS, Jr., Anderson K, et al. Early precursors of site-specific cancers in college men and women. $J$ Natl Cancer Inst 1985;74:43-51.

14. Key TJ, Silcocks PB, Davey GK, et al. A case-control study of diet and prostate cancer. $\mathrm{Br} \mathrm{J}$ Cancer 1997;76:678-87.

15. Van den Brandt PA, Goldbohm RA, Van 't Veer P, et al. A large-scale prospective cohort study on diet and cancer in The Netherlands. J Clin Epidemiol 1990;43:285-95.

16. Prentice RL. A case-cohort design for epidemiologic cohort studies and disease prevention trials. Biometrika 1986;73:1-11. 
17. Van den Brandt PA, Schouten LJ, Goldbohm RA, et al. Development of a record linkage protocol for use in the Dutch Cancer Registry for Epidemiological Research. Int J Epidemiol 1990;19:5538.

18. Goldbohm RA, Van den Brandt PA, Dorant E. Estimation of the coverage of Dutch municipalities by cancer registries and PALGA based on hospital discharge data. Tijdschr Soc Gezondheidsz $1994 ; 72: 80-4$.

19. Willett W. Anthropometric measures and body composition. In: Willett W, ed. Nutritional epidemiology. New York: Oxford University Press, 1990:217-44.

20. Baker J. GLIM 3.77 Reference Manual. Oxford: Numerical Algorithms Group, 1985.

21. Volovics A, Van den Brandt PA. Methods for the analyses of case-cohort studies. Biom J 1997;2:195-214.

22. Schuurman AG, Goldbohm RA, Dorant E, et al. Vegetable and fruit consumption and prostate cancer risk: a cohort study in the Netherlands. Cancer Epidemiol Biom Prev 1998;7:673-80.

23. Van den Brandt PA, Van 't Veer P, Goldbohm RA, et al. A prospective cohort study on dietary fat and the risk of postmenopausal breast cancer. Cancer Res 1993;53:75-82.

24. Netherlands Central Bureau of Statistics. Statistical yearbook of the Netherlands 1990. The Hague: SDU Publishers, 1990.

25. Andersson SO, Baron J, Bergstrom R, et al. Lifestyle factors and prostate cancer risk: a casecontrol study in Sweden. Cancer Epidemiol Biomarkers Prev 1996;5:509-13.

26. Meikle AW, Bishop DT, Stringham JD, et al. Relationship between body mass index, cigarette smoking, and plasma sex steroids in normal male twins. Genet Epidemiol 1989;6:399-412.

27. Gann PH, Hennekens $\mathrm{CH}, \mathrm{Ma} \mathrm{J}$, et al. Prospective study of sex hormone levels and risk of prostate cancer. J Natl Cancer Inst 1996;88:1118-26.

28. Griffiths K, Eaton CL, Davies P. Prostatic cancer: aetiology and endocrinology. Horm Res 1989;32 Suppl 1:38-43.

29. Pienta KJ, Goodson JA, Esper PS. Epidemiology of prostate cancer: molecular and environmental clues. Urology 1996;48:676-83.

30. Demark Wahnefried W, Conaway MR, Robertson CN, et al. Anthropometric risk factors for prostate cancer. Nutr Cancer 1997;28:302-7.

31. Demark-Wahnefried W, Paulson DF, Robertson CN, Anderson EE, Conaway MR, Rimer BK. Body dimension differences in men with or without prostate cancer. J Natl Cancer Inst 1992;84:1363-4.

32. Whittemore AS, Kolonel LN, Wu AH, et al. Prostate cancer in relation to diet, physical activity, and body size in blacks, whites, and Asians in the United States and Canada. J Natl Cancer Inst 1995;87:652-61.

33. Greenwald P, Damon A, Kirmss V, Polan AK. Physical and demographic features of men before developing cancer of the prostate. J Natl Cancer Inst 1974;53:341-6.

34. Thune I, Lund E. Physical activity and the risk of prostate and testicular cancer: a cohort study of 53,000 Norwegian men. Cancer Causes Control 1994;5:549-56.

35. Talamini R, La Vecchia C, Decarli A, et al. Nutrition, social factors and prostatic cancer in a Northern Italian population. Br J Cancer 1986;53:817-21.

36. Graham S, Haughey B, Marshall J, et al. Diet in the epidemiology of carcinoma of the prostate gland. J Natl Cancer Inst 1983;70:687-92.

37. Ross RK, Shimizu H, Paganini Hill A, et al. Case-control studies of prostate cancer in blacks and whites in southern California. J Natl Cancer Inst 1987;78:869-74.

38. Walker AR, Walker BF, Tsotetsi NG, et al. Case-control study of prostate cancer in black patients in Soweto, South Africa. Br J Cancer 1992;65:438-41.

39. Honda GD, Bernstein L, Ross RK, et al. Vasectomy, cigarette smoking, and age at first sexual intercourse as risk factors for prostate cancer in middle-aged men. $\mathrm{Br} \mathrm{J}$ Cancer 1988;57:326-31.

40. Kolonel LN, Yoshizawa CN, Hankin JH. Diet and prostatic cancer: a case-control study in Hawaii. Am J Epidemiol 1988;127:999-1012.

41. Wynder EL, Mabuchi K, Whitmore WF, Jr. Epidemiology of cancer of the prostate. Cancer 1971;28:344-60.

42. Talamini R, Franceschi S, La Vecchia C, et al. Diet and prostatic cancer: a case-control study in northern Italy. Nutr Cancer 1992;18:277-86.

43. Le Marchand L, Kolonel LN, Wilkens LR, et al. Animal fat consumption and prostate cancer: a prospective study in Hawaii. Epidemiology 1994;5:276-82. 
44. Hebert PR, Ajani U, Cook NR, et al. Adult height and incidence of cancer in male physicians (United States). Cancer Causes Control 1997;8:591-7.

45. Hayes RB, de Jong FH, Raatgever J, et al. Physical characteristics and factors related to sexual development and behaviour and the risk for prostatic cancer. Eur J Cancer Prev 1992;1:239-45.

46. Fincham SM, Hill GB, Hanson J, et al. Epidemiology of prostatic cancer: a case-control study. Prostate 1990;17:189-206.

47. Van den Brandt PA, Dirx MJ, Ronckers $\mathrm{CM}$, et al. Height, weight weight change, and postmenopausal breast cancer risk: The Netherlands Cohort Study. Cancer Causes Control 1997;8:39-47.

48. Thompson MM, Garland C, Barrett-Connor E, et al. Heart disease risk factors, diabetes, and prostatic cancer in an adult community. Am J Epidemiol 1989;129:511-7.

49. Mills PK, Beeson WL, Phillips RL, et al. Cohort study of diet, lifestyle, and prostate cancer in Adventist men. Cancer 1989;64:598-604.

50. Gronberg H, Damber L, Damber JE. Total food consumption and body mass index in relation to prostate cancer risk: a case-control study in Sweden with prospectively collected exposure data. J Urol 1996;155:969-74.

51. Ghadirian $\mathrm{P}$, Lacroix A, Maisonneuve $\mathrm{P}$, et al. Nutritional factors and prostate cancer: a casecontrol study of French Canadians in Montreal, Canada. Cancer Causes Control 1996;7:428-36.

52. Yu H, Harris RE, Wynder EL. Case-control study of prostate cancer and socioeconomic factors. Prostate 1988;13:317-25.

53. Pawlega J, Rachtan J, Dyba T. Dietary factors and risk of prostate cancer in Poland. Results of case-control study. Neoplasma 1996;43:61-3.

54. West DW, Slattery ML, Robison LM, et al. Adult dietary intake and prostate cancer risk in Utah: a case-control study with special emphasis on aggressive tumors. Cancer Causes Control 1991;2:85-94.

55. Mettlin C, Selenskas S, Natarajan N, et al. Beta-carotene and animal fats and their relationship to prostate cancer risk. A case-control study. Cancer 1989;64:605-12.

56. Rohan TE, Howe GR, Burch JD, et al. Dietary factors and risk of prostate cancer: a case-control study in Ontario, Canada. Cancer Causes Control 1995;6:145-54. 


\title{
Chapter 8
}

\section{A case-cohort study on prostate cancer risk}

\section{in relation to family history of prostate}

\author{
cancer $^{1}$
}

\author{
Agnes G. Schuurman ${ }^{2}$ \\ Maurice P.A. Zeegers ${ }^{2}$ \\ R. Alexandra Goldbohm ${ }^{3}$ \\ Piet A. van den Brandt ${ }^{2}$
}

\section{Abstract}

We investigated the risk of prostate cancer in relation to a family history of prostate cancer in 58,279 men aged $55-69$ years. We found 704 incident cases after 6.3 years of follow-up. Rate ratios and $95 \%$ confidence intervals for having an affected vs nonaffected father and brother were, respectively $1.44(0.80-2.58)$ and 5.57 (1.61-19.26). We found no evidence for an increasing risk with an increasing percentage of affected family members. The associations we observed were stronger for cases diagnosed before age 70 compared with cases diagnosed after age 70 and for advanced compared with localized tumors.

\footnotetext{
'Published in Epidemiology 1999; 10: 192-5

${ }^{2}$ Dept. of Epidemiology, Maastricht University, Maastricht

${ }^{3}$ Dept. of Consumer Research \& Epidemiology, TNO Nutrition and Food Research Institute, Zeist
} 


\section{Introduction}

Despite a high incidence of prostate cancer in Western countries, few risk factors are known. A positive family history has been reported to be associated with risk $(1,2)$, but limited data from prospective studies are available. With data from the Netherlands Cohort Study we were able to investigate not only a positive family history, but also to take the number of brothers into account as well as the age at diagnosis of brothers and fathers. We were also able to investigate case subgroups (localized and advanced tumors) separately.

\section{Methods}

The cohort

The study design has been described in detail elsewhere (3). Briefly, in 1986, 58,279 men aged 55-69 years who originated from 204 municipal population registries throughout the country completed a self-administered questionnaire on personal and family history of cancer, usual diet, and other risk factors for cancer. We used a case-cohort approach for analyses (4): for calculation of cancer incidence rates, the number of cases for the entire cohort was used as the numerator, while person years at risk (denominator) were estimated using a random male sample of controls, the subcohort $(n=1,630)$. We identified incident prostate cancer cases using computerized record linkage with all nine cancer registries in The Netherlands (5). The control subcohort has been followed up biennially for vital status information. Completeness of cancer follow-up was at least $96 \%$; no subcohort member has been lost to follow-up (6). After 6.3 years of follow-up (September 1986-December 1992), 704 incident, primary prostate cancer cases were identified. During this period, systematic screening for prostate cancer was not instituted in the Netherlands.

\section{Data collection and analysis}

Subjects were asked to report how many brothers they had, whether their father or brother(s) had ever been diagnosed with prostate cancer and, if so, at what age. To take family size into account in analyses, we computed the percentage of family members with prostate cancer: the number of affected family members (fathers and brothers) divided by the number of brothers plus one (father). A percentage was also computed for brothers only.

We excluded subjects with prevalent cancer at baseline other than skin cancer and subjects with incomplete or inconsistent dietary data according to criteria described before (7). A total of 642 cases and 1,525 subcohort members remained for analysis. First, we examined potential confounding factors including age, educational level, fat intake, and consumption of vegetables and fruit. Second, we computed rate ratios (RRs) and $95 \%$ confidence intervals $(\mathrm{Cl})$. We assumed that survival times were exponentially distributed in the followup period (8). We also computed RRs for subgroups of cases diagnosed before and after age 70 and for localized (TO-2, MO) and advanced (T3-4, MO; TO-4, M1) tumors. 


\section{Results}

Of subcohort members and cases, $2.5 \%$ and $4.1 \%$, respectively, had a father or brother with prostate cancer. Table 1 shows descriptive information on subcohort members and cases. Subcohort members and cases with a positive family history were younger compared with subjects without a family history. Furthermore, they less often had a lower educational level. Fat intake and consumption of vegetables and fruit also differed between subjects with and without a family history of prostate cancer but patterns in the distribution were less clear.

Table 1: Distribution of potential confounding factors among subcohort members and cases with a negative and positive family history of prostate cancer, Netherlands Cohort Study (1986-1992).

\begin{tabular}{|c|c|c|c|c|}
\hline \multirow[b]{2}{*}{ Variables } & \multicolumn{2}{|c|}{$\begin{array}{c}\text { Person years in } \\
\text { subcohort (\%) }\end{array}$} & \multicolumn{2}{|c|}{$\begin{array}{l}\text { Number of } \\
\text { cases (\%) }\end{array}$} \\
\hline & $\begin{array}{l}\text { No family } \\
\text { history }\end{array}$ & $\begin{array}{c}\text { Positive family } \\
\text { history }\end{array}$ & $\begin{array}{l}\text { No family } \\
\text { history }\end{array}$ & $\begin{array}{l}\text { Positive family } \\
\text { history }\end{array}$ \\
\hline \multicolumn{5}{|l|}{ Age } \\
\hline $55-59$ & $3417(38.5)$ & $119(47.0)$ & $92(15.0)$ & $6(21.4)$ \\
\hline $60-64$ & 3095 (34.9) & $100(39.1)$ & $217(35.3)$ & $12(42.9)$ \\
\hline $65-69$ & $2355(26.6)$ & $35(13.9)$ & $305(49.7)$ & $10(35.7)$ \\
\hline \multicolumn{5}{|c|}{ Educational level ${ }^{1}$} \\
\hline low & $4176(47.1)$ & $81(31.7)$ & $275(45.2)$ & $10(35.7)$ \\
\hline medium & 3065 (34.6) & $123(48.5)$ & $212(34.8)$ & $10(35.7)$ \\
\hline high & $1574(17.7)$ & $44(17.3)$ & $122(20.0)$ & $8(28.6)$ \\
\hline \multicolumn{5}{|c|}{ Fat intake (quintiles) } \\
\hline 1 (low) & $1763(19.9)$ & $43(16.9)$ & $135(22.0)$ & $5(17.9)$ \\
\hline 2 & $1753(19.8)$ & $54(21.3)$ & $130(21.2)$ & $7(25.0)$ \\
\hline 3 & $1771(20.0)$ & $69(27.2)$ & $123(20.0)$ & $6(21.4)$ \\
\hline 4 & $1787(20.2)$ & $38(14.8)$ & $119(19.4)$ & $4(14.3)$ \\
\hline 5 (high) & $1794(20.2)$ & $50(19.8)$ & $107(17.4)$ & $6(21.4)$ \\
\hline \multicolumn{5}{|c|}{ Vegetable consumption (quintiles) } \\
\hline 1 (low) & $1800(20.3)$ & $62(24.3)$ & $121(19.7)$ & $6(21.4)$ \\
\hline 2 & $1702(19.2)$ & $82(32.1)$ & $130(21.2)$ & $2(7.1)$ \\
\hline 3 & $1760(19.8)$ & $57(22.2)$ & $122(19.9)$ & $9(32.1)$ \\
\hline 4 & $1828(20.6)$ & $35(13.9)$ & $141(23.0)$ & $6(21.4)$ \\
\hline 5 (high) & $1778(20.0)$ & $19(7.4)$ & $100(16.3)$ & $5(17.9)$ \\
\hline \multicolumn{5}{|c|}{ Fruit consumption (quintiles) } \\
\hline 1 (low) & $1810(20.4)$ & $31(12.4)$ & $116(18.9)$ & - \\
\hline 2 & $1748(19.7)$ & $57(22.2)$ & $110(17.9)$ & $9(32.1)$ \\
\hline 3 & $1768(19.9)$ & $47(18.4)$ & $101(16.4)$ & $5(17.9)$ \\
\hline 4 & $1778(20.1)$ & $50(19.8)$ & $140(22.8)$ & $6(21.4)$ \\
\hline 5 (high) & $1763(19.9)$ & $69(27.2)$ & $147(23.9)$ & $8(28.6)$ \\
\hline
\end{tabular}

${ }^{1}$ Because of missing information, percentages may not add up to $100 \%$; low is defined as primary school with/without lower level vocational education, medium as secondary school or medium level vocational education, high as university or higher level vocational education. 
Age-adjusted and multivariate adjusted RRs for prostate cancer according to family history were comparable (Table 2). A positive vs negative family history was associated with an increased prostate cancer risk $(R R=1.77)$. For an affected father the estimate was 1.38 with a $95 \% \mathrm{Cl}$ of $0.76-2.49$, for one or more affected brothers the RR was 5.54 (1.75-17.50). The RR for subjects with less than $50 \%$ of family members affected was 3.09 (1.60-5.98) and $0.95(0.34-2.66)$ when more than $50 \%$ was affected. For subjects with less than $50 \%$ of their brothers affected the RR was $12.26(2.34-64.35)$ and $2.60(0.51-13.26)$ when more

Table 2: Rate ratios (RRs) and $95 \%$ confidence intervals (95\% Cl) for prostate cancer according to the number and percentage of affected first degree family members and age at diagnosis of these family members, Netherlands Cohort Study (1986-1992).

\begin{tabular}{|c|c|c|c|c|}
\hline \multirow[b]{2}{*}{ Exposure } & \multicolumn{2}{|l|}{ Age-adjusted } & \multicolumn{2}{|c|}{ Multivariate adjusted ${ }^{1}$} \\
\hline & $\begin{array}{l}\text { Cases }^{2} \text { I } \\
\text { Person years } \\
\text { in subcohort }\end{array}$ & $\mathrm{RR}(95 \% \mathrm{Cl})$ & $\begin{array}{l}\text { Cases }^{2} I \\
\text { Person years } \\
\text { in subcohort }\end{array}$ & $\mathrm{RR}(95 \% \mathrm{Cl})$ \\
\hline \multicolumn{5}{|l|}{ No. of affected family members } \\
\hline none & $614 / 8868$ & $1.00^{3}$ & $609 / 8814$ & $1.00^{3}$ \\
\hline$\geq 1$ & $28 / 254$ & $1.77(1.06-2.96)$ & $28 / 248$ & $1.77(1.05-2.97)$ \\
\hline \multicolumn{5}{|l|}{ Father with prostate cancer } \\
\hline no & $622 / 8893$ & $1.00^{3}$ & $617 / 8839$ & $1.00^{3}$ \\
\hline yes & $20 / 229$ & $1.36(0.75-2.45)$ & $20 / 223$ & $1.38(0.76-2.49)$ \\
\hline \multicolumn{5}{|c|}{ Brother(s) with prostate cancer } \\
\hline no & $634 / 9097$ & $1.00^{3}$ & $629 / 9037$ & $1.00^{3}$ \\
\hline yes & $8 / 25$ & $6.29(1.92-20.55)$ & $8 / 25$ & $5.54(1.75-17.50)$ \\
\hline \multicolumn{5}{|l|}{$\%$ of affected family members } \\
\hline none & $614 / 8868$ & $1.00^{3}$ & $609 / 8814$ & $1.00^{3}$ \\
\hline $1-49$ & $20 / 125$ & $3.00(1.83-4.89)$ & $20 / 118$ & $3.09(1.60-5.98)$ \\
\hline 250 & $6 / 86$ & $0.99(0.50-1.97)$ & $6 / 86$ & $0.95(0.34-2.66)$ \\
\hline \multicolumn{5}{|l|}{$\%$ of affected brothers } \\
\hline none & $504 / 7232$ & $1.00^{3}$ & $500 / 7175$ & $1.00^{3}$ \\
\hline $1-49$ & $5 / 13$ & $12.74(3.06-53.00)$ & $5 / 13$ & $12.26(2.34-64.35)$ \\
\hline 250 & $3 / 13$ & $3.50(0.95-12.86)$ & $3 / 13$ & $2.60(0.51-13.26)$ \\
\hline \multicolumn{5}{|l|}{$\begin{array}{l}\text { Age (years) at diagnosis family } \\
\text { member }^{4}\end{array}$} \\
\hline no affected family member & $614 / 8868$ & $1.00^{3}$ & $609 / 8814$ & $1.00^{3}$ \\
\hline 275 & $11 / 111$ & $1.37(0.80-2.33)$ & $11 / 111$ & $1.36(0.64-2.89)$ \\
\hline$<75$ & $13 / 113$ & $2.38(1.41-4.03)$ & $13 / 107$ & $2.36(1.10-5.07)$ \\
\hline \multicolumn{5}{|l|}{ Age (years) at diagnosis father } \\
\hline no affected father & $622 / 8893$ & $1.00^{3}$ & $617 / 8839$ & $1.00^{3}$ \\
\hline$\geq 75$ & $11 / 111$ & $1.35(0.64-2.86)$ & $11 / 111$ & $1.34(0.63-2.86)$ \\
\hline$<75$ & $7 / 94$ & $1.58(0.61-4.06)$ & $7 / 88$ & $1.64(0.63-4.23)$ \\
\hline
\end{tabular}

1 Adjusted for age at baseline (continuous), educational level (low, medium, high), total fat intake (continuous), and total vegetable and total fruit consumption (both continuous); ${ }^{2}$ Because of missing information, numbers may not add up to $642 ;{ }^{3}$ Reference category; ${ }^{4}$ In case of more than one affected family member, the youngest age at diagnosis was used. 
than $50 \%$ of their brothers were affected. Age at diagnosis of affected family members before age 75 was associated with a higher relative risk ( $R R=2.36,95 \% \mathrm{Cl}$ : 1.10-5.07) compared with age at diagnosis at age 75 years or older $(R R=1.36,95 \% \mathrm{Cl}$ : $0.64-2.89)$.

In the subgroup of cases diagnosed before age 70, the RRs for a positive family history were increased while in the subgroup of cases diagnosed after age 70 , only the RR for having a brother with prostate cancer was increased (Table 3). RRs for a family history of prostate cancer were higher for advanced prostate tumors than for localized tumors (Table 4).

Table 3: Rate ratios (RRs) and 95\% confidence intervals (95\% $\mathrm{Cl}$ ) for prostate cancer according to age at diagnosis and family history, Netherlands Cohort Study (1986-1992).

\begin{tabular}{|c|c|c|c|c|}
\hline \multirow[t]{2}{*}{ Characteristic } & \multicolumn{2}{|c|}{$\begin{array}{l}\text { Cases diagnosed before age } 70 \\
(n=369)\end{array}$} & \multicolumn{2}{|c|}{$\begin{array}{l}\text { Cases diagnosed at age } 70 \text { and } \\
\text { older }(n=273)\end{array}$} \\
\hline & $\begin{array}{l}\text { Cases/ } \\
\text { Person years } \\
\text { in subcohort }\end{array}$ & $\mathrm{RR}^{1}(95 \% \mathrm{Cl})$ & $\begin{array}{l}\text { Cases/ } \\
\text { Person years } \\
\text { in subcohort }\end{array}$ & $\mathrm{RR}^{1}(95 \% \mathrm{Cl})$ \\
\hline \multicolumn{5}{|c|}{ No. of affected family members } \\
\hline none $^{2}$ & $343 / 8814$ & 1.00 & $266 / 8814$ & 1.00 \\
\hline$\geq 1$ & $21 / 248$ & $2.22(1.37-3.59)$ & $7 / 248$ & $0.90(0.32-2.51)$ \\
\hline \multicolumn{5}{|c|}{ Father with prostate cancer } \\
\hline $\mathrm{no}^{2}$ & $350 / 8839$ & 1.00 & $267 / 8839$ & 1.00 \\
\hline yes & $14 / 223$ & $1.61(0.88-2.95)$ & $6 / 223$ & $0.79(0.27-2.32)$ \\
\hline \multicolumn{5}{|c|}{ Brother(s) with prostate cancer } \\
\hline$n o^{2}$ & $357 / 9037$ & 1.00 & $272 / 9037$ & 1.00 \\
\hline yes & $7 / 25$ & $6.96(2.19-22.12)$ & $1 / 25$ & $4.58(0.41-50.96)$ \\
\hline
\end{tabular}

${ }^{1}$ Adjusted for age at baseline (continuous), educational level (low, medium, high), total fat intake (continuous), and total vegetable and total fruit consumption (both continuous); ${ }^{2}$ Reference category.

\section{Discussion}

An important strength of our study is its prospective design, making information bias unlikely. Another strength is that there is no loss to follow-up of cases and subcohort members $(6,9)$. On the other hand, small numbers limited certain analyses. Furthermore, family history is subject to nondifferential misclassification. Nevertheless, it has been shown that the accuracy of reported family history of cancer $(10)$ or prostate cancer $(11,12)$ in first degree relatives is high. Another limitation is that we could not take into account the age distribution of family members.

A positive association between family history and prostate cancer risk has been previously reported (12-14). In several $(12,15-19)$, but not all $(2,11)$ studies, estimated risks were higher for affected brothers (RRs varying from 1.9 to 5.3 ) than for affected fathers (RRs 
varying from 1.2 to 3.5). These findings support an $\mathrm{X}$-linked or recessive model of inheritance (20), but greater misclassification of the reporting of fathers' history compared with brothers' history of prostate cancer could have influenced results. An autosomal dominant gene has also been proposed as a model of inheritance $(21,22)$.

Table 4: Rate ratios (RRs) and 95\% confidence intervals (95\% Cl) for localized (TO-2, MO) and advanced (T3-4, M0; TO-4, M1) prostate tumors according to family history, Netherlands Cohort Study (1986-1992).

\begin{tabular}{|c|c|c|c|c|}
\hline \multirow[t]{2}{*}{ Characteristic } & \multicolumn{2}{|c|}{$\begin{array}{l}\text { Localized tumors } \\
(n=226)\end{array}$} & \multicolumn{2}{|c|}{$\begin{array}{l}\text { Advanced tumors } \\
(n=213)\end{array}$} \\
\hline & $\begin{array}{l}\text { Cases/ } \\
\text { Person years } \\
\text { in subcohort }\end{array}$ & $\mathrm{RR}^{1}(95 \% \mathrm{Cl})$ & $\begin{array}{l}\text { Cases/ } \\
\text { Person years } \\
\text { in subcohort }\end{array}$ & $\operatorname{RR}^{1}(95 \% \mathrm{Cl})$ \\
\hline \multicolumn{5}{|c|}{ No. of affected family members } \\
\hline none $e^{2}$ & $214 / 8814$ & 1.00 & $198 / 8814$ & 1.00 \\
\hline$\geq 1$ & $10 / 248$ & $1.85(0.90-3.81)$ & $12 / 248$ & $2.37(1.22-4.62)$ \\
\hline \multicolumn{5}{|c|}{ Father with prostate cancer } \\
\hline $\mathrm{no}^{2}$ & $216 / 8839$ & 1.00 & $201 / 8839$ & 1.00 \\
\hline yes & $8 / 223$ & $1.61(0.72-3.56)$ & $9 / 223$ & $1.98(0.93-4.24)$ \\
\hline \multicolumn{5}{|c|}{ Brother(s) with prostate cancer } \\
\hline $\mathrm{no}^{2}$ & 222/9037 & 1.00 & $207 / 9037$ & 1.00 \\
\hline yes & $2 / 25$ & $4.30(0.81-22.86)$ & $3 / 25$ & $5.33(1.36-20.85)$ \\
\hline
\end{tabular}

\footnotetext{
'Adjusted for age at baseline (continuous), educational level (low, medium, high), total fat intake (continuous), and total vegetable and total fruit consumption (both continuous); ${ }^{2}$ Reference category.
}

Some studies have reported an increasing risk of prostate cancer with increasing numbers of affected first degree family members $(2,11,12,16)$. Our estimates, based on small numbers, did not confirm this pattern. Some studies, as the NLCS, showed a higher risk associated with a younger age at diagnosis of affected family members $(12,16)$, but not all (11). We were unable to adjust for the age of family members, but controlling for the age of the subjects might have, albeit indirectly and partially, controlled for family age. When family members were affected, risk of developing prostate cancer before age 70 was increased whereas risk of prostate cancer after age 70 was not. This finding comports with those in one cohort study $(23)$ and two case-control studies $(16,24)$. In one cohort (2) and one casecontrol study (25), associations were not clearly different for younger and older cases. In general, hereditary cancers are known to have earlier onset. Therefore, our findings might indicate a hereditary component for early prostate cancer.

We found stronger associations for advanced prostate tumors than for localized tumors. Our findings, therefore, do not support the suggestion that men with a positive family history of prostate cancer get diagnosed at an early stage because of increased awareness. Moreover, if men with a positive family history are at increased risk of aggressive growing 
prostate tumors, this might counteract the possibility of more early stage diagnoses and the similar proportions in our study might be the net result of these two possibilities. In two other studies no different association for localized and advanced tumors was reported $(15,16)$.

\section{Acknowledgements}

We are indebted to the participants of this study and further wish to thank the regional cancer registries (IKA, IKL, IKMN, IKN, IKO, IKR, IKST, IKW, IKZ), and the Dutch national data base of pathology (PALGA); A. Volovics for statistical advice; S. van de Crommert, J. Nelissen, H. Brants, M. Moll, W. van Dijk, C. Sloot, P. Florax and A. Pisters for assistance; and $\mathrm{H}$. van Montfort, R. Schmeitz, T. van Montfort, and M. de Leeuw for programming and statistical assistance.

\section{References}

1. Key T. Risk factors for prostate cancer. Cancer Surv 1995;23:63-77.

2. Rodriguez $\mathrm{C}$, Calle EE, Miracle McMahill HL, et al. Family history and risk of fatal prostate cancer. Epidemiology 1997;8:653-7.

3. Van den Brandt PA, Goldbohm RA, Van 't Veer P, et al. A large-scale prospective cohort study on diet and cancer in The Netherlands. J Clin Epidemiol 1990;43:285-95.

4. Prentice RL. A case-cohort design for epidemiologic cohort studies and disease prevention trials. Biometrika 1986;73:1-11.

5. Van den Brandt PA, Schouten LJ, Goldbohm RA, et al. Development of a record linkage protocol for use in the Dutch Cancer Registry for Epidemiological Research. Int J Epidemiol 1990;19:5538.

6. Goldbohm RA, Van den Brandt PA, Dorant E. Estimation of the coverage of Dutch municipalities by cancer registries and PALGA based on hospital discharge data. Tijdschr Soc Gezondheidsz 1994;72:80-4.

7. Goldbohm RA, Van den Brandt PA, Brants HAM, et al. Validation of a dietary questionnaire used in a large-scale prospective cohort study on diet and cancer. Eur J Clin Nutr 1994;48:253-65.

8. Volovics A, van den Brandt PA. Methods for the analyses of case-cohort studies. Biom J 1997;2:195-214.

9. Van den Brandt PA, Van 't Veer P, Goldbohm RA, et al. A prospective cohort study on dietary fat and the risk of postmenopausal breast cancer. Cancer Res 1993;53:75-82.

10. Love RR, Evans AM, Josten DM. The accuracy of patient reports of a family history of cancer. J Chronic Dis 1985;38:289-93.

11. Steinberg GD, Carter BS, Beaty TH, et al. Family history and the risk of prostate cancer. Prostate 1990;17:337-47.

12. Whittemore $\mathrm{AS}, \mathrm{Wu} \mathrm{AH}$, Kolonel $\mathrm{LN}$, et al. Family history and prostate cancer risk in black, white, and Asian men in the United States and Canada. Am J Epidemiol 1995;141:732-40.

13. Carter BS, Bova GS, Beaty $\mathrm{TH}$, et al. Hereditary prostate cancer: epidemiologic and clinical features. J Urol 1993;150:797-802.

14. Pienta KJ, Esper PS. Risk factors for prostate cancer. Ann Intern Med 1993;118:793-803.

15. Hayes RB, Liff JM, Pottern LM, et al. Prostate cancer risk in U.S. blacks and whites with a family history of cancer. Int J Cancer 1995;60:361-4.

16. Lesko SM, Rosenberg L, Shapiro S. Family history and prostate cancer risk. Am J Epidemiol 1996;144:1041-7.

17. Narod SA, Dupont A, Cusan L, et al. The impact of family history on early detection of prostate cancer. Nat Med (letter) 1995;1:99-101.

18. Spitz MR, Currier RD, Fueger JJ, et al. Familial patterns of prostate cancer: a case-control analysis. J Urol 1991;146:1305-7.

19. Keetch DW, Rice JP, Suarez BK, et al. Familial aspects of prostate cancer: a case control study. J Urol 1995;154:2100-2.

20. Monroe KR, Yu MC, Kolonel LN, et al. Evidence of an X-linked or recessive genetic component to prostate cancer risk. Nat Med 1995;1:827-9. 
21. Carter BS, Beaty TH, Steinberg GD, et al. Mendelian inheritance of familial prostate cancer. Proc Natl Acad Sci USA 1992;89:3367-71.

22. Gronberg H, Damber L, Damber JE, et al. Segregation analysis of prostate cancer in Sweden: support for dominant inheritance. Am J Epidemiol 1997;146:552-7.

23. Gronberg H, Damber $L$, Damber JE. Familial prostate cancer in Sweden. A nationwide register cohort study. Cancer 1996;77:138-43.

24. Cannon L, Bishop DT, Skolnick M, et al. Genetic epidemiology of prostate cancer in the Utah Mormon genealogy. Cancer Surveys 1982;1:47-69.

25. Andersson SO, Baron J, Bergstrom R, et al. Lifestyle factors and prostate cancer risk: a casecontrol study in Sweden. Cancer Epidemiol Biomarkers Prev 1996;5:509-13. 


\title{
Chapter 9
}

\section{Socioeconomic status in relation to risk of}

\section{prostate cancer $^{1}$}

\author{
Agnes G. Schuurman² \\ Piet A. van den Brandt ${ }^{2}$ \\ R. Alexandra Goldbohm ${ }^{3}$
}

\begin{abstract}
We studied the association between socioeconomic status and prostate cancer incidence and the role of lifestyle factors and medical consumption pattern in explaining this association in the Netherlands Cohort Study (NLCS). The NLCS is a prospective cohort study that started in 1986 among 58,279 men ages 55-69 years. The cohort originates from 204 municipalities in the Netherlands. Data were collected by means of a self-administered questionnaire. After 6.3 years of follow-up 642 incident cases were available for analysis. In age-adjusted analyses, positive associations were observed between prostate cancer risk and highest level of education and social standing. Rate ratios (RR) and $95 \%$ confidence intervals $(\mathrm{Cl})$ for the highest vs lowest exposure category were $1.33(1.02-1.74)$ and 1.27 (0.88-1.83), respectively, and the trend tests were significant (both p-values were 0.01). Additional adjustment was carried out for variables that have been found to be associated with prostate cancer risk in the NLCS and that were associated with socioeconomic status. Adjustment for family history of prostate cancer, intake of sweet peppers, mushrooms, oranges, raisins, cured meat, milk products, linolenic acid, $\beta$-cryptoxanthin, alcohol from white/fortified wines and vitamin supplement use resulted in somewhat lower RRs: 1.26 (0.95-1.67) for level of education and $1.13(0.78-1.65)$ for social standing ( $p$-values trend test 0.09 and 0.04 , respectively). Analyses were repeated in subgroups of latent and nonlatent and localized and advanced tumors. Among nonlatent and advanced tumors, associations were positive for level of education and social standing. In the other subgroups, no associations were observed. We conclude that lifestyle can partly explain an association between socioeconomic status and prostate cancer risk, and not medical consumption patterns.
\end{abstract}

\footnotetext{
${ }^{1}$ Submitted for publication

${ }^{2}$ Dept. of Epidemiology, Maastricht University, Maastricht

${ }^{3}$ Dept. of Consumer Research \& Epidemiology, TNO Nutrition and Food Research Institute, Zeist
} 


\section{Introduction}

For different types of cancer (e.g. cancer of the colon, breast, lung and stomach) an association between incidence and socioeconomic status has been observed (1). Prostate cancer has also been subject to investigations with respect to socioeconomic status but in reviews on socioeconomic status and prostate cancer it was concluded that, thus far, no consistent association has been observed. Although the majority of studies showed no clear association, positive and inverse associations have been reported too (2-4).

Socioeconomic status is not thought to be a direct risk factor but lifestyle variables related to socioeconomic status may be responsible for observed associations. Furthermore, socioeconomic status may be related to a specific medical consumption pattern, such that subjects with a higher socioeconomic status more frequently visit a physician. If so, these subjects could be diagnosed with prostate cancer more often and possibly in an earlier stage of disease, thus resulting in a positive association between socioeconomic status and prostate cancer risk (2). Several previous studies on socioeconomic status were limited by small numbers of cases and mostly reported no adjustment for potential confounding factors. In addition, an association between socioeconomic status and tumor characteristics was only investigated in two case-control studies $(2,5)$. Therefore, we investigated an association between socioeconomic status and prostate cancer incidence in the Netherlands Cohort Study (NLCS). Moreover, we specifically examined whether other dietary or lifestyle factors might explain a possible association and we also studied case subgroups of latent and nonlatent and localized and advanced prostate tumors separately.

\section{Materials and methods}

The cohort study

The study design has been reported in detail elsewhere (6), therefore, we will only briefly outline the design. The NLCS was initiated in September 1986 and includes 58,279 men aged 55-69 years at the beginning of the study who originated from 204 municipal registries throughout the country. The cohort members completed a mailed, selfadministered questionnaire on dietary habits, education, occupation and other risk factors for cancer. For reasons of efficiency in data processing and analysis, the case-cohort approach $(7,8)$ was used. In a case-cohort approach, cases are derived from the entire cohort (providing numerator information for calculation of cancer incidence rates), while accumulated person years at risk in the total cohort are estimated using a random subcohort sample (providing denominator information for the rates). In contrast to nested case-control sampling, this subcohort can be used for multiple disease endpoints. The subcohort $(n=1,688)$ was sampled directly after identification of all cohort members and has been followed up biennially for vital status information. Follow-up for incidence of prostate cancer was established by computerized record linkage with all nine cancer registries in the Netherlands and with the Dutch national data base of pathology reports (PALGA) (9). No subcohort members were lost to follow-up and completeness of follow-up of cancer was at 
least 96 percent (10). After a follow-up period of 6.3 years (September 1986-December 1992), and exclusion of prevalent cancer cases other than skin cancer, 704 incident, confirmed primary prostate cancer cases were available for analysis. In the subcohort, prevalent cancer cases other than skin cancer were also excluded, leaving 1,630 subcohort members for analysis. During our follow-up period, systematic screening for prostate cancer was not instituted in the Netherlands.

\section{The questionnaire}

Questions on highest attained level of education and occupational history were used to represent socioeconomic status. Educational level was classified as low (primary school with or without lower vocational school), medium (secondary school or medium level vocational education), and high (university or higher level vocational school). Information about occupational history was coded according to occupational sector and required training (EGP) and according to social standing (U\&S). For both the EGP score and the U\&S score information on the last occupation was used. The EGP coding scheme is based on four aspects of occupation: occupational group, required training, self-support/ independence and leadership $(11,12)$. Each occupation is classified in (one of) 10 categories according to these aspects. The U\&S score is based on an ordering of occupational titles according to social standing (12). Information on other risk factors for cancer, e.g. usual diet in the year preceding the baseline measurement, and alcohol consumption was also gathered with the self-administered questionnaire.

All questionnaire data were key-entered twice and processed for all incident cases in the cohort and for all subcohort members in a manner blinded with respect to case/subcohort status. This was done in order to minimize observer bias in coding and interpretation of the data.

\section{Data analysis}

Subjects with incomplete or inconsistent dietary data were excluded according to criteria described before (13). This was done because we intended to compute multivariate adjusted RRs with different dietary risk factors in the model and observe the effect of inclusion of these factors. A total number of 642 cases and 1,525 subcohort members remained for analyses.

The EGP score of the last occupation was divided into four categories: blue collar jobs (manual workers), lower white collar jobs (nonmanual workers), upper white collar jobs (professionals and managers) and others (farmers and self-employed people). The U\&S score of the last occupation was divided into five categories ranging from low (e.g. cleaner, garbage collector) to high social standing (e.g. lawyer) $(11,12)$. Rate ratios (RRs) and $95 \%$ confidence intervals $(95 \% \mathrm{CI})$ were computed using the $\mathrm{GLIM}$ statistical package (14). 
Exponentially distributed survival times were assumed in the follow-up period. Since standard software was not available, specific macros were developed to account for the additional variance introduced by using the subcohort instead of the entire cohort (15). Tests for trend were based on likelihood ratio tests and two-sided p-values are used throughout this report. First, analyses were only adjusted for age. Thereafter, multivariate RRs were computed. Factors that were previously shown to be associated with prostate cancer risk in the NLCS and that were associated with socioeconomic status such as family history of prostate cancer (16), intake of sweet peppers, mushrooms, oranges, and raisins (17), cured meat and milk and milk products (18), linolenic acid (19), $\beta$-cryptoxanthin and vitamin supplement use (20), and alcohol from white wine and fortified wines (21) were included in the multivariate model. RRs were also computed in subgroups of latent and nonlatent tumors, and localized and advanced tumors. Latent and nonlatent tumors were defined based on information from the pathology reports. Prostate tumors detected incidentally during transurethral prostate resections were coded latent. Prostate tumors

Table 1: Rate ratios (RR) and $95 \%$ confidence intervals (Cl) for prostate cancer according to three different socioeconomic status indicators, Netherlands Cohort Study (1986-1992).

\begin{tabular}{|c|c|c|c|}
\hline Exposure & $\begin{array}{l}\text { No of cases/ } \\
\text { person years } \\
\text { in subcohort }\end{array}$ & $\mathrm{RR}^{1}(95 \% \mathrm{Cl})$ & $\operatorname{RR}^{2}(95 \% \mathrm{Cl})$ \\
\hline \multicolumn{4}{|c|}{ Highest level of education ${ }^{3}$} \\
\hline low & $285 / 4257$ & 1.00 & 1.00 \\
\hline medium & $222 / 3188$ & $1.05(0.85-1.31)$ & $0.98(0.77-1.23)$ \\
\hline \multirow[t]{2}{*}{ high } & $130 / 1618$ & $1.33(1.02-1.74)$ & $1.26(0.95-1.67)$ \\
\hline & & P-trend 0.01 & P-trend 0.09 \\
\hline \multicolumn{4}{|c|}{ EGP score last profession ${ }^{3}$} \\
\hline blue collar & $224 / 3181$ & 1.00 & 1.00 \\
\hline lower white collar & $66 / 1174$ & $0.81(0.58-1.13)$ & $0.74(0.52-1.04)$ \\
\hline upper white collar & $204 / 2596$ & $1.22(0.95-1.55)$ & $1.13(0.87-1.45)$ \\
\hline \multirow[t]{2}{*}{ other ${ }^{4}$} & $96 / 1376$ & $0.94(0.70-1.27)$ & $0.90(0.67-1.23)$ \\
\hline & & P-trend 0.05 & P-trend 0.16 \\
\hline \multicolumn{4}{|c|}{ U\&S score last profession ${ }^{3}$} \\
\hline 1 (low) & $111 / 1687$ & 1.00 & 1.00 \\
\hline 2 & $129 / 2096$ & $0.92(0.67-1.25)$ & $0.86(0.63-1.19)$ \\
\hline 3 & $170 / 2278$ & $1.14(0.84-1.54)$ & $1.08(0.80-1.47)$ \\
\hline 4 & $100 / 1228$ & $1.31(0.93-1.85)$ & $1.24(0.87-1.78)$ \\
\hline \multirow[t]{2}{*}{5 (high) } & $80 / 1037$ & $1.27(0.88-1.83)$ & $1.13(0.78-1.65)$ \\
\hline & & P-trend 0.01 & P-trend 0.04 \\
\hline
\end{tabular}

\footnotetext{
'Adjusted for age; ${ }^{2}$ Adjusted for age, family history of prostate cancer, intake of sweet peppers, mushrooms, oranges, raisins, cured meat, milk\&milk products, linolenic acid, $\beta$-cryptoxanthin, alcohol from white wine, alcohol from fortified wines, and vitamin supplement use; ${ }^{3}$ Numbers may not add up to 642 because of missing information on last occupation; ${ }^{4}$ Farmers and self-employed people, not included in the trend test.
} 
detected during surgical procedures used in case of suspected prostate cancer (biopsy, radical prostatectomy) were coded nonlatent. The classification into localized tumors (TO-2, $\mathrm{MO}$ ) and advanced tumors (T3-4, M0; T0-4, M1) was based on the TNM staging system (22).

\section{Results}

In table 1 the association between the three different socioeconomic status indicators and risk of prostate cancer is shown. The highest attained level of education was positively associated with prostate cancer risk. In the age-adjusted analyses, RRs in increasing categories were 1.00 (ref), 1.05 and 1.33, with a statistically significant test for trend ( $p$ value of 0.01 ). Also for the U\&S score a weakly positive association was noted; RRs were 1.00 (ref), $0.92,1.14,1.31$ and 1.27 . None of these RRs was statistically significant but a positive trend in risk was observed ( $p$-value of 0.01 ). No clear association for EGP score was apparent. Overall, in the multivariate analyses the observed associations became somewhat weaker. For the level of education, the RR in the highest category (RR of 1.26) and the trend test ( $p$-value of 0.09 ) were no longer statistically significant. Although associations for the U\&S score also largely disappeared in the multivariate models, the test for trend remained statistically significant ( $p$-value of 0.04 ).

The distribution of tumor characteristics across categories of socioeconomic status indicators is shown in table 2 . Overall, about 20 percent of all prostate tumors was classified as latent, about 40 percent was classified as nonlatent and another 40 percent could not be classified according to latency due to missing information. In general, subjects with a higher socioeconomic status were slightly more often classified as having a nonlatent prostate tumor. In the classification based on the TNM staging system, about equal percentages were classified as localized and advanced. Some 30 percent of all cases could not be classified into categories of localized and advanced prostate tumors due to missing information. Also in this classification, subjects with a higher socioeconomic status were more often classified as having an advanced prostate tumor.

Table 3 shows the multivariate adjusted associations between indicators of socioeconomic status and prostate cancer risk separately for latent and nonlatent prostate tumors. In the subgroup of latent tumors, no clear associations were observed. In the subgroups of nonlatent tumors, significant positive trends in risk were observed for the highest level of education as well as for the U\&S score. RRs $(95 \% \mathrm{Cl})$ in the highest vs lowest exposure category were $1.46(1.01-2.12)$ and $1.36(0.83-2.23)$, respectively, and the p-values for the trend test were 0.04 and 0.01 , respectively. 
Table 2: Distribution of prostate tumor characteristics across categories of three indicators of socioeconomic status, Netherlands Cohort Study (1986-1992).

\begin{tabular}{|c|c|c|c|c|c|c|}
\hline \multirow[b]{2}{*}{$\begin{array}{l}\text { Socioeconomic status } \\
\text { indicator }\end{array}$} & \multicolumn{3}{|c|}{ Classification based on TURP ${ }^{1}$} & \multicolumn{3}{|c|}{ Classification based on $\mathrm{TNM}^{2}$} \\
\hline & $\begin{array}{c}\text { Latent } \\
\text { tumors } \\
\mathrm{n}(\%)\end{array}$ & $\begin{array}{c}\text { Nonlatent } \\
\text { tumors } \\
\mathrm{n}(\%)\end{array}$ & $\begin{array}{l}\text { Missing } \\
n(\%)\end{array}$ & $\begin{array}{c}\text { Localized } \\
\text { tumors } \\
\mathrm{n}(\%)\end{array}$ & $\begin{array}{c}\text { Advanced } \\
\text { tumors } \\
n(\%)\end{array}$ & $\begin{array}{l}\text { Missing } \\
\mathrm{n}(\%)\end{array}$ \\
\hline \multicolumn{7}{|c|}{ Highest level of education } \\
\hline low & $60(21.1)$ & $120(42.1)$ & $105(36.8)$ & $99(34.7)$ & $92(32.3)$ & $94(33.0)$ \\
\hline medium & $38(17.1)$ & $98(44.1)$ & $86(38.7)$ & $80(36.0)$ & $66(29.7)$ & $76(34.2)$ \\
\hline high & $15(11.5)$ & $62(47.7)$ & $53(40.8)$ & $45(34.6)$ & $52(40.0)$ & $33(25.4)$ \\
\hline \multicolumn{7}{|c|}{ EGP score last profession } \\
\hline blue collar & $44(19.6)$ & $99(44.2)$ & $81(36.2)$ & $72(32.1)$ & $78(34.8)$ & $74(33.0)$ \\
\hline lower white collar & $18(27.3)$ & $28(42.4)$ & $20(30.3)$ & $26(39.4)$ & $16(24.2)$ & $24(36.4)$ \\
\hline upper white collar & $27(13.2)$ & $98(48.0)$ & 79 (38.7) & $65(31.9)$ & $74(36.3)$ & 65 (31.9) \\
\hline other $^{3}$ & $18(18.8)$ & $37(38.5)$ & $41(42.7)$ & $41(25.0)$ & 31 (32.3) & $24(25.0)$ \\
\hline \multicolumn{7}{|c|}{ U\&S score last profession } \\
\hline 1 (low) & $22(19.8)$ & $47(42.3)$ & $42(37.8)$ & $41(36.9)$ & $30(27.0)$ & $40(36.0)$ \\
\hline 2 & $28(21.7)$ & $53(41.1)$ & $48(37.2)$ & $49(38.0)$ & $38(29.5)$ & $42(32.6)$ \\
\hline 3 & $34(20.0)$ & $70(41.2)$ & $66(38.8)$ & $57(33.5)$ & $66(38.8)$ & $47(27.6)$ \\
\hline 4 & $12(12.0)$ & $52(52.0)$ & $36(36.0)$ & $32(32.0)$ & $34(34.0)$ & $34(34.0)$ \\
\hline 5 (high) & $11(13.8)$ & $40(50.0)$ & 29 (36.3) & $25(31.3)$ & $31(38.8)$ & $24(30.0)$ \\
\hline
\end{tabular}

${ }^{1}$ Latent tumors are those tumors that were detected as a consequence of a transurethral resection of the prostate (TURP), nonlatent tumors are those tumors that were detected during surgical procedures used in case of suspected prostate cancer (biopsy, radical prostatectomy); ${ }^{2}$ Localized tumors: T0-2, M0 and advanced tumors: T3-4, M0 and T0-4, M1; ${ }^{3}$ Farmers and self-employed people.

The association between socioeconomic status and localized and advanced prostate tumors is displayed in table 4. Socioeconomic status seemed not to be strongly associated with localized prostate tumors. Among advanced tumors, positive associations were observed for highest level of education and for the U\&S score; RRs ( $95 \% \mathrm{Cl})$ for the highest vs lowest exposure categories were 1.55 (1.04-2.31) and $1.60(0.91-2.80)$, respectively. The trend test for level of education was of borderline significance ( $p$-value of 0.06 ) and the trend test for the U\&S score was statistically significant ( $p$-value of 0.01 ).

\section{Discussion}

In this study, socioeconomic status was operationalized as highest attained level of education and as occupational group and required training (EGP) and social standing (U\&S) of the last occupation. Our findings indicate that the positive associations observed for level of education and U\&S score became weaker and nonsignificant after inclusion of family history of prostate cancer and several dietary risk factors. When subgroups of latent and nonlatent and localized and advanced prostate tumors were investigated separately, the highest attained level of education and the U\&S score were positively associated with 
Table 3: Rate ratios (RR) and 95\% confidence intervals (Cl) according to three different socioeconomic status indicators, in subgroups of latent and nonlatent prostate tumors, Netherlands Cohort Study (1986-1992).

\begin{tabular}{|c|c|c|c|c|c|}
\hline \multirow[t]{2}{*}{ Exposure } & \multirow[b]{2}{*}{$\begin{array}{l}\text { Person years } \\
\text { of follow-up }\end{array}$} & \multicolumn{2}{|c|}{$\begin{array}{l}\text { Latent tumors } \\
(n=115)\end{array}$} & \multicolumn{2}{|c|}{$\begin{array}{l}\text { Nonlatent tumors } \\
(\mathrm{n}=282)\end{array}$} \\
\hline & & Cases & $\operatorname{RR}^{1}(95 \% \mathrm{Cl})$ & Cases & $\mathrm{RR}^{1}(95 \% \mathrm{Cl})$ \\
\hline \multicolumn{6}{|c|}{ Highest level of education } \\
\hline low & 4257 & 60 & 1.00 & 120 & 1.00 \\
\hline medium & 3188 & 38 & $0.88(0.57-1.36)$ & 98 & $1.02(0.75-1.39)$ \\
\hline high & 1618 & 15 & $0.84(0.46-1.54)$ & 62 & $1.46(1.01-2.12)$ \\
\hline & & & P-trend 0.48 & & P-trend 0.04 \\
\hline \multicolumn{6}{|c|}{ EGP score last profession } \\
\hline blue collar & 3181 & 44 & 1.00 & 99 & 1.00 \\
\hline lower white collar & 1174 & 18 & $1.13(0.63-2.02)$ & 28 & $0.70(0.43-1.12)$ \\
\hline upper white collar & 2596 & 27 & $0.88(0.53-1.46)$ & 98 & $1.22(0.87-1.70)$ \\
\hline other ${ }^{2}$ & 1376 & 18 & $0.88(0.50-1.56)$ & 37 & $0.78(0.51-1.19)$ \\
\hline & & & P-trend 0.91 & & P-trend 0.11 \\
\hline \multicolumn{6}{|c|}{ U\&S score last profession } \\
\hline 1 (low) & 1687 & 22 & 1.00 & 47 & 1.00 \\
\hline $2^{107}$ & 2096 & 28 & $0.97(0.54-1.75)$ & 53 & $0.83(0.54-1.29)$ \\
\hline 3 & 2278 & 34 & $1.18(0.67-2.08)$ & 70 & $1.05(0.69-1.59)$ \\
\hline 4 & 1228 & 12 & $0.91(0.43-1.89)$ & 52 & $1.57(0.99-2.49)$ \\
\hline \multirow[t]{2}{*}{5 (high) } & 1037 & 11 & $0.91(0.42-1.97)$ & 40 & $1.36(0.83-2.23)$ \\
\hline & & & P-trend 0.89 & & P-trend 0.01 \\
\hline
\end{tabular}

${ }^{1}$ Adjusted for age, family history of prostate cancer, intake of sweet peppers, mushrooms, oranges, raisins, cured meat, milk\&milk products, linolenic acid, $\beta$-cryptoxanthin, alcohol from white wine, alcohol from fortified wines, and vitamin supplement use; ${ }^{2}$ Farmers and self-employed people, not included in the trend test.

nonlatent and advanced prostate tumors and not with latent or localized prostate tumors. In the overall analyses as well as in the subgroup analyses, no clear associations were observed for EGP score.

These results partially support the idea that lifestyle variables associated with socioeconomic status are responsible for the observed positive association between socioeconomic status and prostate cancer risk in the NLCS. In the majority of previous studies on socioeconomic status in relation to prostate cancer characteristics between cases and controls were compared (23-32), findings were reported without presenting risk estimates (33-39), or unadjusted risk estimates (40-49) or only adjustment for age (50-58) was reported. Regarding education, in several studies no clear associations were shown (5, $23-26,28,31,33,34-37,40,43,44,50,52,59)$ but also inverse $(32,41,42,47,51,53$, $55)$ and positive $(27,29,30,38,45,46,54,60-62)$ associations were indicated. Results regarding occupational status and prostate cancer risk $(28,44,47,48,50,54,56,63)$ and 
regarding income as a socioeconomic status indicator $(25,26,31,47,49,57,59)$ were also diverse. In one study, the positive age-adjusted association between education and prostate cancer disappeared after additional adjustment for urbanization and farming (5). In three other studies positive associations between education and prostate cancer risk were observed after correction for age, alcohol consumption and race (60), age, smoking and alcohol consumption (61) or age, area and housing tenure (62). Besides age, race and family history of prostate cancer, risk factors for prostate cancer are largely unknown. Therefore, residual confounding by unknown or unmeasured factors may be responsible for the remaining weakly positive association of level of education and U\&S score in our study.

Recall bias is not likely to have taken place because of the prospective nature of our study. Furthermore, selection bias due to loss to follow-up also is unlikely because of the high completeness of follow-up of both cases and subcohort members $(10,64)$. Misclassification of exposure, nevertheless, has to be considered in the interpretation of our results. However, if exposure misclassification has occurred, this is expected to be nondifferential, and estimated risks are most likely biased towards the null value. Socioeconomic status was operationalized as highest attained level of education, EGP score (functional level) and U\&S score (social standing), the last two both based on the last occupation. It seems reasonable to take the most recent occupation instead of the longest occupation when occupation is used as an indicator of socioeconomic status. The highest level of education is relatively stable over time. The level of education can mask important changes in individual circumstances after education is finished and therefore the highest level of education might be a less relevant socioeconomic status indicator for the older generation $(12,65)$. On the other hand, at older ages the level of education is still associated with level of knowledge which is related to lifestyle $(12,65)$. If the EGP score and the U\&S score could be viewed as more reflecting the recent situation, while educational level might be viewed as reflecting a situation several years ago, it is difficult to conclude whether lifestyle variables related to socioeconomic status are important at early stages of prostate cancer occurrence or at later stages since we observed an association for both the level of education and the U\&S score.

It has been hypothesized that a positive association between prostate cancer and socioeconomic status could be explained by a specific medical consumption pattern of men with a higher socioeconomic status (2). These men might visit a physician more frequently and therefore get diagnosed with prostate cancer more frequently and possibly at earlier stages. If true, we would expect a positive association between socioeconomic status indicators and latent or localized prostate tumors and no association in subgroups of nonlatent or advanced prostate tumors. Our results, however, indicated a stronger association between socioeconomic status and nonlatent or advanced prostate tumors 
Table 4: Rate ratios (RR) and 95\% confidence intervals (Cl) for prostate cancer according to three different socioeconomic status indicators, in subgroups of localized (TO-2, MO) and advanced (T3-4, MO; TO-4, M1) prostate tumors, Netherlands Cohort Study (1986-1992).

\begin{tabular}{|c|c|c|c|c|c|}
\hline \multirow[t]{2}{*}{ Exposure } & \multirow[b]{2}{*}{$\begin{array}{l}\text { Person years } \\
\text { of follow-up }\end{array}$} & \multicolumn{2}{|c|}{$\begin{array}{l}\text { Localized tumors } \\
(n=226)\end{array}$} & \multicolumn{2}{|c|}{$\begin{array}{l}\text { Advanced tumors } \\
(n=213)\end{array}$} \\
\hline & & Cases & $\mathrm{RR}^{1}(95 \% \mathrm{Cl})$ & Cases & $\mathrm{RR}^{1}(95 \% \mathrm{Cl})$ \\
\hline \multicolumn{6}{|c|}{ Highest level of education } \\
\hline low & 4257 & 99 & 1.00 & 92 & 1.00 \\
\hline medium & 3188 & 80 & $0.99(0.71-1.39)$ & 66 & $0.88(0.62-1.25)$ \\
\hline \multirow[t]{2}{*}{ high } & 1618 & 45 & $1.20(0.79-1.81)$ & 52 & $1.55(1.04-2.31)$ \\
\hline & & & P-trend 0.42 & & P-trend 0.06 \\
\hline \multicolumn{6}{|c|}{ EGP score last profession } \\
\hline blue collar & 3181 & 72 & 1.00 & 78 & 1.00 \\
\hline lower white collar & 1174 & 26 & $0.89(0.54-1.48)$ & 16 & $0.50(0.28-0.89)$ \\
\hline upper white collar & 2596 & 65 & $1.08(0.74-1.59)$ & 74 & $1.16(0.81-1.67)$ \\
\hline \multirow[t]{2}{*}{ other ${ }^{2}$} & 1376 & 41 & $1.19(0.77-1.83)$ & 31 & $0.85(0.54-1.34)$ \\
\hline & & & P-trend 0.52 & & P-trend 0.28 \\
\hline \multicolumn{6}{|c|}{ U\&S score last profession } \\
\hline 1 (low) & 1687 & 41 & 1.00 & 30 & 1.00 \\
\hline 2 & 2096 & 49 & $0.89(0.56-1.41)$ & 38 & $0.91(0.54-1.52)$ \\
\hline 3 & 2278 & 57 & $0.97(0.62-1.53)$ & 66 & $1.52(0.95-2.42)$ \\
\hline 4 & 1228 & 32 & $1.08(0.64-1.83)$ & 34 & $1.53(0.89-2.63)$ \\
\hline \multirow[t]{2}{*}{5 (high) } & 1037 & 25 & $0.95(0.54-1.67)$ & 31 & $1.60(0.91-2.80)$ \\
\hline & & & P-trend 0.84 & & P-trend 0.01 \\
\hline
\end{tabular}

'Adjusted for age, family history of prostate cancer, intake of sweet peppers, mushrooms, oranges, raisins, cured meat, milk\&milk products, linolenic acid, $\beta$-cryptoxanthin, alcohol from white wine, alcohol from fortified wines, and vitamin supplement use; ${ }^{2}$ Farmers and self-employed people, not included in the trend test.

compared with latent and localized tumors. A disadvantage of these subgroup analyses is that a considerable proportion of cases could not be classified into the different subgroups. However, the percentage of subjects which could not be classified due to missing information does not differ markedly between categories of educational level and categories of the occupation based variables. Therefore, we do not expect this missing information to have influenced our results in any systematic way. Since population screening of prostate cancer was not instituted in the Netherlands during our follow-up period, we also do not expect this to have influenced our results. In one Dutch case-control study, the percentage of incidental cases showed no clear pattern across categories of socioeconomic status (2). In another Swedish case-control study, high level of education was more strongly related to localized than to advanced prostate tumors but the presented risk estimates were only age-adjusted (5). 
In summary, we observed a positive association between two socioeconomic status indicators and risk of prostate cancer. Differences in dietary habits partially explained the observed positive association. A different medical consumption pattern of subjects with high and low socioeconomic status could not explain the observed associations. Unexpectedly, high socioeconomic status was more strongly related to nonlatent and advanced prostate tumors compared with latent and localized tumors. We conclude that dietary risk factors or other unknown risk factors and not medical consumption patterns are important in explaining an association between socioeconomic status and risk of prostate cancer.

\section{Acknowledgements}

We are indebted to the participants of this study and further wish to thank the regional cancer registries (IKA, IKL, IKMN, IKN, IKO, IKR, IKST, IKW, IKZ), and the Dutch national data base of pathology (PALGA); Dr. A. Volovics for statistical advice; S. van de Crommert, J. Nelissen, C. de Zwart, M. Moll, W. van Dijk, P. Florax and A. Pisters for assistance; and H. van Montfort, R. Schmeitz, T. van Montfort, and M. de Leeuw for programming and statistical assistance.

\section{References}

1. Van Loon AJ, Brug J, Goldbohm RA, et al. Differences in cancer incidence and mortality among socio-economic groups. Scand J Soc Med 1995;23:110-20.

2. Van der Gulden JW, Kolk JJ, Verbeek AL. Socioeconomic status, urbanization grade, and prostate cancer. Prostate 1994:25:59-65.

3. Schuman LM, Mandel JS. Epidemiology of prostatic cancer in blacks. Prev Med 1980;9:630-49.

4. Ernster VL, Selvin S, Sacks ST, et al. Prostatic cancer: mortality and incidence rates by race and social class. Am J Epidemiol 1978;107:311-20.

5. Andersson SO, Baron J, Wolk A, et al. Early life risk factors for prostate cancer: a populationbased case-control study in Sweden. Cancer Epidemiol Biomarkers Prev 1995:4:187-92.

6. Van den Brandt PA, Goldbohm RA, Van 't Veer P, et al. A large-scale prospective cohort study on diet and cancer in The Netherlands. J Clin Epidemiol 1990;43:285-95.

7. Prentice RL. A case-cohort design for epidemiologic cohort studies and disease prevention trials. Biometrika 1986;73:1-11.

8. Self SG, Prentice RL. Asymptotic distribution theory and efficiency results for case-cohort studies. Ann Stat 1988;16:64-81.

9. Van den Brandt PA, Schouten LJ, Goldbohm RA, et al. Development of a record linkage protocol for use in the Dutch Cancer Registry for Epidemiological Research. Int J Epidemiol 1990;19:5538.

10. Goldbohm RA, Van den Brandt PA, Dorant E. Estimation of the coverage of Dutch municipalities by cancer registries and PALGA based on hospital discharge data. Tijdschr Soc Gezondheidsz 1994:72:80-4.

11. Van Loon AJ, Goldbohm RA, Van den Brandt PA. Socioeconomic status and breast cancer incidence: a prospective cohort study. Int J Epidemiol 1994;23:899-905.

12. Van Loon AJ, Van den Brandt PA, Golbohm RA. Socioeconomic status and colon cancer incidence: a prospective cohort study. Br J Cancer 1995;71:882-7.

13. Goldbohm RA, Van den Brandt PA, Brants HAM, et al. Validation of a dietary questionnaire used in a large-scale prospective cohort study on diet and cancer. Eur J Clin Nutr 1994:48:253-65.

14. Baker J. GLIM 3.77 Reference Manual. Oxford: Numerical Algorithms Group, 1985.

15. Volovics A, Van den Brandt PA. Methods for the analyses of case-cohort studies. Biom J 1997;2:195-214. 
16. Schuurman AG, Zeegers MPA, Goldbohm RA, et al. A case-cohort study on prostate cancer risk in relation to family history of prostate cancer. Epidemiology 1999;10:192-5.

17. Schuurman AG, Goldbohm RA, Dorant E, et al. Vegetable and fruit consumption and prostate cancer risk: a cohort study in the Netherlands. Cancer Epidemiol Biom Prev 1998;7:673-80.

18. Schuurman AG, Van den Brandt PA, Dorant E, et al. Animal products, calcium and protein and prostate cancer risk in the Netherlands Cohort Study. Br J Cancer (in press).

19. Schuurman AG, Van den Brandt PA, Dorant E, et al. Intake of energy and fat and prostate cancer risk: results from the Netherlands Cohort Study. (provisionally accepted by Cancer).

20. Schuurman AG, Goldbohm RA, Brants HAM, et al. A prospective cohort study on retinol, vitamins $C$ and $E$, and carotenoids and prostate cancer risk. (submitted).

21. Schuurman AG, Goldbohm RA, Van den Brandt PA. A prospective cohort study on consumption of alcoholic beverages in relation to prostate cancer incidence. (provisionally accepted by Cancer Causes Control).

22. Schuurman AG, Goldbohm RA, Dorant E, et al. Anthropometry in relation to prostate cancer risk in the Netherlands Cohort Study. Am J Epidemiol (accepted).

23. Cerhan JR, Torner JC, Lynch CF, et al. Association of smoking, body mass, and physical activity with risk of prostate cancer in the lowa 65+ Rural Health Study (United States). Cancer Causes Control 1997;8:229-38.

24. Vlajinac HD, Marinkovic JM, llic MD, et al. Diet and prostate cancer: a case-control study. Eur J Cancer 1997;33:101-7.

25. West DW, Slattery ML, Robison LM, et al. Adult dietary intake and prostate cancer risk in Utah: a case-control study with special emphasis on aggressive tumors. Cancer Causes Control 1991;2:85-94.

26. Kolonel LN, Yoshizawa CN, Hankin JH. Diet and prostatic cancer: a case-control study in Hawaii. Am J Epidemiol 1988;127:999-1012.

27. Hsing AW, Wang RT, Gu FL, et al. Vasectomy and prostate cancer risk in China. Cancer Epidemiol Biomarkers Prev 1994;3:285-8.

28. Talamini R, Franceschi S, La Vecchia C, et al. Smoking habits and prostate cancer: a casecontrol study in northern Italy. Prev Med 1993;22:400-8.

29. Walker AR, Walker BF, Tsotetsi NG, et al. Case-control study of prostate cancer in black patients in Soweto, South Africa. Br J Cancer 1992;65:438-41.

30. Checkoway H, DiFerdinando G, Hulka BS, et al. Medical, life-style, and occupational risk factors for prostate cancer. Prostate 1987;10:79-88.

31. De Stefani E, Fierro L, Barrios E, et al. Tobacco, alcohol, diet and risk of prostate cancer. Tumori 1995;81:315-20.

32. Wynder EL, Mabuchi K, Whitmore WF, Jr. Epidemiology of cancer of the prostate. Cancer 1971;28:344-60.

33. Hsing AW, Comstock GW, Abbey H, et al. Serologic precursors of cancer. Retinol, carotenoids, and tocopherol and risk of prostate cancer. J Natl Cancer Inst 1990;82:941-6.

34. Hsing AW, McLaughlin JK, Schuman LM, et al. Diet, tobacco use, and fatal prostate cancer: results from the Lutheran Brotherhood Cohort Study. Cancer Res 1990;50:6836-40.

35. Mettlin C, Selenskas S, Natarajan N, et al. Beta-carotene and animal fats and their relationship to prostate cancer risk. A case-control study. Cancer 1989;64:605-12.

36. Pawlega J, Rachtan J, Dyba T. Dietary factors and risk of prostate cancer in Poland. Results of case-control study. Neoplasma 1996;43:61-3.

37. Niijima T, Koiso K. Incidence of prostatic cancer in Japan and Asia. Scand J Urol Nephrol Suppl 1980;55:17-21.

38. Schuman LM, Mandel JS, Radke A, et al. Some selected features of the epidemiology of prostatic cancer: Minneapolis-St. Paul, Minnesota case-control study, 1976-1979. In: Magnus K, ed. Trends in cancer incidence: causes and practical implications. Washington: Hemisphere Publishiong corporation, 1982:345-54.

39. Graham S, Haughey B, Marshall J, et al. Diet in the epidemiology of carcinoma of the prostate gland. J Natl Cancer Inst 1983;70:687-92.

40. Ewings $P$, Bowie C. A case-control study of cancer of the prostate in Somerset and east Devon. Br J Cancer 1996;74:661-6.

41. Oishi K, Okada K, Yoshida O, et al. Case-control study of prostatic cancer in Kyoto, Japan: demographic and some lifestyle risk factors. Prostate 1989;14:117-22. 
42. Fincham SM, Hill GB, Hanson J, et al. Epidemiology of prostatic cancer: a case-control study. Prostate 1990;17:189-206.

43. Hirayama T. Life-style and mortality. A large-scale census-based cohort study in Japan. Basel: Karger, 1990.

44. Key TJ, Silcocks PB, Davey GK, et al. A case-control study of diet and prostate cancer. Br J Cancer 1997;76:678-87.

45. Newell GR, Fueger JJ, Spitz MR, et al. A case-control study of prostate cancer. Am J Epidemiol 1989;130:395-8.

46. Rimpela $\mathrm{AH}$, Pukkala El. Cancers of affluence: positive social class gradient and rising incidence trend in some cancer forms. Soc Sci Med 1987;24:601-6.

47. Mishina $T$, Watanabe $H$, Araki $H$, et al. Epidemiological study of prostatic cancer by matchedpair analysis. Prostate 1985;6:423-36.

48. Vagero D, Persson G. Occurrence of cancer in socioeconomic groups in Sweden. An analysis based on the Swedish Cancer Environment Registry. Scand J Soc Med 1986;14:151-60.

49. Jackson MA, Kovi J, Heshmat MY, et al. Characterization of prostatic carcinoma among blacks: a comparison between a low-incidence area, Ibadan, Nigeria, and a high-incidence area, Washington, DC. Prostate 1980;1:185-205.

50. Severson RK, Nomura AM, Grove JS, et al. A prospective study of demographics, diet, and prostate cancer among men of Japanese ancestry in Hawaii. Cancer Res 1989;49:1857-60.

51. Mills PK, Beeson WL, Phillips RL, et al. Cohort study of diet, lifestyle, and prostate cancer in Adventist men. Cancer 1989;64:598-604.

52. Ghadirian P, Lacroix A, Maisonneuve P, et al. Nutritional factors and prostate cancer: a casecontrol study of French Canadians in Montreal, Canada. Cancer Causes Control 1996;7:428-36.

53. Rohan TE, Howe GR, Burch JD, et al. Dietary factors and risk of prostate cancer: a case-control study in Ontario, Canada. Cancer Causes Control 1995;6:145-54.

54. Yu H, Harris RE, Wynder EL. Case-control study of prostate cancer and socioeconomic factors. Prostate 1988;13:317-25.

55. Hayes RB, de Jong FH, Raatgever J, et al. Physical characteristics and factors related to sexual development and behaviour and the risk for prostatic cancer. Eur J Cancer Prev 1992;1:239-45.

56. Andersson SO, Baron J, Bergstrom R, et al. Lifestyle factors and prostate cancer risk: a casecontrol study in Sweden. Cancer Epidemiol Biomarkers Prev 1996;5:509-13.

57. Coughlin SS, Neaton JD, Sengupta A. Cigarette smoking as a predictor of death from prostate cancer in 348,874 men screened for the Multiple Risk Factor Intervention Trial. Am J Epidemiol 1996;143:1002-6.

58. Talamini R, La Vecchia C, Decarli A, et al. Nutrition, social factors and prostatic cancer in a Northern Italian population. Br J Cancer 1986;53:817-21.

59. Williams RR, Horm JW. Association of cancer sites with tobacco and alcohol consumption and socioeconomic status of patients: interview study from theThird National Cancer Survey. J Natl Cancer Inst 1977;58:525-47.

60. Hiatt RA, Armstrong MA, Klatsky AL, et al. Alcohol consumption, smoking, and other risk factors and prostate cancer in a large health plan cohort in California (United States). Cancer Causes Control 1994;5:66-72.

61. La Vecchia C, Negri E, Franceschi S. Education and cancer risk. Cancer 1992;70:2935-41.

62. Faggiano F, Zanetti R, Costa G. Cancer risk and social inequalities in Italy. J Epidemiol Community Health $1994 ; 48: 447-52$.

63. Ilic M, Vlajinac $\mathrm{H}$, Marinkovic $\mathrm{J}$. Case-control study of risk factors for prostate cancer. $\mathrm{Br} \mathrm{J}$ Cancer 1996;74:1682-6.

64. Van den Brandt PA, Van 't Veer P, Goldbohm RA, et al. A prospective cohort study on dietary fat and the risk of postmenopausal breast cancer. Cancer Res 1993;53:75-82.

65. Van Loon AJ, Goldbohm RA, Van den Brandt PA. Lung cancer: is there an association with socioeconomic status in The Netherlands? J Epidemiol Community Health 1995;49:65-9. 


\section{Epilogue |}

The main objectives of the studies described in this thesis were to investigate whether dietary or other environmental factors are associated with prostate cancer incidence (hypothesis 1) and whether these factors are more strongly associated with the occurrence of nonlatent or advanced prostate tumors than with latent tumors (hypothesis 2 ). The hypotheses were stated in general words to avoid a long list of hypotheses per investigated factor, but it is obvious that several individual hypotheses are covered by these broadly stated ones. In chapters 2-6 results from the Netherlands Cohort Study (NLCS) on different dietary factors as potential risk factors for prostate cancer were described and results for some nondietary risk factors were described in chapters 7-9. A summary of the observed associations in the NLCS is displayed in table 1. Overall, consumption of vegetables and fruit, meat, fish, cheese, eggs and alcohol and intake of vitamins, calcium, protein, energy, fat, and fatty acids does not seem to be strongly related to the risk of prostate cancer. Nevertheless, for certain individual vegetables and fruits, vitamin supplements, cured meat, milk and milk products, as well as for $\beta$-cryptoxanthin, oleic acid and linolenic acid, alcohol from white or fortified wines, body mass index early in life and socioeconomic status associations were suggestive of a relationship with prostate cancer risk.

\section{Evaluating the findings from the NLCS}

If the findings from the NLCS comport with findings reported in other studies on prostate cancer risk factors, this would support a conclusion of a certain factor being a risk factor for prostate cancer. In the individual chapters in this thesis our findings were related to other findings reported in the literature. The overall null associations observed in the NLCS for consumption of vegetables and fruit, meat, fish, cheese, eggs and alcohol, and intake of vitamins, energy and fat gain support from other studies, although it has to be mentioned that also positive and inverse associations have been indicated for certain dietary factors. We observed a positive association between two socioeconomic status indicators and risk of prostate cancer and this association also gains support from previous studies, although null associations and inverse associations have been reported too. Our null associations observed for intake of calcium, protein and specific fatty acids gain little or no support from other studies since these factors have not been investigated in the majority of studies on prostate cancer risk factors. In addition, the suggested positive associations between risk of prostate cancer and specific vegetables and fruits, cured meat, $\beta$-cryptoxanthin, alcohol from white or fortified wines and body mass index (BMI) at age 20 and the suggested inverse associations for certain other vegetables and fruits, vitamin supplements and gain in BMI during lifetime are also difficult to evaluate since these factors have been investigated only in a few other studies. One association observed in the NLCS which is consistent with results from other studies is the positive association for family history of prostate cancer. Overall however, there is hardly any consistency in results from diverse 
Table 1: Results from the Netherlands Cohort Study on diet, anthropometry, family history of prostate cancer and socioeconomic status as potential risk factors for prostate cancer occurrence.

\begin{tabular}{|c|c|c|}
\hline Chapter & $\begin{array}{l}\text { Factors not associated with prostate cancer } \\
\text { risk }\end{array}$ & Observed associations (+ or -) \\
\hline 2 & $\begin{array}{l}\text { total vegetable consumption } \\
\text { total fruit consumption }\end{array}$ & $\begin{array}{l}\text { consumption of kale }(-) \text {, raw endive }(-) \text {, } \\
\text { leek }(+) \text {, sweet peppers }(+) \text {, } \\
\text { mushrooms }(+) \\
\text { consumption of mandarins }(-) \text {, oranges }(+) \text {, } \\
\text { apples and pears }(-) \text {, raisins }(-)\end{array}$ \\
\hline 3 & $\begin{array}{l}\text { intake of vitamins } \mathrm{C} \text { and } \mathrm{E} \\
\text { intake of retinol, } \alpha \text {-carotene, } \beta \text {-carotene, } \\
\text { lycopene, lutein/zeaxanthin }\end{array}$ & $\begin{array}{l}\text { intake of } \beta \text {-cryptoxanthin }(+) \\
\text { consumption of vitamin supplements }(-) \\
\text { interaction between vitamins and alcohol } \\
\text { consumption }\end{array}$ \\
\hline 4 & $\begin{array}{l}\text { total meat consumption } \\
\text { fish consumption } \\
\text { cheese consumption } \\
\text { consumption of eggs } \\
\text { intake of calcium, total protein, vegetable } \\
\text { protein, animal protein }\end{array}$ & $\begin{array}{l}\text { consumption of cured meat }(+) \text {, } \\
\text { consumption of milk and milk products (+) }\end{array}$ \\
\hline 5 & $\begin{array}{l}\text { total energy intake } \\
\text { intake of total fat, total fatty acids } \\
\text { intake of saturated fat, monounsaturated fat, } \\
\text { polyunsaturated fat } \\
\text { intake of palmitic acid, stearic acid, linoleic } \\
\text { acid, arachidonic acid, eicosapentaenoic } \\
\text { acid, docosahexaenoic acid }\end{array}$ & intake of oleic acid $(+)$, linolenic acid (-) \\
\hline 6 & $\begin{array}{l}\text { total alcohol intake } \\
\text { intake of alcohol from beer, red wine, liquor }\end{array}$ & $\begin{array}{l}\text { intake of alcohol from white wine }(+) \text {, fortified } \\
\text { wines }(+)\end{array}$ \\
\hline 7 & $\begin{array}{l}\text { height } \\
\text { body mass index at baseline age } \\
\text { lean body mass }\end{array}$ & $\begin{array}{l}\text { body mass index at age } 20(+) \\
\text { gain in body mass index during lifetime (-) }\end{array}$ \\
\hline 8 & number of brothers with prostate cancer & $\begin{array}{l}\text { father with prostate cancer }(+) \\
\text { brother(s) with prostate cancer }(+)\end{array}$ \\
\hline 9 & $\begin{array}{l}\text { occupational group and required training } \\
\text { (functional level) }\end{array}$ & $\begin{array}{l}\text { level of education (+) } \\
\text { social standing }(+)\end{array}$ \\
\hline
\end{tabular}

studies and to a large extent this is caused by limited available data. Also, chance findings from the NLCS or any other study cannot be excluded, thus complicating the evaluation of consistency. Furthermore, the different methodology used in different studies is also contributing to inconsistencies in results. One important issue in this respect is the issue of exposure measurement. As has been described in the previous chapters, several studies had limited exposure information or used dietary questionnaires that have not been 
validated. In the NLCS an extensive validated semi-quantitative food frequency questionnaire was used and it was concluded that diet was reasonably well measured (1). If misclassification has occurred in our study, this is expected to be nondifferential which may have led to an underestimation instead of an overestimation of observed effects. Another issue related to the different methods used in the diverse studies is the issue of residual confounding. Several results presented in the literature were unadjusted or only age-adjusted and residual confounding in these studies cannot be excluded. However, since risk factors for prostate cancer are largely unknown it is also not known which potential confounding factors should be taken into account in analyses besides age, and family history of prostate cancer. Compared to most other studies, an advantage of the NLCS is the extensive exposure information on e.g. diet, anthropometry, family history of prostate cancer, and education. With this information, we were able to consider several potential confounding factors but residual confounding in our study can also not be excluded.

Taking all considerations into account, a straightforward answer to the first set of hypotheses cannot be given. From our own investigations, nevertheless, we cannot conclude that diet is not associated with risk of prostate cancer. Also for the nondietary risk factors that were studied an association with risk of prostate cancer might exist (anthropometry and socioeconomic status) or has more or less been established (family history of prostate cancer).

\section{Latent vs nonlatent or advanced prostate tumors}

The second hypothesis underlying this investigation stated that environmental factors, and perhaps specifically dietary factors, are more strongly related to the risk of nonlatent or advanced prostate tumors than to latent tumors. Latent tumors have been defined as incidental findings during transurethral resection of the prostate (TURP) which is performed in case of problems associated with benign prostatic hyperplasia, or as screen-detected tumors $(2,3)$. Throughout this thesis, three different classifications were used to separately investigate latent and nonlatent or advanced prostate tumors. In one classification, latent tumors were classified as those tumors that were detected during a TURP treatment. Nonlatent tumors were classified as those tumors that were detected during surgical procedures used in case of suspected or diagnosed prostate cancer (biopsy, radical prostatectomy). For this purpose, all pathology reports that were available from the national database on pathology reports (PALGA) per prostate cancer case were used. The pathology reports were screened for terms indicating surgical procedures in combination with terms indicating accidental findings of adenocarcinoma of the prostate. Since systematic screening for prostate cancer was not instituted in the Netherlands during our follow-up period from September 1986 to December 1992, we assumed no screendetected tumors among our prostate cancer cases. About $38 \%$ of all cases could not be 
grouped according to latency due to lack of evidence in the pathology reports. Another classification used in the NLCS distinguished tumors in localized and advanced cancer, based on the TNM classification. Localized prostate cancers were defined as TO-2, MO and advanced prostate cancers as T3-4, M0 and T0-4, M1. Some $32 \%$ of all cases could not be classified due to missing information. A third classification upon which some case subgroup

Table 2a: Comparison of the classification of latent and nonlatent prostate tumors with the classification of localized and advanced prostate tumors, Netherlands Cohort Study. ${ }^{1}$

\begin{tabular}{lllll}
\hline & Localized & Advanced & Missing & Total \\
\hline Latent (\%) & $50(43.5)$ & $19(16.5)$ & $46(40.0)$ & $115(100)$ \\
Nonlatent (\%) & $86(30.5)$ & $114(40.4)$ & $82(29.1)$ & $282(100)$ \\
Missings (\%) & $90(36.7)$ & $80(32.7)$ & $75(30.6)$ & $245(100)$ \\
Total & 226 & 213 & 203 & 642 \\
\hline
\end{tabular}

Table $2 \mathrm{~b}$ : Comparison of the classification of latent and nonlatent prostate tumors with the classification based on differentiation grade of prostate tumors, Netherlands Cohort Study. ${ }^{1}$

\begin{tabular}{llllll}
\hline & $\begin{array}{l}\text { Well } \\
\text { differentiated }\end{array}$ & $\begin{array}{l}\text { Moderately } \\
\text { differentiated }\end{array}$ & $\begin{array}{l}\text { Poorly+ } \\
\text { undifferentiated }\end{array}$ & Missing & Total \\
\hline Latent (\%) & $59(51.3)$ & $34(29.6)$ & $13(11.3)$ & $9(7.8)$ & $115(100)$ \\
Nonlatent (\%) & $62(22.0)$ & $117(41.5)$ & $83(29.4)$ & $20(7.1)$ & $282(100)$ \\
Missings (\%) & $70(28.6)$ & $78(31.8)$ & $64(26.1)$ & $33(13.5)$ & $245(100)$ \\
Total & 191 & 229 & 160 & 62 & $\mathbf{6 4 2}$ \\
\hline
\end{tabular}

Table 2c: Comparison of the classification of localized and advanced prostate tumors with the classification based on differentiation grade of prostate tumors, Netherlands Cohort Study. ${ }^{1}$

\begin{tabular}{llllll}
\hline & $\begin{array}{l}\text { Well } \\
\text { differentiated }\end{array}$ & $\begin{array}{l}\text { Moderately } \\
\text { differentiated }\end{array}$ & $\begin{array}{l}\text { Poorly+ } \\
\text { undifferentiated }\end{array}$ & Missing & Total \\
\hline Localized (\%) & $86(38.1)$ & $86(38.1)$ & $37(16.4)$ & $17(7.5)$ & $226(100)$ \\
Advanced (\%) & $29(13.6)$ & $86(40.4)$ & $80(37.6)$ & $18(8.5)$ & $213(100)$ \\
Missings (\%) & $76(37.4)$ & $57(28.1)$ & $43(21.2)$ & $27(13.3)$ & $203(100)$ \\
Total & 191 & 229 & 160 & 62 & $\mathbf{6 4 2}$ \\
\hline
\end{tabular}

\footnotetext{
${ }^{1}$ Numbers and percentages displayed in tables 2a-c are based on 642 cases which were used in all analyses regarding dietary risk factors.
} 
analyses were based, was the classification in differentiation grade (well, moderately and poorly and undifferentiated tumors). Only $9 \%$ of all cases could not be classified according to differentiation grade of the tumor.

Tables 2a-c show the distribution of cases comparing the three different classifications used in the NLCS. The majority of latent tumors were also classified as localized and well or moderately differentiated. However, some nonlatent tumors were also classified as localized tumors and well or moderately differentiated tumors. Of all tumors that could not be classified according to latency, about equal numbers were classified as localized or advanced tumors and into categories based on differentiation grade. Comparison of the classification of localized and advanced tumors with the classification based on differentiation grade showed that localized prostate tumors were mostly classified as well and moderately differentiated tumors and advanced prostate tumors were mostly classified as moderately or poorly and undifferentiated tumors. Nevertheless, some localized tumors were classified as poorly and undifferentiated tumors and some advanced tumors as well differentiated. Unfortunately, there is no gold standard available for the classification of latent and nonlatent or advanced prostate tumors. For this reason the three different classifications were used in this thesis. It has to be mentioned, nevertheless, that the classifications used in the NLCS as well as in other studies in which case subgroups were separately investigated, are either a diagnostic classification (latent vs nonlatent) or a prognostic classification (localized vs advanced; well, moderately, poorly and undifferentiated). Whether these classifications are relevant in answering a question about the etiology of latent and nonlatent or advanced prostate tumors remains to be proven.

A summary of the main findings of the NLCS on dietary and nondietary risk factors and their association with localized and advanced prostate tumors is shown in table 3. Overall, we can conclude that neither dietary nor the investigated nondietary risk factors are more strongly related to advanced prostate tumors compared with localized prostate tumors. The only factors related more strongly to advanced prostate tumors are two nondietary factors, namely family history of prostate cancer in fathers and brothers and socioeconomic status. For consumption of alcoholic beverages, observed associations were even stronger for localized prostate tumors. In the previous chapters, our results from the subgroup analyses were compared to results from other studies in which case subgroups were also separately investigated. Overall, we can conclude that there is limited data on different tumor subgroups and results were mostly inconsistent.

Irrespective of which classification was used in our study, we observed no consistent stronger associations for the different investigated potential risk factors with nonlatent, advanced or poorly and undifferentiated prostate tumors compared with latent, localized and well differentiated prostate tumors. Therefore, the second hypothesis cannot be supported with data from the NLCS. 
Table 3: Results from the Netherlands Cohort Study on diet, anthropometry, family history of prostate cancer and socioeconomic status in relation to localized and advanced prostate tumors.

\begin{tabular}{|c|c|c|c|c|}
\hline \multirow[t]{2}{*}{ Chapter } & \multicolumn{2}{|c|}{$\begin{array}{l}\text { Localized prostate tumors } \\
(\mathrm{TO}-2, \mathrm{MO})\end{array}$} & \multicolumn{2}{|c|}{$\begin{array}{l}\text { Advanced prostate tumors } \\
\text { (T3-4, M0; TO-4, M1) }\end{array}$} \\
\hline & no association & association (+or -) & no association & association (+or -) \\
\hline 2 & $\begin{array}{l}\text { total vegetables } \\
\text { total fruit }\end{array}$ & & $\begin{array}{l}\text { total vegetables } \\
\text { total fruit }\end{array}$ & \\
\hline 3 & $\begin{array}{l}\text { vitamins } C \text { and } E \\
\text { retinol, } \alpha \text {-carotene, } \\
\beta \text {-carotene, } \beta \text { - } \\
\text { cryptoxanthin, } \\
\text { lutein/zeaxanthin }\end{array}$ & $\begin{array}{l}\text { lycopene (+) } \\
\text { vitamin suppl. (-) }\end{array}$ & $\begin{array}{l}\text { vitamins } C \text { and } E \\
\text { retinol, } \alpha \text {-carotene, } \\
\beta \text {-carotene, } \\
\text { lycopene, } \\
\text { lutein/zeaxanthin }\end{array}$ & $\begin{array}{l}\beta \text {-cryptoxanthin (+) } \\
\text { vitamin suppl. (-) }\end{array}$ \\
\hline 4 & $\begin{array}{l}\text { total meat, total fish } \\
\text { cured meat, milk and } \\
\text { milk products, eggs, } \\
\text { calcium, protein }\end{array}$ & cheese $(+)$ & $\begin{array}{l}\text { total meat, total fish } \\
\text { cured meat, milk and } \\
\text { milk products, } \\
\text { cheese, calcium, } \\
\text { protein }\end{array}$ & eggs (-) \\
\hline 5 & $\begin{array}{l}\text { total fat(ty acids), } \\
\text { saturated fat, } \\
\text { monounsaturated fat, } \\
\text { polyunsaturated fat }\end{array}$ & energy (+) & $\begin{array}{l}\text { energy, total fat(ty } \\
\text { acids), saturated fat, } \\
\text { monounsaturated fat, } \\
\text { polyunsaturated fat }\end{array}$ & \\
\hline 6 & & $\begin{array}{l}\text { total alcohol }(+) \text {, } \\
\text { beer }(+) \text {, red wine } \\
(+) \text {, white/ fortified } \\
\text { wines }(+) \text {, liquor }(+)\end{array}$ & $\begin{array}{l}\text { total alcohol, beer, } \\
\text { red wine, liquor }\end{array}$ & $\begin{array}{l}\text { white/fortified wines } \\
(+)\end{array}$ \\
\hline 7 & $\begin{array}{l}\text { height, body mass } \\
\text { index, lean body } \\
\text { mass }\end{array}$ & $\begin{array}{l}\text { body mass index at } \\
\text { age } 20(+) \text {, gain in } \\
\text { BMI }(-)\end{array}$ & $\begin{array}{l}\text { height, body mass } \\
\text { index, lean body } \\
\text { mass, body mass } \\
\text { index at age } 20 \text {, gain } \\
\text { in body mass index }\end{array}$ & \\
\hline 8 & & $\begin{array}{l}\text { prostate cancer } \\
\text { father }(+) \\
\text { prostate cancer } \\
\text { brother }(+)\end{array}$ & & $\begin{array}{l}\text { prostate cancer } \\
\text { father }(+)^{1} \\
\text { prostate cancer } \\
\text { brother }(+)^{1}\end{array}$ \\
\hline 9 & $\begin{array}{l}\text { level of education } \\
\text { functional level } \\
\text { social standing }\end{array}$ & & functional level & $\begin{array}{l}\text { level of education (+) } \\
\text { social standing (+) }\end{array}$ \\
\hline
\end{tabular}

'Associations were stronger for advanced cases compared with localized cases. 


\section{Further research}

Thus far, several questions regarding prostate cancer etiology are still unanswered. Further studies are warranted, which should be designed with special emphasis on exposure and disease measurement, but also research into mechanisms is desirable.

One important issue regarding exposure measurement deals with the question which factors might be relevant and also at what level these factors could play a role in prostate cancer occurrence. Notwithstanding the inconsistent results, dietary risk factors for prostate cancer seem plausible because of the large geographical variation in incidence rates and the corresponding variation in dietary habits. Compared to Western diets, Asian diets are generally lower in total and saturated fat and such a diet has frequently been suggested to be associated with lower prostate cancer risk $(4,5)$ although it cannot be excluded that confounding plays a role in explaining this suggested association, based on ecologic correlation studies. Nevertheless, observations from correlational studies can be used to identify potentially important factors which need to be thoroughly investigated in epidemiological research. The issue of fat and prostate cancer is an example which has frequently been investigated in cohort as well as in case-control studies, however, results are mostly inconsistent $(6,7)$. Besides methodological problems, another reason for not finding clear associations might be that the investigated consumption level in most studies was too high. On average, the consumption level measured in the NLCS and most other studies is of a relatively narrow range and, in general, represents a higher consumption than the average consumption level in countries with low prostate cancer incidence rates. The possibility that consumption of fat at lower levels is important in prostate cancer etiology can therefore not be ruled out. From experimental research it was shown that changing the diet of nude mice with palpable tumors (originally transplanted) into a $2.3 \%$ fat diet or a $11.6 \%$ fat diet, resulted in a marked decrease in tumor growth rate compared with animals on the unchanged $40.5 \%$ fat diet (8). Also in other animal studies with transplanted prostate tumors, a fat reduction or a fat-free diet inhibited tumor growth. However, in chemically induced carcinogenesis models in rats mostly no effect of fat was observed (9). Results from animal studies are worthy of consideration and may be used to indicate potentially important (levels of) risk factors, but one also has to bear in mind that animal studies have their limitations. For example, the extrapolation of results from animal studies to humans is hampered by the fact that experimental animals can be exposed to potential risk factors at extreme levels which are not feasible for humans. Furthermore, animal model systems with transplanted prostate tumors might not be useful because it does not represent the evolutionairy stages of prostate cancer in men and only represents an end stage (10). In fact, none of the available animal model systems is similar to human prostate cancer in histology, biochemical properties, molecular and genetic characteristics, embryological origin, natural history and biological behaviour (11). 
Further observations of dietary differences between countries with high and low prostate cancer incidence rates and results from experimental or epidemiological research indicated that soy consumption $(8,12,13)$, vitamin $D(14,15)$, fructose $(16)$, phosphorus $(17)$, and selenium (18-21) might be associated with a lower rate of prostate cancer. Results on soy intake and prostate cancer, however, were inconsistent (12) and in some studies no association was observed for vitamin $D(22-24)$, and selenium (25). Because there is only limited evidence from epidemiological studies further studies are needed to resolve these issues. Preferably large-scale and prospective epidemiological studies should be conducted. Extreme variation in dietary exposure variables is recommended which may be established by including special exposure groups into the study design.

In addition to several dietary factors, also hormonal factors should be considered in the etiology of prostate cancer. Androgens are essential for the growth and functioning of the prostate and in experimental animals androgens can produce prostate cancer $(26,27)$. Furthermore, surgical castration in men prevents prostate cancer (28). Increased levels of dihydrotestosterone, a metabolite of testosterone, have been hypothesized to lead to increased cell division, activation of proto-oncogenes and inactivation of tumor suppressor genes, thus finally resulting in prostate cancer (29). However, a role for testosterone or dihydrotestosterone in prostate cancer etiology has not been resolved yet $(5,26,27,30)$. Other factors such as estradiol (26-28) insulin-like growth factor I (31-33) and sex hormonebinding globulin (26-28) have also been subject to investigations, but thus far with mostly inconsistent findings. Since the exact role of hormones in the development of prostate cancer has not been established, hormones or other factors involved in prostate biology should also be studied in future research.

A second issue regarding exposure measurement deals with the accuracy of measurements. In the NLCS, a food frequency questionnaire was used to estimate usual diet but, as with other methods of dietary assessment, the estimated intake is subject to (random) misclassification. As a surrogate for actual dietary intake biochemical indicators can be used, which do not rely on the memory or capacity of subjects under study. For certain nutrients that vary widely in concentration within foods, or for which food composition tables are inaccurate, biochemical indicators could be the only way of estimating intake (34). However, biochemical indicators are most likely not fully representative of dietary intake because of influences of absorption, metabolism and shortterm biologic variation (35). Nevertheless, these efects within the body give ground to another reason for using biochemical indicators, namely, if one is concerned with the biologic available dosis of nutrients rather than the estimated intake (34). Unfortunately, however, for many nutrients of current interest such as total fat and fiber, biochemical markers do not yet exist (35). Furthermore, it has to be mentioned that biochemical measures are also subject to problems of misclassification or other biases. Although the 
use of biochemical indicators needs to be evaluated per nutrient of interest, this area of exposure assessment may prove valuable, especially if long-term intake of specified nutrients can be assessed.

A third issue relating to exposure measurement deals with the induction times associated with individual exposure factors (36). Since prostate cancer exhibits a long preclinical phase, diet or other factors may influence prostate cancer occurrence at many stages during life. Because of the limited understanding of the pathogenesis of (prostate) cancer it is unknown at what period of time before diagnosis diet or other factors are important (35). In our study the usual diet in the year preceding the baseline measurement was assessed. Five annually repeated measurements of the food frequency questionnaire were conducted and from these measurements it was concluded that the single measurement of diet in the NLCS can characterize dietary habits for a period of at least five years (37). Nevertheless, diet or other risk factors early in life might be more important in explaining patterns of prostate cancer occurrence than exposure to putative risk factors more recent in time before diagnosis. For example, the prostate rapidly grows under stimulation of male hormones around puberty, and this might be a critical time period for initiation of prostate cancer. To our knowledge, only two case-control studies published results on diet during adolescence in association with prostate cancer risk but overall found no clear associations $(38,39)$. A limitation of these studies is the retrospective assessment of early diet which may have resulted in misclassification. The hormonal environment in utero might also play an etiologic role in the development of prostate cancer decades later (29). Some studies on birth weight, as a marker for the hormonal environment in utero, have been conducted (4042) but data are too sparse for definite conclusions. Therefore in future studies, ideally, exposure measurement should repeatedly be assessed during life to be able to determine the induction periods for different exposure factors. Another advantage of repeated exposure measurements during life is that retrospective assessment of exposure status and the corresponding methodological problems may be prevented.

A fourth issue relating to exposure measurement deals with component causes (36). Disease may not be produced by one specific event, condition or characteristic, but by a set of conditions and events (component causes) which are all necessary to produce disease. Therefore, it may be important not to investigate separate factors, but to investigate combinations of different exposure variables. For example, we found no clear overall effect of the intake of several vitamins, but in the absence of alcohol consumption, for certain vitamins a protective effect was observed (43). Although there is no straightforward explanation for our finding, biological interaction needs to be considered and investigated in other studies. Calcium, phosphorus and vitamin D have also been proposed to be interacting components in prostate growth, differentiation and cancer risk (17). It seems very likely that other dietary or nondietary potential risk factors for prostate 
cancer also biologically interact. In addition, genetic polymorphisms controlling hormone synthesis, metabolism, and bioactivity may be involved in different pathways (17) but this also needs to be explored in future studies. The issue of component causes is very complex since most of the component causes for prostate cancer are still unknown. Furthermore, each component cause of a sufficient cause may act at a different point in time but the relevant induction periods for component causes are also largely unknown.

Regarding disease measurement, there is still the complicating factor that the natural history of prostate cancer is unknown. Based on the observation of similar prevalence of latent prostate tumors, it has been proposed that additonal malignant events and not solely tumor growth is required for a latent tumor to progress to a clinically evident one $(44,45)$; if only tumor growth was required the prevalence of clinical prostate cancer would be similar worldwide, which is not the case. With current histopathologic techniques, however, prostate tumors that remain clinically silent cannot be distinguished from tumors that will become clinically apparent and finally progress into metastatic disease $(17,46)$. Therefore, research into etiology is needed which may elucidate the pathway by which prostate cancer develops. If prostate tumors could be characterized by their biological potential, or molecular markers could be used, this may guide research and risk factors could be studied separately by type of prostate tumor.

One final point to give direction to future research regarding prostate cancer etiology deals with research on biologic mechanisms. Most proposed mechanisms to explain an observed association between a certain risk factor and prostate cancer incidence involve the male endocrine system, as was discussed in several of the previous chapters. Androgens may be a mediator of dietary or nondietary influences on prostate carcinogenesis. For example, fat intake may increase sex hormone levels finally resulting in activation of protooncogenes and deactivation of tumor suppressor genes $(7,29)$. Also, anthropometric measures may be related to prostate cancer risk by modulating endogenous hormone levels or growth factors (47-49). Since the exact role of hormones in the development of prostate cancer remains poorly understood, as well as the mediating role of hormones for non-hormonal risk factors, this may very well be one of the most promising research topics.

\section{Concluding remarks}

From the investigations described in this thesis no strong dietary risk factors for prostate cancer were identified. Nevertheless, we cannot conclude that diet is not important in prostate cancer occurrence. Our results do also not support the hypothesis that dietary factors are more strongly related to nonlatent or advanced prostate tumors than to latent tumors. Future epidemiological studies on prostate cancer risk factors should preferably collect exposure data prospectively at different points in time. In addition, to allow for large variation in exposure variables and a reasonable number of cases for analyses these 
studies should be large-scale. Important research issues are dietary or other environmental factors as well as potential endogenous risk factors, for which there is still limited evidence. Furthermore, biological interaction between putative risk factors needs to be considered. Most certainly, not only epidemiologists but also other disciplines like biochemistry, pathology, endocrinology, urology, molecular biology and toxicology should participate. A multidisciplinairy cooperation which makes use of the different skills and perspectives of researchers from different disciplines will be needed to unravel the multifactorial etiology of prostate cancer.

\section{References}

1. Goldbohm RA, Van den Brandt PA, Brants HAM, et al. Validation of a dietary questionnaire used in a large-scale prospective cohort study on diet and cancer. Eur J Clin Nutr 1994;48:253-65.

2. Boyle P, Maisonneuve P, Napalkov P. Geographical and temporal patterns of incidence and mortality from prostate cancer. Urology 1995;46:47-55.

3. Boyle P, Maisonneuve P, Napalkov P. Incidence of prostate cancer will double by the year 2030: the argument for. Eur Urol 1996;29:3-9.

4. Kolonel LN. Nutrition and prostate cancer. Cancer Causes Control 1996;7:83-94.

5. Nomura AM, Kolonel LN. Prostate cancer: a current perspective. Epidemiol Rev 1991;13:200-27.

6. Giles G, Ireland P. Diet, nutrition and prostate cancer. Int J Cancer 1997; Suppl 10:13-7.

7. Schuurman AG, Van den Brandt PA, Dorant E, et al. Intake of energy and fat and prostate cancer risk: results from the Netherlands Cohort Study. (provisionally accepted by Cancer).

8. Fair WR, Fleshner NE, Heston W. Cancer of the prostate: a nutritional disease? Urology 1997;50:840-8.

9. Zhou JR, Blackburn GL. Bridging animal and human studies: what are the missing segments in dietary fat and prostate cancer? Am J Clin Nutr 1997;66:1572s-80s.

10. Pollard M. Re: Decreased growth of established human prostate LNCaP tumors in nude mice fed a low-fat diet. J Natl Cancer Inst 1996;88:56-7.

11. Pylkkanen L, Makela S, Santti R. Animal models for the preneoplastic lesions of the prostate. Eur Urol 1996;30:243-8.

12. Messina MJ, Persky V, Setchell KDR, et al. Soy intake and cancer risk: a review of the in vitro and in vivo data. Nutr Cancer 1994;21:113-31.

13. Landstrom M, Zhang JX, Hallmans G, et al. Inhibitory effects of soy and rye diets on the development of Dunning R3327 prostate adenocarcinoma in rats. Prostate 1998;36:151-61.

14. Corder EH, Guess HA, Hulka BS, et al. Vitamin D and prostate cancer: a prediagnostic study with stored sera. Cancer Epidemiol Biomarkers Prev 1993;2:467-72.

15. Getzenberg RH, Light BW, Lapco PE, et al. Vitamin D inhibition of prostate adenocarcinoma growth and metastasis in the Dunning rat prostate model system. Urology 1997;50:999-1006.

16. Giovannucci E, Rimm EB, Wolk A, et al. Calcium and fructose intake in relation to risk of prostate cancer. Cancer Res 1998;58:442-7.

17. Clinton SK, Giovannucci E. Diet, nutrition, and prostate cancer. Annu Rev Nutr 1998;18:413-40.

18. Clark LC, Dalkin B, Krongrad A, et al. Decreased incidence of prostate cancer with selenium supplementation: results of a double -blind cancer prevention trial. Br J Urol 1998;81:730-4.

19. Yoshizawa K, Willett WC, Morris SJ, et al. Study of prediagnostic selenium level in toenails and the risk of advanced prostate cancer. J Natl Cancer Inst 1998;90:1219-24.

20. Criqui MH, Bangdiwala S, Goodman DS, et al. Selenium, retinol, retinol-binding protein, and uric acid. Associations with cancer mortality in a population-based prospectivecase-control study. Ann Epidemiol 1991;1:385-93.

21. Coates RJ, Weiss NS, Daling JR, et al. Serum levels of selenium and retinol and the subsequent risk of cancer. Am J Epidemiol 1988;128:515-23.

22. Gann $\mathrm{PH}, \mathrm{Ma} \mathrm{J}$, Hennekens $\mathrm{CH}$, et al. Circulating vitamin $\mathrm{D}$ metabolites in relation to subsequent development of prostate cancer. Cancer Epidemiol Biomarkers Prev 1996;5:121-6.

23. Nomura AMY, Stemmermann GN, Lee J, et al. Serum vitamin D metabolite levels and the subsequent development of prostate cancer (Hawaii, United States). Cancer Causes Control 1998;9:425-32. 
24. Braun MM, Helzlsouer KJ, Hollis BW, et al. Prostate cancer and prediagnostic levels of serum vitamin D metabolites (Maryland, United States). Cancer Causes Control 1995;6:235-9.

25. Hartman TJ, Albanes D, Peitinen $P$, et al. The association between baseline vitamin $E$, selenium, and prostate cancer in the Alpha-Tocopherol, Beta-Carotene Prevention Study. Cancer Epidemiol Biomarker Prev 1998;7:335-40.

26. Gann PH, Hennekens $\mathrm{CH}$, Ma J, et al. Prospective study of sex hormone levels and risk of prostate cancer. J Natl Cancer Inst 1996;88:1118-26.

27. Signorello LB, Tzonou A, Mantzoros CS, et al. Serum steroids in relation to prostate cancer risk in a case-control study (Greece). Cancer Causes Control 1997;8:632-6.

28. Dorgan JF, Albanes D, Virtamo J, et al. Relationships of serum androgens and estrogens to prostate cancer risk: results from a prospective study in Finland. Cancer Epidemiol Biomarker \& Prev 1998;7:1069-74.

29. Ross RK, Henderson BE. Do diet and androgens alter prostate cancer risk via a common etiologic pathway? J Natl Cancer Inst 1994;86:252-4.

30. Wilding G. Endocrine control of prostate cancer. Cancer Surv 1995;23:43-62.

31. Wolk A, Mantzoros CS, Andersson SO, et al. Insulin-like growth factor 1 and prostate cancer risk: a population-based, case-control study. J Natl Cancer Inst 1998;90:911-5.

32. Chan JM, Stampfer MJ, Giovannucci E, et al. Plasma insulin-like growth factor-I and prostate cancer risk: a prospective study. Science 1998;279:563-6.

33. Mantzoros CS, Tzonou A, Signorello LB, et al. Insulin-like growth factor 1 in relation to prostate cancer and benign prostatic hyperplasia. Br J Cancer 1997;76:1115-8.

34. Hunter D. Biochemical indicators of dietary intake. In: Willett W, ed. Nutritional epidemiology. New York: Oxford University Press, 1998:174-243.

35. Willett WC. Nutritional epidemiology. In: Rothman KJ, Greenland S, eds. Modern epidemiology. Philadelphia: Lippincot-Raven, 1998:623-42.

36. Rothman KJ, Greenland S. Causation and causal inference. In: Rothman KJ, Greenland S, eds. Modern Epidemiology. Philadelphia: Lippincot-Raven, 1998:7-28.

37. Goldbohm RA, Van 't Veer P, Van den Brandt PA, et al. Reproducibility of a food frequency questionnaire and stability of dietary habits determined from five annually repeated measurements. Eur J Clin Nutr 1995;49:420-9.

38. Andersson SO, Baron J, Wolk A, et al. Early life risk factors for prostate cancer: a populationbased case-control study in Sweden. Cancer Epidemiol Biomarkers Prev 1995;4:187-92.

39. Slattery ML, Schumacher MC, West DW, et al. Food-consumption trends between adolescent and adult years and subsequent risk of prostate cancer. Am J Clin Nutr 1990;52:752-7.

40. Platz EA, Giovannucci E, Rimm EB, et al. Retrospective analysis of birth weight and prostate cancer in the Health Professionals Follow-up Study. Am J Epidemiol 1998;147:1140-4.

41. Tibblin G, Eriksson M, Cnattingius S, et al. High birth weight as a predictor of prostate cancer risk. Epidemiology 1995;6:423-4.

42. Ekbom A, Hsieh CC, Lipworth L, et al. Perinatal characteristics in relation to incidence of and mortality from prostate cancer. BMJ 1996;313:337-41.

43. Schuurman AG, Goldbohm RA, Brants HAM, et al. A prospective cohort study on retinol, vitamins $C$ and $E$, and carotenoids and prostate cancer risk. (submitted).

44. Carter HB, Piantadosi S, Isaacs JT. Clinical evidence for and implications of the multistep development of prostate cancer. J Urol 1990;143:742-6.

45. Carter BS, Carter HB, Isaacs JT. Epidemiologic evidence regarding predisposing factors to prostate cancer. Prostate 1990;16:187-97.

46. Huncharek M, Muscat J. Genetic characteristics of prostate cancer. Cancer Epidemiol Biomarkers Prev 1995;4:681-7.

47. Giovannucci E, Rimm EB, Stampfer MJ, et al. Height, body weight, and risk of prostate cancer. Cancer Epidemiol Biomarkers Prev 1997;6:557-63.

48. Andersson SO, Wolk A, Bergstrom R, et al. Body size and prostate cancer: a 20-year follow-up study among 135006 Swedish construction workers. J Natl Cancer Inst 1997;89:385-9.

49. Schuurman AG, Goldbohm RA, Dorant E, et al. Anthropometry in relation to prostate cancer risk in the Netherlands Cohort Study. Am J Epidemiol (accepted). 


\section{| Summay |}

Although the incidence of prostate cancer is high in Western countries, possible risk factors for prostate cancer are largely unknown. Environmental factors are thought to be important in the etiology of prostate cancer, for example because of the large differences in incidence rates worldwide. A role for environmental factors in the occurrence of prostate cancer is further supported by the observation that migrants tend to acquire the prostate cancer pattern of their new home. Prostate cancer is often distinguished in latent and nonlatent prostate cancer. Latent prostate tumors are usually defined as those tumors that have been detected incidentally; Nonlatent tumors are detected because of clinical symptoms of prostate cancer. The observation of similar prevalence of latent prostate cancer across countries with high and low rates of prostate cancer incidence might also implicate that environmental factors are important in the occurrence of prostate cancer.

The assocation between several dietary factors but also some nondietary factors and prostate cancer incidence is described in this thesis. Broadly stated, the hypotheses underlying these investigations are as follows: 1) environmental factors, specifically dietary factors, are associated with prostate cancer risk, and 2) these factors are more strongly related to nonlatent or advanced prostate tumors than to latent tumors.

The analyses regarding associations between dietary factors (vegetables and fruit, vitamins, animal products, energy, fat and alcohol) and some nondietary factors (family history of prostate cancer, anthropometry, and socioeconomic status) and the incidence of prostate cancer (first hypothesis) were carried out within the context of the Netherlands Cohort Study (NLCS) on diet and cancer. The NLCS is a prospective cohort study, which started in 1986 with a total of 58,279 men aged $55-69$ years. All men completed a selfadministered questionnaire on dietary habits and other risk factors for cancer. For the analyses presented in this thesis, all incident prostate cancer cases detected during a follow-up period of 6.3 years (September 1986- December 1992) were included with a total of 704 cases. To investigate the second hypothesis, analyses were repeated in subgroups in which prostate tumors were classified on certain characteristics (latent and nonlatent; well, moderately and poorly differentiated tumors; localized and advanced tumors).

In chapter 1 of this thesis the literature on previous prospective studies on diet and prostate cancer is reviewed. Overall, this review shows that previous studies only briefly investigated diet in relation to risk of prostate cancer. The majority of studies had limited exposure measurements and a limited number of prostate cancer cases. For almost all investigated dietary exposures, it can be concluded that, thus far, results from previous studies are inconsistent. 
The results of the analyses from the NLCS regarding different dietary factors and their association with risk of prostate cancer are described in chapters two to six. Per investigated dietary factor we investigated whether a higher intake was associated with the occurrence of prostate cancer. For the following dietary risk factors no association with prostate cancer risk was observed: intake of total vegetables and fruit (chapter 2); intake of retinol, vitamins $C$ and $E, \alpha$-carotene, $\beta$-carotene, lycopene and lutein+zeaxanthin (chapter 3); intake of meat, fish, eggs, calcium and protein (chapter 4); the total energy and fat intake, and the intake of saturated fat, mono and polyunsaturated fat and different individual fatty acids (chapter 5); the total alcohol consumption and the intake of alcohol from beer and liquor such as brandy and whiskey (chapter 6). For increasing intake of leek, oranges, sweet pepper, and mushrooms (chapter 2); $\beta$-cryptoxanthin (chapter 3); cured meat and milk and milk products (chapter 4); oleic acid (chapter 5); and alcohol from white wine and fortified wines (chapter 6 ) we observed an increased prostate cancer risk. Results for some other dietary factors indicated that a higher consumption was associated with a decrease in prostate cancer risk: intake of pulses, kale, raw endive, mandarins and raisins (chapter 2); intake of supplements containing vitamin A, C, or E (chapter 3); and linolenic acid intake (chapter 5).

In chapters seven to nine results from the analyses of several nondietary risk factors and their association with prostate cancer incidence are described. The height of a subject, as well as the body mass index and the lean body mass were not related to risk of prostate cancer in the NLCS. These anthropometric measures referred to the age of a subject at baseline (55-69 years). For a high body mass index at age 20 vs a lower body mass index, a positive association with later risk of prostate cancer was observed (chapter 7). Our analyses also showed that having a father or brother(s) with prostate cancer is related to an increased prostate cancer risk. The association was stronger for affected brothers than for an affected father. No evidence for an increasing risk with increasing numbers of affected family members was found (chapter 8 ). The highest attained level of education and the last occupation of a subject were used as measures for the socioeconomic status. Occupation was classified according to occupational sector and required training (EGP score) and social standing (U\&S score). A higher vs a lower education and U\&S score were associated with an increased prostate cancer risk. For the EGP score no associations were found (chapter 9).

All analyses were repeated in subgroups to investigate whether certain potential risk factors are differently associated with different subgroups of prostate cancer. Overall, we can conclude that the investigated factors are not differently associated with latent and nonlatent prostate tumors, or with well, moderately and poorly differentiated tumors, or with localized and advanced prostate tumors. The only factors related more strongly to advanced prostate tumors compared to localized tumors are two nondietary factors, namely 
family history of prostate cancer in the father and/or brothers and socioeconomic status.

In the individual chapters our results are discussed and also compared with results from other studies on risk factors for prostate cancer. Only the positive association between family history of prostate cancer and risk of prostate cancer has consistently been reported from other studies. All other results are inconsistent between the different studies. The NLCS is one of the few studies that extensively investigated different (dietary) factors in relation to risk of prostate cancer. Other advantages of the NLCS compared to other studies are the large number of cases upon which the analyses are based and the availability of data on several potential risk factors for prostate cancer so that confounding could be extensively investigated. In addition, our study offered the possibility to separately investigate subgroups of prostate cancer. Misclassification could have influenced the results from the NLCS. Misclassification, nevertheless, is expected to be nondifferential thus leading to an underestimation instead of an overestimation of the strength of association. Although different risk factors have been evaluated as potential confounding factors, residual confounding cannot totally be excluded. Finally, some of our results may have been chance findings.

From the results of the NLCS we cannot conclude that diet or the other investigated environmental factors are not associated with risk of prostate cancer. Specific factors involved in prostate cancer etiology, however, cannot yet be specified. The second hypothesis which stated that environmental factors are more strongly related to nonlatent or advanced prostate tumors than to latent tumors cannot be supported with data from the NLCS. Few other studies also investigated this issue, and the results are all inconsistent.

The epilogue of this thesis ends with several suggestions for further research. Future research on risk factors for prostate cancer is still important and should be aimed at factors for which there is limited evidence yet. Because the exact role of hormones in the etiology of prostate cancer is unknown, this issue also deserves attention. To be able to determine if different factors play a role at different points in time in prostate cancer etiology, exposure measurements per subject should repeatedly be assessed during life. For example, it cannot be excluded that certain factors are imporant early in life and not in the recent years before diagnosis. Biological interaction between different putative risk factors seems plausible, and this also deserves further investigation. Besides research on risk factors for prostate cancer, research on the natural history of prostate cancer as well as on biological mechanisms explaining prostate cancer etiology is needed. 
3 


\section{Samenvatting}

Hoewel prostaatkanker een hoge incidentie heeft in Westerse landen, is er omtrent mogelijke oorzaken nog weinig bekend. Van omgevingsfactoren wordt gedacht dat ze belangrijk zijn in de etiologie van prostaatkanker, ondermeer vanwege de grote internationale variatie in het voorkomen van prostaatkanker. Ook is het zo dat onder migranten die verhuizen van een gebied met een lage prostaatkankerincidentie naar een gebied met een hoge incidentie, een stijging van de incidentie wordt gezien. Bij prostaatkanker wordt vaak een onderscheid gemaakt tussen latente prostaattumoren, die gezien hun aard en grootte min of meer per toeval worden ontdekt,en niet-latente vormen van prostaatkanker waarbij (duidelijke) klinische symptomen wijzen op het bestaan ervan. Uit onderzoek blijkt dat het voorkomen van latente tumoren ongeveer gelijk is verdeeld over de wereld, in tegenstelling tot niet-latente prostaatkanker. Ook dit verschil in voorkomen van latente en niet-latente prostaatkanker zou er op kunnen wijzen dat omgevingsfactoren belangrijk zijn bij het ontstaan van prostaatkanker.

In dit proefschrift wordt de relatie beschreven tussen verschillende voedingsfactoren en een aantal factoren buiten de voeding en de incidentie van prostaatkanker. De algemene hypotheses die aan het onderzoek ten grondslag liggen zijn de volgende: 1) omgevingsfactoren, met name voedingsfactoren, zijn geassocieerd met het risico op prostaatkanker, en 2) deze factoren zijn sterker gerelateerd aan niet-latente of meer agressieve vormen van prostaatkanker dan aan latente tumoren.

De analyses betreffende de associaties tussen voedingsfactoren (inname van groente en fruit, vitamines, dierlijke produkten, energie, vet, en alcoholconsumptie) en een aantal nietvoedingsfactoren (voorkomen van prostaatkanker in de familie, antropometrische factoren, en sociaal economische status) en de incidentie van prostaatkanker (eerste hypothese) werden uitgevoerd met gegevens van de Nederlandse Cohort Studie (NLCS) naar voeding en kanker. De NLCS is een prospectief cohortonderzoek, gestart in 1986 onder 58.279 mannen in de leeftijd van 55-69 jaar. Alle personen vulden een uitgebreide schriftelijke voedingsvragenlijst in en tevens werd informatie over andere mogelijke risicofactoren voor kanker verzameld. Voor de in dit proefschrift beschreven analyses werd gebruik gemaakt van een follow-up periode van 6,3 jaar (september 1986 - december 1992). Gedurende deze periode ontwikkelden 704 mannen prostaatkanker. Om de tweede hypothese te onderzoeken werden analyses herhaald in subgroepen waarbij de tumoren werden ingedeeld op bepaalde karakteristieken (latent en niet-latent; goed, matig en slecht gedifferentieerde tumoren; gelokaliseerde en niet-gelokaliseerde tumoren).

In hoofdstuk 1 van dit proefschrift wordt een literatuuroverzicht gegeven van andere cohortstudies waarin voeding in relatie tot prostaatkanker werd onderzocht. Hieruit blijkt dat 
de uitgevoerde studies tot nu toe weinig uitgebreid zijn geweest. De meeste studies hebben een beperkte meting van voedingsfactoren gehanteerd. Verder waren in de analyses meestal slechts een beperkt aantal mannen met prostaatkanker betrokken. Voor vrijwel alle onderzochte voedingsfactoren kan worden geconcludeerd dat resultaten uit de diverse onderzoeken tot dusverre inconsistent zijn.

In de hoofdstukken twee tot en met zes worden de resultaten besproken van de analyses binnen de NLCS naar de relatie tussen diverse voedingsfactoren en het risico op prostaatkanker. Voor de verschillende voedingsfactoren werd steeds gekeken of een toenemend gebruik verband hield met het ontstaan van prostaatkanker. Voor de volgende voedingsfactoren werd geen duidelijk verband gevonden met het risico op prostaatkanker: de totale inname van groenten en fruit (hoofdstuk 2); inname van retinol, vitamines $C$ en $E$, $\alpha$-caroteen, $\beta$-caroteen, lycopeen en luteïne+zeaxanthine (hoofdstuk 3 ); consumptie van vlees, vis, kaas, eieren, calcium en eiwit (hoofdstuk 4); de totale energie- en vetinname, en de inname van verzadigd vet en enkel- en meervoudig onverzadigd vet en een aantal individuele vetzuren (hoofdstuk 5); de totale alcoholconsumptie alsmede de inname van alcohol uit bier en uit sterke drank zoals jenever en whiskey (hoofdstuk 6). Voor bepaalde voedingsfactoren was er een aanwijzing dat een hogere inname gepaard ging met een verhoogd risico op prostaatkanker. Dit geldt voor factoren zoals: prei, sinaasappels, paprika en champignons (hoofdstuk 2); $\beta$-cryptoxanthine (hoofdstuk 3); vleeswaren, melk en melkprodukten (hoofdstuk 4); oliezuur (hoofdstuk 5); alcohol uit witte wijn en alcohol uit wijnen zoals port en sherry (hoofdstuk 6). De resultaten voor sommige andere voedingsfactoren gaven een aanwijzing dat een hogere consumptie ervan mogelijk een beschermende werking zou hebben op het ontstaan van prostaatkanker: de inname van peulvruchten, boerenkool, rauwe andijvie, mandarijnen en rozijnen (hoofdstuk 2); supplementen met vitamine A, C of E (hoofdstuk 3); de inname van linoleenzuur (hoofdstuk 5).

In de hoofdstukken zeven tot en met negen worden de resultaten beschreven van de analyses naar een aantal factoren buiten de voeding en hun relatie met het ontstaan van prostaatkanker. Zowel de lengte van een persoon alsmede de Quetelet Index en de vetvrije massa bleken in onze studie niet gerelateerd te zijn aan het risico op prostaatkanker. Het betrof hier de antropometrische gegevens ten tijde van de beginmeting van de NLCS. Een hoge ten opzichte van een lagere Quetelet Index van een persoon op 20-jarige leeftijd leek het risico op prostaatkanker op latere leeftijd te verhogen (hoofdstuk 7). Het voorkomen van prostaatkanker bij de vader en/of broer(s) van een persoon bleek ook het risico op prostaatkanker voor die persoon te verhogen. Dit verband was sterker voor het voorkomen bij broers dan bij de vader. Er kon niet worden aangetoond dat het risico toeneemt bij een toenemend aantal familieleden met prostaatkanker (hoofdstuk 8). De hoogst behaalde opleiding en het laatst uitgeoefende beroep van een persoon werden gebruikt als maten 
voor sociaal economische status. Beroep werd ingedeeld naar beroepssector en benodigde opleiding (EGP-score) en naar aanzien (U\&S-score). Een hogere ten opzichte van een lagere opleiding en U\&S-score waren gerelateerd aan een verhoogd prostaatkankerrisico. Voor de EGP-score werd geen associatie aangetoond (hoofdstuk 9).

Alle analyses werden herhaald in subgroepen om te onderzoeken of bepaalde potentiële risicofactoren verschillend zijn geassocieerd met verschillende subgroepen van prostaatkanker. Over het algemeen kan gesteld worden dat de door ons onderzochte factoren niet verschillend zijn geassocieerd met latente en niet-latente prostaatkanker, of met goed, matig of slecht gediffentieerde tumoren, of met gelokaliseerde en nietgelokaliseerde tumoren. Alleen de gevonden associaties voor het voorkomen van prostaatkanker in de familie en de sociaal economische status bleken sterker te zijn voor niet-latente of niet-gelokaliseerde tumoren in vergelijking met de associaties in de subgroep van latente of gelokaliseerde tumoren.

In de individuele hoofdstukken worden de gevonden resultaten bediscussieerd en tevens vergeleken met resultaten uit andere onderzoeken naar prostaatkanker. Slechts het positieve verband tussen het voorkomen van prostaatkanker in de familie en het risico op prostaatkanker wordt consistent in de literatuur gerapporteerd. Alle andere resultaten zijn inconsistent tussen de verschillende studies. De NLCS is één van de weinige onderzoeken waarin uitgebreid verschillende (voedings)factoren in relatie tot prostaatkanker zijn onderzocht. Andere voordelen van de NLCS ten opzichte van andere studies zijn de grote aantallen waarop de analyses zijn gebaseerd en de grote beschikbaarheid van gegevens waardoor ook confounding uitgebreid kon worden onderzocht. Tevens bood de NLCS de mogelijkheid om subgroepen van prostaatkanker apart te onderzoeken. Misclassificatie zou de resultaten uit de NLCS kunnen hebben beïnvloed. De verwachting is echter dat eventuele misclassificatie nondifferentieel is waardoor de gevonden resultaten een onderschatting, maar geen overschatting van het werkelijke verband kunnen geven. Hoewel verschillende factoren als mogelijke confounder zijn onderzocht, kan residuele confounding niet worden uitgesloten. Verder is het uiteraard mogelijk dat sommige bevindingen op basis van toeval zijn ontstaan.

Uit de resultaten van de NLCS kan niet worden geconcludeerd dat voeding of enkele andere onderzochte omgevingsfactoren niet met het risico op prostaatkanker zijn geassocieerd. Specifieke (voedings)factoren kunnen echter nog niet worden aangeduid, daarvoor is eerst verder onderzoek noodzakelijk. De tweede hypothese die stelde dat omgevingsfactoren sterker aan niet-latente of agressievere vormen van prostaatkanker zijn geassocieerd, kon met de resultaten uit de NLCS niet worden bevestigd. Slechts in enkele andere onderzoeken werden ook subgroepen apart bestudeerd, en de resultaten waren wederom inconsistent. 
De epiloog van dit proefschrift wordt afgesloten met een aantal suggesties voor verder onderzoek naar mogelijke oorzaken van prostaatkanker. Toekomstig onderzoek blijft relevant en zou zich moeten richten op factoren waarover nog weinig bekend is. Ook de rol van hormonen in het ontstaan van prostaatkanker verdient aandacht. Om te kunnen bepalen op welk moment in de tijd bepaalde factoren een rol kunnen spelen zouden meerdere expositiemetingen per persoon moeten worden uitgevoerd over langere tijdsperioden. Het is immers niet uit te sluiten dat bepaalde factoren al vroeg in het leven van belang zijn, en niet in de recente jaren voordat de diagnose wordt gesteld. Een biologische interactie tussen potentiële risicofactoren lijkt plausibel en hiervoor is ook nader onderzoek nodig. Behalve onderzoek naar risicofactoren is ook onderzoek nodig naar de natuurlijke ontwikkeling van prostaatkanker, alsmede naar de biologische mechanismen die de etiologie van prostaatkanker kunnen verklaren. 


\section{Dankwoord |}

De mensen die mij gedurende de afgelopen viereneenhalf jaar hebben bijgestaan, wil ik op deze plaats graag bedanken. Uiteraard begin ik met mijn promotor Piet van den Brandt en mijn co-promotor Sandra Bausch-Goldbohm. Als initiators van de Nederlandse Cohort Studie (NLCS) naar voeding en kanker heb ik veel bewondering voor jullie, want het is niet eenvoudig zo'n grootschalig onderzoek op te zetten. Bovendien zorgen jullie er al jarenlang voor dat het 'goed blijft draaien'. Een tijdlang mee te mogen werken aan zo'n groot en complex epidemiologisch onderzoek is voor mij heel uitdagend en leerzaam geweest. Piet, tijdens mijn AIO-schap, maar ook al daarvoor gedurende de laatste fase van mijn studie, heb ik je gezien als een serieuze, hardwerkende wetenschapper die weet waar de puntjes nog op de ' $i$ ' moeten worden gezet. Bedankt voor je vertrouwen en voor de energie die je in mij hebt gestoken. Sandra, jouw inzicht in complexe zaken en de bereidheid mee te denken werkte voor mij duidelijk stimulerend. Ik heb jouw inbreng en kritische blik daarom altijd zeer op prijs gesteld. Voor jullie beiden heb ik veel bewondering.

Het grote cohortonderzoek waarop dit proefschrift is gebaseerd, kent inmiddels vele medewerkers en oud-medewerkers die ieder op hun eigen wijze bijdragen of hebben bijgedragen aan de instandhouding ervan. Anita Botterweck, je bent sinds het begin van mijn aanstelling mijn kamergenoot geweest en we hebben veel lief en leed gedeeld in het proces naar een proefschrift toe. Bedankt voor je luisterend oor en je bereidheid te helpen waar dat mogelijk was. Weldra zal ook voor jou het 'hora est' klinken. Spannend! Elisabeth Dorant, je hebt op veel momenten met mij mee willen denken. Dank je wel voor al je waardevolle adviezen. Sacha van de Crommert en Harry van Montfort, moeilijke computerzaken werden door jullie altijd snel en vakkundig opgelost. Ik ben blij dat jullie altijd bereid waren mij te helpen bij de wat lastiger zaken. Miranda Dirx, Jeanne van Loon, Matty Weijenberg, en Maurice Zeegers, bedankt voor jullie belangstelling en behulpzaamheid in verschillende fasen van het onderzoek en jullie bijdrage aan een prettige werksfeer. Jolanda Nelissen, Conny de Zwart, Marijke Moll, Cobie Martens en Ton van Moergastel, jullie werkzaamheden (bijvoorbeeld het invoeren vragenlijsten, het opzetten van databases en het controleren van ingevoerde gegevens) zijn onontbeerlijk voor het voortbestaan van het NLCS-cohort. Het is prettig om te werken met mensen die met toewijding en precisie hun werk doen. Ook vanuit TNO-Voeding in Zeist wordt een belangrijke bijdrage geleverd aan de instandhouding van het NLCS-cohort. Bij naam wil ik graag noemen Henny Brants, Laura Voorrips en Willy van Dijk. Met vragen kon ik gelukkig ook altijd bij jullie terecht. Andere personen die hier niet met naam zijn genoemd, maar die in de afgelopen jaren bij het cohort betrokken zijn geweest, wil ik bedanken voor het werk dat is verzet. De samenwerking met cohortmedewerkers heb ik als prettig ervaren. 
Met veel plezier heb ik de afgelopen jaren op de Capaciteitsgroep Epidemiologie in Maastricht gewerkt. Een Capaciteitsgroep met rond de vijftig medewerkers maakt natuurlijk dat je niet met iedereen evenveel contact hebt (gehad). Verschillende mensen echter hebben ertoe bijgedragen dat ik de sfeer zowel op het werk en ook daarbuiten als collegiaal, uitdagend, kritisch, vriendschappelijk, persoonlijk, en stimulerend heb ervaren. Een aantal contacten hoop ik ook in de toekomst te kunnen blijven onderhouden.

Een speciaal plekje in het dankwoord voor de 'epi-ladies' Monique de Kok, Helen Klip, Cecile Ronckers, Loes van Herten, Peggy van den Hoogen en Anita Botterweck. Bedankt voor jullie belangstelling, adviezen en gezelligheid in de afgelopen jaren. Ik wens jullie veel sterkte, plezier en voldoening bij al jullie 'epi-werkzaamheden'.

Een proefschrift is niet iets wat alleen maar je werk is, het bepaalt een groot deel van je tijd, ook nog 'buiten werktijd'. Daarom wil ik hier een aantal vrienden die sterk betrokken zijn geweest de afgelopen jaren niet ongenoemd laten. Monique Ross, Ed Ouwehand, Jan Havinga, Gonnie Dam, Natascha Tahitu, Brenda Beukema en Tietsia Huijzer, jullie hebben allemaal op je eigen manier met mij meegeleefd en omdat het anders niet zo vaak wordt gezegd, wil ik jullie op deze plaats bedanken voor jullie vriendschap die mij zeer waardevol is. Ingrid Steenhuis, jij hebt zowel 'op het werk' als ook 'buiten het werk' echt alles van het begin tot het einde meegemaakt. Ook de vriendschap met jou betekent erg veel voor mij. Jaap Schuurman en Petra Schuurman-Heeres wil ik op deze plaats ook noemen, jullie hebben mij de ruimte gegeven mij mijn eigen keuzes te laten maken en dat is voor mij erg belangrijk en ook goed geweest. Bedankt voor jullie steun en afleiding. Hans, als laatste wil ik jou bedanken voor het vertrouwen dat je in me hebt, en de steun en liefde die ik van jou ervaar. Je bent me erg dierbaar. 


\section{| Curriculum vitae |}

Agnes Schuurman werd geboren op 17 december 1969 in Garrelsweer (Gr.). Na het behalen van het HAVO-diploma aan het Fivel-College te Delfzijl (1987) volgde zij de Hogere Beroepsopleiding tot Verpleegkundige (HBO-V) aan de Rijkshogeschool Groningen. Deze opleiding werd afgerond in 1991 en vervolgens startte zij de studie Gezondheidswetenschappen aan de Universiteit Maastricht. In 1994 behaalde zij het doctoraaldiploma Gezondheidswetenschappen. Tijdens haar studie specialiseerde zij zich op het gebied van de epidemiologie en zij studeerde af op een epidemiologisch onderzoek naar de associatie tussen exogeen hormoongebruik en het risico op postmenopauzale borstkanker. Voor dit afstudeeronderzoek kreeg zij de studentenprijs (Faculteit Gezondheidswetenschappen) van de Stichting Wetenschapsbeoefening van de Universiteit Maastricht. Sinds december 1994 is ze aangesteld als assistent in opleiding bij de Capaciteitsgroep Epidemiologie van de Universiteit Maastricht. Binnen deze functie werkte ze aan het onderzoek naar risicofactoren voor prostaatkanker, waar dit proefschrift het resultaat van is. Daarnaast werden verschillende onderwijstaken vervuld. Haar postacademische opleiding bestond uit het volgen van verschillende (epidemiologische) cursussen in binnen- en buitenland. 


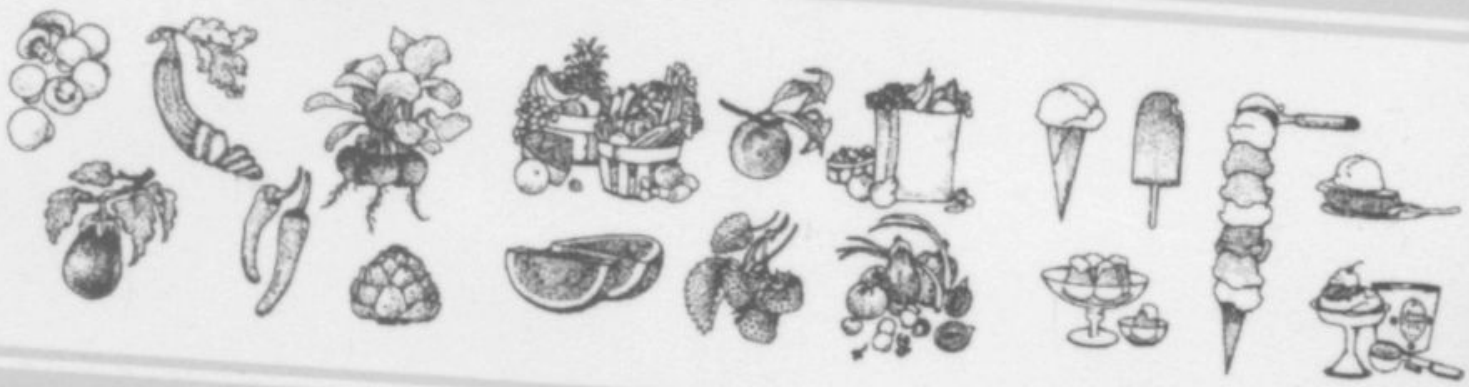

